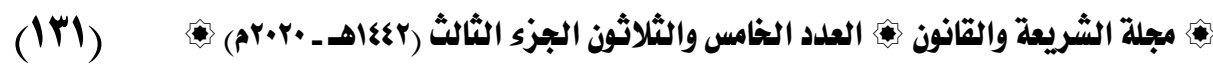

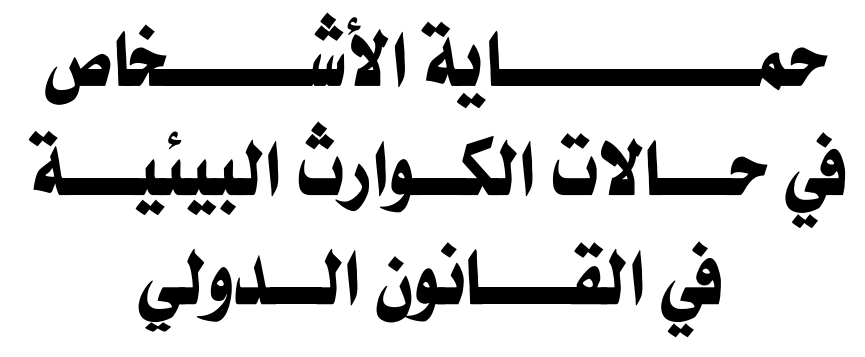

$$
\begin{aligned}
& \text { الدكتـــــور } \\
& \text { كربه محمد رجب الهباغ } \\
& \text { حكتوراه في القانوة الضولي الهام } \\
& \text { كلية الحقوق - جامهة المنوفية }
\end{aligned}
$$


(ITr)

حماية الأشخاص في حالات الكوارث البيئية في التانون الدولي 


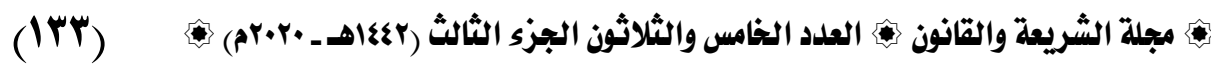
حماية الأشخاص في حالة الكوارث البيئية في القانون الدولي كريم محمد رجب الصباغ

قانون دولي عام ، كلية الحقوق ، جامعة المنوفية ، مصر .

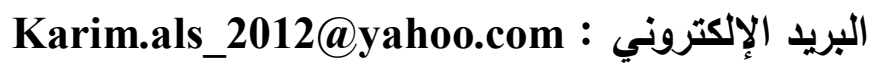

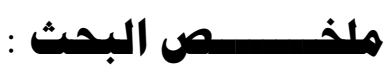

من المستقر علية أن الكوارث البيئية تعـد أخطر تهديــ للحيـاة الإنسانية،

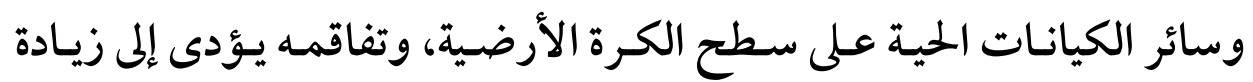
التدهور البيئي وانتشاره على المستوى الدولي ، ولا يخفى أن أمر انتشار الجائحسة.

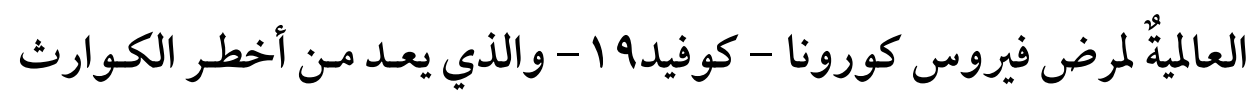

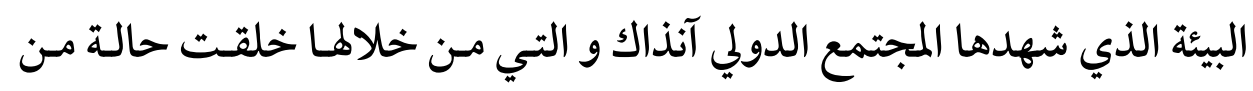
القلق والذعر على حياة الإنسان بسبب انتشار هـذا الوبـاء العـالمي في معظم

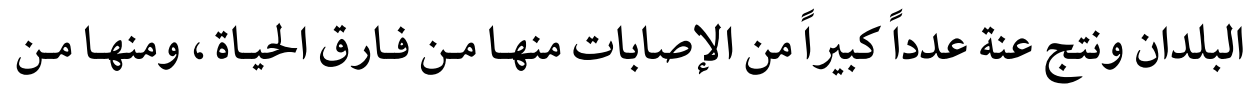
تماثل للشفاء من جر اء هذا الوباء العالمي .

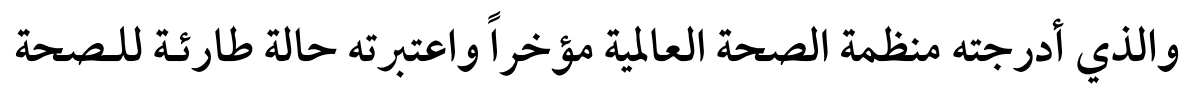

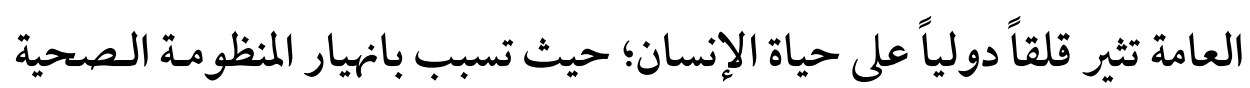

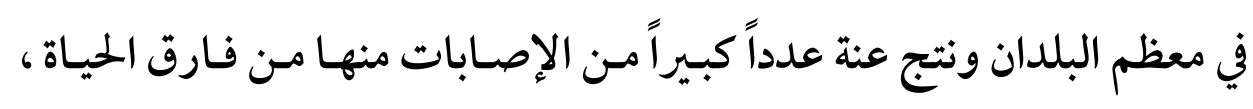

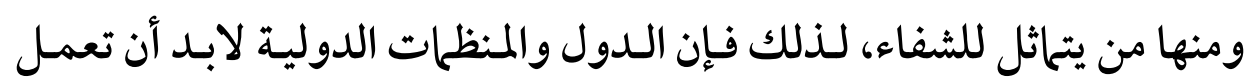
ضمن خطة واحدة يكون في مقـدمتها وضـع آلية لحمايـة الأشـخاص من تلك

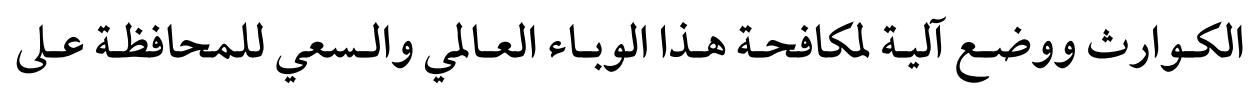
التنمية الصحية العالمية الشاملة. 
(1rצ) حماية الأشخاص في حالات الكوارث البيئية في القانوز الدولي

و يعتبر التعاون الـدولي مسؤولية تلقى عـلى عـاتق جميع الفواعل المكونـة

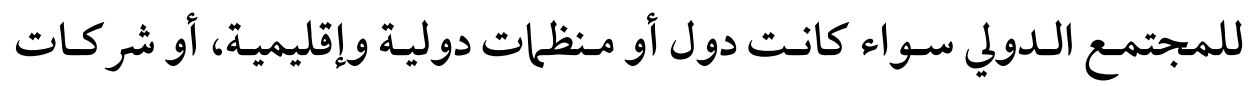
عـابرة للقـارات أو غيرهـا مـن الفواعـل الدوليـة، حيـث أن ثـار التعـاون تـؤتي

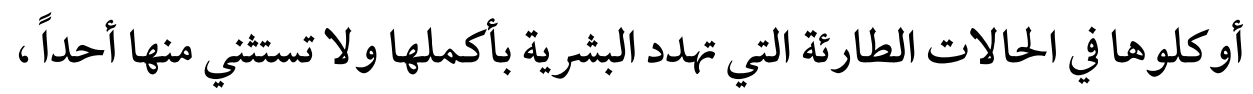

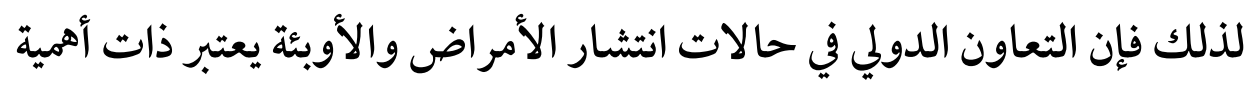

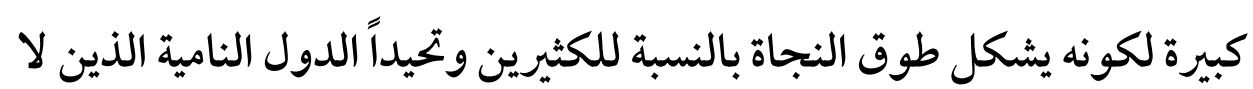
مأوى ولا غـذاء ولا دواء بسبب سـوء الوضـع الصحي في هـذه البلدان وقلة

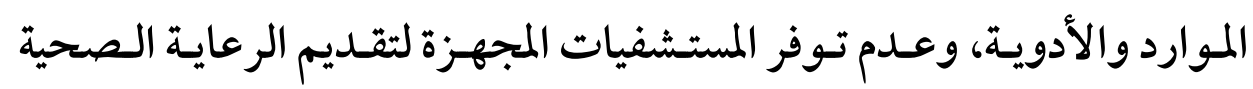

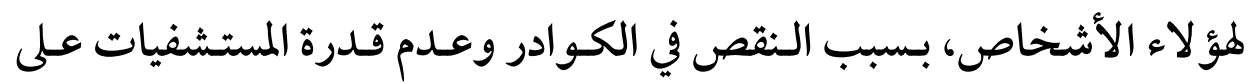
استيعاب أعداد كبيرة من الأفراد. كما يتطلب الأمن البيئي العالمي تعاوناً دوليّاً وإقليمياً ومحلياً لحاية البيئة، مع المعادئ المحافظة على مواردها الطبيعية، من أجل إيباد ربط وثيتق بين البيئة والتنميـة بمفهومها الشامل سواء في البلدان المتقدمة أو النامية . الكلمات المفتاحية : كوارث بيئية ، قانون دولي ، المجتمع الدولي ،

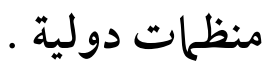


Protection of People in environmental Disasters

\section{in International Law}

Karim Mohammed Rajab Elsabbagh.

International Public of Law, El Monofeia University, Egypt.

E-mail: Karim.als_2012@yahoo.com.

\section{Abstract:}

It is well established that environmental disasters are the most dangerous threat to human life, and other living entities on the surface of the globe, and its exacerbation leads to an increase in environmental degradation and its spread at the international level, and it is no secret that the global pandemic of Corona virus disease - Covid 19 - is one of the most dangerous environmental disasters. What the international community witnessed at the time and through which it created a state of anxiety and panic over human life due to the spread of this global epidemic in most countries and resulted in a large number of injuries, including from the death of life, and some of them recovered as a result of this global epidemic.

Which was recently listed by the World Health Organization as a public health emergency of international concern to human life; As it caused the collapse of the health system in most countries and resulted in a large number of injuries, including the death of life, and some of them recovered, so countries and international organizations must work within one plan, at the forefront of which is the development of a mechanism to protect people from these disasters and a mechanism to combat this epidemic Global 
and striving to maintain comprehensive global health development.

International cooperation is a responsibility that bears on the shoulders of all the constituent actors of the international community, whether they are states, international and regional organizations, transcontinental companies, or other international actors, as the fruits of cooperation come to be entrusted to them in emergency situations that threaten humanity as a whole and do not exclude anyone from it. International cooperation in cases of disease and epidemics is of great importance because it constitutes a lifeline for many, and it is the developing countries who have no shelter, food or medicine due to the poor health situation in these countries and the lack of resources and medicines, and the lack of hospitals equipped to provide health care to these people, due to The shortage of staff and the inability of hospitals to accommodate large numbers of people.

Global environmental security also requires international, regional and local cooperation to protect the environment, while preserving its natural resources, in order to create a close link between environment and development in its comprehensive sense, whether in developed or developing countries

Keywords: Environmental disasters, International law , International community, International organizations . 


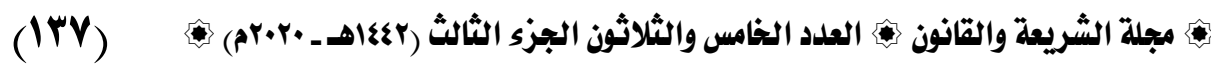

تقديه:

شـهد العـالم في السـنوات الأخـيرة، زيـادة في الكـوارث البيئيـة مـن حيـث

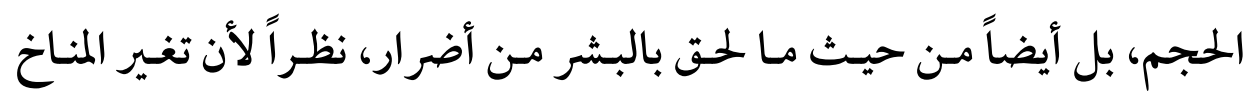

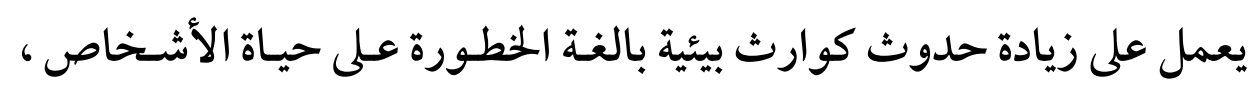

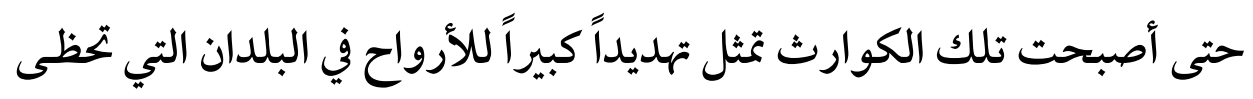

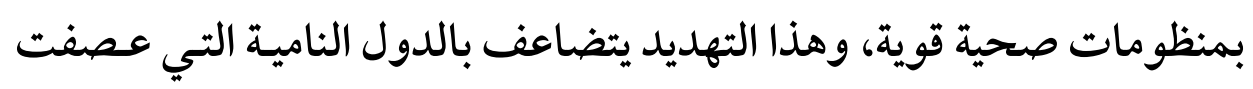

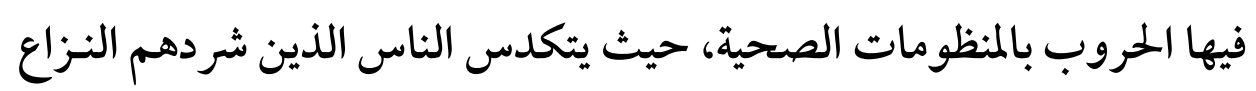
في أماكن تشحّ فيها الموارد المنقذة لمستلزمات الحياة البشرية.

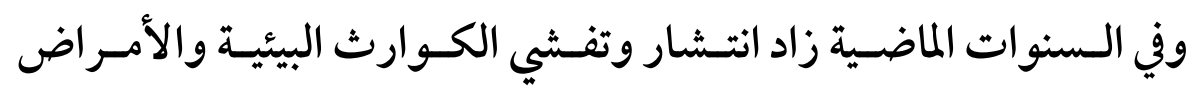

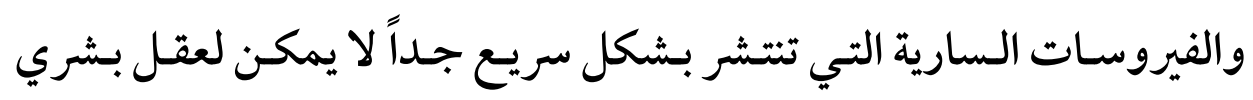

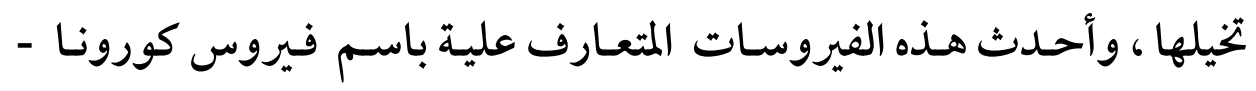
COVID 19-

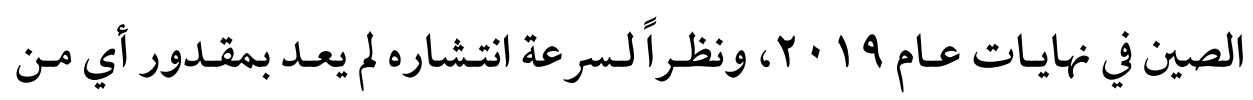

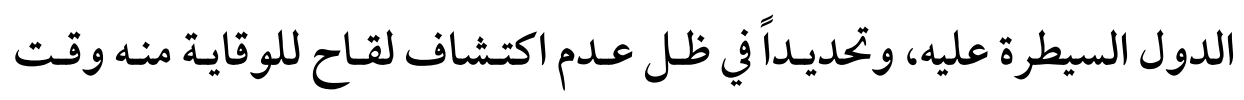
ظهوره آنذاك، الأمر الذي أرهق الدول وجعلها وأمسام مسؤولية كبيرة في حمايـة الأشخاص من انتشار هذا الوياء.

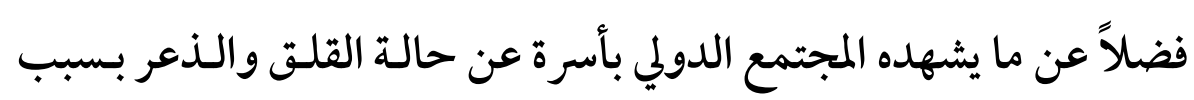

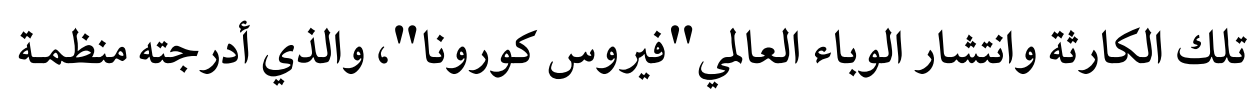

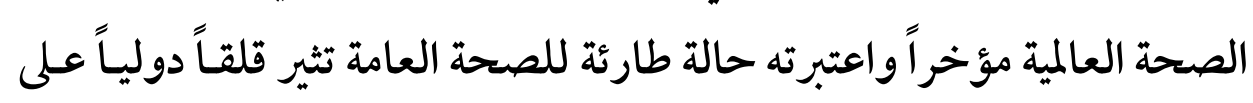
حياة الإنسان؛ حيث تسبب بانهيار المنظومة الصحية في معظم البلدان ونتج عنة 


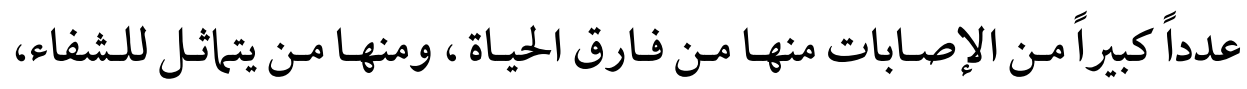

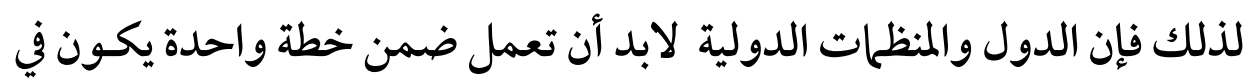

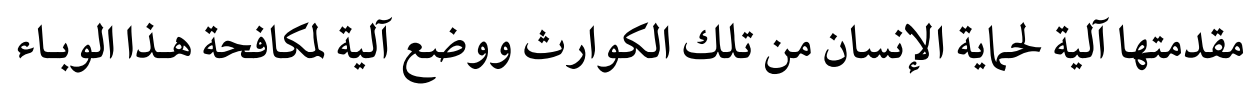
العالمي والسعي للمحافظة على التنمية الصحية العالمية الشاملة. ويعتبر التعاون والتضامن الدولي مسؤولية تلقى على عـاتق جميـع الفواعـل

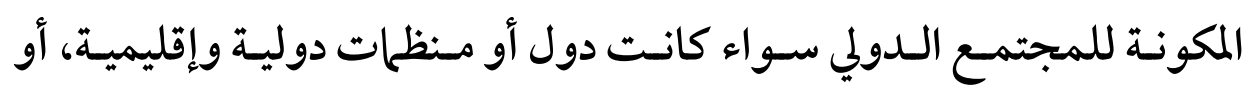
شركات عابرة للقارات أو غيرها من الفواعل الدولية، حيـث أن ثـار التعـاون

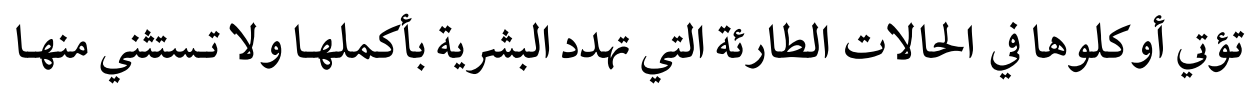
أحداً ، لذلك فإن التعاون الدولي في حـالات انتشار الأمراض والأل الأوبئة يعتبر ذات أهمية كبيرة لكونه يشكل طوق النجاة بالنسبة للكثيرين وتحيداً الدول

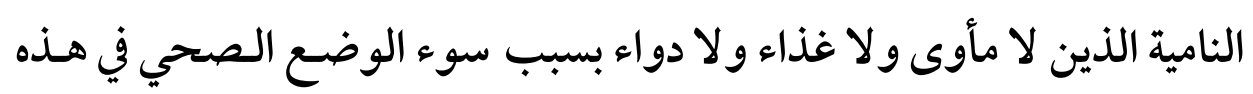

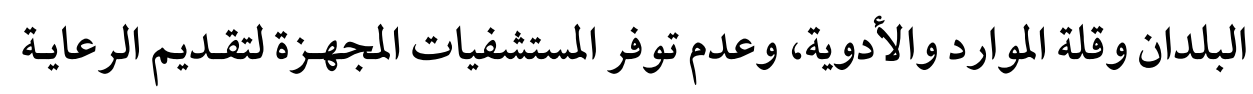
الصحية لمؤلاء الأشخاص، بسبب النقص في الكوادر وعدم قدرة المستشفيات على استيعاب أعداد كبيرة من الأفراد. ومسن الواضـح أنـه ينبغي إعطساء الأولويـة القصوى للحفــاظ عـلى صـحة

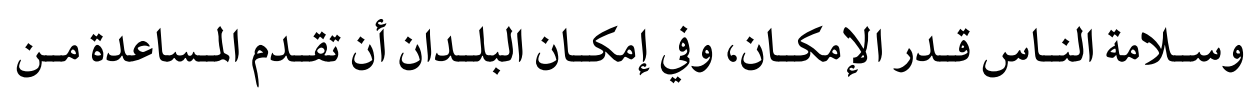
خلال إنفاق المزيد لدعم نظمها الصحية، بها ذلك الإنفاق على معدات الوقاية

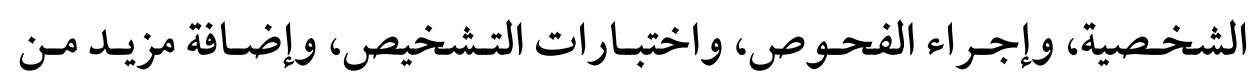

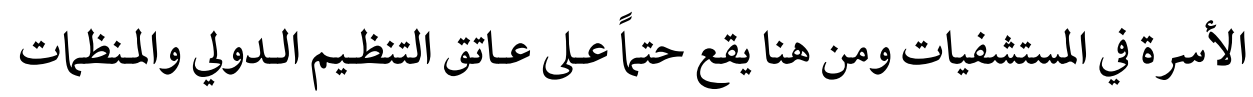




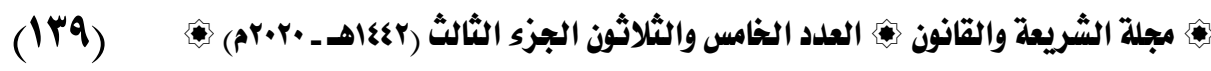
الإنسانية تكثيف الدعم والاستجابة الفورية والمُنسَّقة لمواجهه تلك الكوارث الكوارث

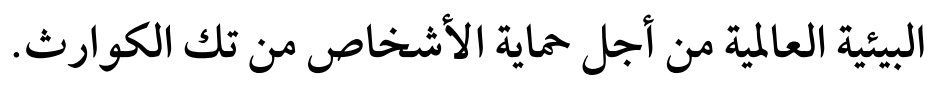

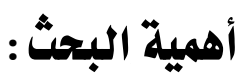

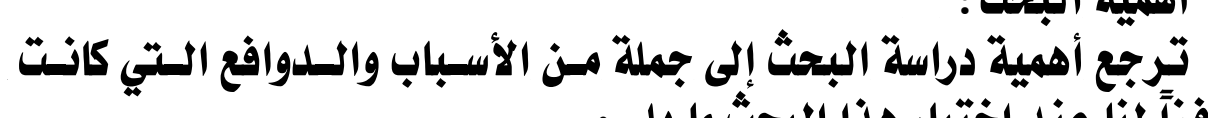

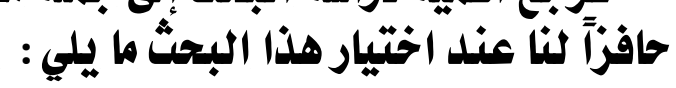

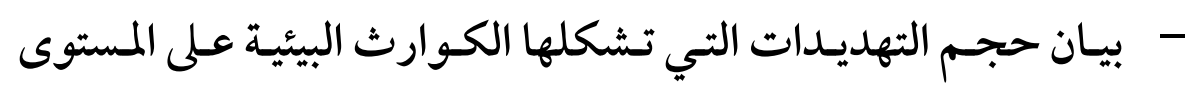
الدولي والإقليمي من أجـل الحمايـة الصحية للأشخاص للعسيش في بيئة ذات موارد طبيعية غير ملوثة تضمن له القدرة على البقاء على قيد الحياة. - الوقوف بالدراسة على القواعد الدولية لحمايـة الإنسسان من الكوارث

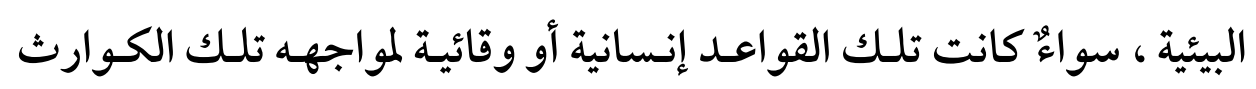

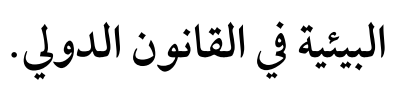
- - تحديد طبيعة الآليات الدولية لحماية الإنسان من تلك الكـوارث البيئية وذلـك مـن أجـل الوقـوف عـلى بيـان دور المـنظات الدوليـة الحكوميـة وغيـير

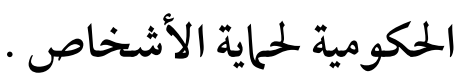

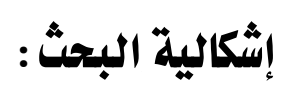
- - تكمن مشكلة البحث في عدم كفاية الأطر القانونية القائمة حالياً لحاية

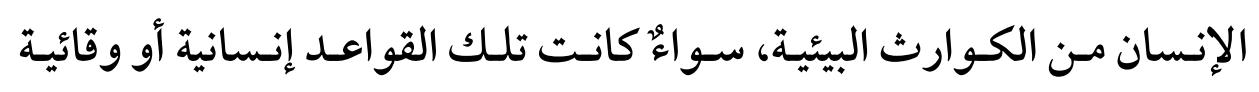

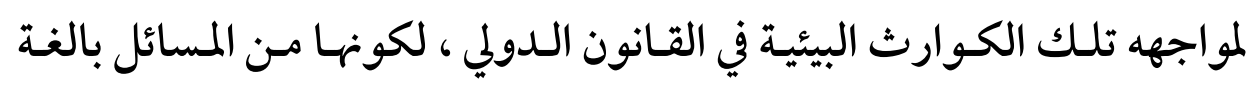

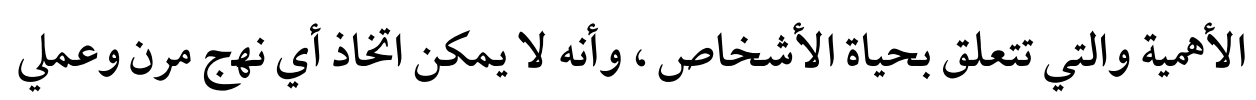
بشأنه ما لم تتوصل جميع الدول إلية، بغض النظر عن مستوياتها العلمية والتقنية

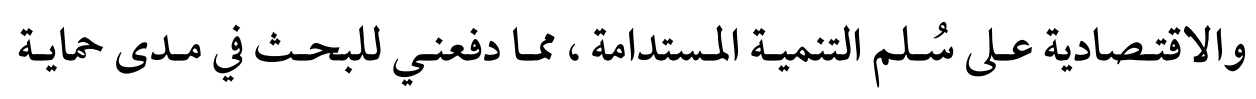


(15*)

حماية الأشخاص في حالات الكوارث البيئية في القانوز الدولي

الإنسان من تلك الكوارث الفتاكة، لبيان القواعد الدولية ومعرفة مدى كفيتها لحاية الأشخاص من الأوبئة التي تهدد بحياة الإنسان إلى الخطر ، وكذا وطرق مكافحتها.

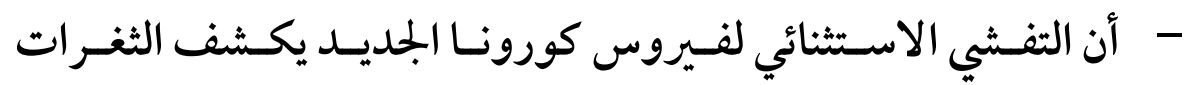

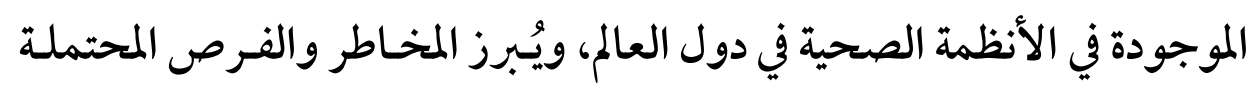

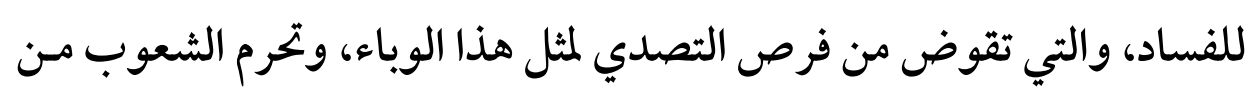
الرعاية الصحية المناسبة.

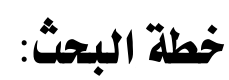
تقتضى دارسـة حمـاية الأشـخاص في حـالات الكـوارث البيئية في القـانون

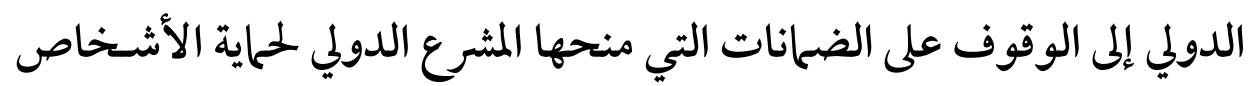

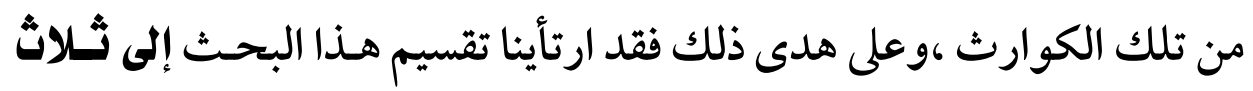
مباحث نعقبهم بخاتهة وذلك على النحو التالي:

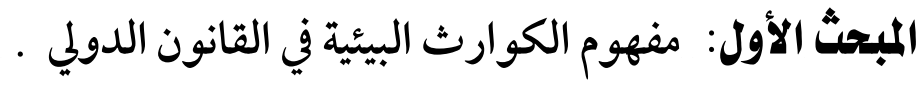

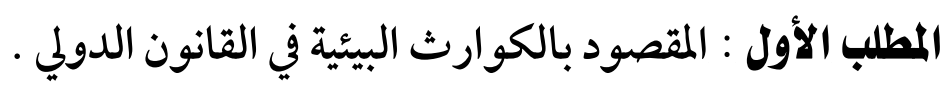

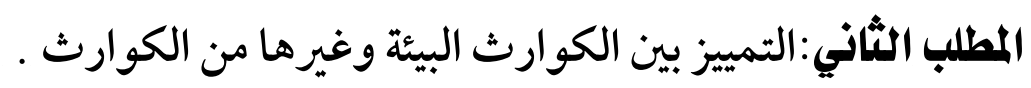
المبحث الثاني: القواعد الدولية لحلحية الأشـاص مسن الكسوارث البيئية في

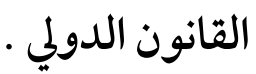
المطلب الأول : المبادئ الإنسانية لمواجهه الكوارث البيئية في القانون الدولي.

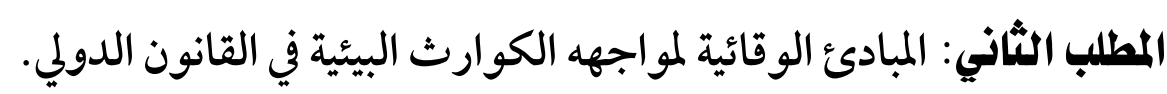
المبحث الثالث: الآليات الدولية لحماية الأشخاص مـن الكـوارث البيئية في القانون الدولي . 


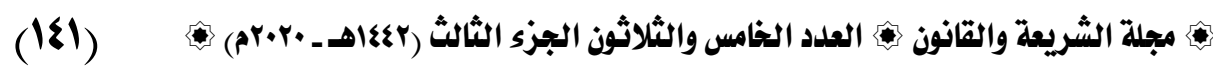

المطلسب الأول : دور المنظلات الدوليـة الحكوميـة في حمايـة الأشـخاص مـن الجن

$$
\text { الكوارث البيئية . }
$$

المطلب الثاني: دور المنظلات الدولية غير الحكومية في حماية الأشخاص من

$$
\text { الكوارث البيئية . }
$$

خاتهة: ونستعرض فيها أهم النتائج والتوصيات التي توصلنا إليها في هذه

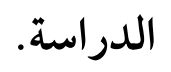


(I\&r)

حماية الأشخاص في حالات الكوارث البيئية في القانون اللدولي

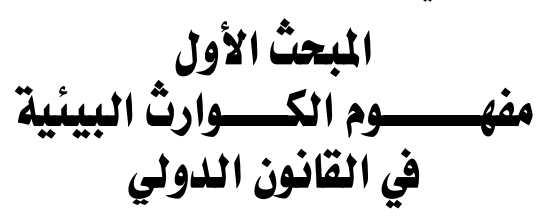

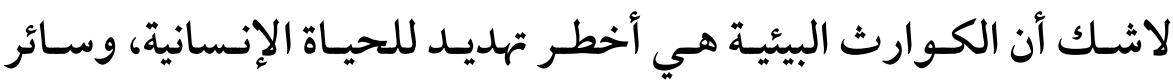

الكيانات الحية على سطح الكـرة الأرضـية، وتفاقمهـ يؤدى إلى زيـادة التدهور

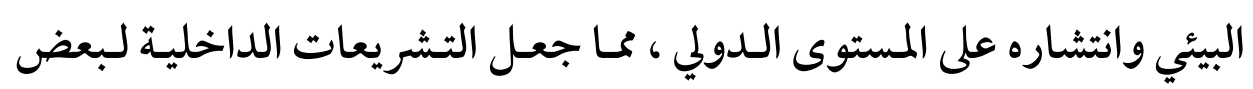

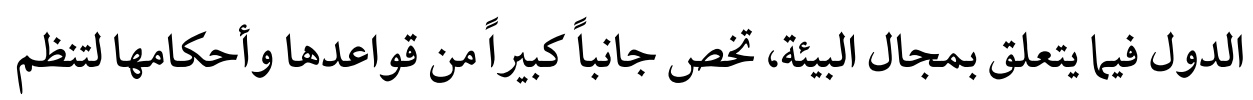

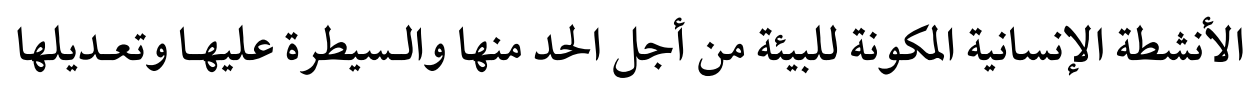
واتخاذ التدابير الملائمة لمكافحتها ('). وقد تؤدى تلك الكوارث البيئية نتيجة دخول مواد غريبة نتج عنها إخلال

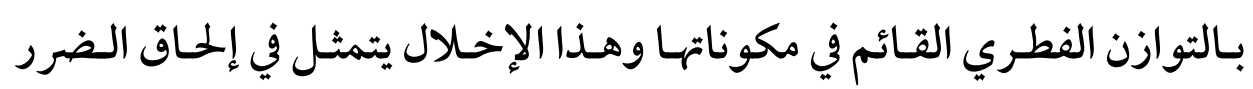

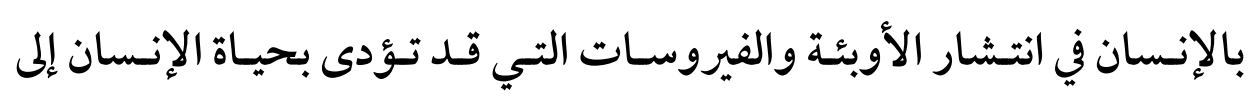

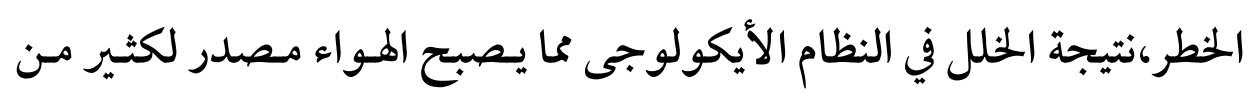
المخاطر والمضار التي تهدد كل مظاهر الحياة(†).

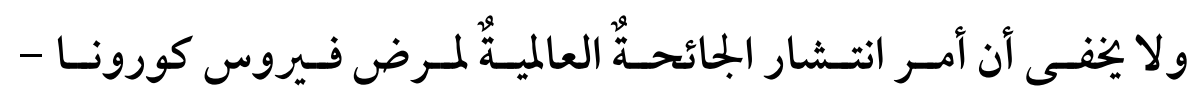
كوفيد9 1 - والذي يعد من أخطر الكوارث البيئة الذي شهدها المجتمع الدولي (1) د. بوجلال صلاح الدين، الحق في المساعدة الإنسانية ، دراسة مقارنة في ضوء أحكام

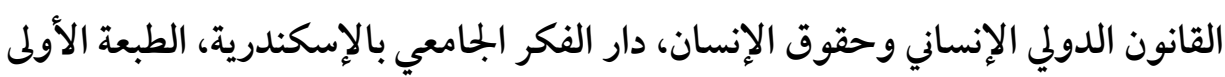

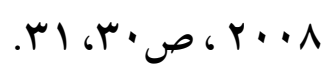

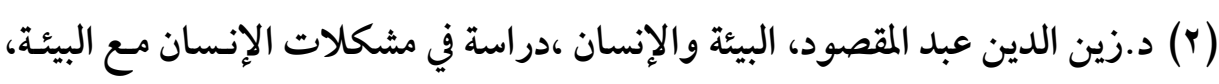

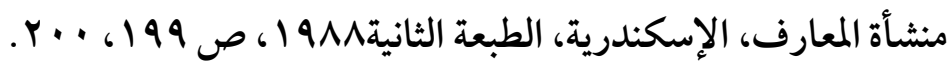




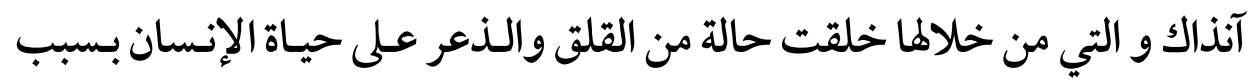
انتشار هذا الوباء العالمي في معظم البلدان ونتج عنة عدداً كبيراً من الإصابات منها من فارق الحياة ، ومنها من تماثل للشفاء من جراء هذا الوياء (1). وعلى ذلك حتى يمكنتـا بيـان مفهوم الكوارث البيئيـة في القـانون الـدولي

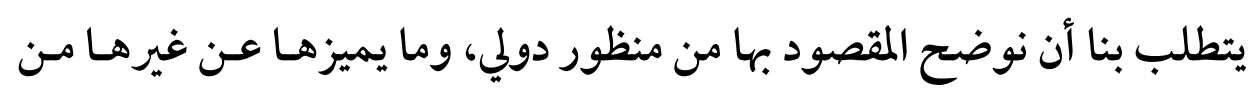
الكوارث؛ وذلك من خلال التقسيم التالي:

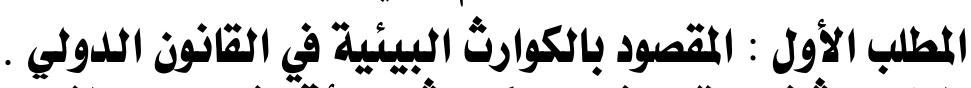

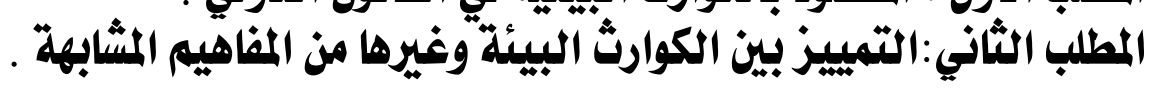

$$
\text { المقصود بالكوارث الأولبئية }
$$

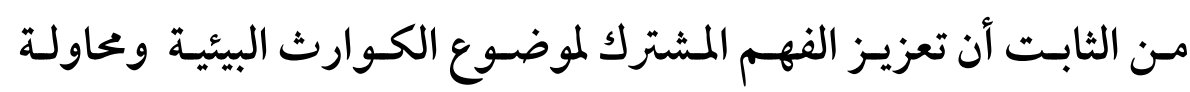

التوصل إلى حد أدنى من الاتفاق العالمي حسول مـا يتعلق بها مـن إشـكاليات ،

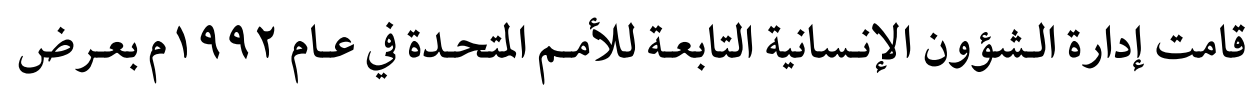

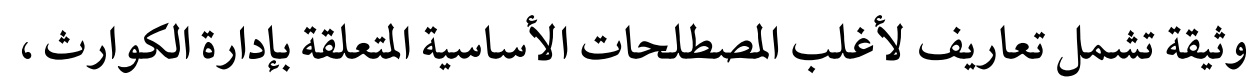
وذلك لاستخدامها بصفة عامة مـن قبل السلطات والمارسين والمختصين في هذا المجال ، ومن بينها مصطلح الكارثة البيئية ، والذذي يتمحسور في حـدوث

(1) Rothe 'Camilla! Schunk 'Mirjam! Sothmann 'Peter؛ Bretzel ، Gisela؛ Froeschl، Guenter؛ Wallrauch 'Claudia؛ Zimmer ، Thorbjörn! Thiel' Verena! Janke ‘Christian "Transmission of 2019nCoV Infection from an Asymptomatic Contact in Germany".New England Journal of Medicine. doi:10.1056/NEJMc2001468. 


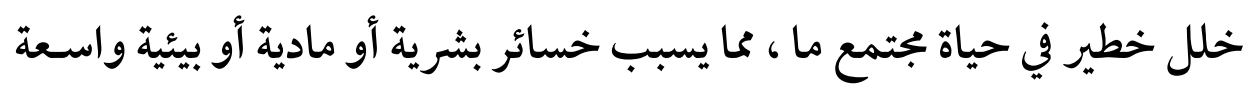
النطاق ، تفوق قدرة المجتمع المضار على مواجهتها بالاعتماد على موارده الذاتية ('). والكوارث هي أخطار كبيرة، غالباً ما تكون مفاجئة تصيب الإنسان والبيئة

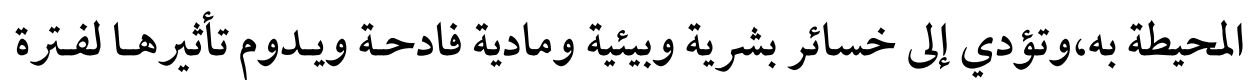

$$
\text { طويلة من الزمن (†). }
$$

وعلى ذلك نتنـاول في هـذا المطلـب المقصصود بـالكوارث البيئيـة في القـانون

$$
\text { الدولي من خلال الفرعين التاليين: }
$$

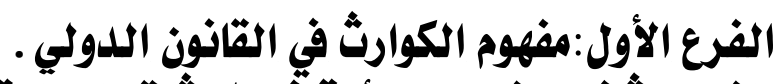

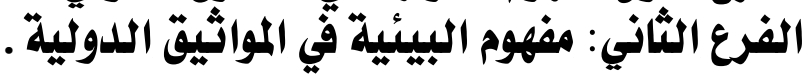

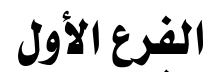 \\ مفهوم الكوارث في القانوز الدولي}

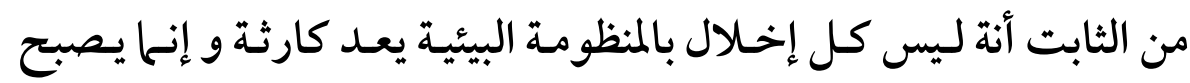

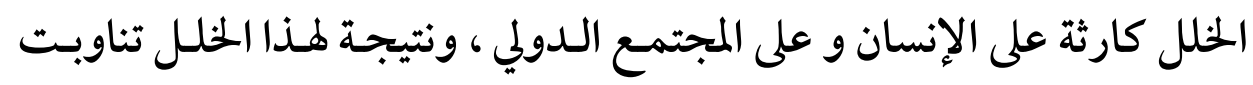

المنظومة أنشطة بشرية ومواد صناعية ،لا تستطيع المنظومة تمثلها في دورة الحياة

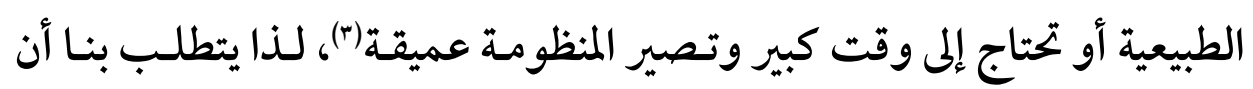

$$
\text { نوضح المقصود بالكوارث في القانون الدولي؟ }
$$

(1) Internationally agreed glossary of basic terms related to disaster management, Department of Humanitarian Affairs (D. H. A ) Geneva, December 1992, p .27 .

راجع في ذلك:د. جمال حواش، د.عزة عبد الله، التخطيط لإدارة الكوارث وأعحال

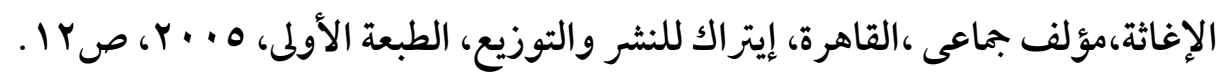

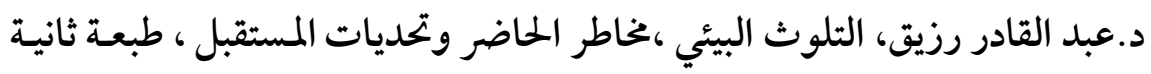

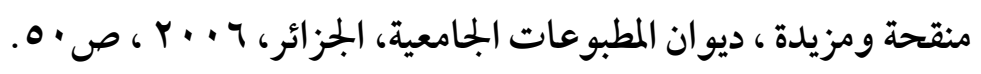


تناولت الوثائق الدولية المتعددة مصطلح الكارثة بصفة عامة ولكنها لم تتفق فيها بينها على تعريـف واضـح ومحدد لها ولكنها تعـد محساولات للوصـول إلى مفهوم لا يخرج عن النطاق المحدد للكارثة (1).

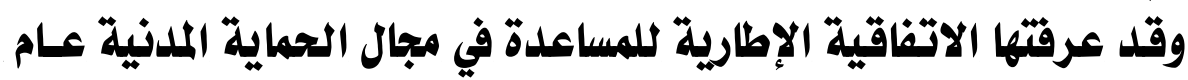
r...

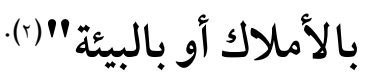
ويؤخذ على هذا التعرف بأنة لم يوضح الوضع الاستثنائي وما إذا كان مقيداً

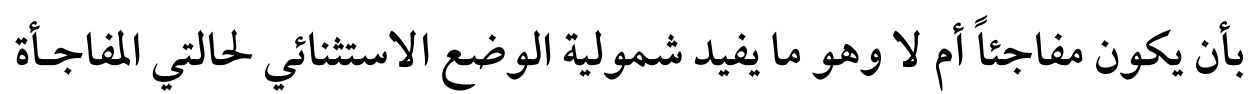

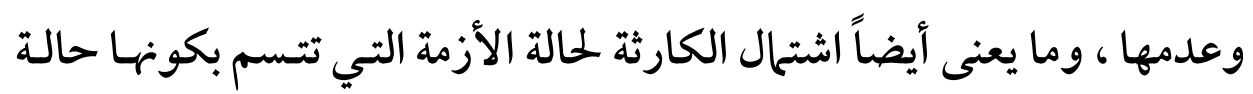
مفاجئة ، أو بها بعض عناصر و وعنى المفاجأة "(r).

(1) وتعـد مـن هـذه المحاولات على سبيل المثال : اتفاقية البلدان الأمريكية لتسهيل

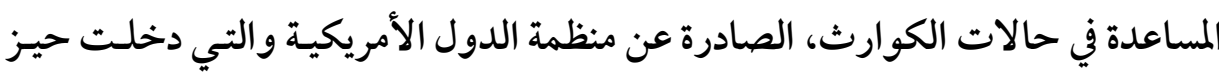

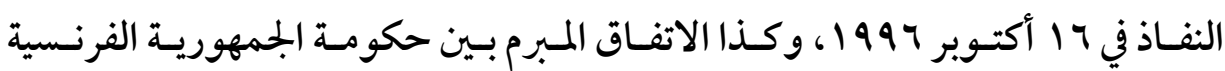

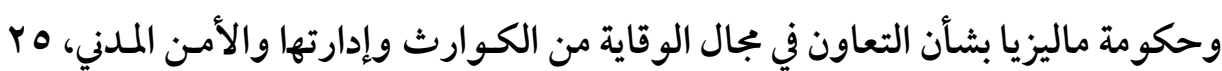

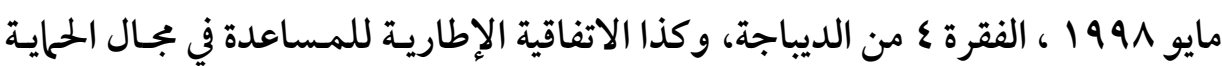

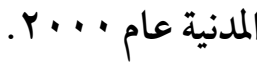
راجع في ذلك: المادة ا فقرة ت ،الاتفاقية الإطارية للمساعدة في بجال الحماية المدنية

$$
\text { عام .... }
$$

د. إبـر اهيم محمـد العنـاني، النظـام الـدولي في مواجهـة الأزمـات والكـوارث ، دار

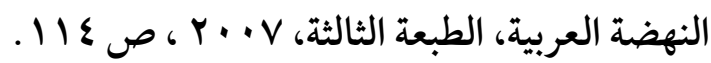


(1\{7)

حماية الأثخاص في حالات الكوارث البيئية في القانون اللدولي

وحيث تناول المقرر الخاص المعنى بحماية الأشخاص في حالات الكوارث، بأن فئن

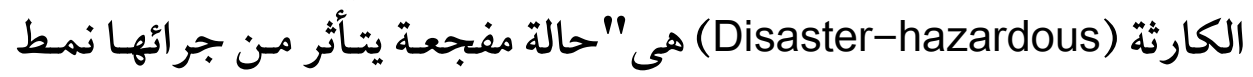

الحيـاة اليوميـة فجـأة ويسصبح النـاس بــدون مسساعدة ويعـانون مـن ويلاتهـا

ويسصيرون في حاجـة إلى حمايـة، وملابـس ،وملجــأ ، وعنايـة طبيـة واجتماعيـة

$$
\text { واحتياجات الحياة الضرورية الأخرى"((). }
$$

\section{وفى تعريف الإستراتيجية اللدولية للحلد من الكـوارث ISDR فيما يتعلق} بمفهوم الكارثة فقد تناولته بعدة مفاهيم: - ماهيم

- - اضطر اب في أداء المجتمع أو التجمعات يتضمن خسائر كبيرة وآثـار

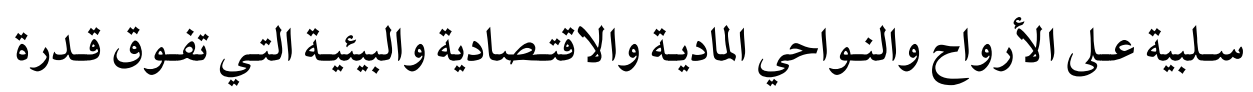
المجتمع أو التجمع العمراني المتأثر على مواجهتها باستخدام موارده الذاتية. - - هي حدث يتأثر به عدد كبير من الناس مسبباً خسائر فادحة في الأرواح والممتلكات والمصادر الطبيعية وتأثير مباشر على الاقتصاد القومي والاجتهاعي.

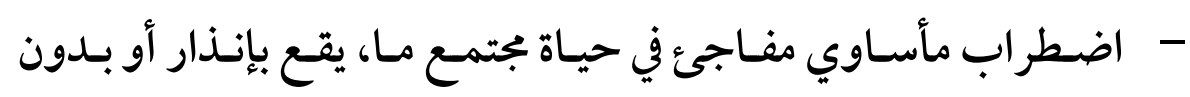

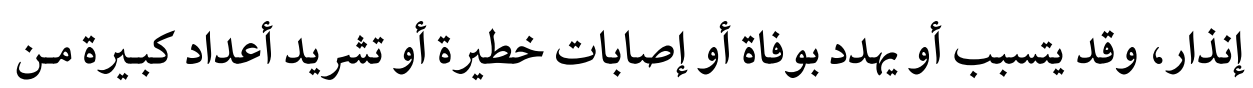
الأفر اد تفوق قدرة الطوارئ والسلطات.

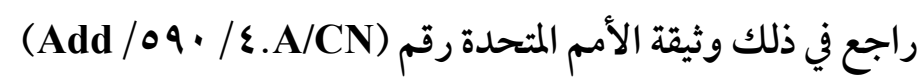

H. Fischer, "International disaster response law treaties: trends, patterns, and lacunae" in IFRC, International disaster response law.principles and practice: reflections, prospects and challenges (2003), at pp. 24-44 


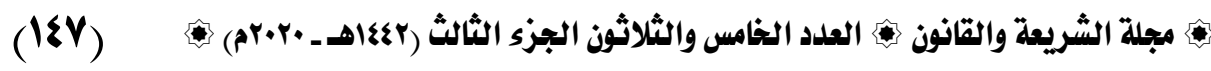

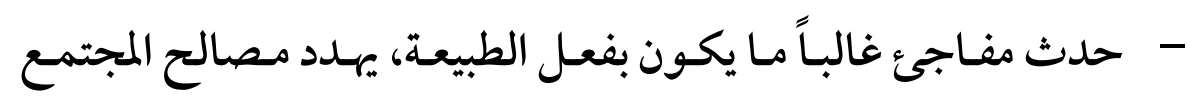
الاجتماعية والاقتصادية ويخل بالتوازن الطبيعي،والاستقرار ومن شأن الكارثة أن تربك و تشل الحياة اليومية للمواطن (1).

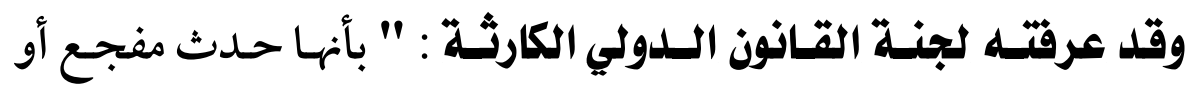
سلسلة أحداث مفجعة تؤدى إلى وقوع خسائر في الأرواح على نطاق كبير، أو

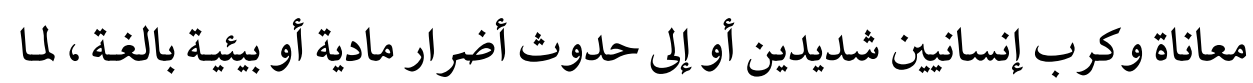
يخل بشكل خطير بسير المجتمع "(r).

\section{بينمـا عرفتهـا المنظمسة اللدوليـة للحمايــة الملدنيـة (ICDO) عسلى أنها}

"حوادث غير متوقعة ناجمة عن قوى الطبيعة أو بسبب فعل الإنسان وترتب

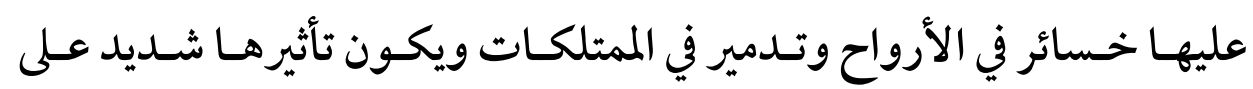
الاقتصاد الوطني والحياة الاجتحاعية وتفوق إمكانيات مواجهتها قدرة الموارد الوطنية وتتطلب مساعدة دولية "(r).

(1) International Decade for Natural Hazard Reduction, IDNDR program forum : A safer world in the 21 st century : Disaster and Risk Reduction , International Forest Fire News ( IFFN ) . No.21, October 1999, Pp. 84 -87

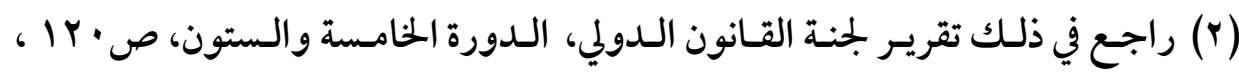

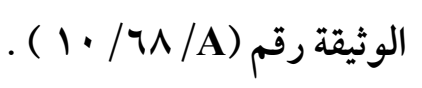

(r) وحرى بالذكر تعد المنظمة الدولية للحماية المدنية هى منظمة حكومية دولية هدفها

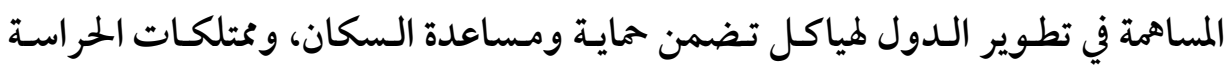

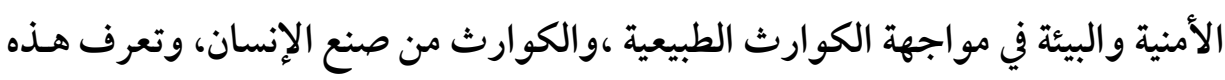

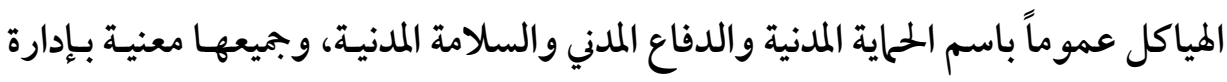


وعرف الاتحاد الدولي للصليب الأحمر الكارثة بأنها “"اختلال خطير في أداء

المجتمع، وهـو مـا يشكل خطراً جسياً وواسع الانتشار يهـدد حيـاة الإنسان

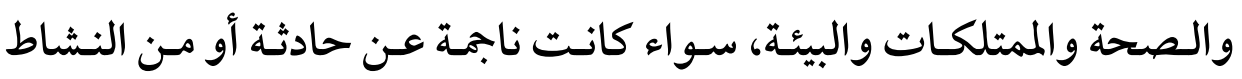

الطبيعي أو الإنساني، وسواء ظهرت فجأة أو نتيجة عمليـات طويلة الأجل،

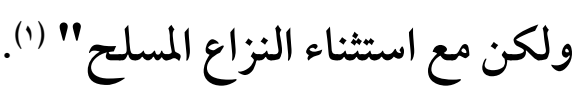

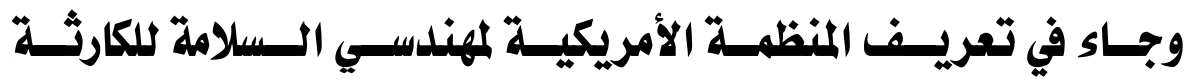

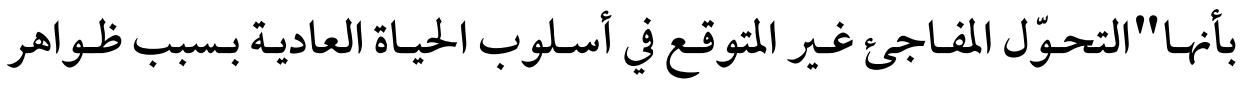

طبيعية أو من فعل إنسان تتسبب في العديد من الإصابات والوفيات أو الخسائر

المادية الكبيرة" (ن).

وعرفها البعض بأنها حدث ينجم عنة خسائر كبيرة في الأرواح والممتلكـات

وتلوث للبيئة، وقد تكون طبيعية أو بفعل الإنسان سواء كان هذا الفعل إرادياً

حالات الطوارئ ، والتي أنشأتها بجموعة من الدول بهدف تعزيز حماية الأشـخاص من

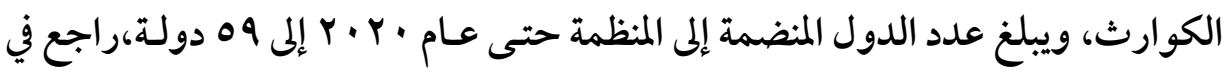

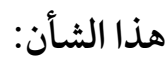

International Civil Defense Organization (ICDO)

http://www.icdo.org

(1) Fidler, David P. "Governing Catastrophes: Security, Health and Humanitarian Assistance." International Review of the Red Cross 866 (June 2007) : 247-70.

(2) The ICDO is the intergovernmental organization which federates national civil protection, civil defense, civil safety and emergency management structures as foreseen under the terms of General Assembly resolution 2034 of 7 December 1965. 


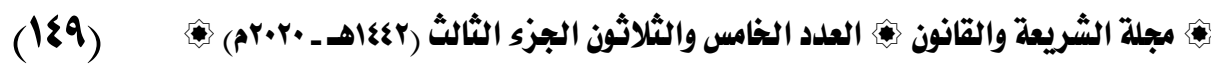

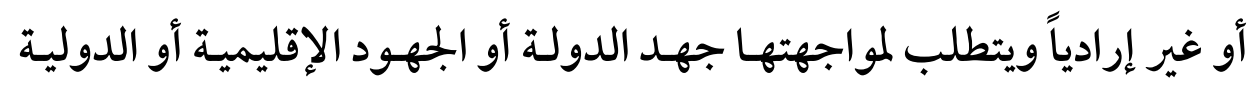
وفق حجم الكارثة وحجم الخسائر التي تنجم عنه/(1). دليل الدفاع الملدي الصناعي الكارثة "هي حادثة كبيرة ينجم عنها خسائر جسيمة في الأرواح والممتلكات وقد تكون كارثة طبيعية مردها فعـل الطبيعة (سيول، زلازل، عواصف.. الخ) وقد تكون كارثة فنيـة سببتها يـد الإنسان

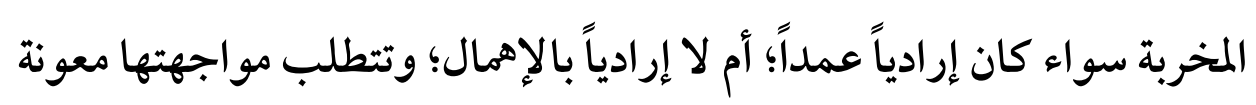
الأجهزة الوطنية كافة حكومية وأهلية؛ أو الدولية إذا كانت قـدرة مواجهتها

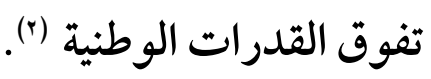
ومن خلال ما سبق يمكن القول أن الكارثة هي حدث مفجع يأتي فجأة ، قـد

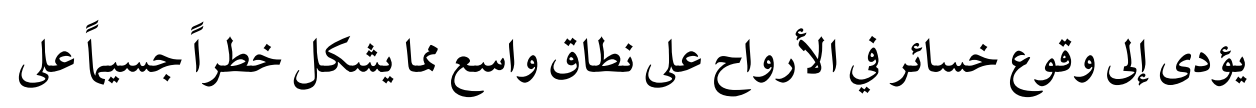
صحة و حياة الأشخاص والمجتمع البيئي على أوسع نطاق ، مما يكون له تـأثير مباشر على الاقتصاد القومي والاجتهاعي .

(1) د. جمال الدين أحمـد حواش ، إدارة الأزمات والكـوارث ضرورة حقيقيـة ، المؤتمر

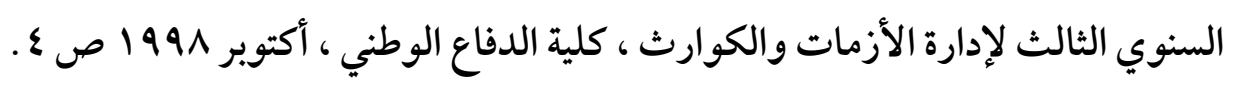

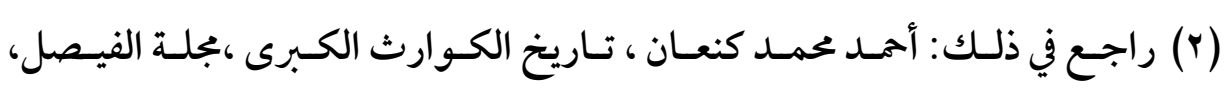

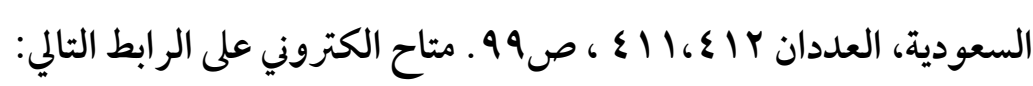
https://books.google.com.eg 
(10.) حماية الأشخاص في حالات الكوارث البيئية في القانوز الدولي

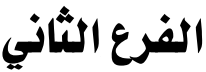 \\ مفهوم البيئة في القانّون الدولي}

ترجع أهمية البيئة للإنسان بصفة عامة في كونها أصل نشأته ،و بدايـة مادته

فمنها خلق و عليها و فيها يجيا و يـارس دوره المنوط بـه،و في باطنها يقبر و

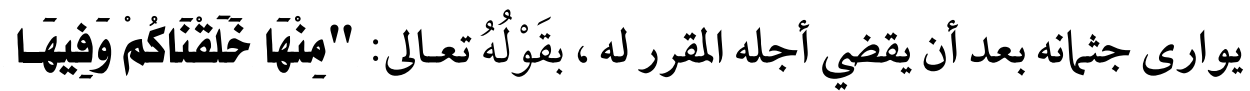

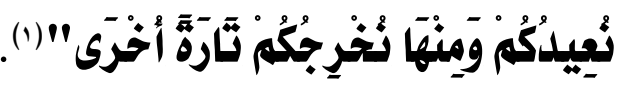

ويعد مدلول- البيئة- من المصطلحات التي تستخدم لأكثر مـن معنى أو

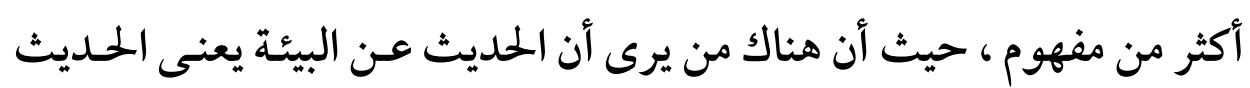

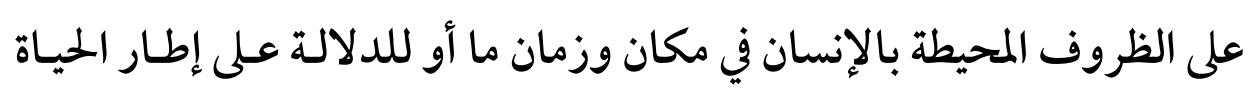
والطبيعة (ץ).

وهناك مـن يعكس التصور لهـذا المفهوم باعتبـار التلـوث ومـا يلحقـه مـن

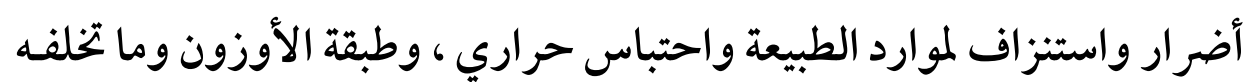
الحروب من آثار وخيمة أو من تطورات بيولوجية نوويـة قد تؤدى إلى انتشار الأوبئة والفيروسات في البيئة (r). ولكي يمكننا بيان مفهوم البيئة في القانون الدولي تجدر الإشارة إلى مـا أبمـع علية الفقه الدولي من محاولات للتوصل إلى تعريف موحـد للبيئة فقـد تعـددت

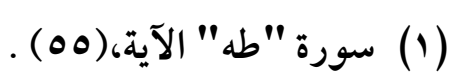

(ץ) د.محمد طلعت الغنيمى،بعض الاتجاهـات الحديثة في القـانون الدولي العام، قانون

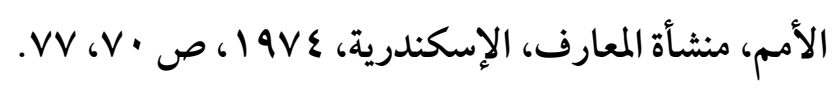

(3) Ensemble des éléments naturels $t$ artificiel qui entourent un individu humain animal ou vegetal, ou une espèce ", le petite la rousse illustré, Paris , 1990 . p 377. 


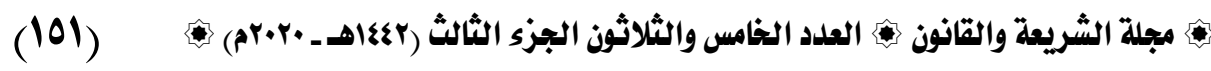
التعريفات بتعدد من تناولها؛ فمنهم من عرف البيئة على أنها الإطار الذي يعيش فيه الإنسان بها يضم من ظـاهر ات طبيعيـة، وبـشرية، يتـأثر ويسؤثر بهـا، ويكـل على مقو مات حياته من غذاء وكساء و مأوى، ويـارس فيـه علاقاته مـع أقرانـه من البشر (1)، في حسين عرفهـا البعض بأنها بجموعـة القواعـد القانونيـة الدوليـة العرفية والاتفاقية المتفق عليها بين الدول للحفاظ على البيئة من التلوث(؟). وقد عرفها البعض "بأنها بجموعه العوامل والظروف الطبيعية والاقتصادية و الثقافية التي تتجاوز في توازن دقيق ،وتشكل الوسط الطبيعي لحيـاة الإنسسان و الكائنات الأخرى ويككمها ما يسمى بالنظام البيئي "(r). ومنهم من عرفها " بأنها بجموعه من العلاقات المتبادلة بـين الكائنـات الحيـة وبيئتها الطبيعية التي يعيش فيه الإنسان ويكصل منه عـلى مقومـات حياته، مـن غذاء ،و كساء، ودواء ،ومأوى ،يهارس فيه علاقاته مع أقرانه من بني البشر (؛. (1) د.أحمد أبو الوفا، تأملات حـول الحلايـة الدوليـة للبيئة مـن التلوث، المجلـة المصرية

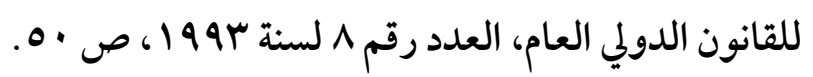

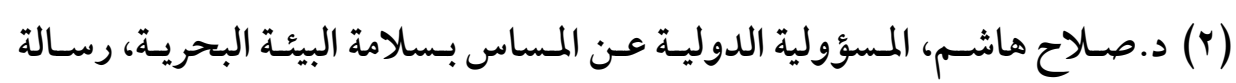
دكتوراه، جامعة القاهرة، 1991 19، ص بr.

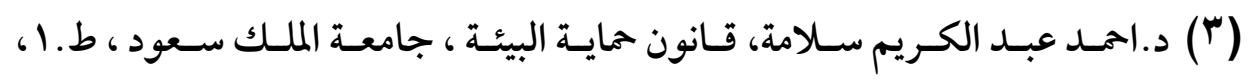
199V (ع) د.سعيد محمد الحفار،الموسوعة البيئية العربية،المجلد الأول، مطابع الدوحـة الحديثة

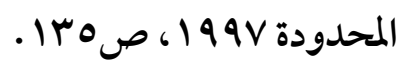




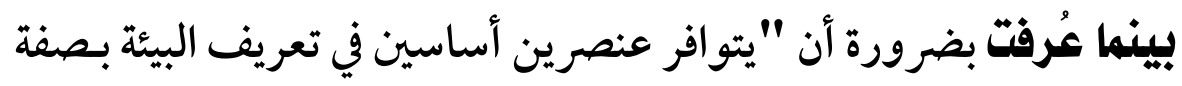
عامة سواء في القانون الوطني للدولة أو قواعد القانون الدوى للبيئة:

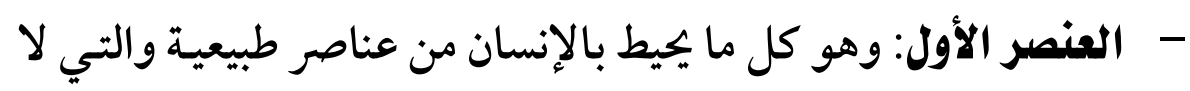

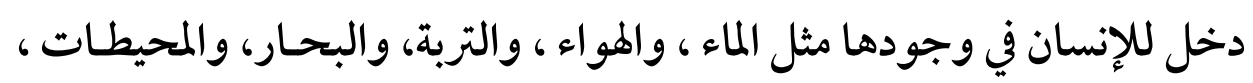

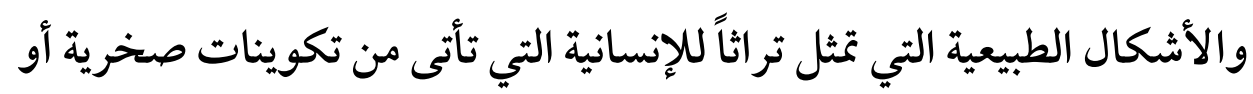
جبلية أو رملية وتمثل قيمة ثقافية عالمية وأيضاً النباتات والحيوانات") - - العنصر الثاني: يتمثل في البيئة الصناعية التي أسهم الإنسان بتدخله في ولئ

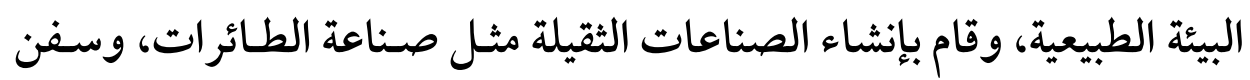
الطائرات، وسفن الفضاء والصناعات النووية "(؟). وفى تعريف منظمة اليونسكو للبيئة تعريفاً واسعاً على أنها "هي الجزء الذي ولئي

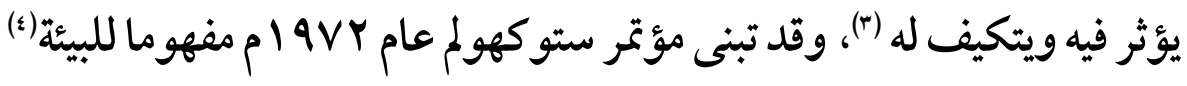

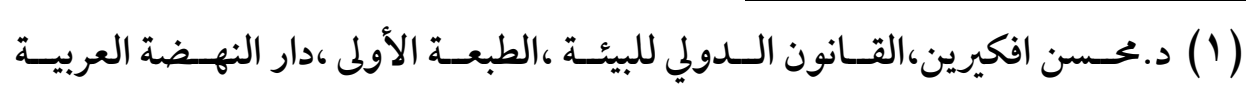

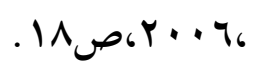

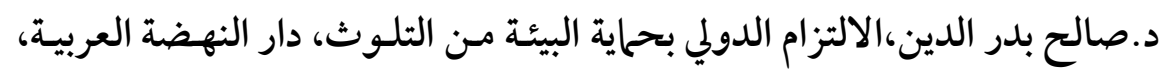

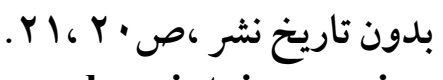

(3) The World Bank supported the creation and maintainsongoing support of UIS, especially the development of consultative mechanisms, new survey strategies, and strengthening national education statistics programmes.

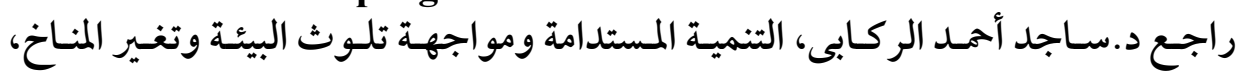

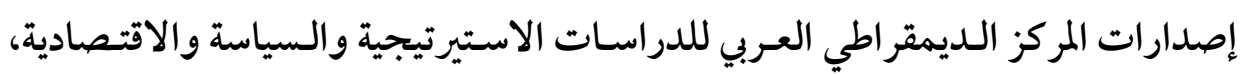

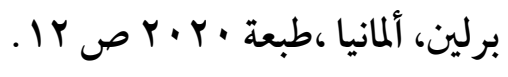

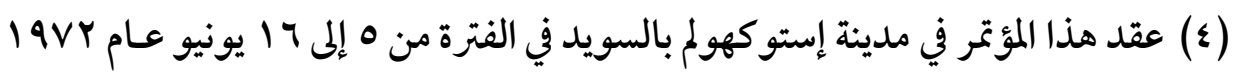

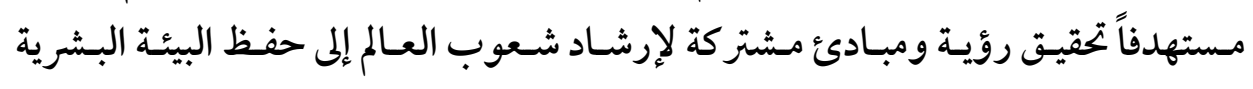




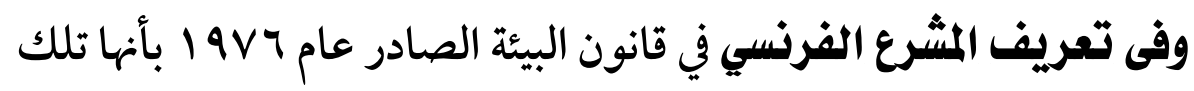

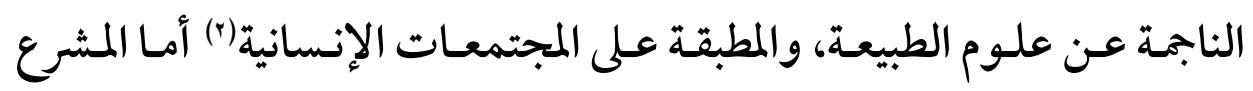
المصري فقد عرف البيئة بأنها "المحيط الحيوي الذي يشمل الكائنات الحية وما

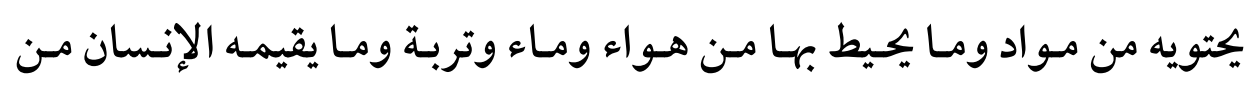
منشآت (r).

ومن خلال ما سـبق يمكـن القـول أن مفهوم البيئة بمعناهـا الواسع يمثل

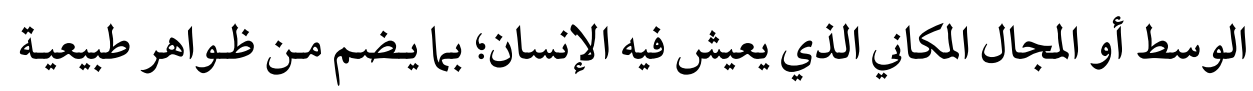

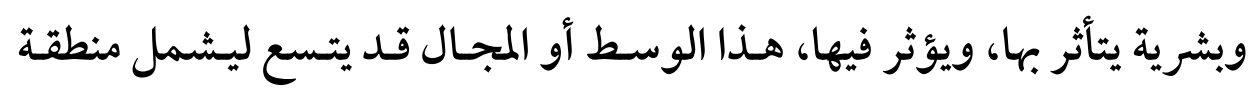

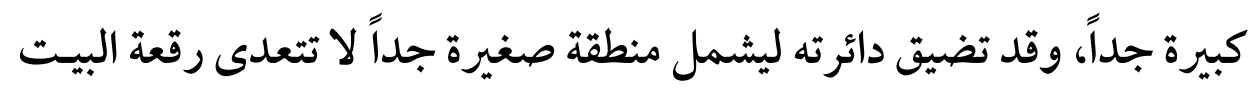
الذي يسكن فيه الإنسان.

وتنميتها ،و كذلك بحثث السبل لتشجيع الحكومات والمنظات الدولية للقيام بـا يجـب

$$
\text { لحماية البيئة وتحسينها. }
$$

Depuis la Conférence des Nations Unies sur l'environnement tenue à Stockholm en 1972, la relation entre les droits de l'homme et l'environnement a fait l'objet d'une attention accrue de la part des États, des institutions internationales et de la société civile.

(1) MICHEL PRIEUR, Droit de l'environnement, DALLOZ,PARIS,4 édition, 2001, P 40.

(2) "Les deux sens habituels du mot environnement il subsiste neamoins deux sens differents dans la langue actuelle; Celui qui est issu des sciences de la nature et applique aux societes humaines" Prieur (M) “Droit de l'environnement",2e edition, Dollaz, Paris, 1991, P.3.

$$
\text { راجع في ذلك القانون رقم ع لسنة \199 ا. }
$$


(108)

حماية الأشخاص في حالات الكوارث البيئية في القانون الدولي

$$
\text { التمييز بين الكوارثي الثاني البيئة }
$$

لتحديد أي من قواعد القانون الـدولي التي يجوز تطبيقها في حالة بعينها،

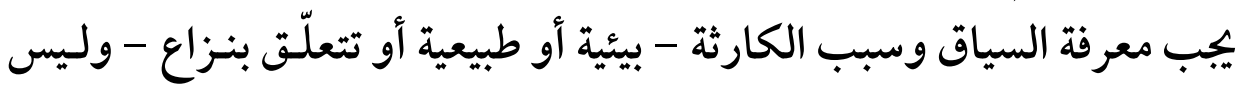
نطاقها، ومدى احتياجات المتأثرين بها، حتى يتسنى تطبيق القانون الإنساني.

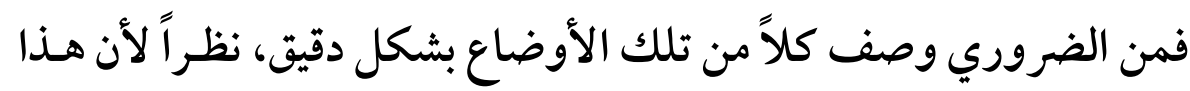

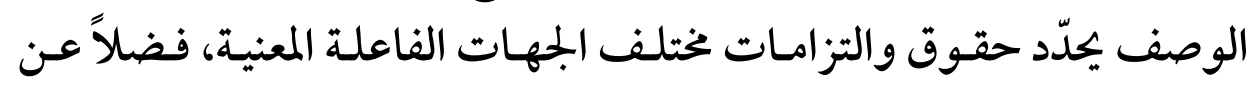

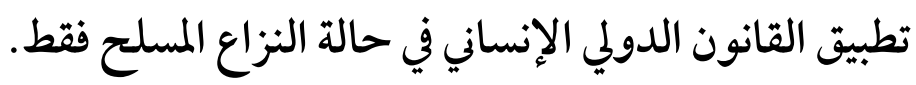

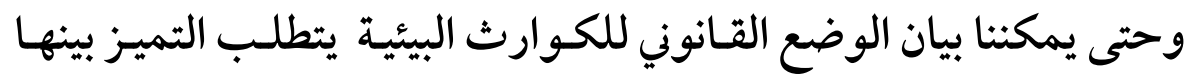
وغيرها من الكوارث على النحو التالي :

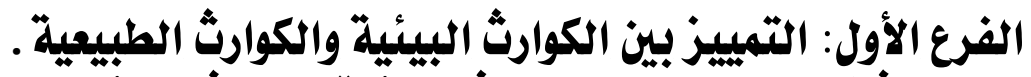

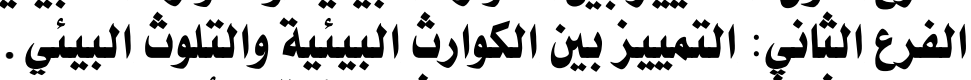

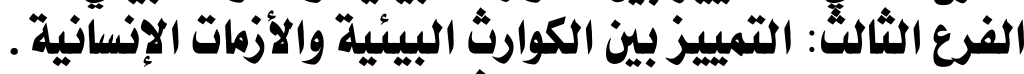

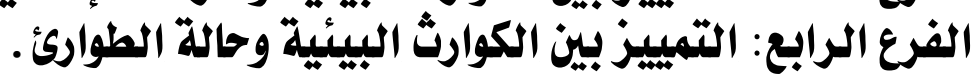

$$
\text { التمييز بين الكوارث الأولٍ البيئية }
$$

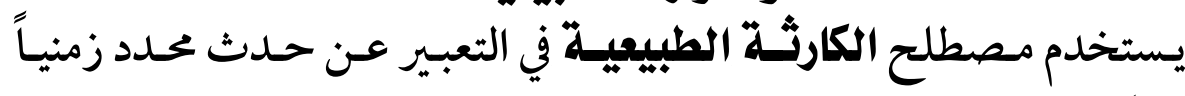

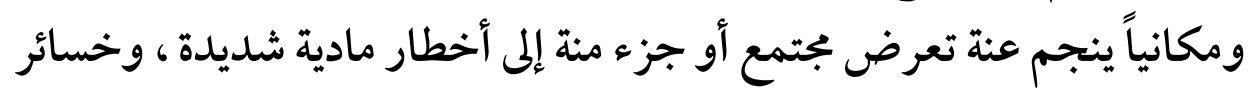

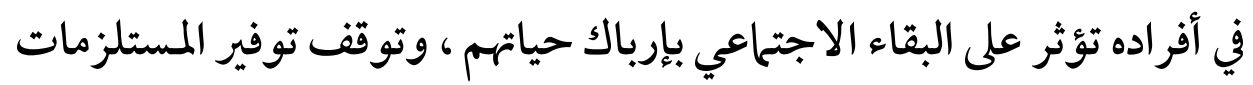

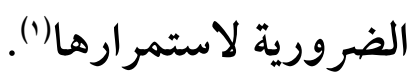

(1) د.منى صلاح الدين شريف، إدارة الأزمات في قطاع الغزل و النسيج ، رسالة دكتوراه

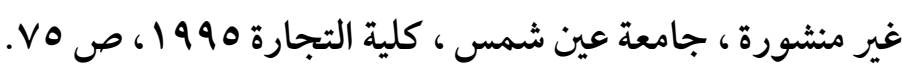




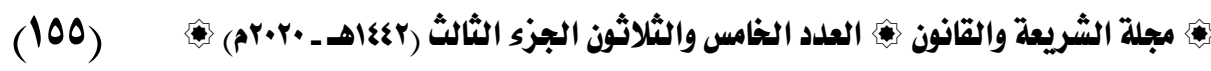
أما مصطلح الكارثة البيئية فيستخدم في وقوع حـدث نجـم عنة خسائر كبيرة في الأرواح والممتلكات وتلوث للبيئة،سواءُ أكانت إرادية أو غير إرادية،

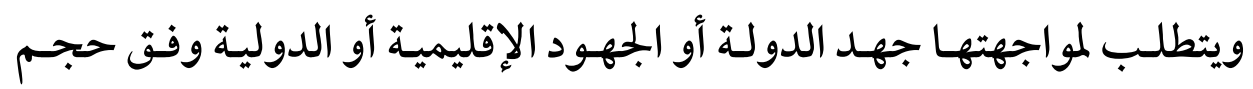
الكارثة وحجم الخسائر التي تنجم عنه|(1).

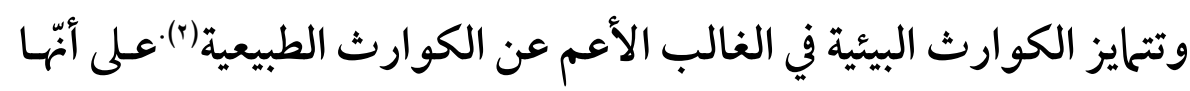

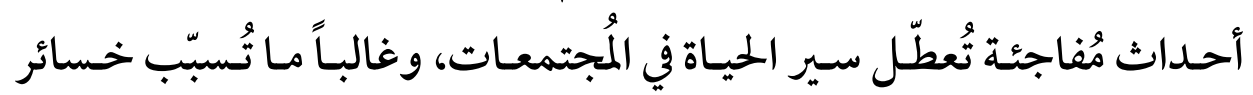

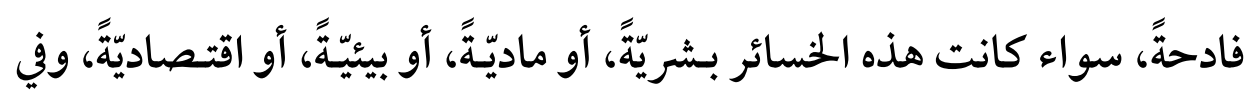

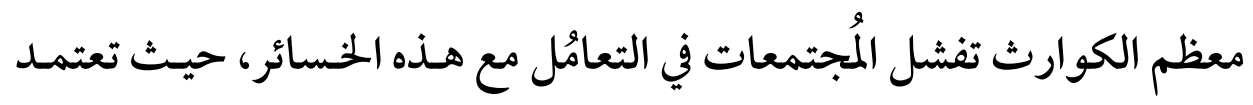

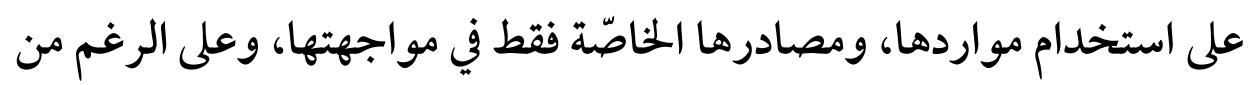

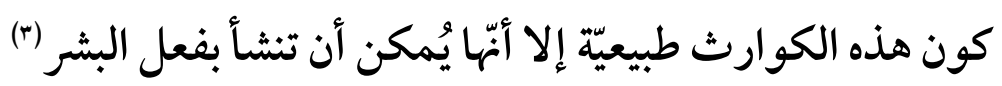

(1) د.جمـال الدين أحمـد حسواش ، إدارة الأزمات والكـوارث ضرورة حقيقيـة ،مرجـع سابق ص ع. (ץ) وتجدر الإشارة أن ما يميز الكوارث البيئية عن التلوث الحاصل على البيئة، أن الآثار

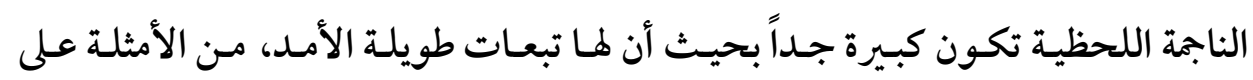
الكوارث البيئة التسرب النفطي والكوارث الحاصلة على المنشآت النووية مثل كارثة تشيرنوبيل وكارثة فوكوشيا.

(3) Jared M. Diamond, Collapse: How Societies Choose to Fail or Succeed, 2005 


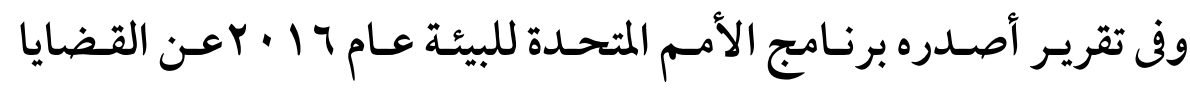

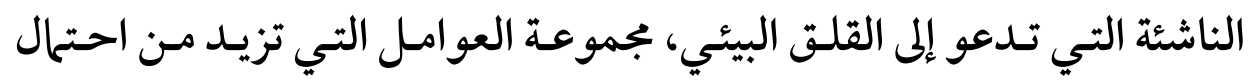

انتقال العوامل الممرضة مثل فيروس "كورونا" من الحيوانات إلى البشر (().

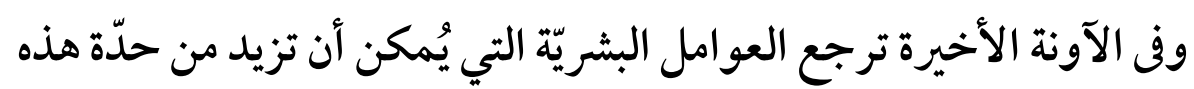

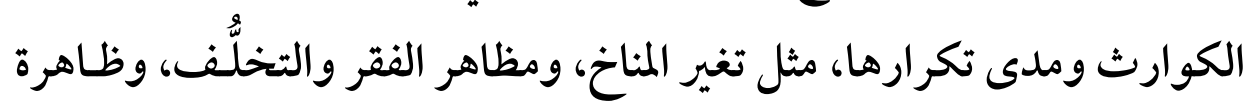
التوسُع العمراني غير المدروس، وغيرها (†).

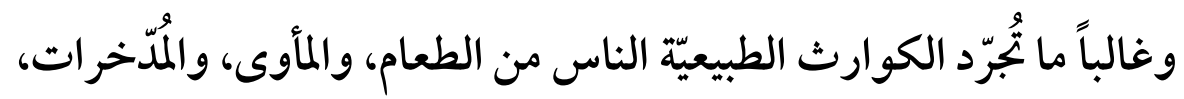
وقد تتسبّب في تشتّت العـائلات، وإغـلاق المدارس والمر افتق الطبيّة، وتأخبّر

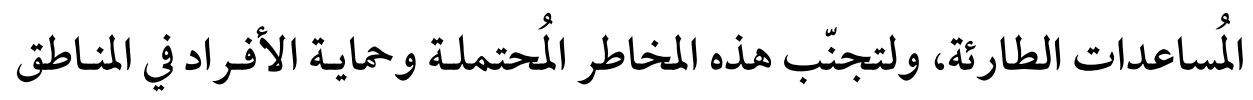

المعرّّة للخطر، يجب تطوير نظام إنذار مُبكّر يتنبّأ بموقع وشدّة الكارثة (r).

(1) ويوجز التقرير هذه العوامل في التعديات التي تطال التنوع الحيوي، كإزالة الغابات

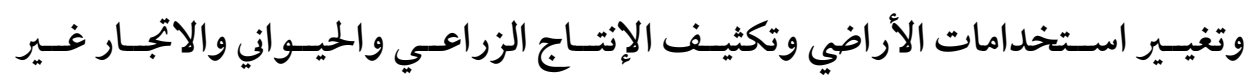

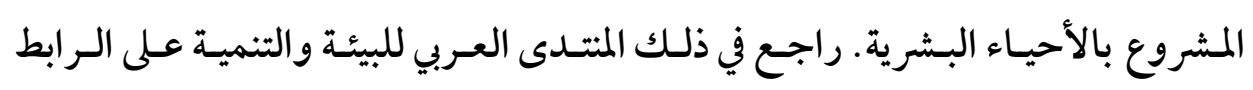
http://afedmag.com : الالكتروني

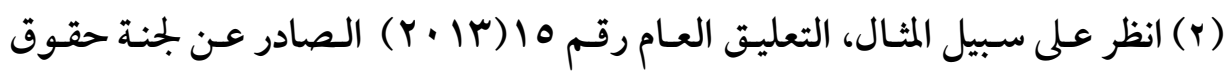

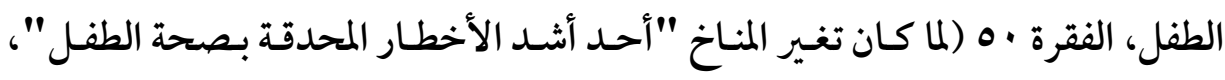

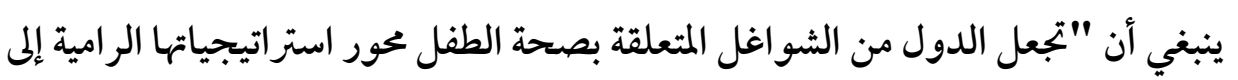

$$
\begin{aligned}
& \text { التكيف مع تغير المناخ والتخفيف من آثاره") . } \\
& \text { (r) انظر على سبيل المثال: }
\end{aligned}
$$

Ashgar Leghari v. Federation of Pakistan (Lahore High Court Green Bench, 2015) Massachusetts v. Environmental Protection 


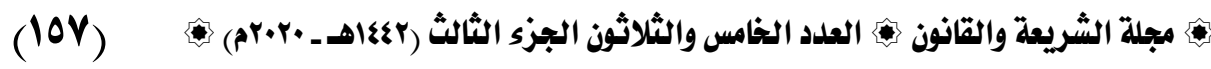

في حين ذهبـت اتفاقيـة تـامبير المتعلقـة بتقـديم مـوارد الاتصـالات السلكية

و اللاسـلكية للحـد مـن الكـوارث ولعمليـات الإغاثـة الصادرة عـام1991 في

المادة ا / ج إلى تعريف الكارثة الطبيعيـة بأنها : "حسدوث خلل خطير في حيـاة

ججتمع ما ، محا يشكل تهديداً واسع النطاق لحياة البشر أو صحتهم أو متلكـاتهم

أو للبيئة ، سواء كان ذلك الخلل ناجمـاً عن حـادث أو سـبب طبيعي أو نشاط

بشري ، وسواء حدث بصورة مفاجئة أو تطور نتيجة لعمليـات معقـدة طويلـة

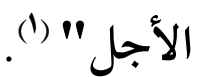

وقد عرفت المبادى التوجيهية التشغيلية المتعلقة بحقوق الإنسان والكوارث

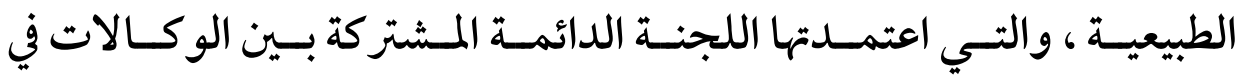

عامج · · r م ، حيث عرفت الكارثة الطبيعية بأنها : "آثار الأحداث التي تسبيت

Agency (U.S. Supreme Court, 2007) ؛Urgenda Foundation v. Kingdom of the Netherlands (District Court of The Hague, 2015

(1) Tampere Convention on the Provision of Telecommunications Resources for Disaster Mitigation and Relief Operations, 1998 , Art. $1(6)$.

وتجدر الإشارة إلى أن الاتحاد الدولي لجمعيات الصليب الأحمر والهلال الأمر قد استخدم

نفس التعريف مع استثناء النزاعات المسلحة،وذلك في المادة Y / ا من المبادئ التوجيهية المتعلقة بتسهيل وتنظيم المساعدات الدولية للإغاثة والانتعاش الدولي على الصعيد المحلي في حالات الكوارث الصادرة عام V · . . ، و التي عرفت الكارثة بأنها :

"Disaster, means a serious disruption of the functioning of society which poses a significant,, widespread threat to human life, health, property or the environment, whether arising from accident, nature or human activity, whether developing suddenly or as the result of long - term processes, but excluding armed conflict " 
فيها مخاطر طبيعية من قبيل الزلازل وثورات البراكين وانهيارات التربة وأمواج

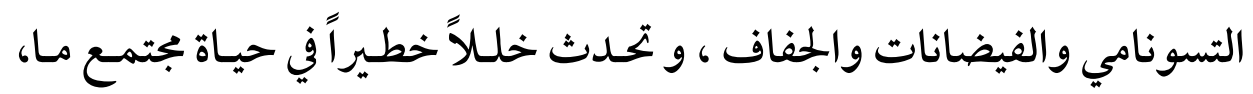
ينتج عنه خسائر بشرية أو مادية أو اقتصادية أو بيئية واسعة النطاق، تفوق قدرة المجتمع المتضرر على مواجهتها بالاعتهاد على موارده الخاصة فقط (1) .

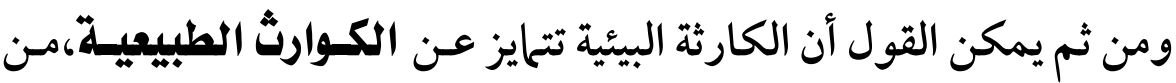

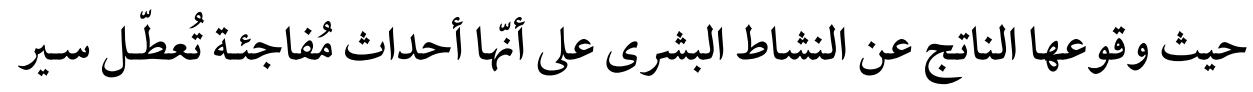
الحياة في المُجتمعات، وغالباً ما تُسبّب خسائر فادحةً، و بشريّةً.

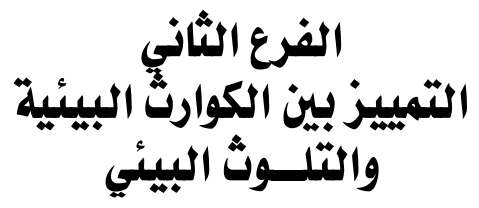

تكمن أهمية البيئة في إمكانية وجود حق الإنسان في بيئة نظيفـة متوازنة على

الأقل في نطاق القـانون، (*) فالبشر ترتبط مـواهبهم العمليـة العلميـة و الثقافيـة

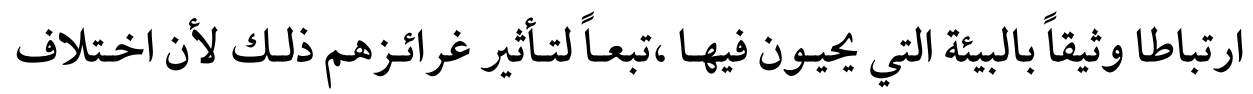

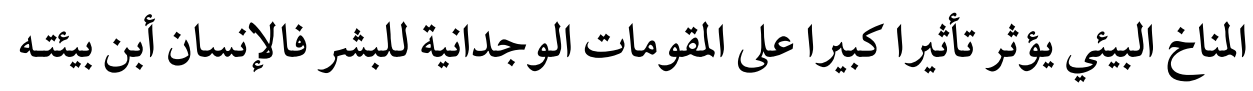

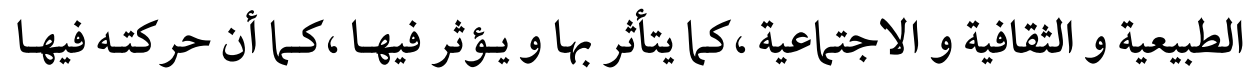
تعتمد على نوع العلاقة التي تربط بينه و بين هذه البيئة.

(1) Brookings-Bern project on internal Displacement Human Rights and Natural Disaster : Operational Guidelines and Field Manual on Human Rights Protections in Situations of Natural Disaster (2008), p.1.

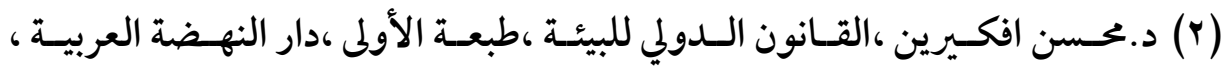

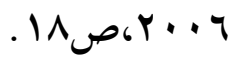




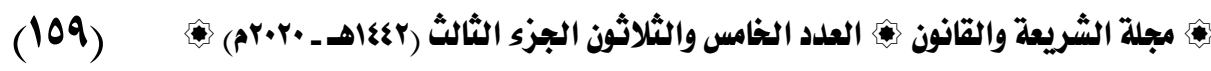

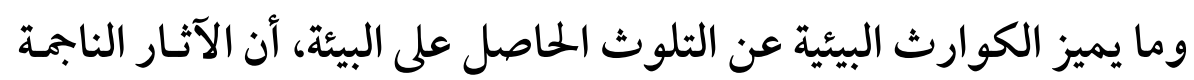

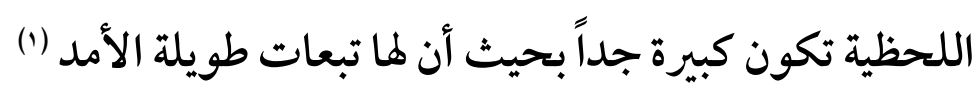

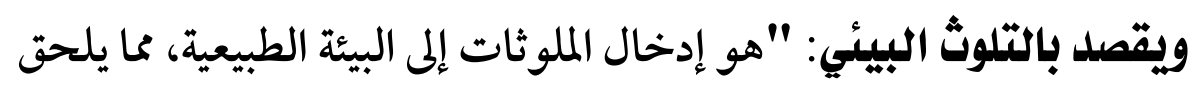

الضرر بها، ويسبب الاضطر اب في النظام البيئي، وهذه الملوثات إمـا أن تكسون

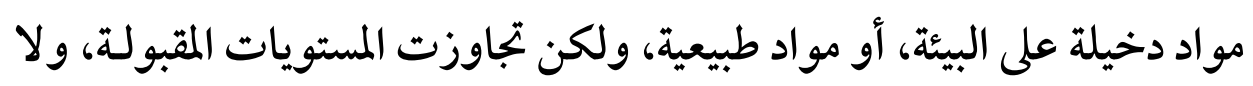

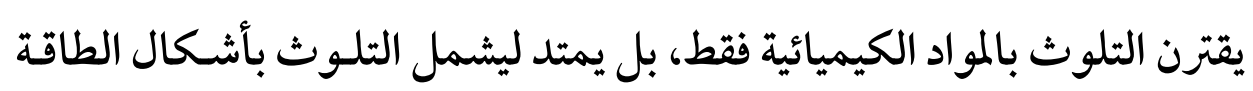

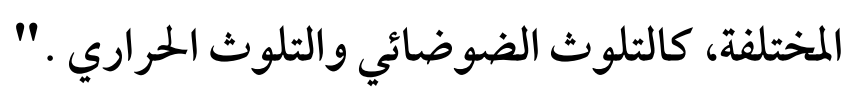

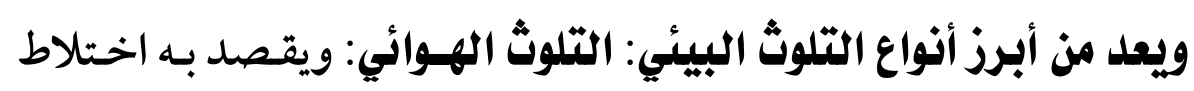

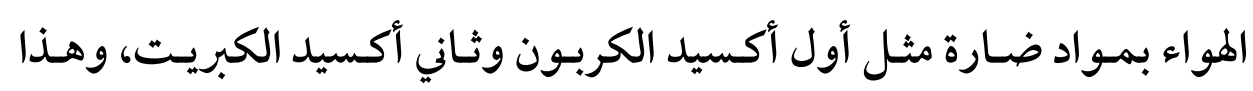

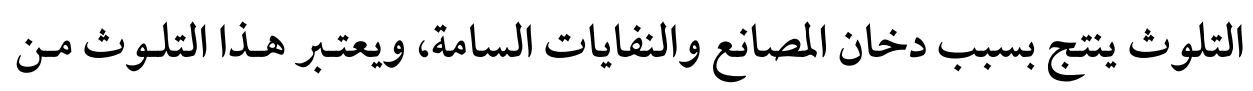

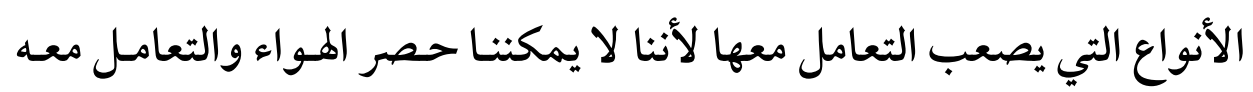
كحادة مثلم) نتعامل مع تلوث التربة(؟).

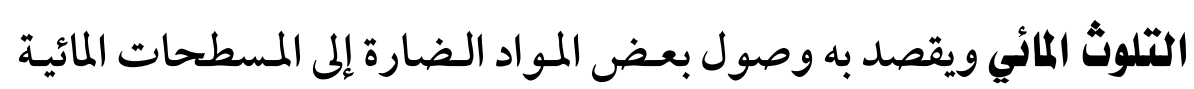

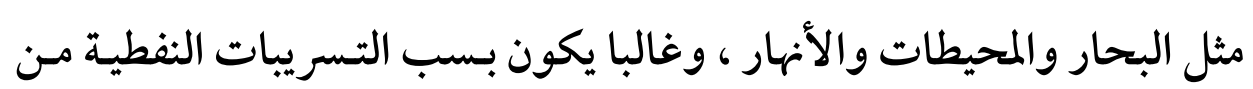
مكررات النفط القريبة مـن السواحل والمسطحات المائيـة، وقـد يكون بسبب

(1) Rone Rodiere, Martin Remond-Gouilloud ; La mer droits des hommes ou proie des etets, editions A .Pidone Paris, 1980 .p110.

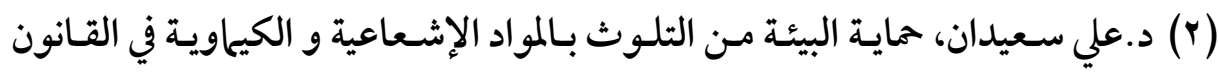

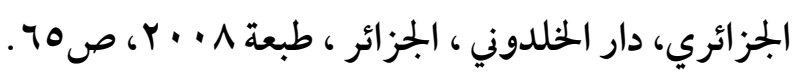




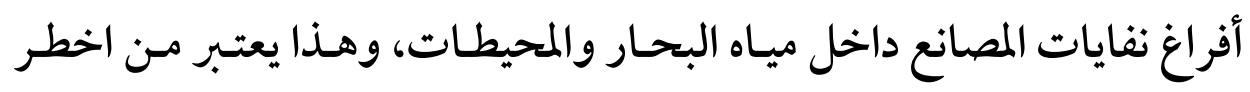
أنواع التلوث لأنه يؤدي إلى قتل الكائنات البحرية(1). التلوث الضوضائي: يقصد به الأصوات المزعجة وغير المرغوبة والتي تؤثثر

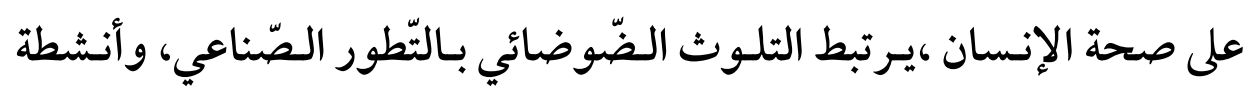

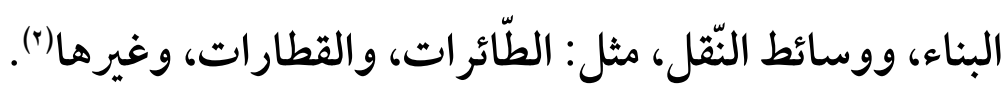

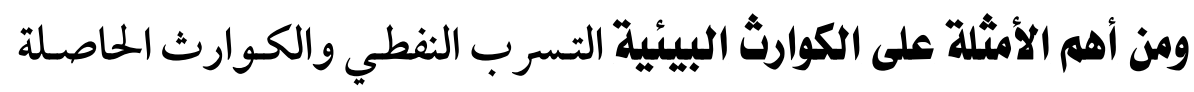
على المنشآت النووية مثل كارثة تشيرنوبيل، وهي حادثة نووية إشعاعية وقعت عام T1 9 في المفاعل رقم ع من محطة تشيرنوبل للطاقة النووية قرب مدينة بريبيات في

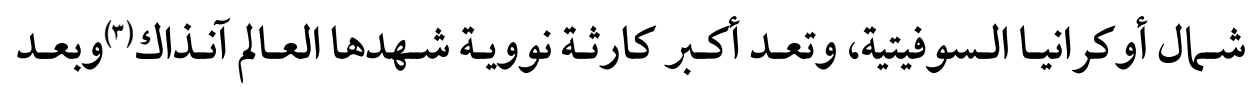

(1) Daniel M, Schwartz \& others, The Environment and Violent Conflict: A Response to Gleditsch's Critique and Some Suggestions for Future Research, Environmental change and security project report, Issue 6, 2000. P. 81.

$$
\begin{aligned}
& \text { (ץ) د.عبد المقصود زين الدين، قضايا بيئية معاصرة، المواجهة والمصالحة بين الإنسان }
\end{aligned}
$$

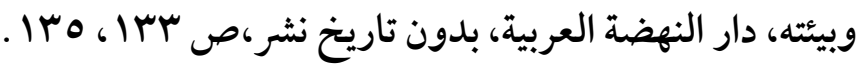

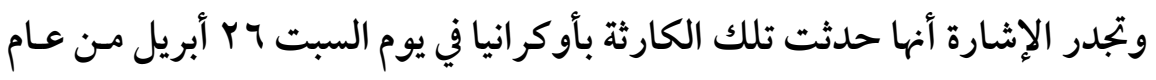

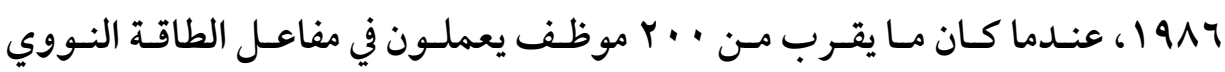

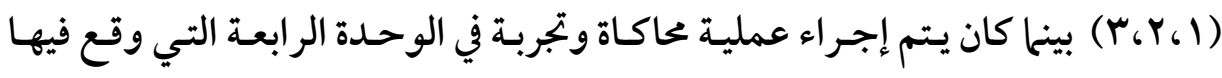

$$
\begin{aligned}
& \text { الانفجار ، وقدرت خسائر تلك الكارثة بثلاثة مليارات الدولارات،راجع في هذا المعنى : } \\
& \text { د.أبو الخير عطية، الالتزام الدولي بحماية البيئة البحرية من التلوث، رسالة دكتوراه جامعه }
\end{aligned}
$$

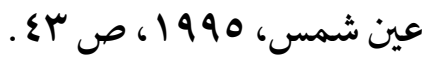


عشرات السنوات مازالت أثار تلك الكارثة تؤثر على صحة الإنسان والأطفال

$$
\text { حتى الآن (1). }
$$

ويعد كارثة وباء فيروس "كرونا " الذي أصاب المجتمع الدولي بالذعر الدي

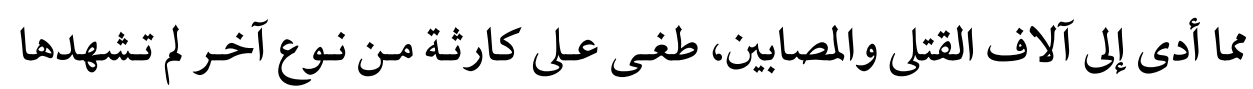

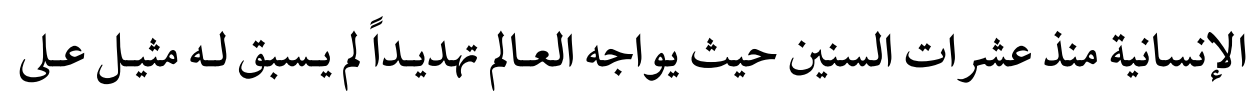

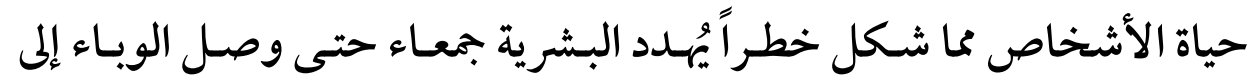

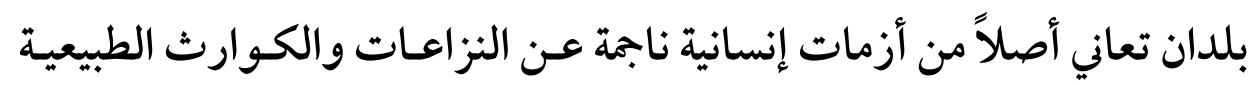
وتغيّر المناخ (r).

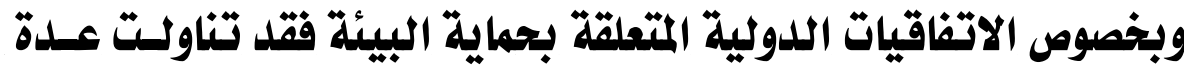

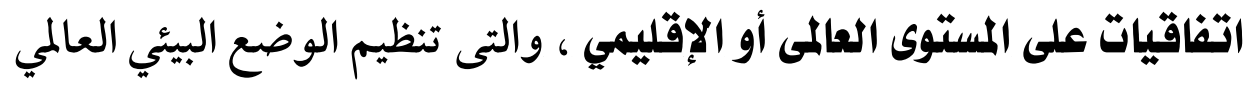

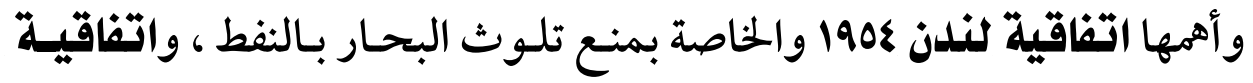

(1) إذ إن نقص مادة اليود في غذاء الأطفال الذين يعيشون في المنطقة الملوثة جعلهم أكثر

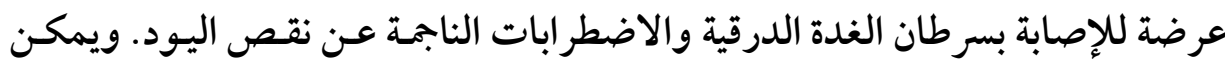

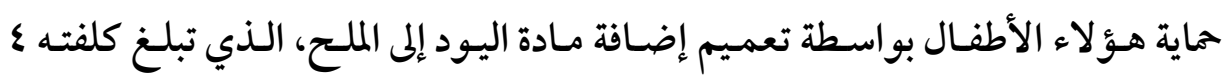

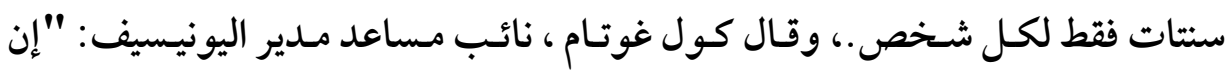

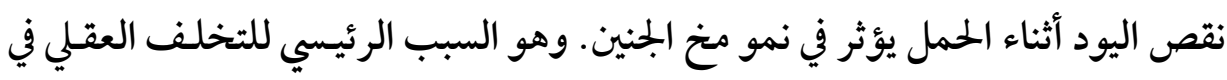

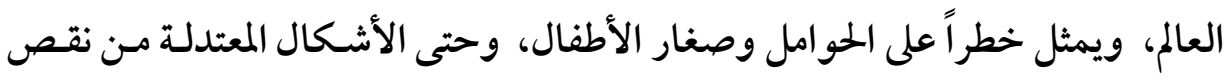

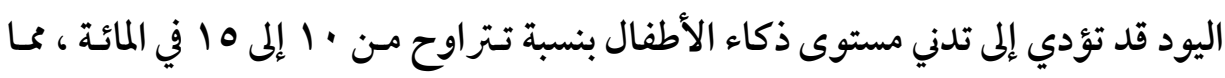
يؤدي إلى ضعف أدائهم في المدارس ويحد من إنتاجيتهم كبالغين" راجع في ذلك الكان : https://www.unicef.org/arabic/health/ukraine

(2) BY THE DEPARTMENT OF GLOBAL COMMUNICATIONS United Nations Mobilizes Globally in Fight against COVID19.https://www.un.org/ar/coronavirus. 
باريس •197 بشأن التجارب المذريـة ، واتفاقية 1979 بـشأن التدخل في أعسالي

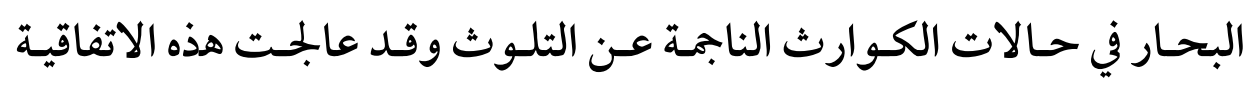
القواعد المنظمة للإجر اءات الضرورية لحاية الشواطئ في حالات وقوع أضرار

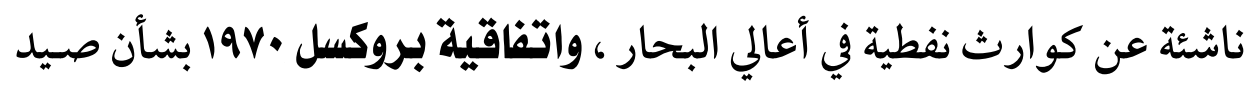

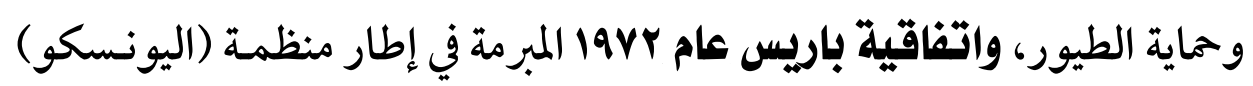

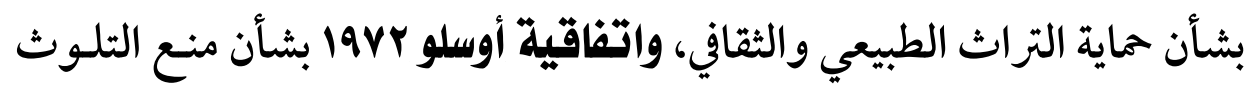
البحري من خلال إلقاء النفايـات مـن الطائرات والسفن، ومجموعـة المبـادئ

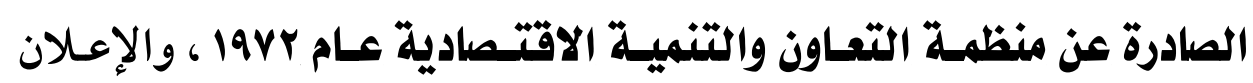
العـالمي للبيئة في اسـتوكهولهم سـنة larr ويعتبر بمثابـة اللبنـة الأولى في صرح

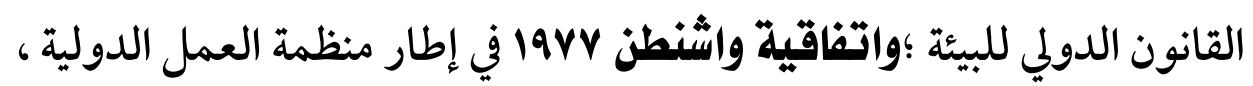

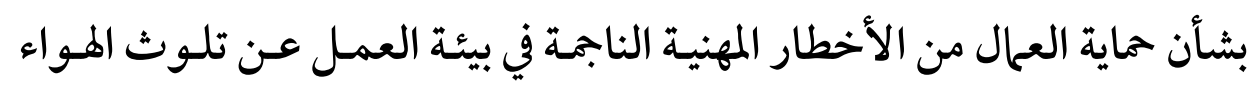
وعن الضوضاء والاهتزازات، والميثاق العالمي للطبيعة سنة •191 ، واتفاقيات

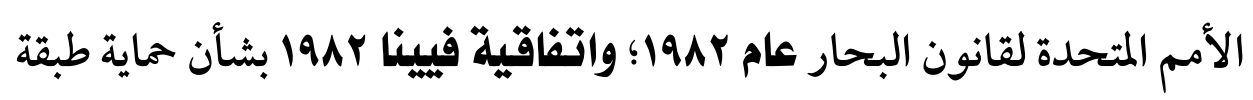
الأوزون(1)؛والاتفاقية اللدولية المبرمة سنة 1917 بشأن المساعدة المتبادلة في حالة وقـوع حساث نـووي؛ كما صـدر في هذا السياق مجموعة مـن الإعلانـات والمواثيق الدولية التي احتوت بدورها على العديـد مـن المبادئ المتعلقة بالبيئة

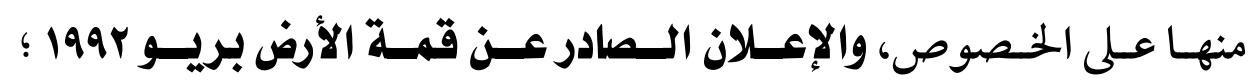

(1) وقد قررت أن على الدول الأطر اف أن تتعاون معاً في ترقية التنمية ونقل التكنولوجيا

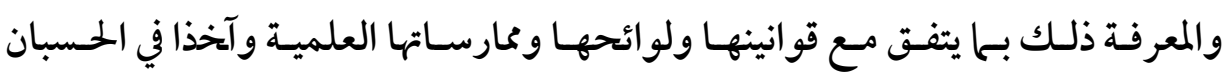
حاجات الدول النامية . 


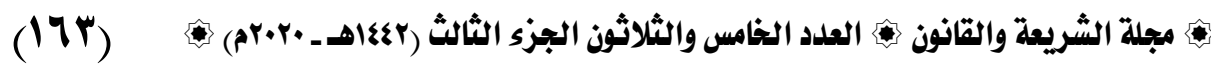

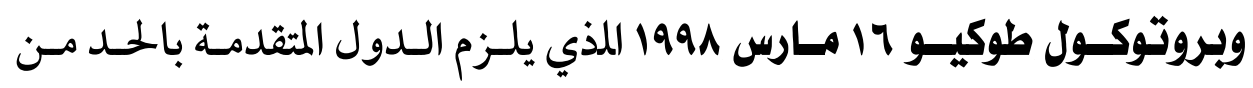
الأنشطة الاقتصادية.

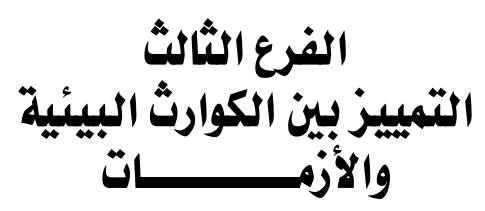

غنى عن البيان أن الكوارث Disasters والأزمات Crises مصطلحات

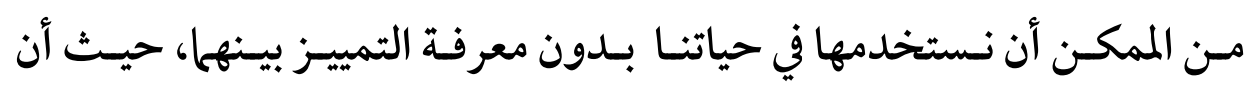

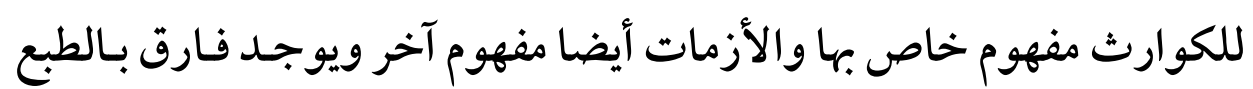
بين كل منهم لابد من معرفته.

ويخضع مـصطلح الأزمـة لعـدة مفـاهيم ؛ فمـن حيـث المنظور الاجتماعي

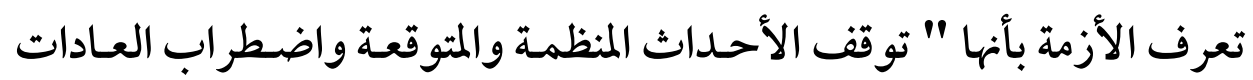
والعرف، مما يستلزم التغيير السريع لإعـادة التوازن ولتكسوين عـادات جديـدة أكثر ملائمة" (1).

فمن حيث المنظور السياسي تعـرف الأزمة بأنها" حالة أو مشكلة تأخـذ

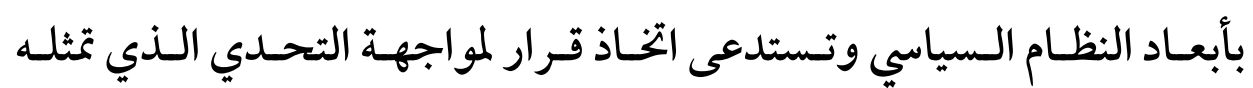

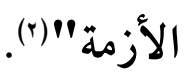

ومن حيث المنظور الإنساني تعرف الأزمة بأنة عبارة عن المعانـاة مـن وضـع

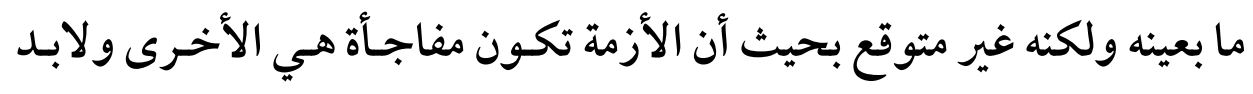
(1) د.السيد عليوة، إدارة الأزمات والكوارث، حلول عملية وأساليب وقائية، القاهرة

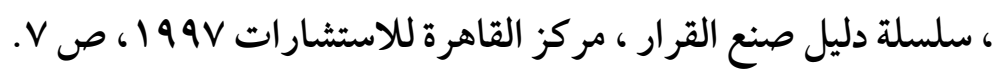

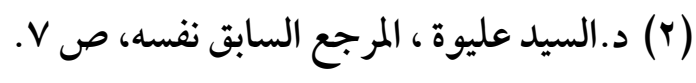


على الأشخاص من التدخل السريع من أجل إنقاذ البشرية من تلك الأزمة مـن خلال القرارات السريعة التي يتخذها الأفر اد"). ومن حيث المنظور الاقتصادي تعـرف الأزمـة بأهها "الانقطساع المفـاجئ في

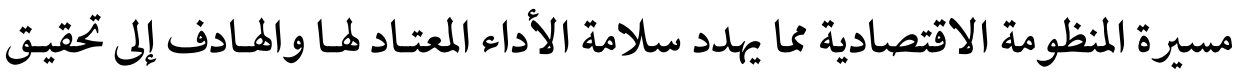
غايتها'"( مستره

ويرجـع حسدوث الكـوارث البيئيــة إلى أنـة لا يوجــ أسبـاب معينة تؤدي

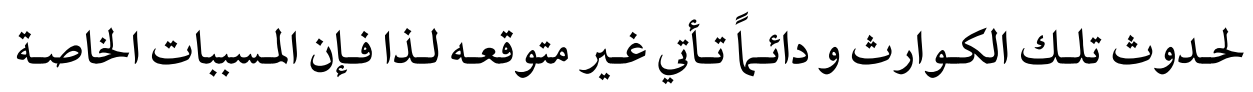
بالكوارث غير مفهومة أو معلومة للبعض وفى الغالب الأعم قد يكون للإنسان تدخل فيها سو اء بقصد كما في الحروب والنزاعات المسلحة ، وقـد تكسون بغير

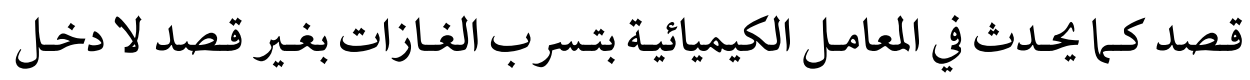
للإنسان بها . فضلاً عن كون التغيير البيئي في المناخ العام من الممكن أن يؤدي إلى حدوث

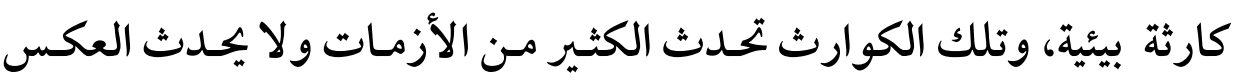

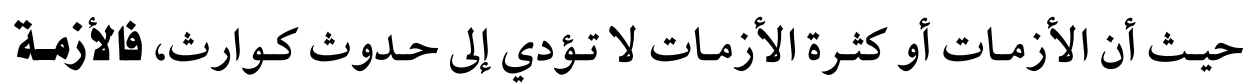

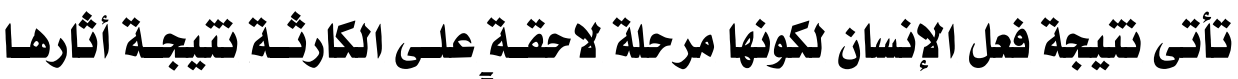

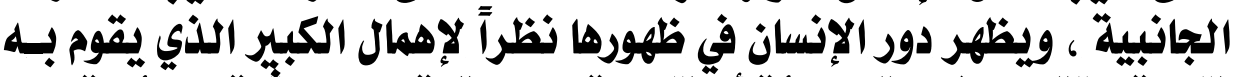

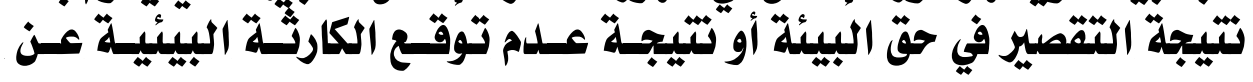

(1) Patricia Buirette, Philippe Lagrange, le droit international humanitaire , la Découverte, paris, 2008, p 3, 4.

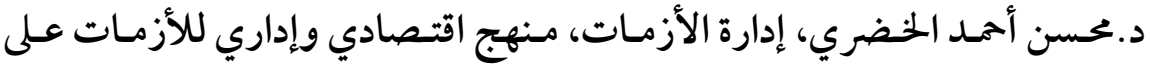

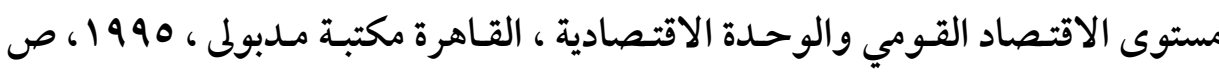




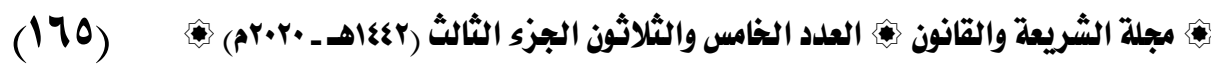
طريـق أخـذ كافة الاحتياطـات الخاصـة بتجنـب وتفـادي الكثير مـن الأمسور

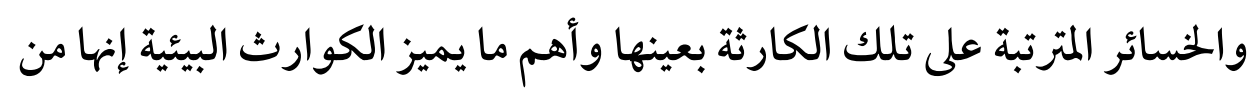

$$
\text { صنع البشر ومن الممكن أن تأتي فجأة وغير متوقعة (1). }
$$

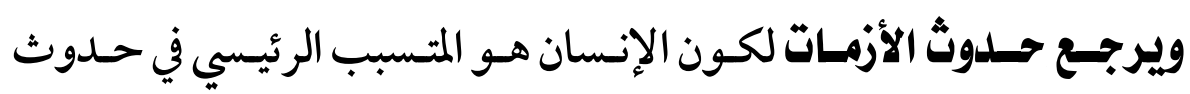

الأزمات فإنه يوجد الكثير من المسببات إلي تحدث الأزمة والتي من بينها ما يلي :

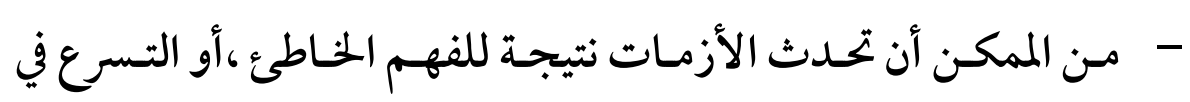

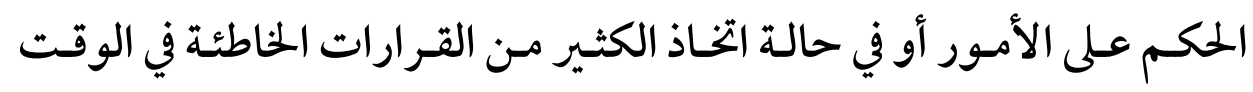
الخاطئ، فكل تلك الأمور تؤدي إلى حدوث الأزمة.

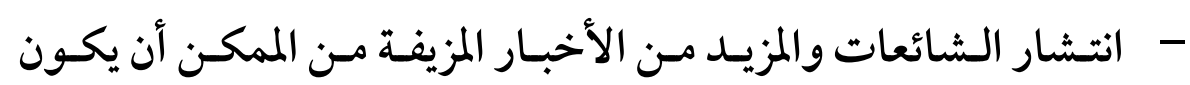
المسبب الرئيسي في حدوث الأزمات.

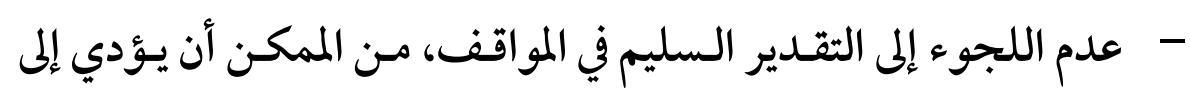

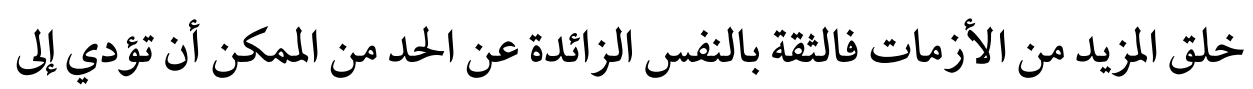
عدم تقدير الطرف الأخر ومدى قوته هو الأخر مما يؤدي إلى خلق الأزمة. - - مي حالة كثرة الأخطاء التي يقع بها الأفر اد سواء إن كان الأمر مقصوداً أو غير مقصود.

- - كما أن الأزمات من الممكن أن تترتب على الكوارث وخاصة الكوارث

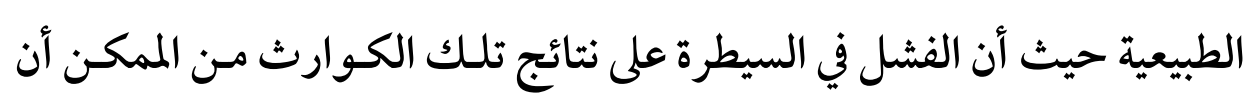

(1) Michel Bélanger , Droit international humanitaire général , Gualino éditeur , paris , 2e édition , 2007 , p 16 
(179)

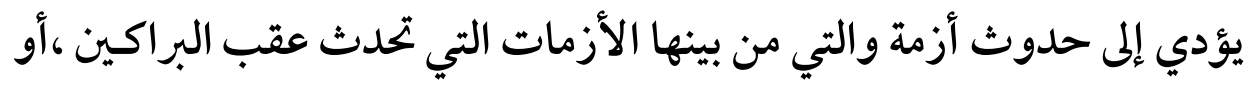
الزلازل تكون من صنع البشر والطبيعة لا دخل لها بها.

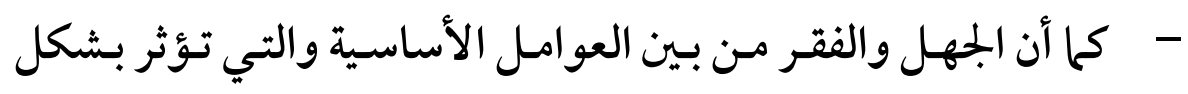
مباشر على حدوث الأزمة وتطورها فتظهر بنـاء على تلك الأمور الاستغلال

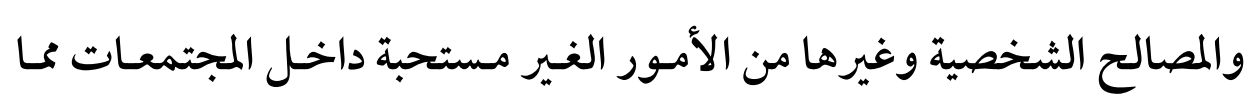
يتسبب في حدوث الأزمة. ومن خلال مـا سبق يمكن القـول أنة لكي يتمّم تطبيق القـانون الإنساني،

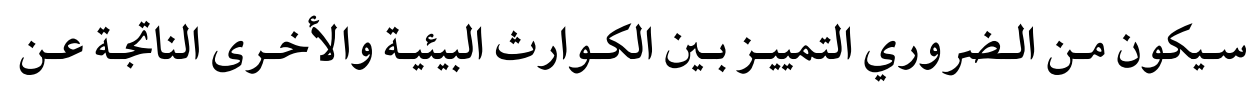

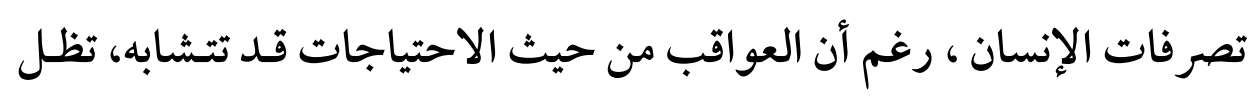

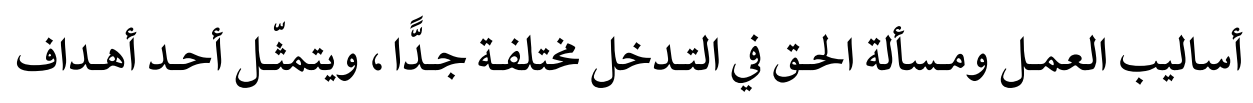
القانون الإنساني في منع الحروب البيولوجية من إحداث كوارث بيئية، وبالتالي تعتبر محظورة المجهات ضـدّ البيئة الطبيعية، وضدّ الأعيان الضرورية لحيـاة المدنيين وضدّ الأعمال أو المنشآت التي تضمّ قوى خطرة ، قد تتسبّب بـأضرار

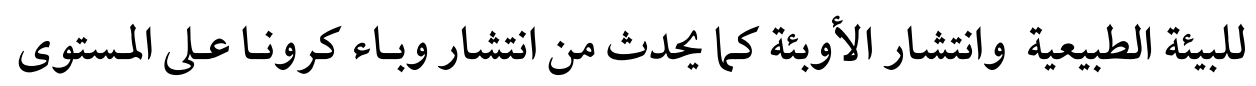

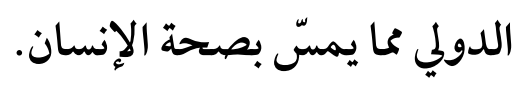




\section{التمييز بين الكوارثق البيئية الفية}

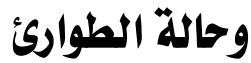

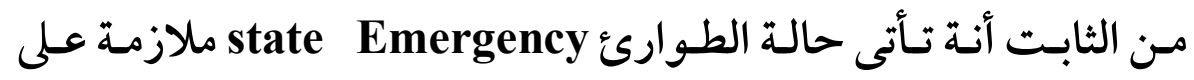

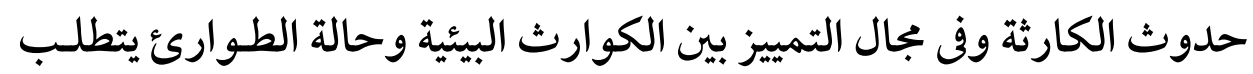

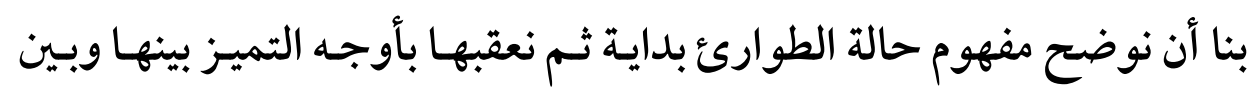
الكارثة البيئية(1). وتعد حالة الطوارئ مـن ضـمن المفـاهيم التي يستخدمها البعض أحياناً

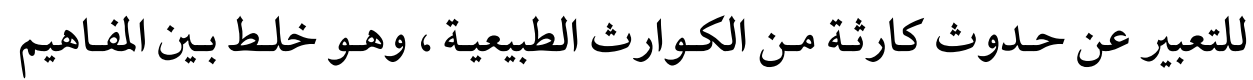

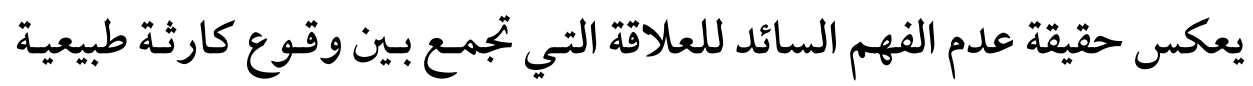
وإعلان حالة الطوارئ(†).

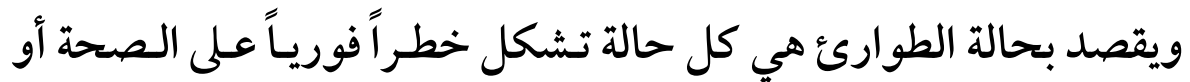
الحياة أو الملكية الشخصية أو البيئة (r).

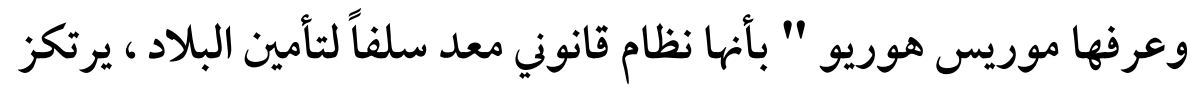

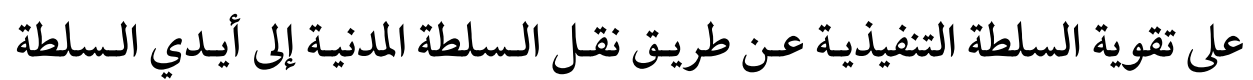

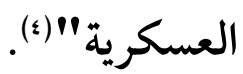

(1) Y.Loussouarn et P.Bourel : Droit international privé, DOLLOZ, 3 siemme ed.1988, p5.

(2) Quarantelli.E.L, Emergencies, Disaster and Catastrophs are Different Phenomena , Disaster Research Center, University of Delawaer, 2000, p.2

(3) UK Government Advice on Definition of an Emergency on 20076-6.

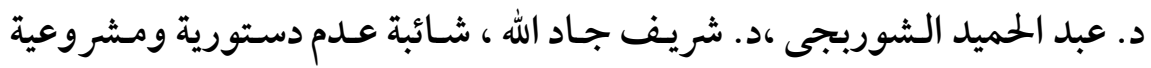

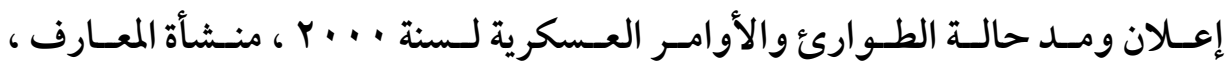

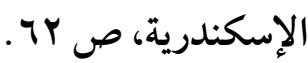


(171) حماية الأشخاص في حالات الكوارث البيئية في القانفو الدولي

وتتطلب معظم حالات الطوارئ تدخلاً عاجلاً بهدف الحيلولة دون تفاقم

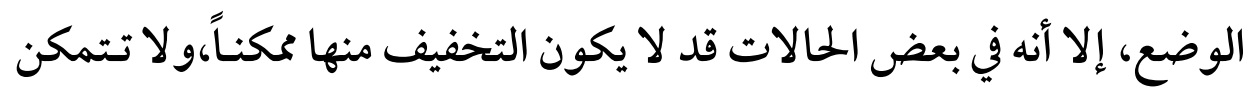

هيئات الاستجابة للطوارئ إلا من تقديم رعاية ملطفة عقب وقوع الكارثة (1).

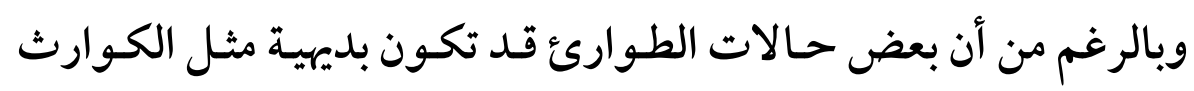

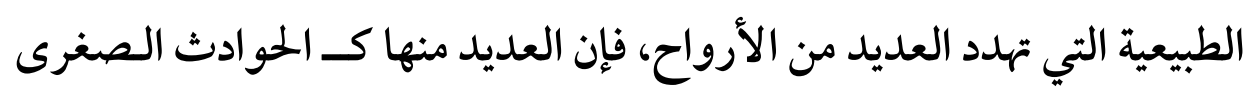

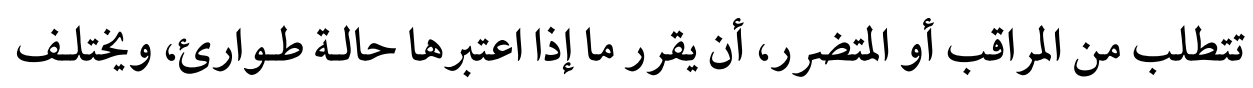

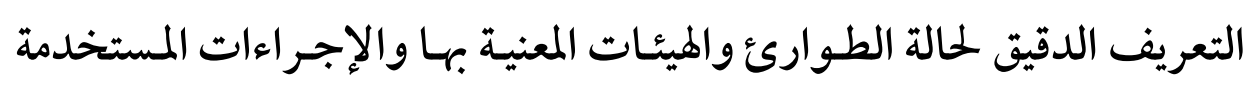
خلالها باختلاف البلد، وعادةً ما تحدد الحكومة هذه المتغيرات، وتكون هيئاتها

$$
\text { هي المسؤولة عن تخطيط وإدارة الطوارئ (†). }
$$

وتتحايز الكوارث البيئية وحالة الطوارئ حيـث أن حالة الطوارئ لارئ لا تظهر

إلا عقب حدوث الكارثة أو وضع استثنائي آخر، من أجل السيطرة عليها عن

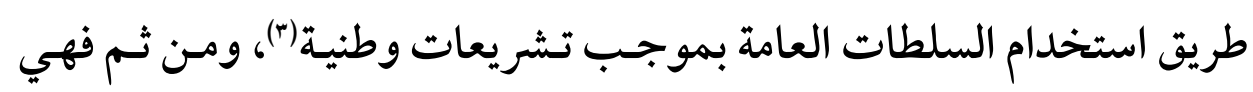

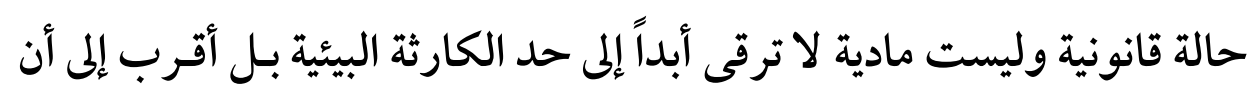
تكون نتيجة لما . ت المانه

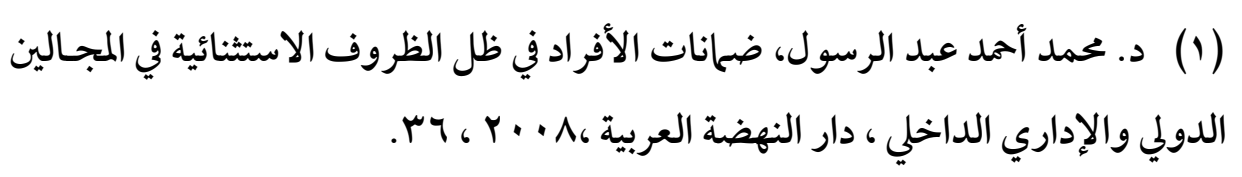

(2) DE LAUBADERE (André) , Le contrôle juridictionnel du pouvoir discrétionnaire dans la jurisprudence récente du Conseil d'Etat, Mélanges, Waline, T II, Paris, 1974, p.531.

(3) CHETRIT (Thierry), Le plan vigipirate: une illustration de cooperation civilo-militaire dans le domaine de la sécurité, Droit et Défense, $n^{\circ} 4,1995, p p .57$ et $s$. 


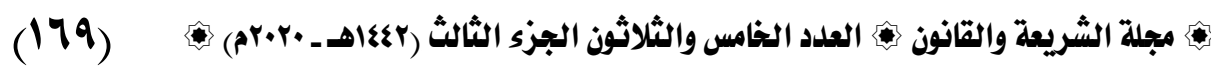

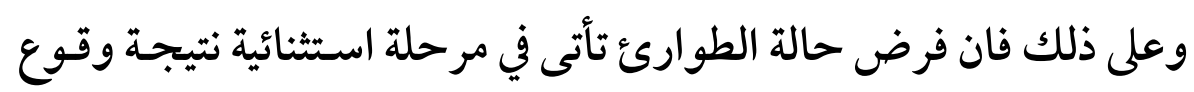

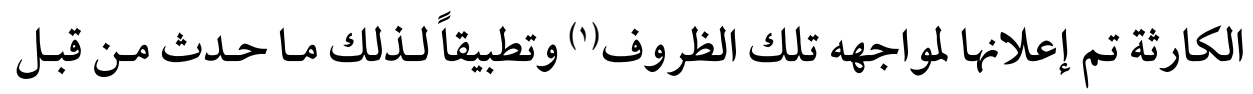

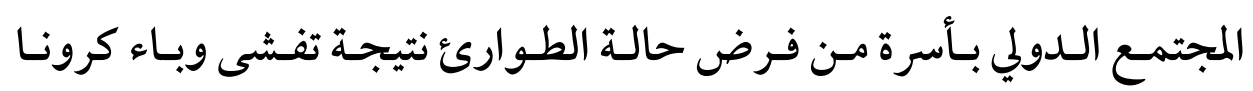

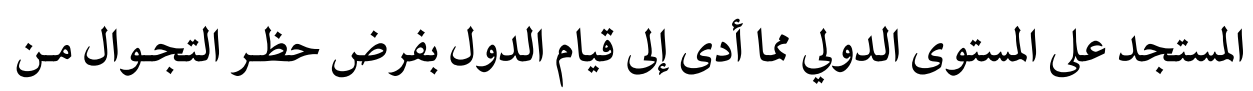

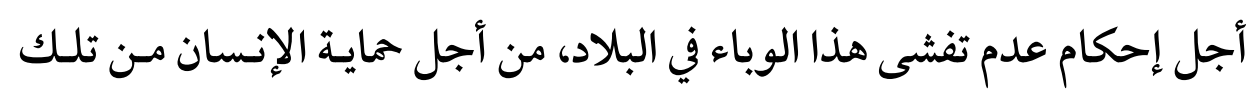
الكارثة. وتطبيقاً لـذلك استخدمت منظمـة الصحة العالمية (WHO) مصطلح حالة الطوارئ الدولية أو تحديـدا "حالة طوارئ صـحية عامـة ذات اهـتحام دولي" ( PHEIC) عندما يكون هناك "حدث غير عادي" في ججال الصحة

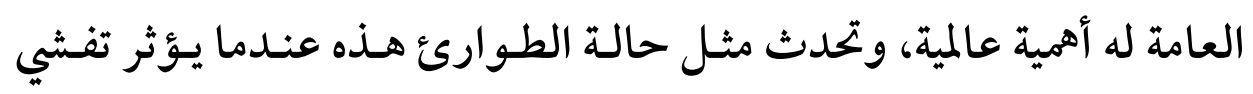
مرض على أكثر من دولة، وتكون هناك حاجة إلى إستراتيجية تنسيق دُولية،

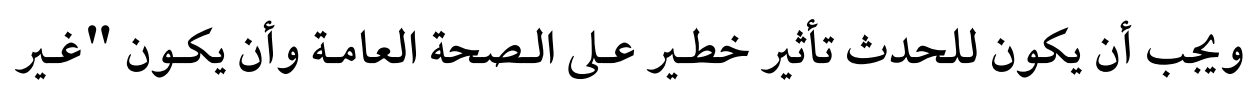
عادي" وأن يأتي بشكل غير متوقع (ץ).

راجع في هذا المعنى د. محمد مصطفى يونس ، حقوق الإنسان في حالات الطوارئ

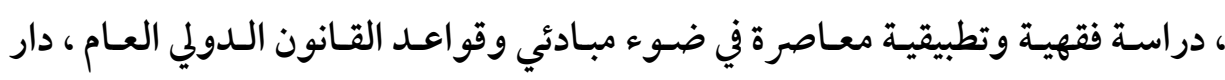

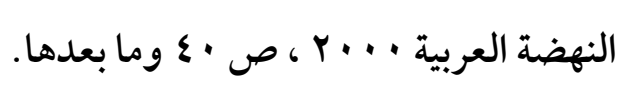

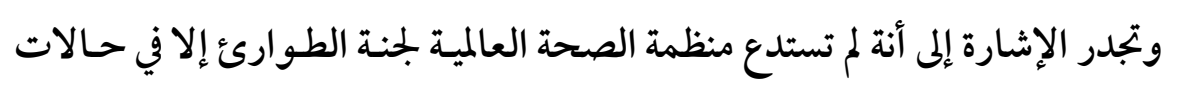

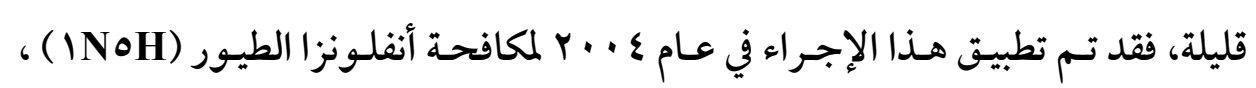

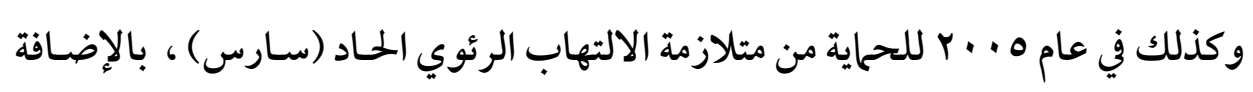

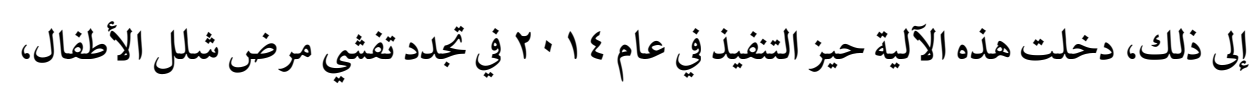


(IV*) حماية الأشخاص في حالات الكوارث البيئية في القانون الدولي

\section{المبحث الثاني

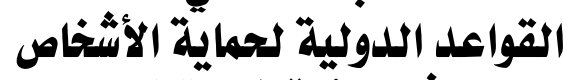 \\ من الكوارث البيئية في الثقانوز الدولية الأشخدي}

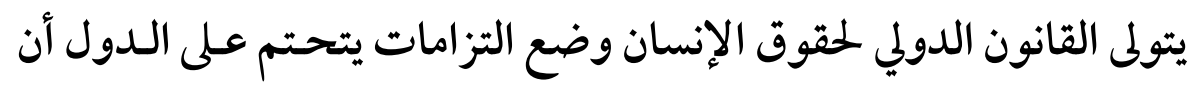

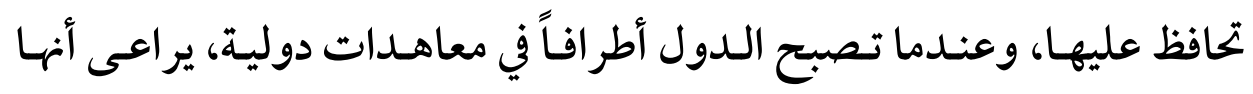
تضطلع بالتزامـات وواجبـات في إطار القـانون الدولي تتصل بـاحترام وحماية وتطبيق حقوق الإنسان، والالتزام بالاحترام يعني أنه يتعين على الدول أن تمتنع عن التدخل في حقوق الإنسان أو تقليص التمتع بها(1).

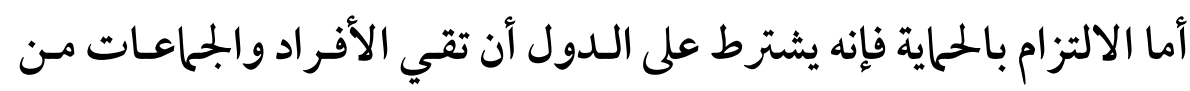

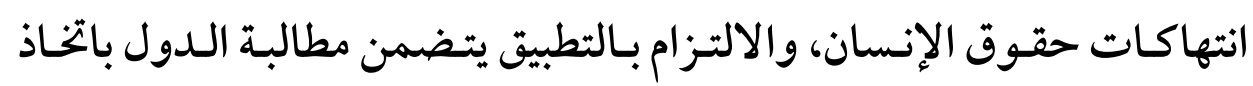
إجراءات إيجابية لتيسير التمتع بحقوق الإنسان الأساسية(†).

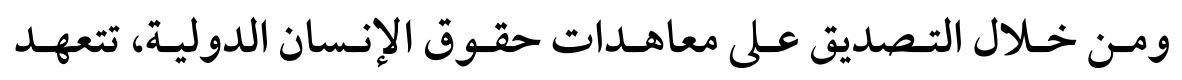
الحكومـات بوضـع تــابير وتسشريعات محليـة تــسم بالاتفـاق مـع التزاماتهـا

الذي كان يُعتقد أنه تم استئصاله، وفي حمى الإيبو لا في غرب إفريقيا، عـلاوة على فيروس

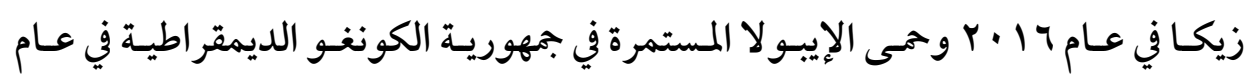

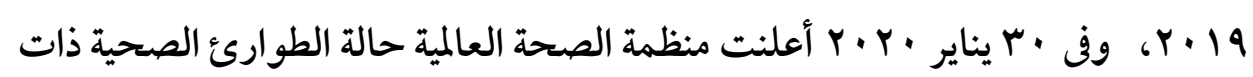
البعد الدولي من أجل تفشي فيروس كورونا الذي راح ضحيته ألاف القتلى.

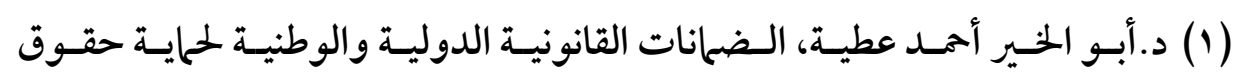

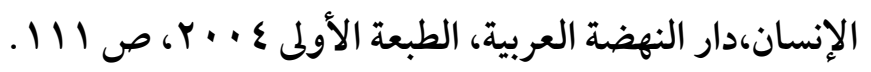

(2) Charles R. BeiTZ, The Idea of Humain Rights ,oxford universTy Press, Newyourk, 2015 p.9 


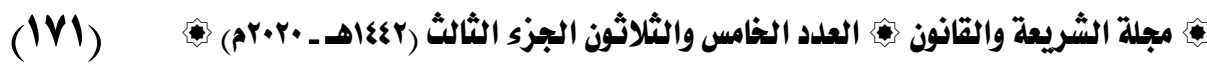

وواجباتها التعاقدية، ومن ثم فإن النظام القـانوني المحلي يـوفر الحمايـة القانونيـة

الأساسية لحقوق الإنسان المكفولة في إطار القانون الدولي (1).

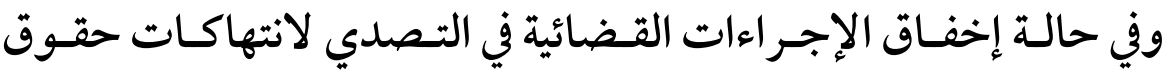

الإنسان، يلاحظ أن الآليات والإجراءات المتعلقة بالثظلمات الفردية متاحة على

المستويين الإقليمسي والـدولي مـن أجـل المساعدة في القيـام عـلى نحسو حقيقي

باحترام وتنفيذ وتطبيق معايير حقوق الإنسان الدولية على الصعيد المحلي (†).

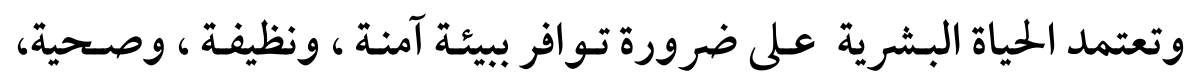

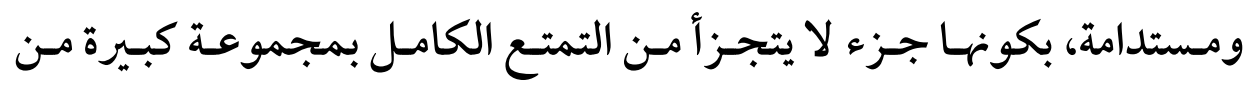

حقوق الإنسان، من بينها الحق في الصحة (").

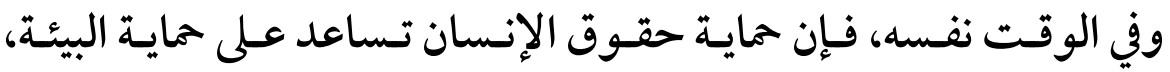

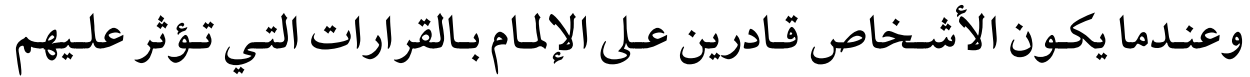

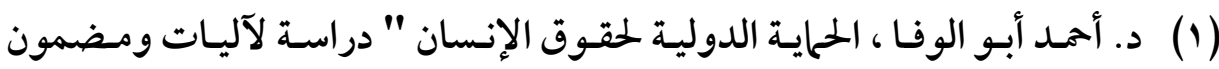

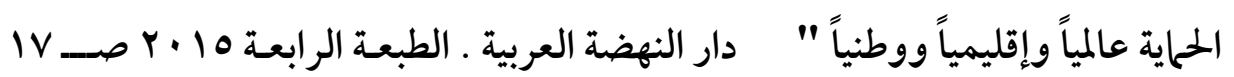

$.1 \times 9$.

(2) Humberto Calamari of Panama, Vice-Chairman of the UN General Assembly's Third Committee, presiding, in 1958, over a meeting on the draft International Covenant on Civil and Political Rights - which built on the achievement of the Universal Declaration of Human Rights, using it as its foundation . The Foundation of International

Human,Rights,Lawhttps://www.un.org/ar/sections/universal declaration/foundation-international-human-rights-law/index.html (r) د. صلاح الدين عامر، مقدمه لدراسة القانون الدولي العام ، دار النهضة العربية طبعة . r tra 
(IVr)

حماية الأشخاص في حالات الكوارث البيئية في القانون الدولي

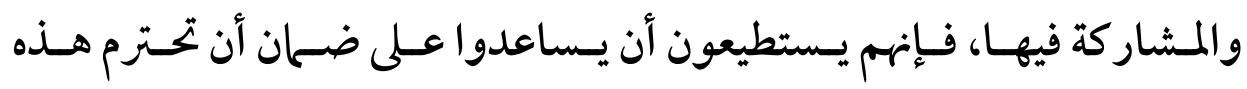
القرارات حاجتهم إلى بيئة مستدامة.

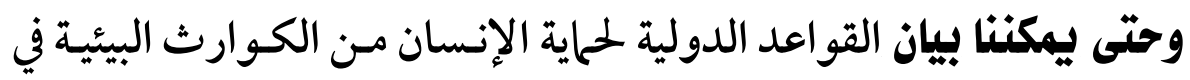

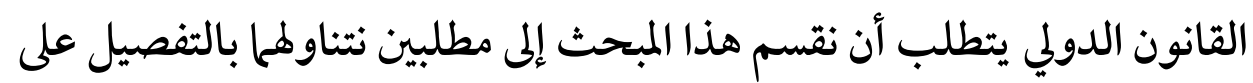

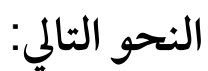

المطلب الأول: المبـادئ الإنسانية لمواجهـهـ الكسوارث البيئيسة في القـانوز

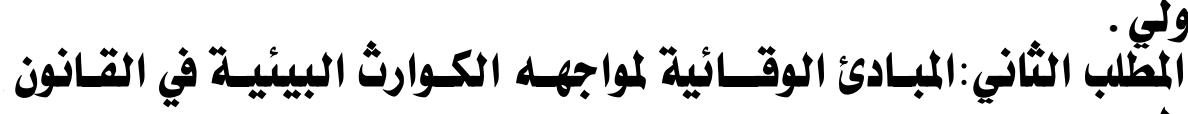

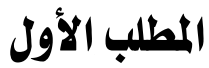

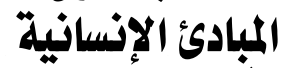 \\ لمواجهه الكوارثُ البيئية في الثقانوز اللدولي}

كما لاشـك فيـه تعُد المبادئ الإنسانية Human principles في القـانون

الدولي هي روح التعـاون لمواجهه الكوارث البيئية(1) وذلك مـن أجـل تحسين

معالجة المشاكل الدولية المتعلقة بحرايـة البيئة Protect the environment، من جانب كل الدول على قدم المساواة، والتعاون عن طريق الاتفاقيات المتعددة

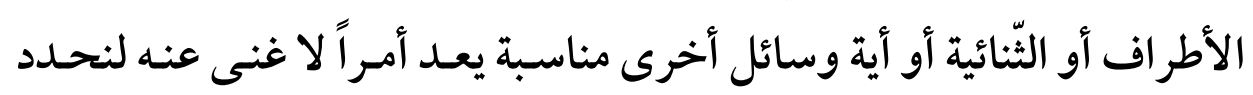
بفعالية ونمنع ونقلل وننهي كل الاعتداءات على البيئة الناجمة عن أنشطة يـتم ممارستها في جميع المجالات وذلك مع احترام سيادة ومصالح كل الدول (†).

(1) SCHMIDT Pia, signaux précoces et leçons tardives: le principe de précaution 1896-2000 quelques points récapitulatifs, AEE (Agence Européenne de l'Environnent) , Copenhague, 2002, p 9.

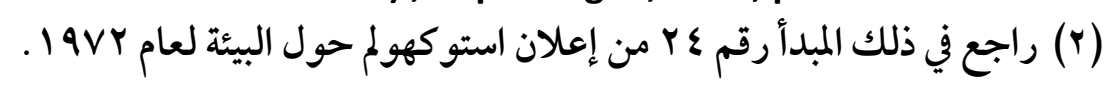




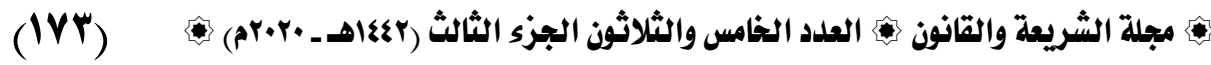

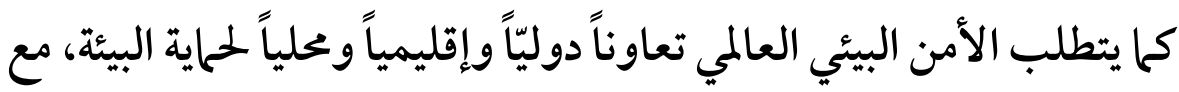
المحافظة على مواردها الطبيعية، من أجل إييـاد ربط وثيتق بين البيئة والتنمية

بمفهومها الثامل سواء في البلدان المتقدمة أو النامية (1). وعليـه نحـاول مـن خـلال هـــا المطلـب بيـان المبـادئ الإنسـانية لمواجهـهـ الكـوارث البيئية في القـانون الـدولي وبلـورة مبـادئ الحمايـة الدولية للبيئة مـن انتشار الأوبئة؛ وعلية نقسم هـذا المطلـب إلى فرعـان نتنـاولما بالتفصيل على لى

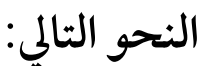
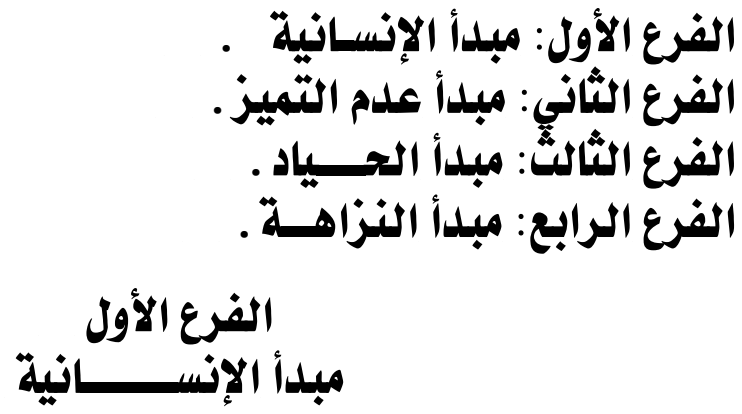

يقصد بمبدأ الإنسانية أن كل البشر تتم معـاملتهم بـصورة إنسانية آدمية وبصورة متساوية في كل الظروف من خلال إنقاذ الحياة وتخفيف المعانـاة، مـع

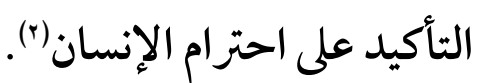

(1) TROUCHE Angélique, Le principe de précaution entre unité et diversité étude comparative des systems communautaire et $\mathrm{OMC}$, mémoire master 2 recherche droit européen, université Paris 1 panthéon Sorbonne, 2009, p 286.

(2) Rubin, Olivier; Dahlberg, Rasmus , A Dictionary of Disaster Management, A Dictionary of Disaster Management. Oxford University Press,2017,p9. 
(IV\&) حماية الأشخاص في حالات الكوارث البيئية في الثانون الدولي

ويعد هدف الاستجابة الإنسانية هو حماية الحياة والصحة - مـن الكـوارث

البيئية- والتأكيد على احترام كل البش مبدأ الإنسانية مـ أجل الفهـم المتبـادل

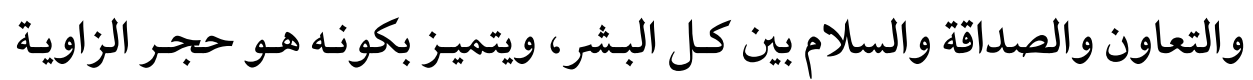

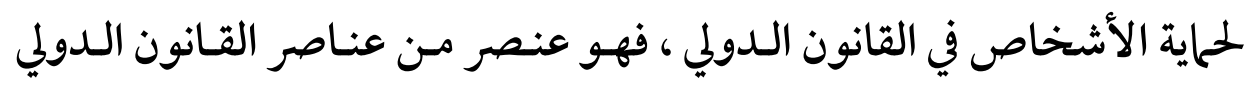
الإنساني،والقانون الدولي لحقوق الإنسان، يهتدي به في تطوير القوانين المتعلقة بحماية الأشخاص في حسالات الكـوارث ، ويمثل مبـدأ الإنسانية أحسد دعـائم العمل الإنساني الذي تسترشد به المنظلات الإنسانية العاملة في بجال الإغاثة، أثناء النزاعات المسلحة وحالات الطوارئ الأخرى (1)، ويـرى البعض ألن مبـدأ الإنسانية يعنى السعي الدائم نحو تدارك وتخفيف معاناة الضحايا(+).

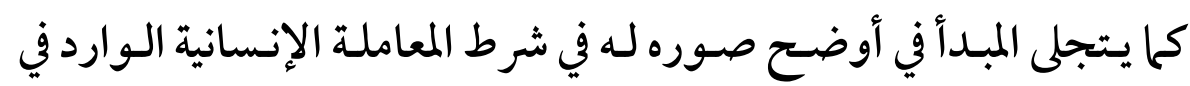

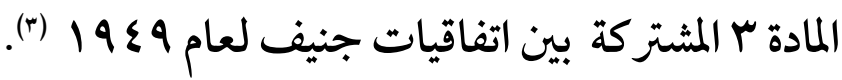

(1) د. ماهر جميل أبو خوات ، المساعدات الإنسانية الدولية، دراسـة تحليلية وتطبيقية

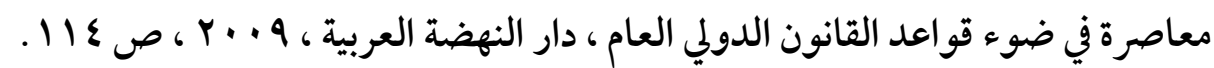

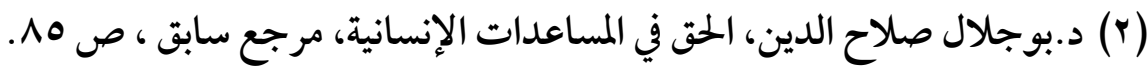

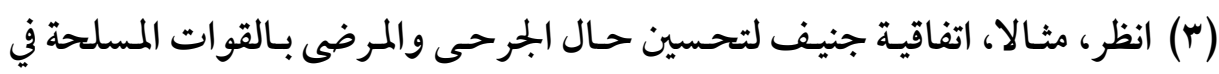

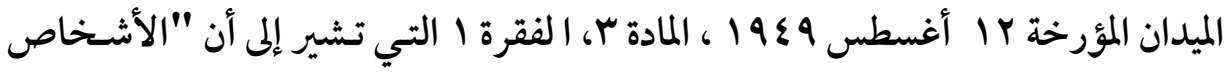

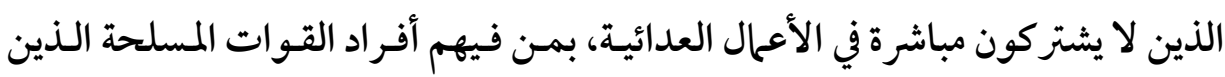

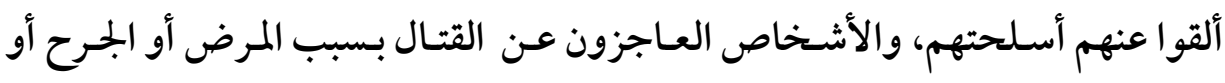

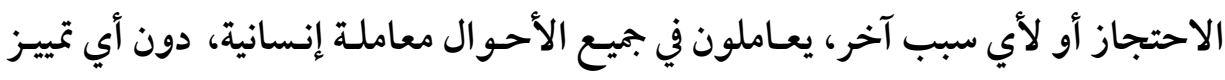

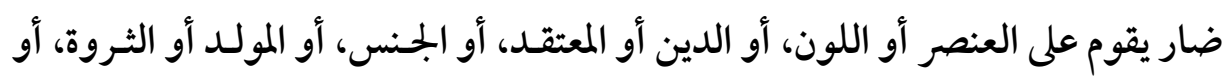
أي معيار مماثل آخر ". 
ويعتبر المبـدأ أحـد دوافـع تقـديم المساعدات في حسالات الكـوارث البيئيـة

وحيث أكدت محكمة العدل الدولية في قضية قناة كورفو بأنه من المبادئ العامـة

المسلم بها في النظام القانوني الدولي و"مطلقة وقت السلم أكثر منها في وقـت

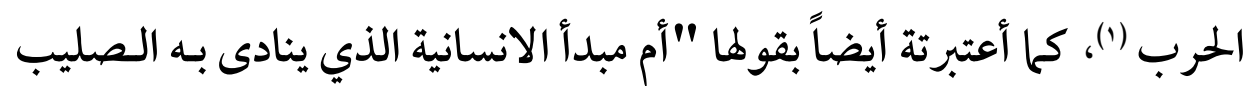

الأحمر، يعد شرطاً أساسياً لكل عمل إنساني" (().

وحيـث أكـــ الاتحــاد الـدولي لجمعيـات الـصليب الأحمـر وحركـة الهـلال

$$
\text { الأمر IFRC) )، أن مبدأ الإنسانية يشمل كلا من: }
$$

- - الدعوة إلى أصل الحركة وهو الرغبة في المساعدة دون تمييز بين المصابين

$$
\text { أثناء الصراع. }
$$

- - الدعوة إلى البعد الثنائي للحر كة وهما البعد القومي والبعد العالمي.

$$
\text { - - الدعوة إلى حماية الحياة والصحة. }
$$

(1) Corfu Channel case (United Kingdom of Great Britain and Northern Ireland v. Albania), I.C.J.Reports 1949, p. 4 at p. 22 .

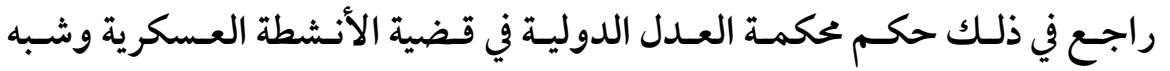

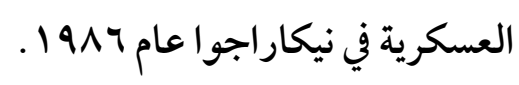

I.C.j:Reports 1986, para,243,p.115

(3) Consequences of the Fundamental principle of Humanity The consequences of the principle of Humanity are not so much boundaries and guidelines for the action, as the other Fundamental Principles are: the principle of Humanity is rather a constant reminder of what the objectives of the Movement are. The principle of Humanity expresses what the Movement places beyond anything else: the need to act in order to prevent and alleviate human suffering. The International 
(IV7) حماية الأشخاص في حالات الكوارث البيئية في القانفز الدولي

وينسب تعلق بيكتيت (Pictet) على مبادئ الصليب الأحمر ثلاثتة عناصر

لمبـدأ الإنسـانية "الحيلولـة دون المعانـة وتخفيفهـا، وحمايـة الأرواح والـصحة،

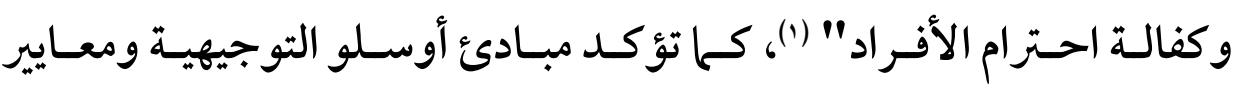

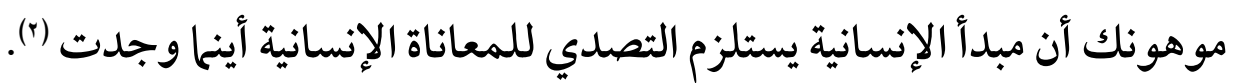

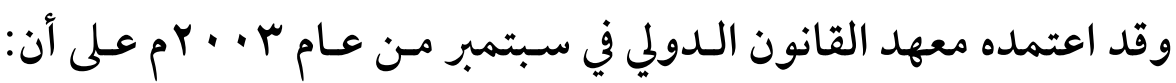

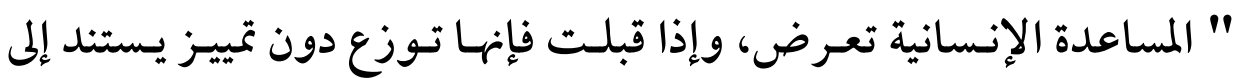
أسباب محظورة ، مع مر اعاة احتياجات الفئات الأشد ضعفاً" (r). ومن ثم يمكن القول أن الإنسانية تعني السلوك أو التصرف تجاه الآخرين ،

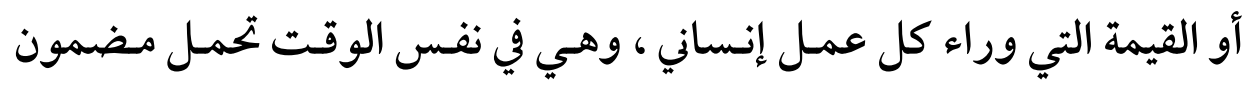

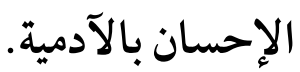

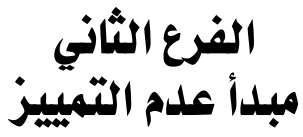

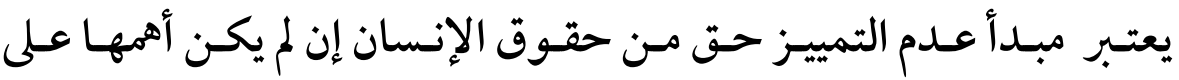

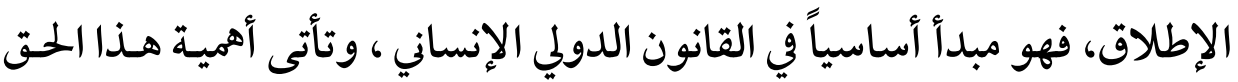
كونه أساس تمتع الفرد بجميع الحقوق والحريات الأخرى على قدم المساواة مع معائ

Federation of Red Cross and Red Crescent Societies is the world's largest.4/12/2018. https://www.ifrc.org.

(1) Jean Pictet, The Fundamental Principles of the Red Cross Proclaimed by the Twentieth International Conference of the Red Cross, Vienna, 1965 Commentary (Geneva, Henry Dunant .Institute, 1979) , pp. 21-27; also available from www.icrc.org

(2) Oslo Guidelines, para.20; Mohonk Criteria, p. 196

(3) Institute of International Law, Resolution on Humanitarian Assistance .2 September2003, p. 4 


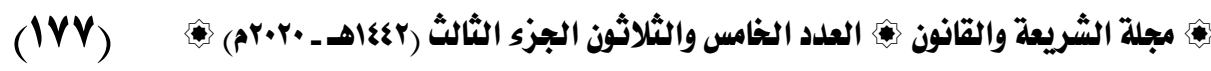

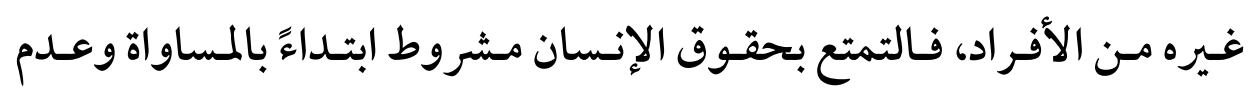
التمييز (1)

ويمكن القول أن الحق في المساواة وعدم التمييز هو بمثابـة حـق عـام تتفـرع عنه حقوق الإنسان الأخرى أو هـو نقطة الانطلاق لكافة الحقوق والحريـات

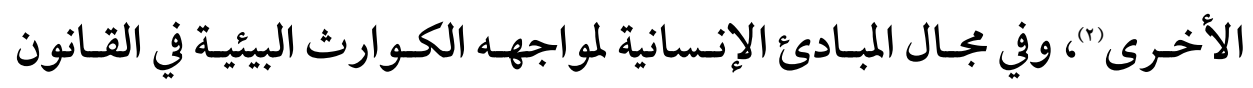

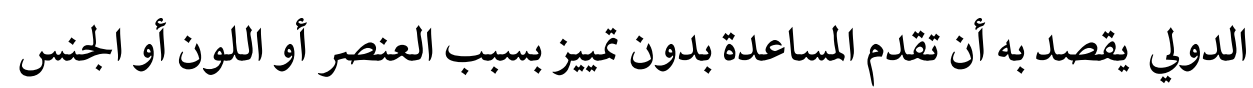

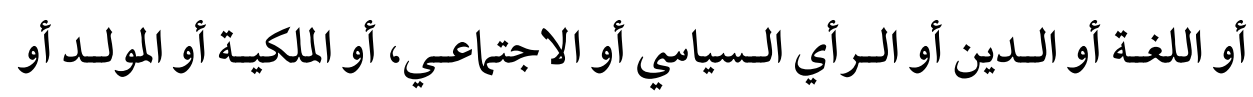
العمر، أو الأصل الوطني أو الانتهاء إلى أقلية وطنية أو أي وضع آخر (r).

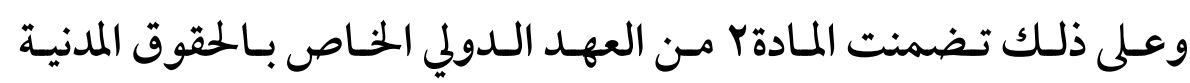
والسياسية على ضرورة أن تلزم كل دولة طرف باحترام الحقوق المعترف بها في العهد وبضمان هذه الحقوق لجميع الأفراد الموجودين في إقليمها والخاضعين

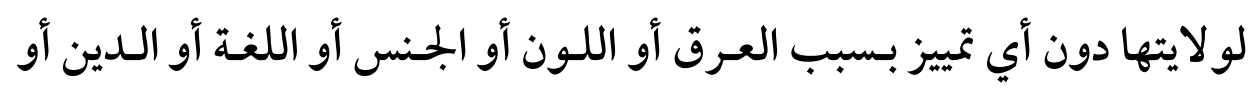

(1) راجع في ذلك :جون ماري هنكرتس، ولويز دوزالدبك، القانون الدولي الإنساني العرفي،

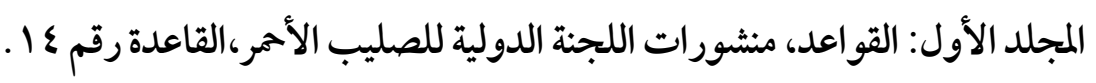
(2) Keba Mbaye, "ARTICLE 2, Paragraph 1", La Charte des Nations Unies Commentaire article par article, 2nd edn, Jean .Pierre Cot and Alain Pellet, eds (Paris, ECONOMICA, 1991) , p. 83

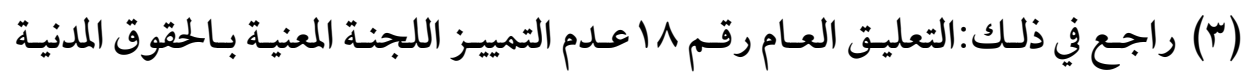

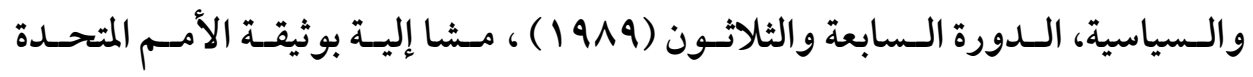
$(.) \cdot / \varepsilon 0 / \mathbf{A}$ 
( 1 YA) حماية الأشخاص في حالات الكوارث البيئية في التانون الدولي الرأي السياسي أو غير السياسي، أو الأصل القومي أو الاجتحاعي، أو الثروة أو

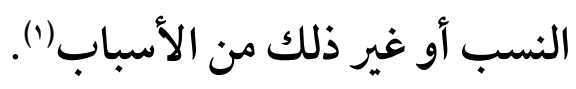

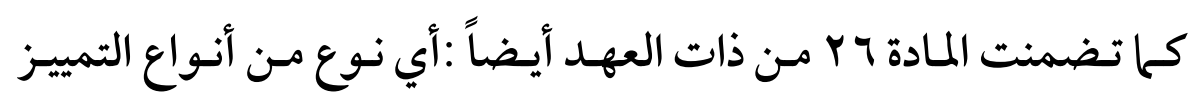
بمقتضى القانون وتكفل لجميع الأفر اد حماية واحدة وفعالة ضـد التمييز القـائم

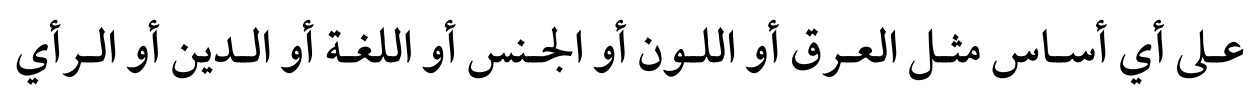

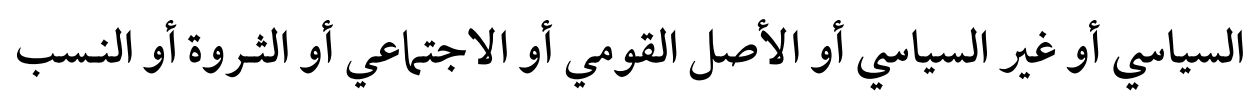

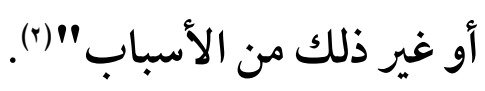

وبمقتضى العهد في أوقات الطوارئ العامـة يقتضي بأنه لا يجيوز أن تشمل

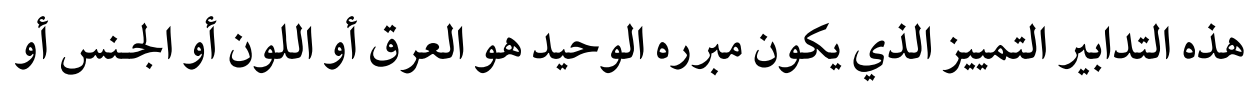
اللغة أو الدين أو الأصل الاجتماعي.

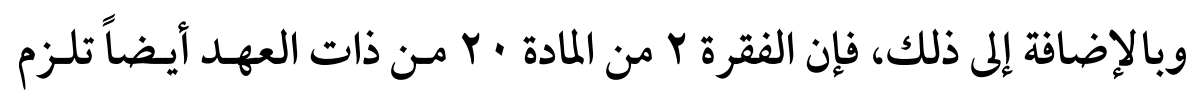

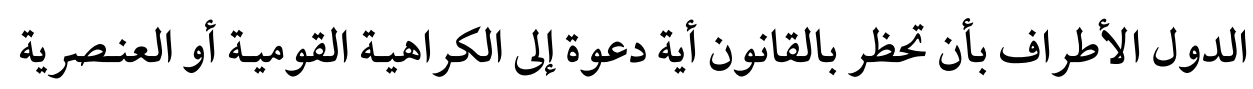

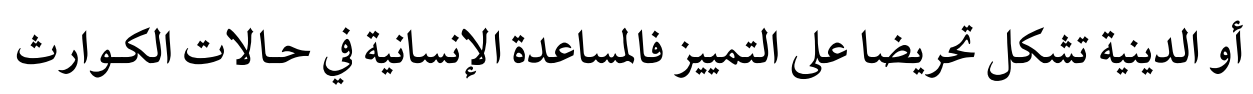
لا تكون مقبولة إلا إذا قامت على أساس عدم التمييز بين الأشـخاص اللـذين

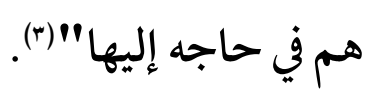

(1) راجـع في ذلـك: الفقـرة ا مـن المـادة ب مـن العهـد الـدولي الحـاص بـالحقوق المدنيـة

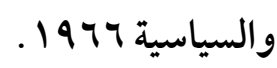
(r) راجع في ذلك: المادةج Y من العهد الدولي الخاص بالحقوق المدنية والسياسية .

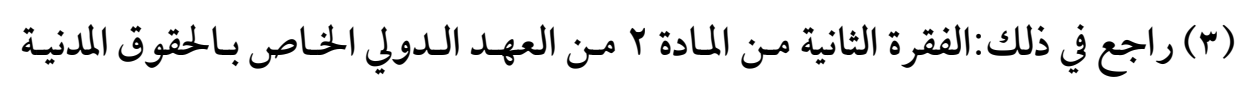
والسياسية . 


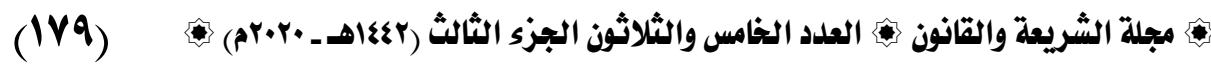
وبموجب المادة • V من البروتوكول الإضافي الأول لاتفاقيات جنيف يُعَدـ

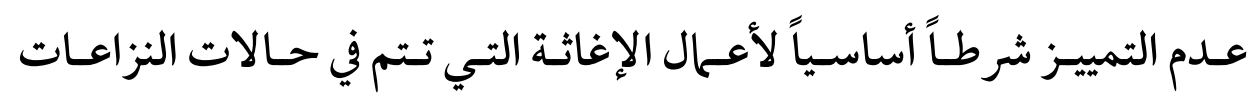
والكوارث، وحيث تضمن أن أعمال الإغاثة تقدم عندما لا تتوفر لدى السكان

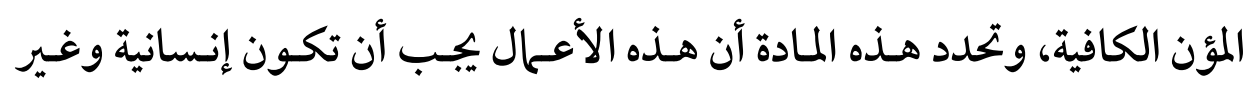
متحيزة من حيث الطابع، وتجرى دون تمييز بجحف، وبالمثل يُذكَر عـدم التمييز

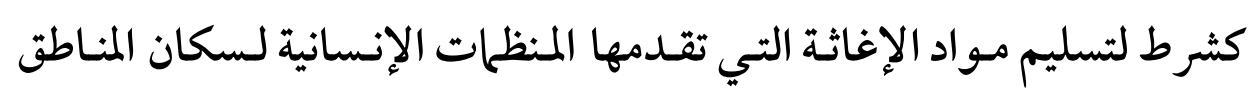
المحتلة (1).

وبناء على ذلك ينبغي ألا تنطوي أعحال تقديم المساعدة الإنسانية على أي

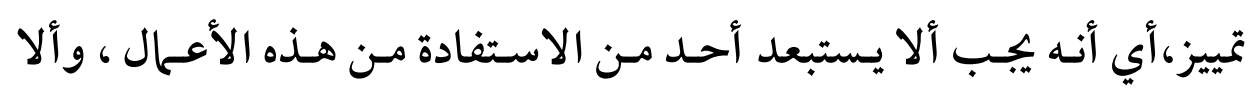
يكون هناك أي تمييز بين المستفيدين على أي أسـاس عرقي أو ديني وغيره،

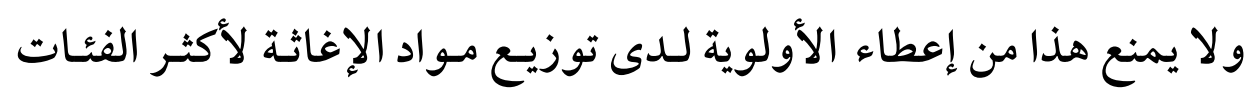

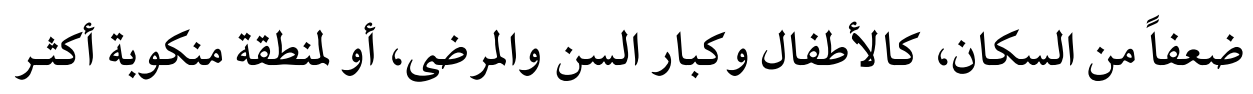

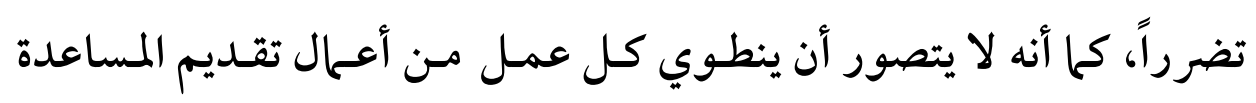

$$
\text { الإنسانية على عدم تمييز (َ). }
$$

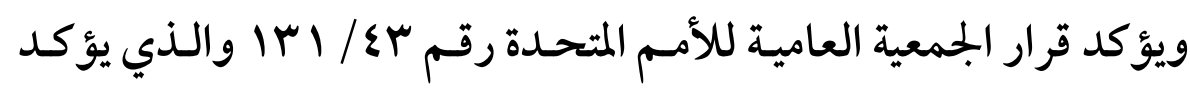

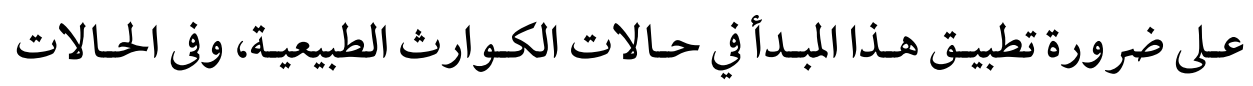

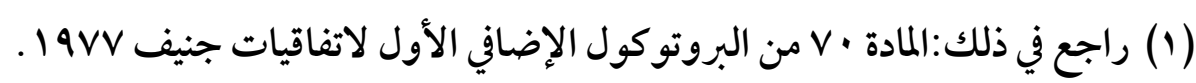

(2) Gayle Tzemach Lemmon, A Syrian War By Other Means, The Politicizing of Humanitarian Aid, Foreign Affairs, August, 2016,p17. 
(1A•) حماية الأشخاص في حالات الكوارث البيئية في القانفز الدولي

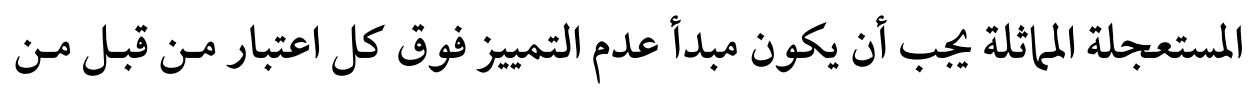
يستطيعون تقديم المساعدة الإنسانية (1).

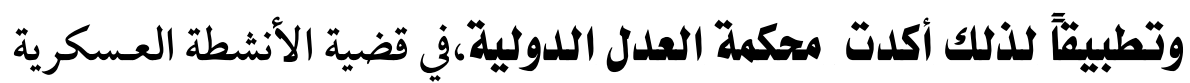
وشـبه العسكرية في نيكـار اغوم عـام ؟191 أن المساعدة حتى لا تأخـذ طـابع التدخل في الشؤون الداخلية لدولة ما،لايجب فقط أن تكسون المساعدة مطابقة

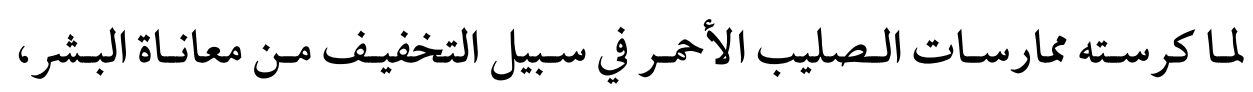
والحفاظ على الحياة والصحة وضمان احترام الشخصية الإنسانية، ولكن يجب مُبـ أن تُنح دون تمييز لكل من هو في حاجة إليها(ن).

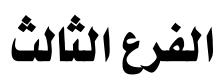

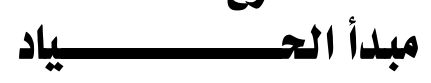

يعد مبدأ الحياد من المبادئ الإنسانية لمواجهـه الكسوارث البيئية في القـانون

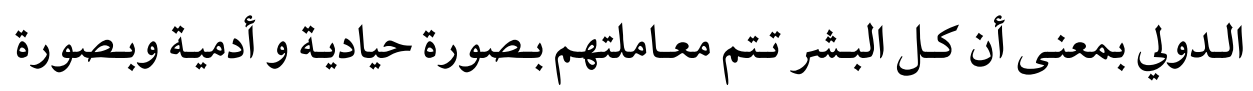
متساوية في كل الظروف مـن خـلال إنقـاذ الحياة وتخفيف المعانـاة عـنهم جـراء تلك الكوارث. ومبدأ الحياد في بجال تقديم المساعدات الإنسانية يتميز بمـدلول آخر يقـوم

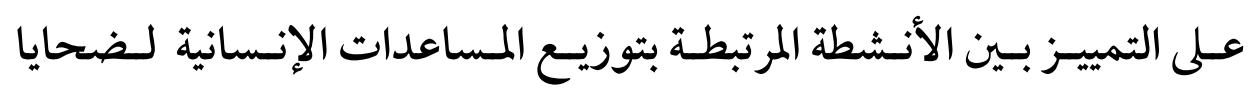

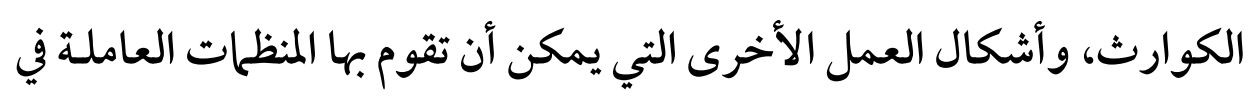

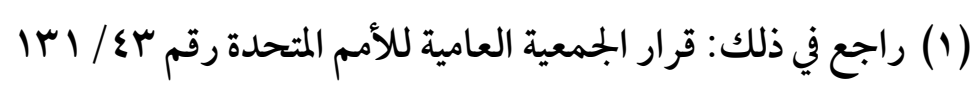

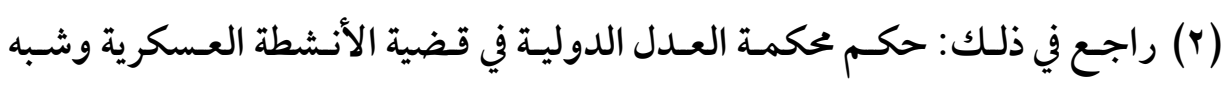

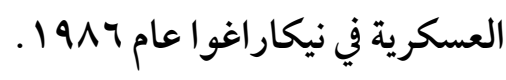




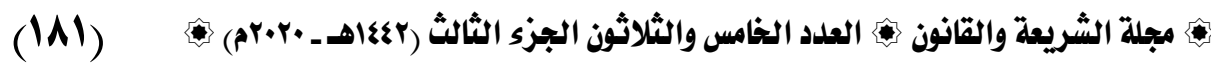
مجال المساعدات الغذائية والطبية، فيجـب على المنظلات الإنسانية والعـاملون معها بذل أقصى جهد للتمييز بين المقاتلين والمدنيين أي غير المقاتلين، فالمدنيين هم وحدهم الذين لهم الحق في الحصول على المساعدات الإنسانية (')

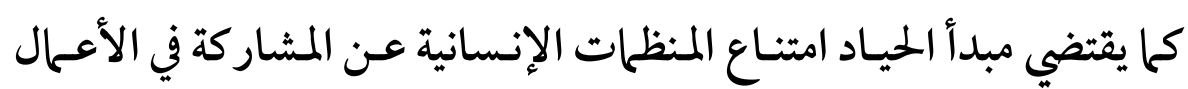

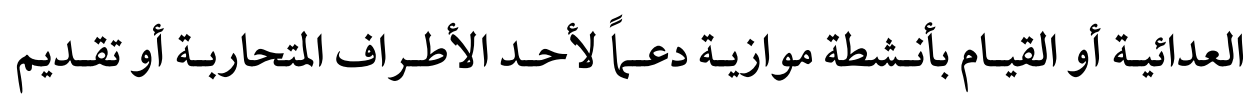

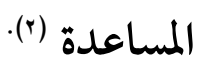

كما أن احترام مبدأ الحياد يوجب على المنظات العاملة في بجال الإغاثة أن تتجنب اتخاذ أي موقف أو تصرف بشأن أسباب النزاع مثل التنديد بانتهاكات

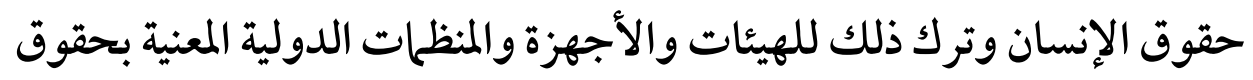
الإنسان كمنظمة العفو الدولية ومجلس حقوق الإنسان (r).

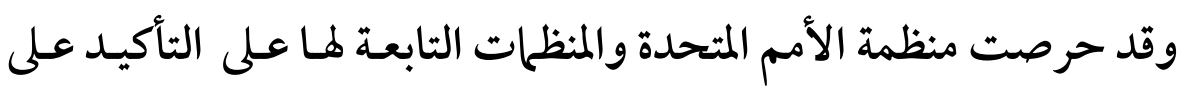
وجـوب احسترام مبـدأ الحيـاد في المسـاعدات الإنسانية، فالعديـد مـن قـرارات الجمعية العامة تؤكد على وجوب احترام موظفي الهيئات التي تقدم المساعدات

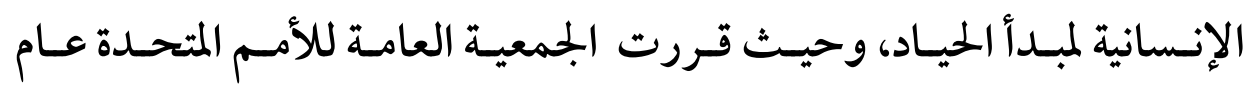

(1) Noelle Quenivet, "Humanitarian assistance a right or a policy? Case study: the security council and the armed conflict in the former Yogoslavia " . The Journal of Humanitarian Assistance, http: www. Jha. oc / articles/ a 030.

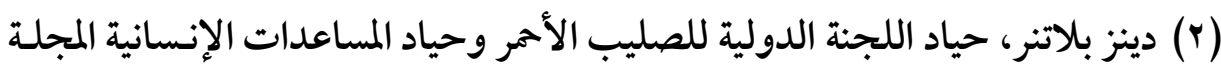

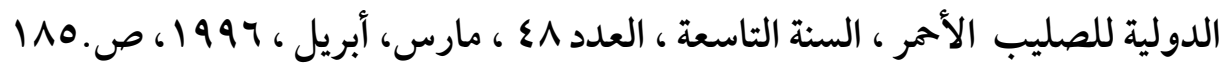

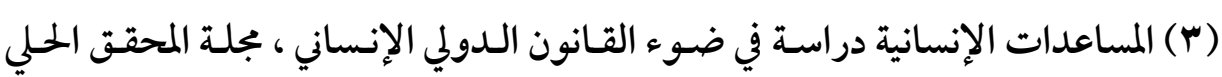

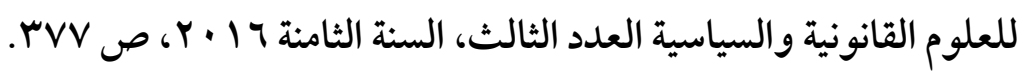


(IAT)

حماية الأشخاص في حالات الكوارث البيئية في القانوز الدولي

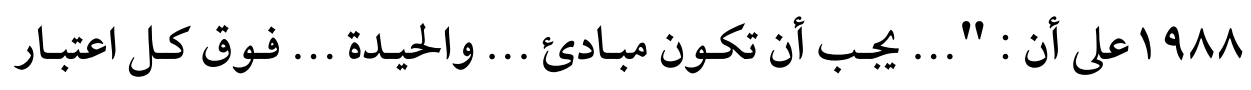

لدى جميع من يقدمون مساعدة إنسانية" (1).

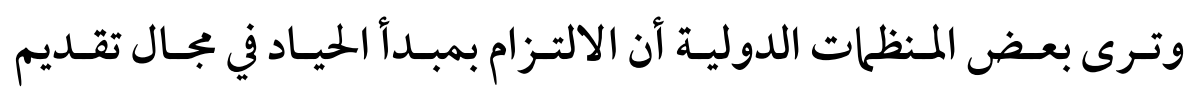

المساعدات يعني أن تمتنع المنظمات الإنسانية عن التدخل في النزاع القـائم بأي

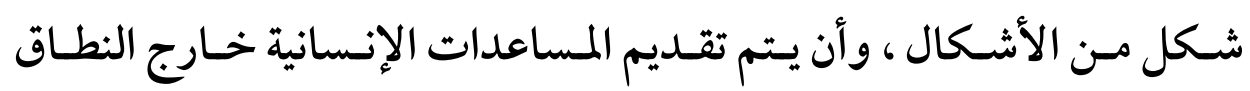

السياسي وبعيداً عن توزيع مواد الإغاثة لطرف دون الآخر (†).

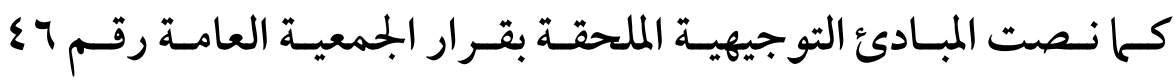

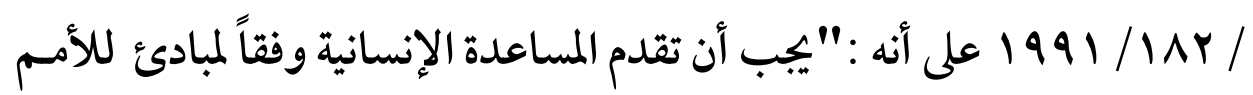

$$
\text { المتحدة الإنسانية والحياد والنزاهة"(r). }
$$

كما أكدت على هذا المبدأ العديد من الوثائق التي أصدرتها مـنظات تعمل بمجال الإغاثة ، فقد أشير لمبدأ الحياد في المبادئ الإنسانية أثناء العمليات التي التي التئي

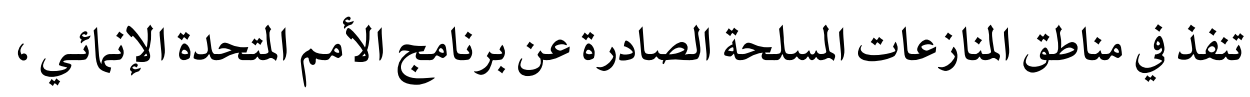
وكذلك معايير للمساعدة الإنسانية في حالات الطوارئ المعقدة.

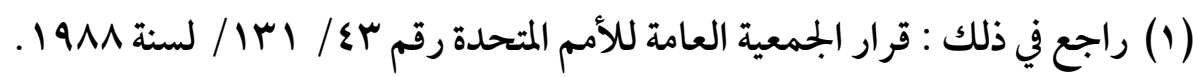

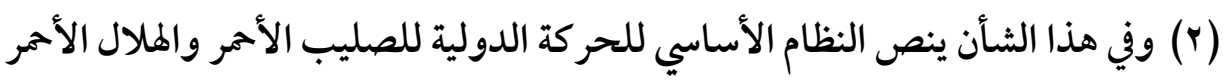

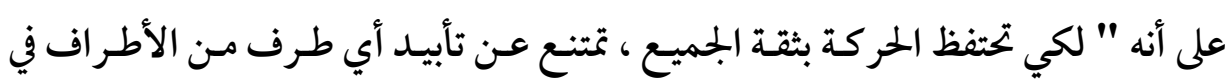

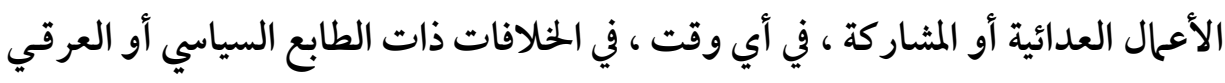

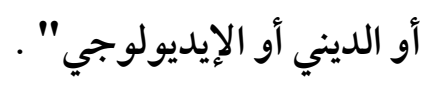

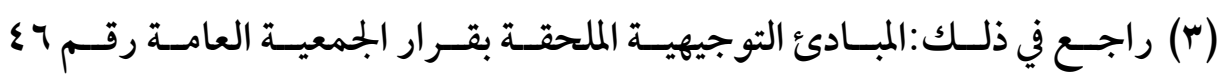




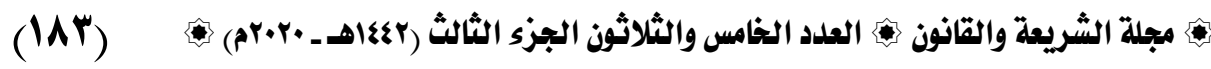

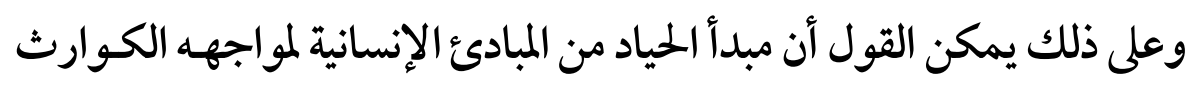

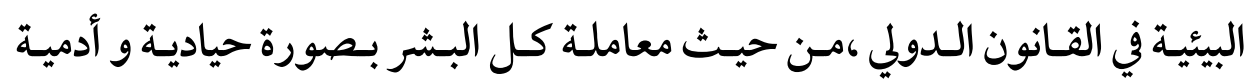
وبصورة متساوية في كل الظروف مـن خلال إنقاذ الحياة وتخفيف المعاناة عنهم جر اء تلك الكوارث وتحقيق مصالح كل الضحايا ، وعلى المنظلات الإنسانية ألا تتدخل في أي خلافات ذات طابع سياسي أو أيديولوجي أو ديني .

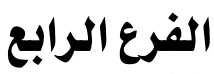

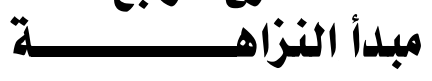

يعد من المبادئ الإنسانية لمواجهه الكوارث البيئية في القـانون الـدولي مبـلـأ

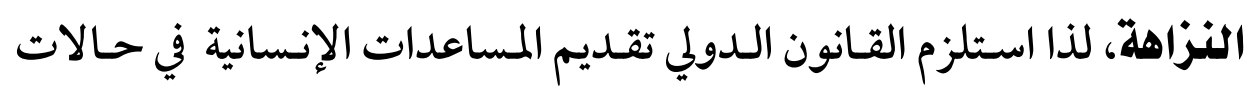
الكوارث البيئية بأن يدار العمل الإنساني بمعيار موضوعي، دون أبون أي اعتبارات أخرى في تقديم المساعدات

ويقـصد بتطبيـق النزاهـة integrity في بجـال الدراسـة مراعـاة الأولويـة

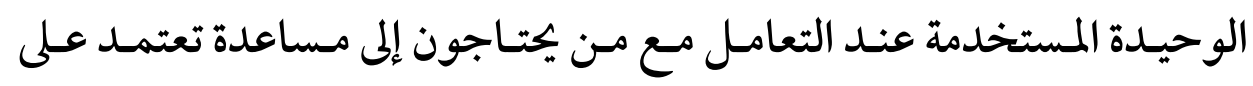
الحاجة، إذ لا بـــ أن تتناسب درجـة المساعدة مـع درجـة الحاجـة وعـدم التميز

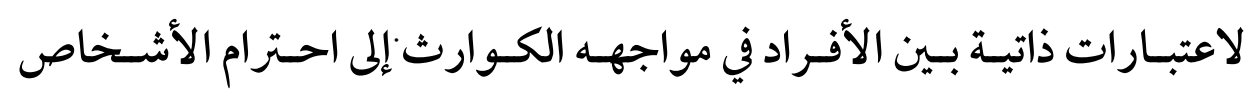

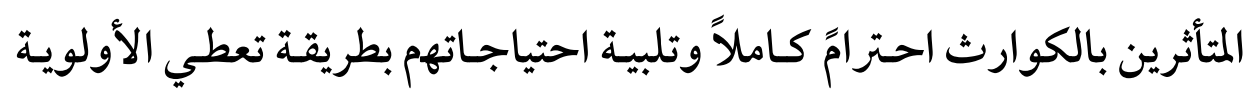
للأشخاص المعرضين للخطر بوجه خاص (1).

( 1 ) Peter MacAlister-Smith, Draft international guidelines for humanitarian assistance operations .Heidelberg, Germany: Max Planck Institute for Comparative Public Law and International Law, .(1991), para. 6(a) 


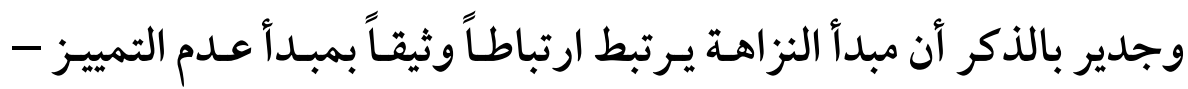

السابق الإشارة إليه - ويدل على ذلك أن عدداً كبيراً من الوثائق الدولية المعنية بالإغاثة في حالات الكوارث الطبيعية تعرف النزاهة بالإحالة مباشرة إلى عـدم التمييز (1)

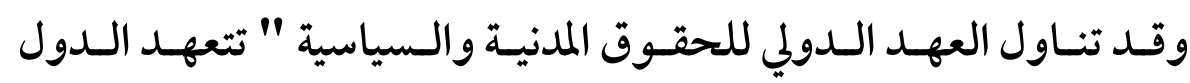
الأطر اف في العهـد بكفالـة تساوى الرجـال والنساء في حسق التمتـع بجميـع الحقوق المدنية والسياسية المنصوص عليها في هذا العهد" (؟). كحا تناول البروتوكول الإضافي الأول لاتفاقيات جينيف مفهوم النزاهة بأنه

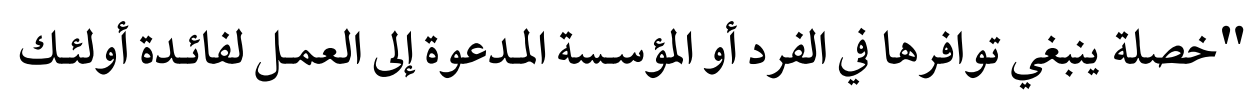
الذين يعانون من تلك الأوبئة: (().

(1) من ذلك على سبيل المثال : معايير موهونك للمساعدة الإنسانية في حسالات الطوارئ

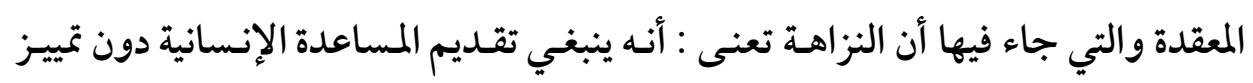

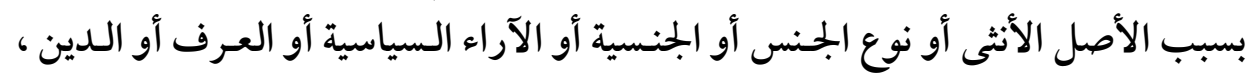

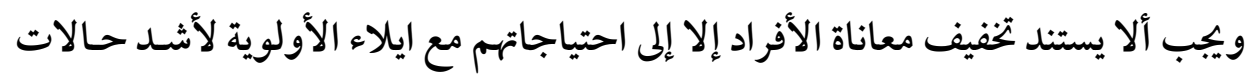

$$
\text { الكرب إلحاحاً " انظر في ذلتك : والأنين }
$$

Ebersole, J. M., "The Mohonk crhteria for humanitarian assistance in complex emergencies, Task Force on Ethical and Legal Issues in Humanitarian Assistance",P.196

$$
\begin{aligned}
& \text { وأيضاً المبادئ التوجيهية المستكملة المتعلقة باستخدام الأصول العسكرية وأصول الحماية }
\end{aligned}
$$

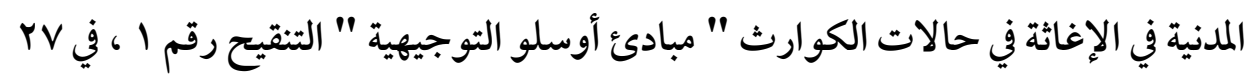

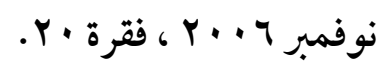

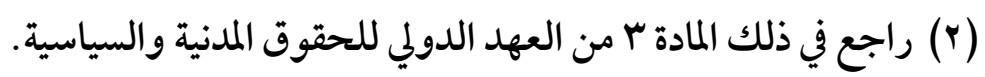

(3) Claude Pilloud et al., Commentary on the Additional Protocols of 8 June 1977 to the Geneva Conventions of 12 August 1949 
كحا تضمن مشروع المبادئ التوجيهية الدولية لعمليات المساعدة الإنسانية على أنه "ينبغي تقديم المساعدة الإنسانية بنزاهـة ودون تمييز بجحف لئف إلى جميع الأشخاص الذين يكونون في حاجة ماسة إليها"(1).

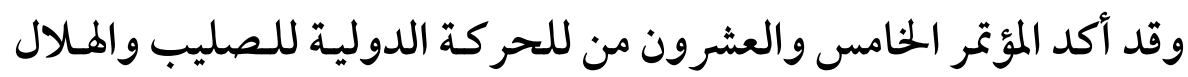

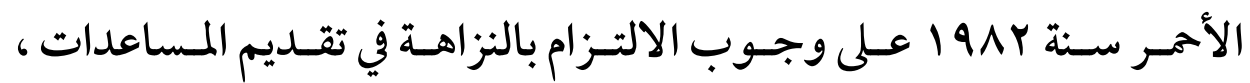

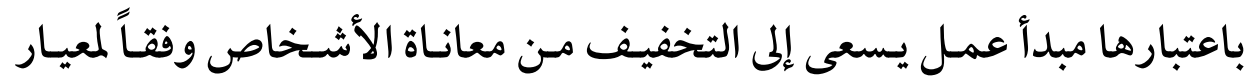

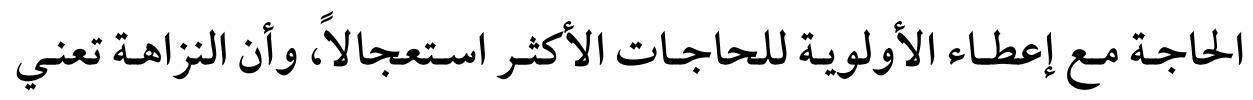
الابتعاد عن التميز سواء بالنسبة للجنس ، الجنسية، المعتقـد الـديني ، أو الر أي لئي السياسي (ن) ونظراً لأهمية مبدأ النزاهة في العمل الإنساني فقد حرصـت الجمعية العامـة للأمم المتحدة على التأكيد على وجـوب الالتزام بمبـدأ النزاهـة كأحـد المبادئ

(Geneva: International Committee of the Red Cross, 1987), paragraph 2800-2801 (citing th "Proclamation of the Fundamental Principles of the Red Cross", adopted by resolution IX of the 20th International Conference of the Red Cross,Vienna 1965), and .Pictet, Commentary, pp. 33-51

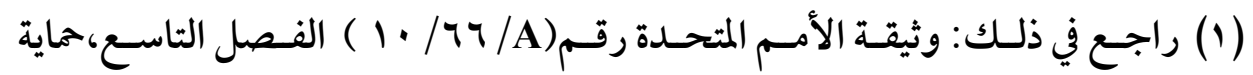
الأشخاص في حالات الكوارث، الفقرة ه، ص هبr.

(ץ) راجع في ذلك: الفقرة Y (ب) مـن المادة ع من المبادئ التوجيهية لتسهيل وتنظيم

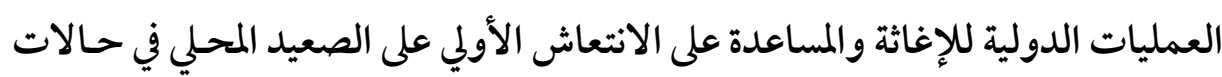

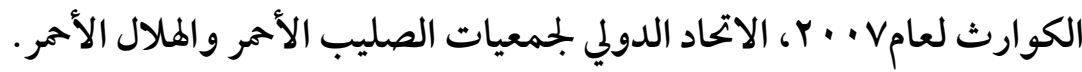


(114) حماية الأشخاص في حالات الكوارث البيئية في القانوز الدولي

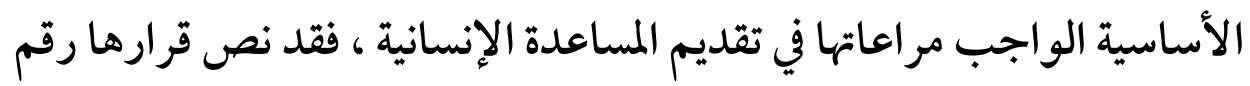

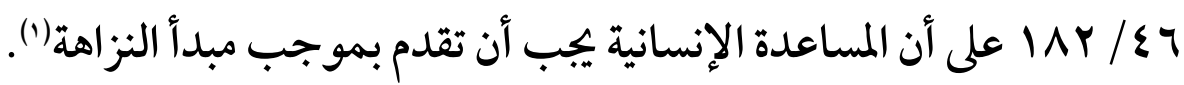

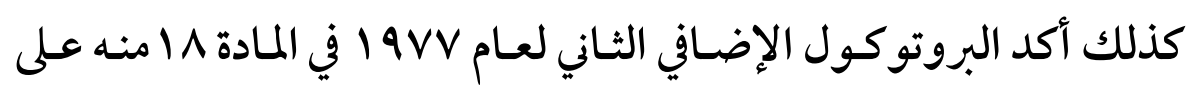

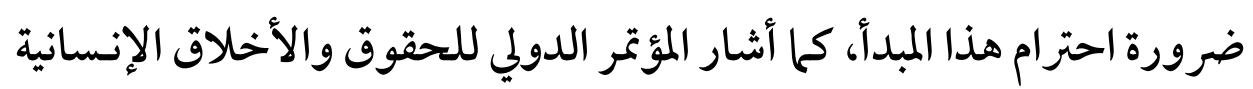
إلى ضرورة أن تسمو النزاهة على أي اعتبارات أخرى وتفرض نفسهراعلى إسلى كل قادر على المساعدات الإنسانية. وإدر اكـاً لأهميـة مـدونات الـسلوك الـوظيفي في تعزيـز الالتـز ام بمبـادئ

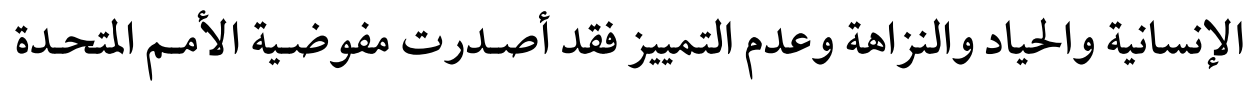
لحقـوق الإنسسان في عـام 1999 مدونـة لقواعـد سـلوك موظفيها في المقـر وفي الميدان على السواء، والتي نصت على الالتزامات القانونية التي تقع على موظفي الأمم المتحدة و المبادئ الأخلاقية التي على الجميع أن يتمسكوا بها (†).

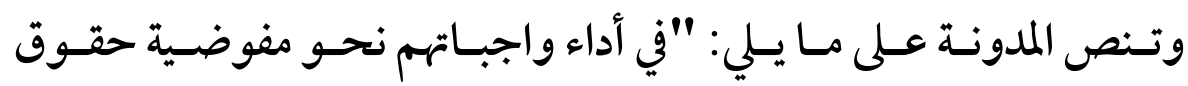
الإنسان، ومن أجل بلوغ أعلى مستوى مـن الجـودة والنزاهـة والبراعة المهنيـة، يلتزم الموظفون بمبادئ ميثاق الأمم المتحدة باحترام ودعم وتعزيز مبـدأ الأمـم

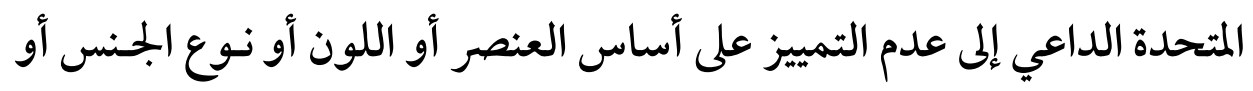

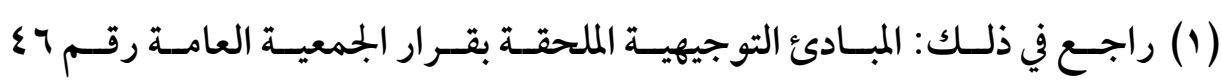
$.1991 / \mathrm{MAY} /$ (ץ) وهذه المدونة كما جاء على لسان المفوض السامي " تكمل أحكام الميثاق ولوائح

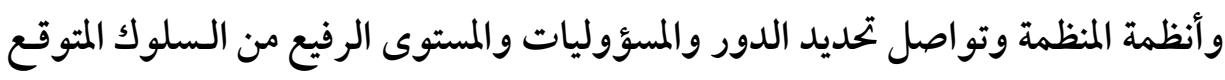

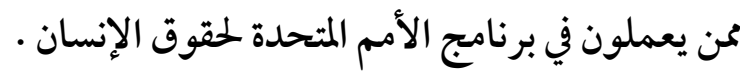




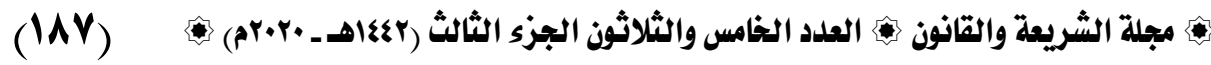
اللغة أو الدين أو الرأي أو الأصل القومي أو الاجتحاعي أو الثروة أو المولد أو أي وضع آخر، و كذا أداء وظائفهم دون إبطاء وبكفاءة وبروح المبادرة والمقدرة وحسن النوايا والنزاهة والبراعة المهنية في بميع الأوقات(1). وهـذا لا يـستثني الاخـتلاف في طريقـة وأسـلوب التعامـل مـع الأفـــاد في حالات خختلفة بناءً على النوع والعمر (؟). وعلى ذلك يمكن القول بتطبيق مبدأ النزاهة في المساعدات الإنسانية يتطلب مراعاة الأولوية الوحيدة المستخدمة عند التعامل مع من يحتاجون إلى المساعدة، إذ لا بد أن تتناسب درجة المساعدة مع درجة الحاجـة وعـدم التميز لاعتبـارات

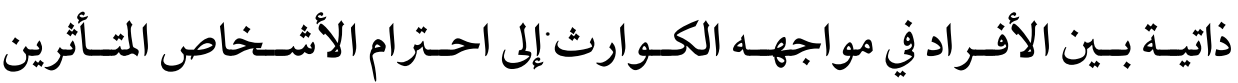
بالكوارث احترامً كاملاًٌ وتلبية احتياجاتهم.

(1) راجع في ذلك:المعايير المنطبقة على موظفي حقوق الإنسان وغـيرهم مـن العـاملين في الأمم المتحدة، الفصل الثاني والعشرون، الجزءء الخامس ،موظفي حقوق الإنسان، صــ-

وبتجدر الإشارة إلى أن هنـاك خـسة معـايير يمكنها أن تـؤدي لحـدوث التمييز وهي:

$$
\text { الجنسية، والعرق، والمعتقدات الدينية، والطبقة الاجتحاعية، والآراء السياسية. }
$$

Five criteria which could lead to discrimination are mentioned: nationality, race, religious beliefs, class or political opinions. However, other factors which may lead to a discrimination are not mentioned. Depending on circumstances, a different treatment based on sex may be a discrimination or not The International Federation of Red Cross and Red Crescent Societies is the world's largest. https://www.ifrc.org 
(IAA) حماية الأشخاص في حالات الكوارث البيئية في القانون الدولي

\section{المطلب الثاني

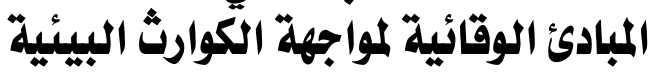 \\ في القانوز الدولي}

لاشك إن ارتباط الإنسان بالطبيعة منذ الأزل جعلته دائم التأمل والتفكر

في أحوالهـا وتقلباتها وفي مختلـف مكوناتها النباتيـة والحيوانيـة، لـذلك فـاهتحام

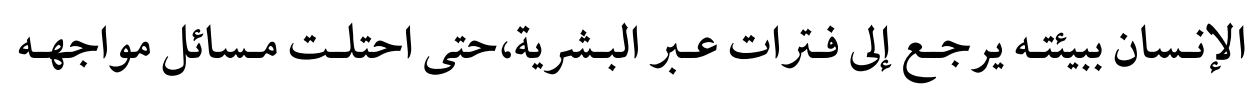

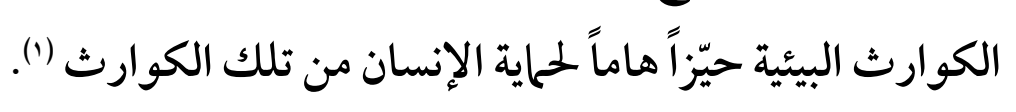

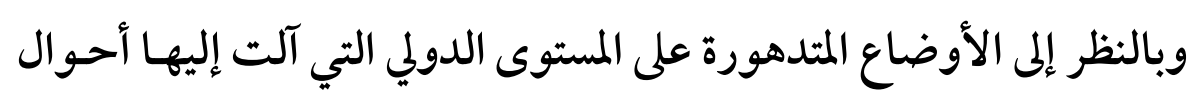

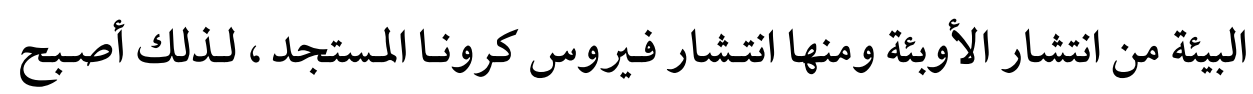

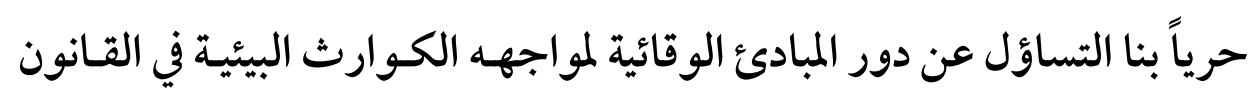

$$
\text { الدولي. }
$$

وعليه نحاول من خلال هذا المطلب الإجابة على هذا التساؤل من حيث

بيان المبادئ الوقائية لمواجهه الكوارث البيئية في القانون الـدولي ،وعلية نقسم هذا المطلب إلى فرعان نتناولما بالتفصيل على النحو التالي:

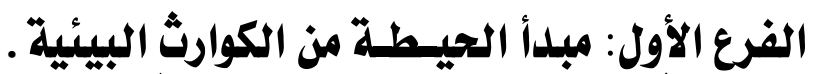

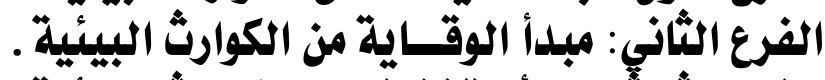

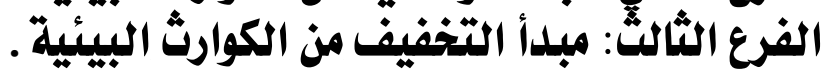

(1) FRANZ-XAVER Perrez, the world summit on sustainable development: environment, precaution and trade- a potential for success and/or failure, RECIEL, Avril 2003, p 15. 
$(119)$

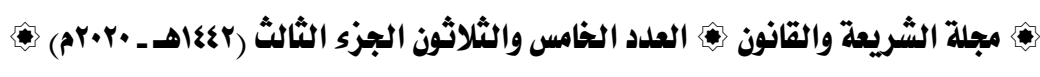

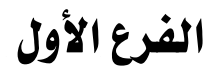 \\ مبلأ الحيطة من الكوارث البيئية}

يعد مبدأ الحيطة أحد المبادئ المامة لتحقيق السلم البيئي، وتحقيق المصالحة المبة المئية

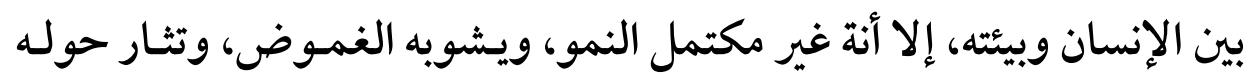

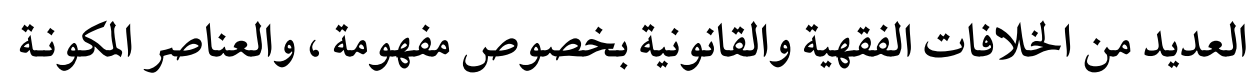

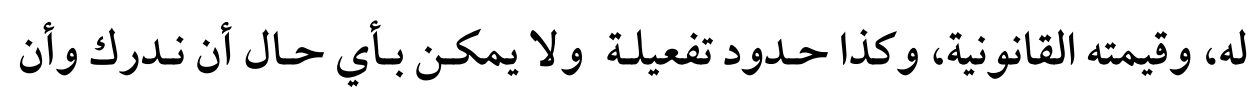

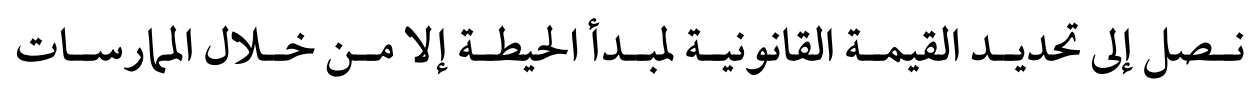
والتطبيقات المستقرة الواضحة (1).

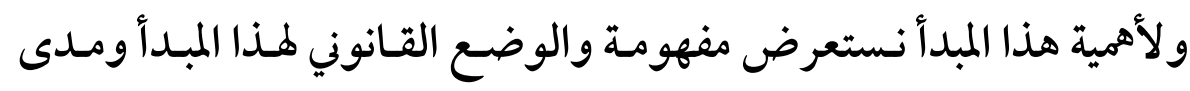
إلزامية مواجهة الكوارث البيئية وذلك فيها يلي:

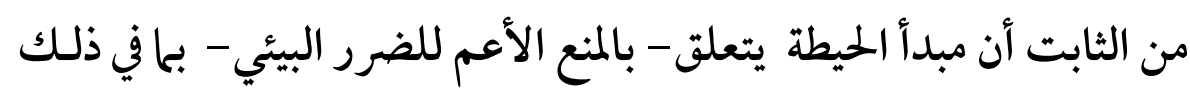

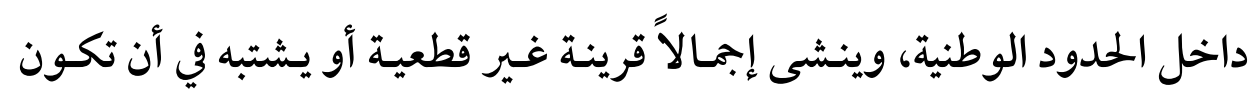
منطوية على خطر التسبب في ضرر للعموم أو للبيئة في غياب دليل على أنها لا تشكل خطراً.

وعلى الرغم من عدم وجود تعريف مقبول عالمياً لمبدأ الحيطة يمكننا محاولة

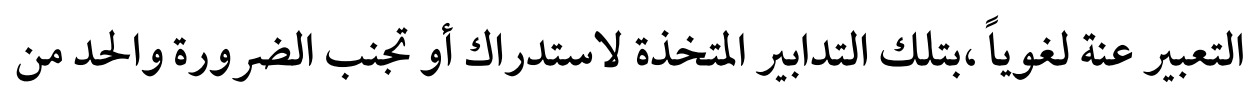

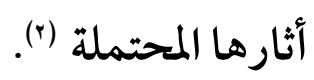

(1) DAVANTURE Sandrine, Les relations entre les règles des accords multilatéraux sur l'environnement et celles de l'OMC, Université Paris 2 Panthéon Assas, DEA, 2003, p 3.

(2) N. de SADELEER, Les principes de pollueur-payeur, de prévention et de précaution, Essai sur la genèse et la portée juridique de quelques 


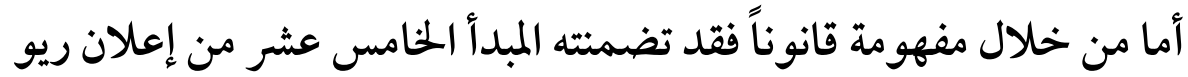

المتعلق بشأن البيئة والتنمية "تتخذ الدول على نطاق واسع تـدابير احتياطيـة

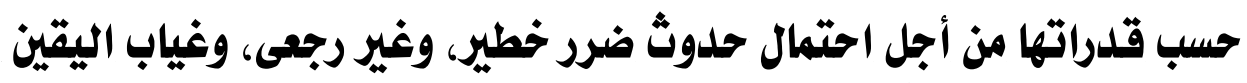

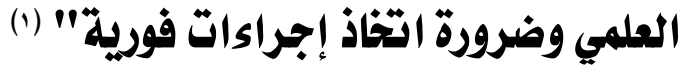

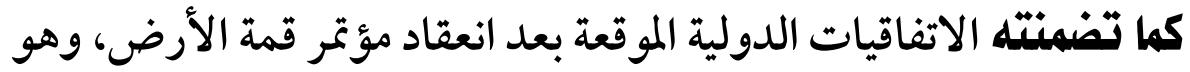

بذلك يعطى معنى أولياً للمبـدأ تضضمنت ضـرورة اتخـاذ تــلـابير احتياطيـة لحماية البيئة التي يعيش فيها الإنسان من الكوارث البيئية (r). وحيث أكدت نصوص القانون الدولي مدى إلزامية مبـدأ الحيطة ميسا جعله الإنها

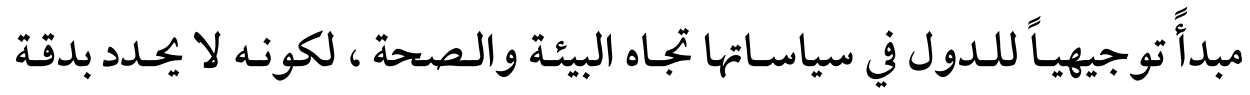
الالتزامات الواجب القيام بها مما جعله بجرداً مـن أيـة قيمة قانونيـة في القـانون التعاهدى ، كما يتلاحظ بـذكر بعض اتفاقيـات دولية تنص صر احسة وبـشكل دقيق ، وبصيغة آمرة على وجوب تطبيقه دون حاجة إلى تدخل آليات تنفيذية.

principles du droit de l'environnement, Bruylant, Bruxelles, Universités Francophones,-1999,p.21.

(1) Agenda 21 , Rapport de la conférence des nations unies sur l'environnement et le , Rio de Janeiro 3 -14 juin 1992, volume 1, anexe 2 résolutions adoptées par la développement .p.245 ; conférence, NU, New York 1993 septièmes, rencontres Internationales D'AIX en Provence, paris, A ,Pedone 1999, pp.69-77

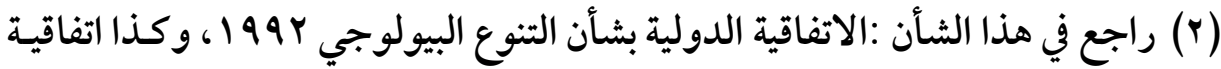

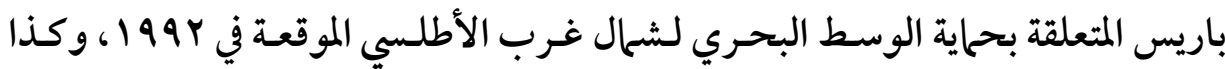

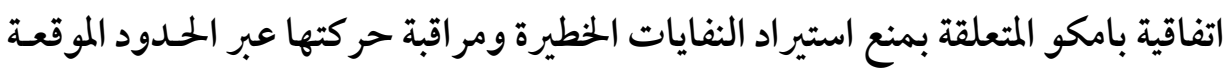

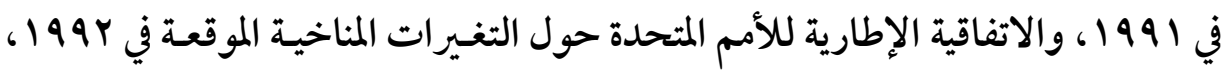

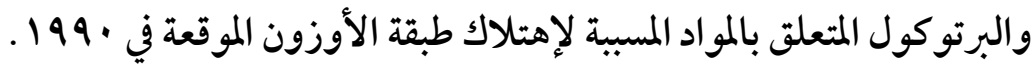




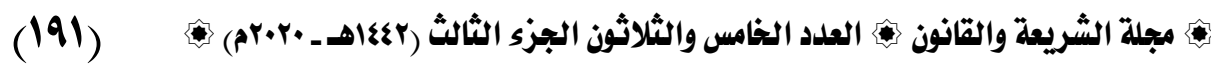

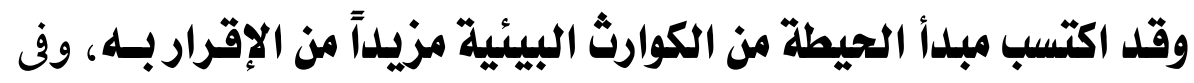

هذا الشأن قررت لجنة القانوز الدولي أن ما تضمنته المادة م من مشاريع المواد

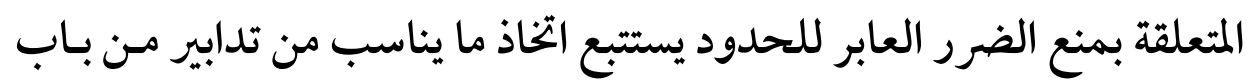

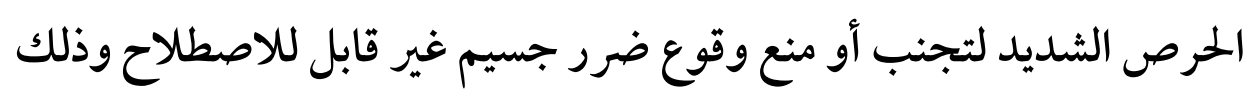
حتى في حال عدم وجود يقين علمي لتفشى الفيروسات البيئية القاتلة (1).

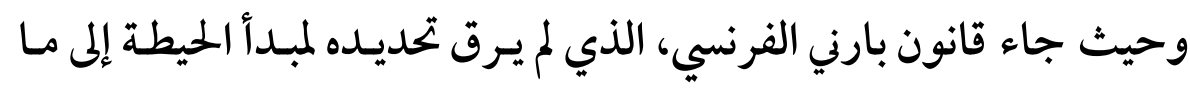

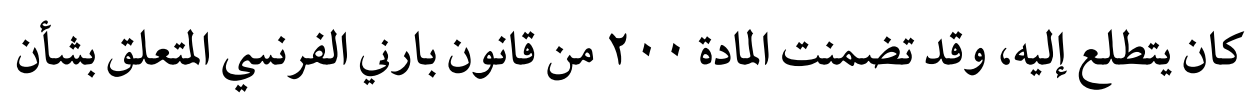
التلوث البيئي "إن غياب اليقين العلمي و التقني لا يجبـ أن يؤخر مـن اتخـاذ

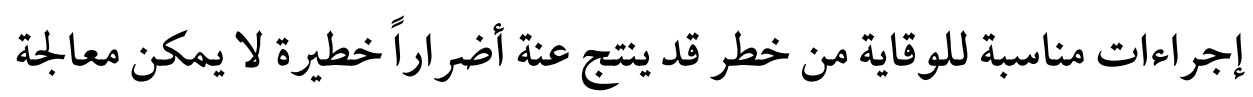
نتائجه بتكلفة اقتصادية مقبولة" (†).

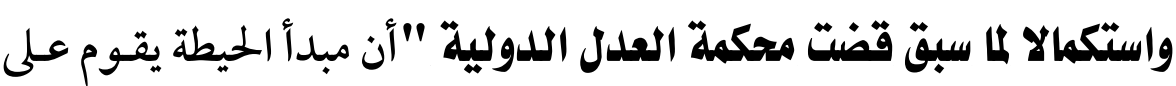
عنصرين يتطلب تحققها لتجنب الكوارث البيئة بتضمن الأول الوعي بوجود (1) راجع في ذلك المادة ب فقرة · ل و والمادة V والمادة · ل من مشاريع المواد المتعلقة بمنع

$$
\text { الضرر العابر للحدود. }
$$

(2) La Loi Barnier n95-101 du 2 février 1995, l'article 200-1L paragraphe trois stipule comme suit : " l'absence de certitudes, compte tenu des connaissances scientifiques et techniques du moment, ne doit pas retarder l'adoption de mesures effectives et proportionnées visant à prévenir un risque de dommages graves et irréversibles à l'environnement, à un coût économiquement acceptable " 
مخاطر أو استمرارها، ويتضمن الثاني الوعي بجوانب اليقين العلمي عن طريق الحيطة بالمسألة المعنية" (1).

وحيث أكدت على أن مبدأ التحوط من الكوارث البيئية يعد صلب القانون

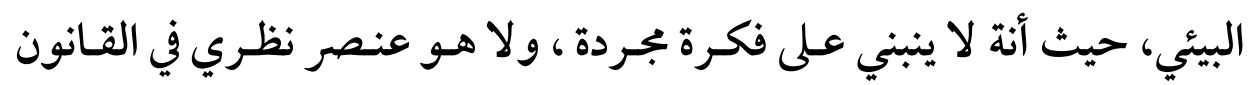

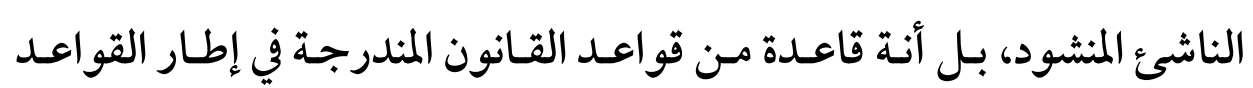
العامة للقانون الدولي بصيغتها القائمة حالياً(")

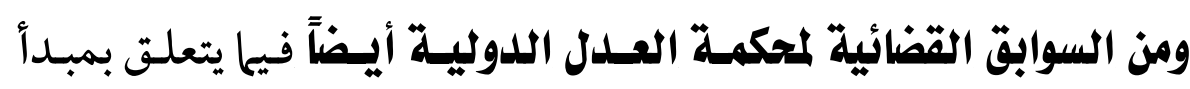
الحيطة "قضية التجارب النووية الفرنسية الثانية في المحيط الهنسي سـنسة r99ابيز فرنسا ونيوزيلنــلـا" حيـث طلبـت نيوزيلنـدا مـن المحكمـة أن تـأمر باتخاذ تدابير احترازية لوقف تلك التجارب على أساس الحيطة ، كما طلبت من

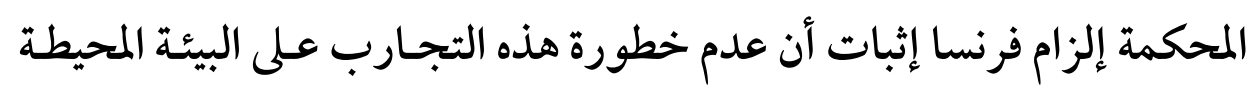

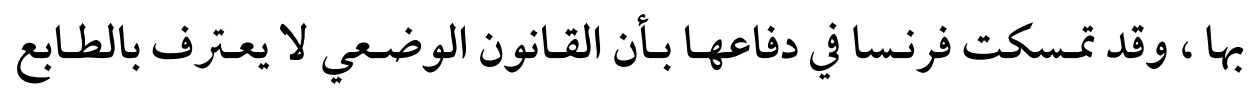

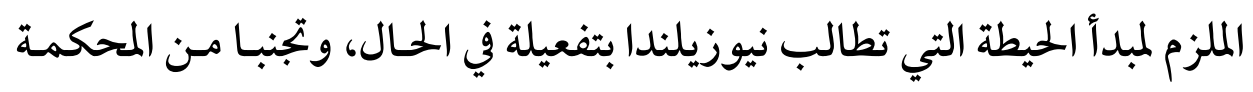

(1) انظر الر أي المستقل للقاضي كانسادو ترينيداد، قضية طاحونتي اللبـاب على نهر أوروغواي، الفقرة rا مشار إلية في الدورة الخامسة والستون من لجنة القـانون الدولي

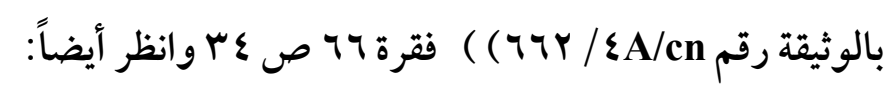

Arie Trouwborst, Precautionary Rights and Duties of States Leiden, Martinus Nijhoff Publishers, 2006 .

(2) Cass R. Sunstein, Laws of Fear: Beyond the Precautionary Principle (New York, Cambridge University Press, 2005) ; Linda Cameron, "Environmental risk management in New Zealand is there scope to apply a. more generic framework?", New Zealand Treasury

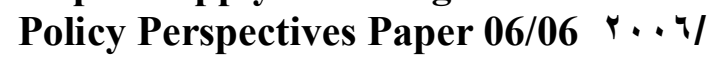




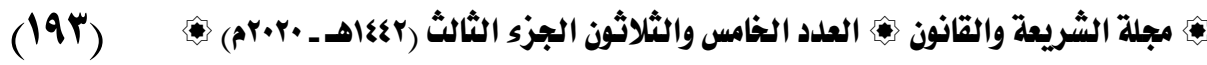

الخـوض في طبيعـة مبـدأ الحيطـة رأت أن تتجاهـل مطالـب نيوزيلنـدا وتغـض

الطرف عن مطلبها في تفعيل المبدأ، وأكثر من ذلك أن تغض الطرف عن اتخاذ

موقف من القضية و الفصل فيها بحجة خطاً في الإجر اءات الشكلية و ذلك في

قرارها الصادر Y r سبتمبر 1990 حيث ورد فيه "إن الطلب الذي تقـدمت بـه

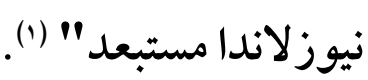

ومن السوابق القضائية للمحكمة الأوربية لحقوق الإنسان والتي تناولت

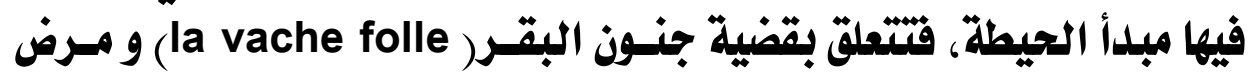

كروتزفيلد جاكوب (CreutsfeldtJakob) الذي يصيب الإنسان، و تطبيقـا

لمبـدأ الحيطة أصـدرت اللجنـة الأوروبيـة لحقـوق الإنسان في ع Y مـايو 1997

قراراً يقضى بالحظر المؤقت لاستيراد لحوم البقر من بريطانيا في تلك الآونة ، مـا

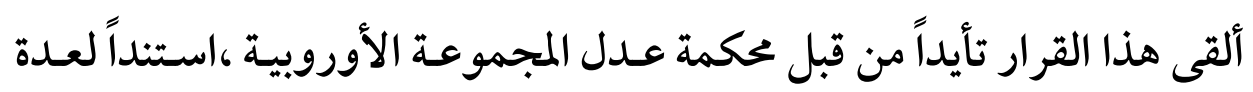

قرارات متعلقة بالرقابة الصحية عـلى المنتجـات الحيوانيـة المطبقـة فيها بـين دول

الاتحاد الأوروبي في تبادلات بعض الحيوانات الحيـة (؟)، وقـل خلـصت المحكمـة

عدم توفر القرائن العلمية التي تثبت علافـة السببية بـين مـرض البقـر والمرض

الذي يـصيب الإنسـان، مـشيرة كـذلك إلى مسساس هـذا الحظر بقاعـدة حريـة

(1) C.I.J, Demande d'examen de la situation au titre du paragraphe 63 de l'arrêt rendu par la Cour le 20 décembre 1974, Recueil 1995 dans I'affaire des Essais nucléaires, affaire Nouvelle-Zélande contre la France, p 23, Par douze voix contre trois, Dit que :" la Nouvelle demande en indication de measures conservatoires présentée par la Nouvelle-Zélande à la même date doit être écartée ". disponible sur le site de la C.I.J : www.CIJ.org.

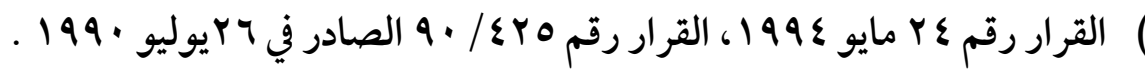


(198) حماية الأشخاص في حالات الكوارث البيئية في القانون الدولي

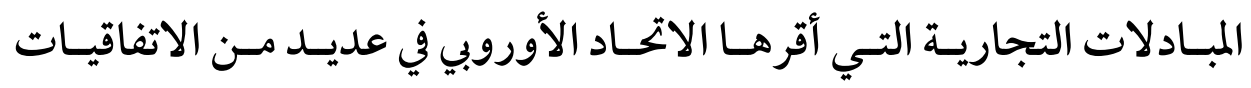

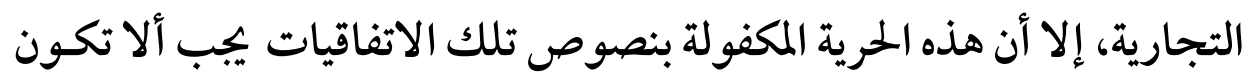
سبباً لتهديـد الصحة العامـة و لا سببا لخرق المبادئ القانونية العامـة للاتحـاد الأوروبي، على غرار مبدأ التناسب الذي فسرته المحكمة على ضوء مبدأ الحيطة و الذي من مقتضاه أنه في حال غياب اليقين العلمي حول إمكانية وجـود أو درجـة خطر قـد يمسس بصحة الإنسان، يمكـن للمؤسسات و الميئـات اتخـاذ إجراءات حمائية دون انتظار اليقين العلمي الذي يبين بجلاء الخطر و الضرر المرتبط بالفعل المحظور (1). وعلى ذلك يمكننا القول أن مبدأ الحيطة لا يخرج عن اتخاذ التدابير للخوف

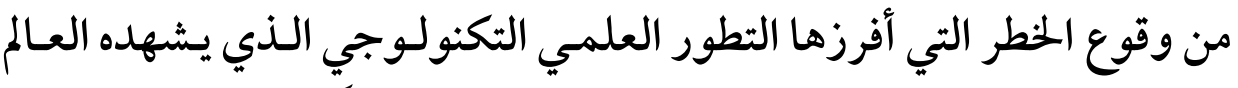

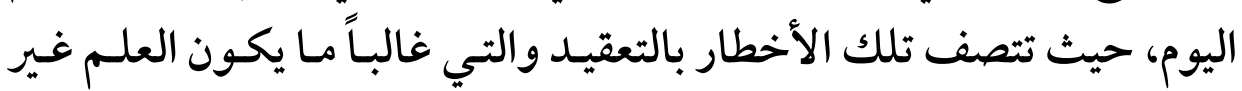

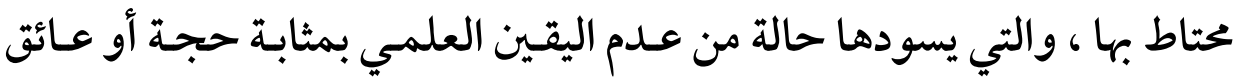

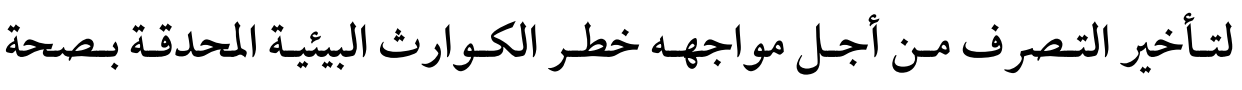

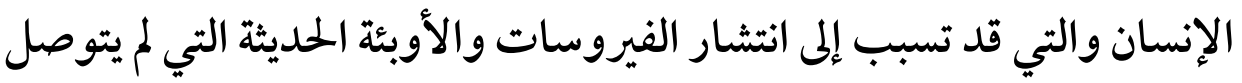

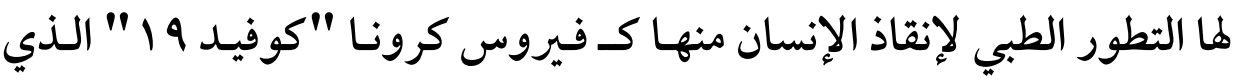
راح ضحيته عدد كبير بحياة البشر على المستوى الدولي.

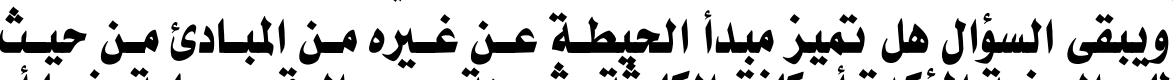

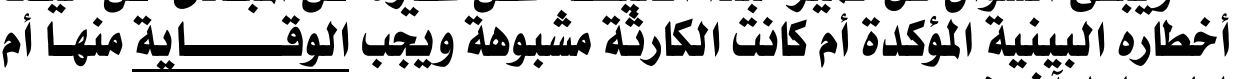
لها مدلول آخرى؟ نتعرف على ذلك من خلال مبدأ الوقـاية الذي نتناوله في الفرع التالي:

(1) CJCE, affaire National Farmers contre l'Union Européenne, affaire $\mathbf{N}^{\circ}$ C-157/96 du 5/5/1998, CJCE, Affaire Royaume-Uni contre La Commission Européenne, Affaire $N^{\circ}$ C-180/96 du 5/5/1998. 


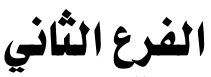 \\ مبلدأ الوقـــاية من الكوارث البئيئية}

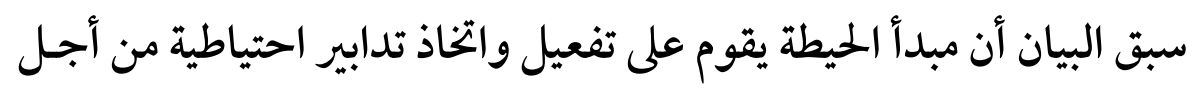
المحافظة على البيئة من أية كوارث، وليس البحث في مواجهه أو تجنب ظـاهرة

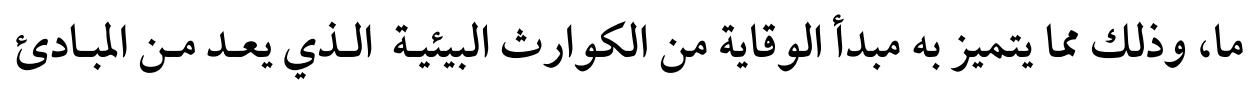
الجديدة للقانون الدولي البيئي (1). حيث أن أغلب أهدافه تلزم الدول بأن تتخذ في إطار التعاون الددولي جميـع التدابير الوقائية اللازمة لمنع وقوع الأضرار البيئية شريطة أن يكسون ذلك بأقل

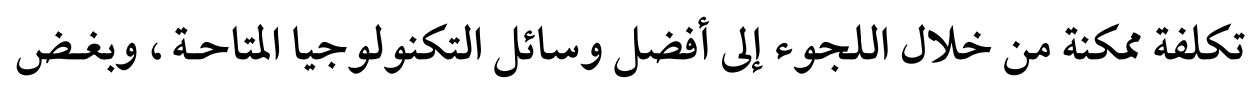
النظر عـن ماهيـة هـذه التـدابير سـواءً تمثلـت في خطر إقامة النشاط الإنساني المحتمل أن يسبب أضرار للبيئة (†).

وعلى الرغم مـن التطور العلمي المائل في شـتى المجـالات المختلفـة عـلى

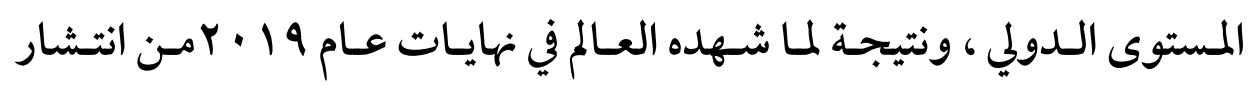

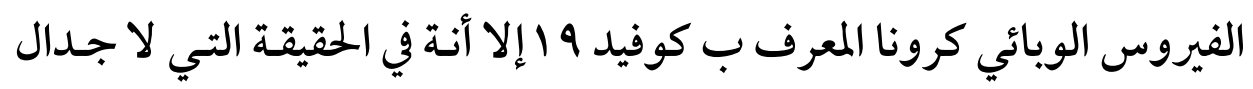

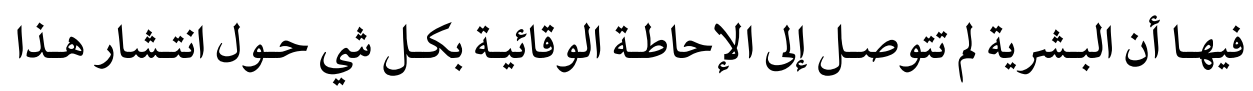

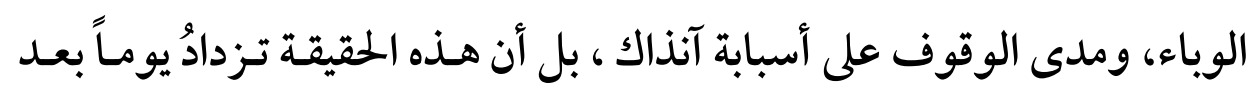

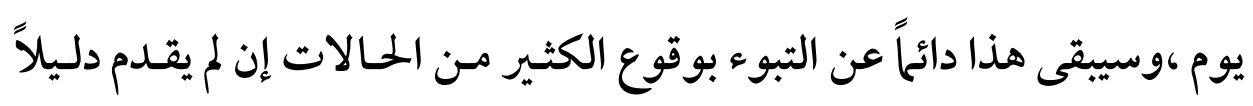

(1) THIEFFRY Patrick, Le contentieux naissant des organismes génétiquement modifiés : précaution et measures de sauvegarde, RTDE (Revue Trimestrielle du Droit Européen) n ${ }^{\circ}$, France, 1999, p 82.

(2) Arabic Compendium of International Law UNEP Environmental Law Publication, 1995,p202. 


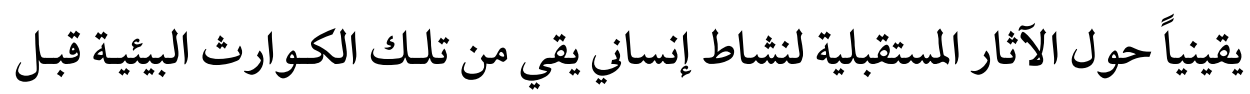

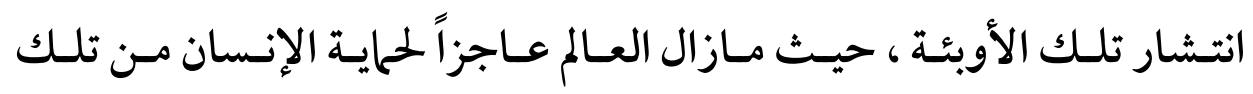

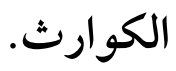

ويرجع تاريخ ظهور هذا المبــلـأ إلى بـدايات السبعينات مـن التـرن الماضي

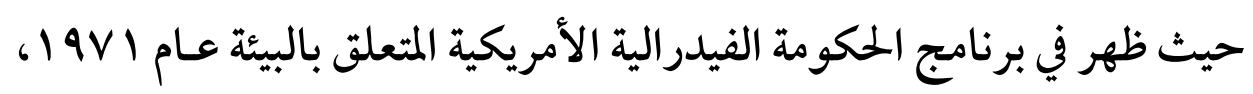

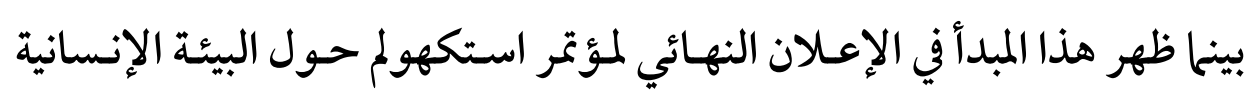

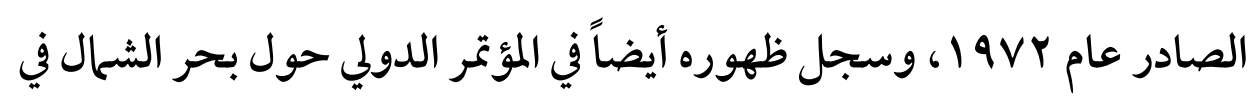

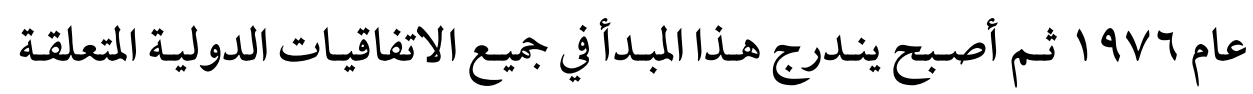

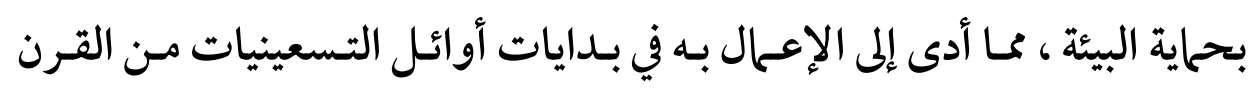

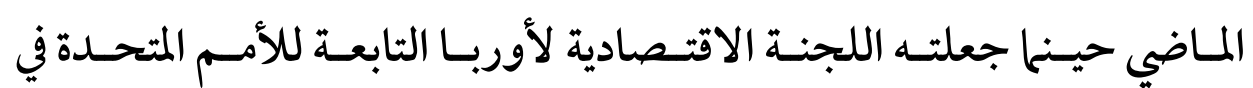
مايو ، 199 مبدأَعاماً يجب أن يجكم السياسات البيئة للدول(1). ولأهمية هذا المبدأ نستعرض مفهومـة والوضـع القـانوني لإقرار هـذا المبـدأ ومدى إلزامية مواجهة الكوارث البيئية وذلك فيها يلي: تستخدم مصطلح الوقايـة للدلالة على مـا نقوم بـه لتجـاوز سبق شي مـا،

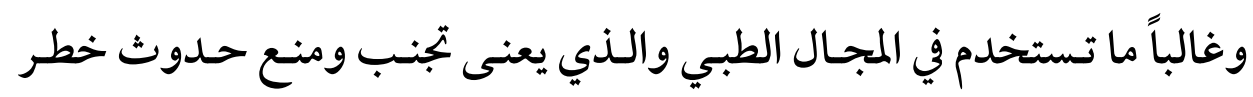
صحي على حياة الإنسان(r)، ويقصد بـه "أن يقوم على أسـاس منـع استخدام

(1) د. محمد صافف يوسف، دارسة في إطار القانون الدولي للبيئة ، دار النهضة العربية ،

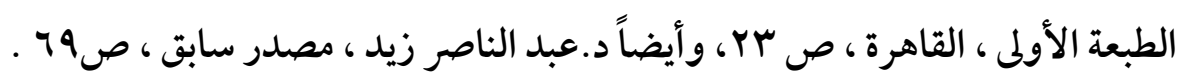
(2) KAESSNER Eva Zbinden, Le Principe de précaution en suisse et au plan international, Document de synthèse du groupe de travail interdépartemental " Principe de précaution », Suisse, Août 2003, p7. 


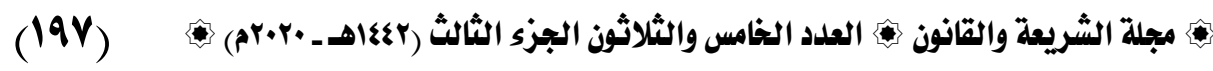

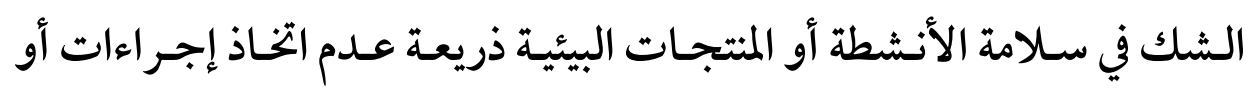
تدابير تضمن السلامة البيئية من أجل مواجهه المخاطر البيئية المحتملة استباقها ، وعدم انتظار اليقين العلمي لإثبات سلامة الأنشطة" (1).

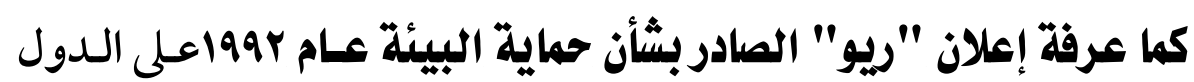
أن تطبق على نطاق واسع النهج الوقائي بحسب مـا يتوافق مع إمكانياتها في

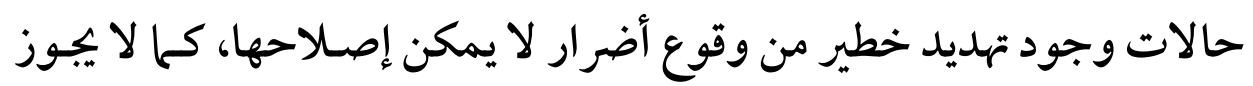

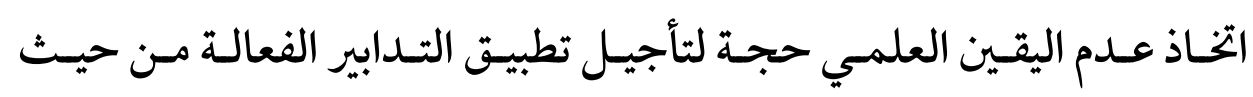
التكاليف من أجل الحيلولة دون وقوع التدهور البيئي(ن). وحـرى بالـذكر لا يكتمـل أيّ مـدخل إلى المبـدأ الوقائي مـن دون التطرّق بإيجاز إلى الفرق بين المبدأ الوقائي والنهج الوقائي.

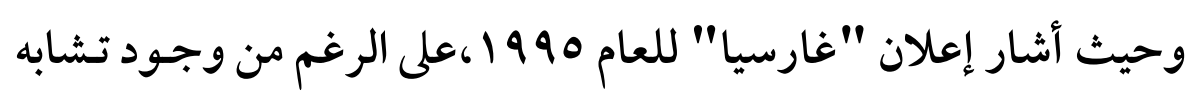

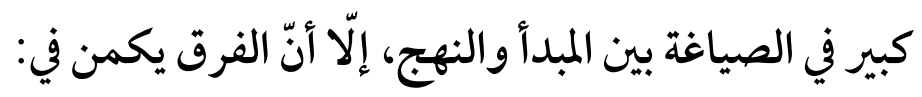

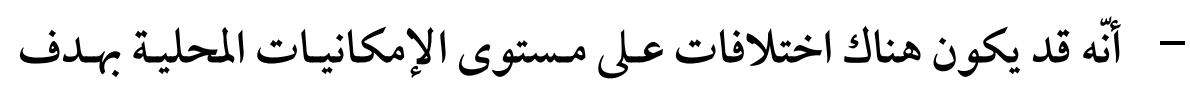
تطبيق النهج لحاية الإنسان من تلك الكوارث البيئية.

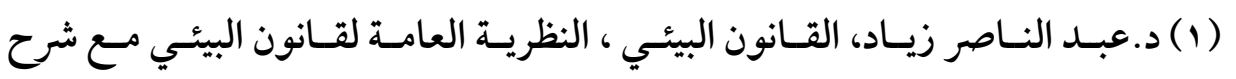

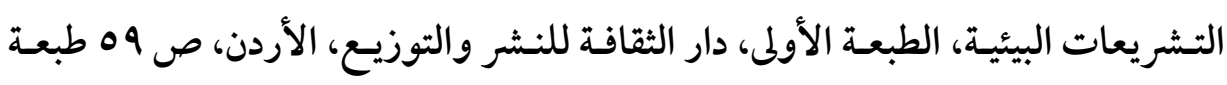
r. Ir (r) راجع في ذلك :المادة 10 من إعلان "ريو" الصادر في العام 199 ـ . 
أنّها تدعو إلى تطبيق تدابير فعّالة من حيث بذل شـتى الجههود بهـدف تطبيق

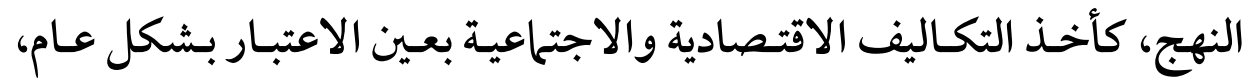

يعتبر النهج أخف حدّة وأكثر ليونة من المبدأ (1).

وكحا ذكرت "ريكووردا" في هذا الإطار، إنّ الفرق بين "المبـأ الوقائي"

والنهج الوقائي" منتشر ومثير للجدل في بعض الأحيان، فضلاً عن أنة في إطار

المفاوضات التي تناولت الإعلانـات الدولية، حيـث عارضـت الأمـم المتحـدة

اسـتعمال مصطلح "مبـدأ" لما هـذا الأخـير مـن دلالات في المجحـال القـانوني،

انطلاقاً من فكرة أنّ "مبدأ القانون" هو مصدر من مصادر التشريع.

وذلك مما يعني أنّ "المبدأ" هو إلزامي، بالتالي يمكن محكمة مـا أن تنقض

حكماً أو تؤكده من خلال تطبيق المبدأ الوقائي (^).

و في هذا الإطار يمكن القول أنه لا يُعتبر المبدأ الوقائي مجرد فكـرة بسيطة

أو مبتغى الضرورة بل مصدراً من مصادر التشريع، هـذا هـو الوضـع القـانوني للمبدأ الوقائي في الاتحاد الأوروبي.

(1) Allen L. Springer, The International of Pollution: Protection of the global Environment in a World of Sovereign States, Westport. Connecticut Quorum Books, 1983.p232.

(2) EDLINGER Sophie, Les limites du principe de précaution à travers les jurisprudences de la Cour de justice des Communautés européennes et du Conseil d'Etat, D.E.A. de Droit International et Communautaire, Université de Droit et Santé de Lille II, 2002-2003, p 25. 


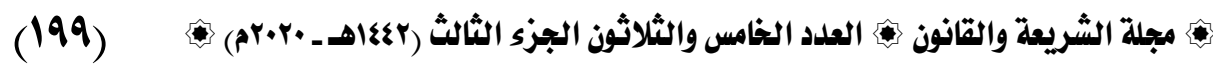
و في المقابل، غالباً ما لا يحمل مصطلح "النهج" معنى "المبدأ" نفسه، إلّا

$$
\text { أنّه في بعض الحالات قد يكون "النهج" ملزماًً"). }
$$

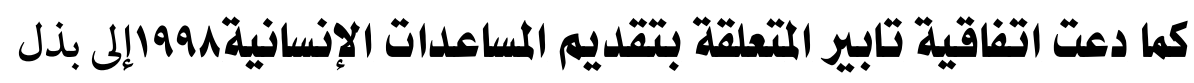

الجههود والتعاون بين المنظلات الدولية الحكومية وغير الحكومية في عـدة أمسور

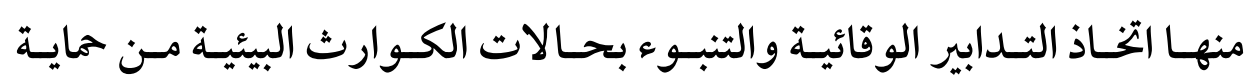

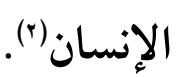

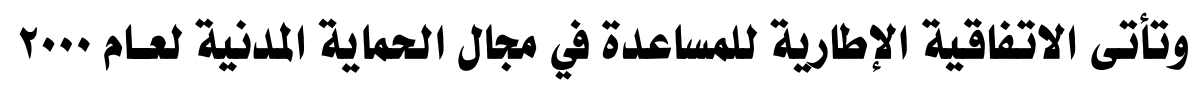

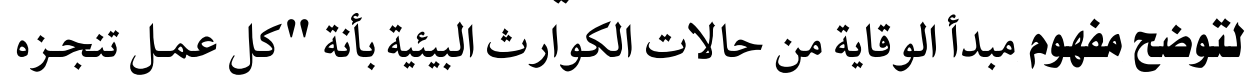

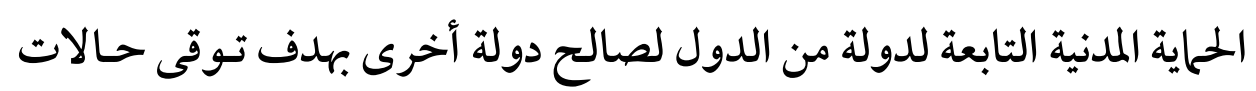

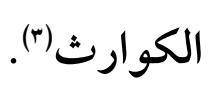

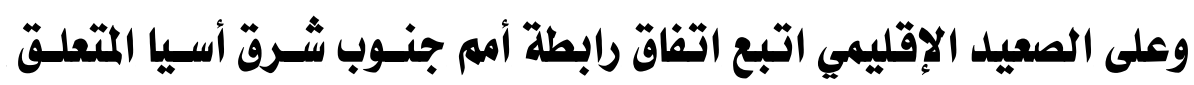

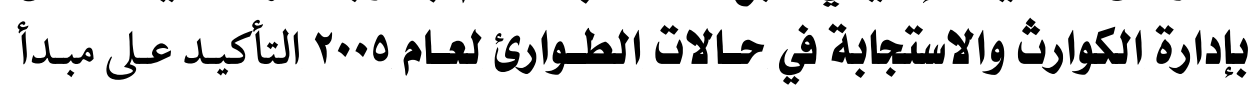
الوقاية من حالات الكوارث البيئية بإلزام الدول الأطراف بأن تعطى الأولويـة

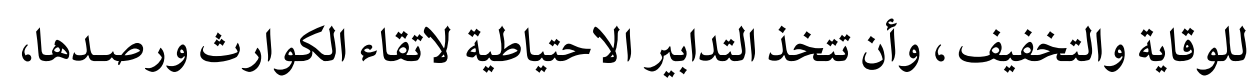

$$
\begin{aligned}
& \text { (1) النهج الوقائي هو عبارة عن "منظار " خاص يُستعمل لتحديد المخاطر، ويتمتع بـه }
\end{aligned}
$$

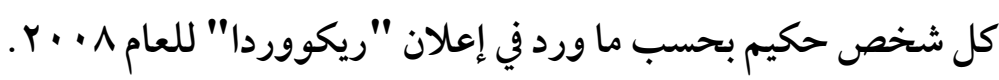

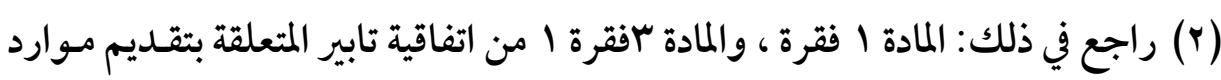

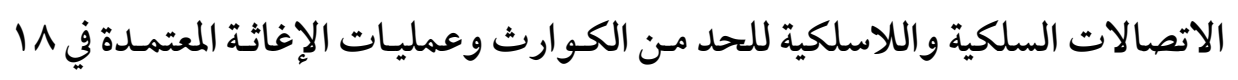

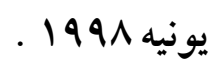

راجع في ذلك المادة ا فقرة د، ، من الاتفاقية الإطارية للمساعدة في مجال الحلايـة

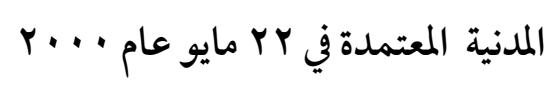




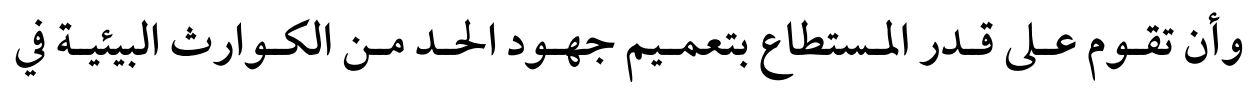

سياسات التنمية المستدامة ، والتخطيط المستقبلي على كافة المستويات (1). ولمزيد من الإقرار بمبدأ الوقاية نجد بعض النظم القانونية في قانون الاتحساد

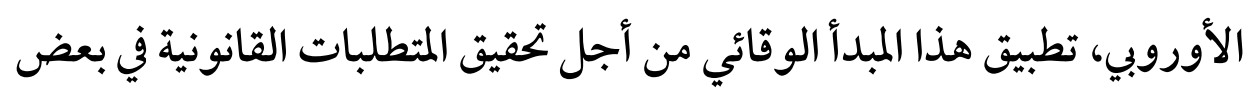

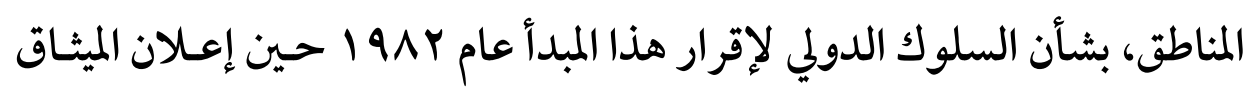
العالمي للطبيعة الذي اعتمدته الجمعية العامة للأمم المتحدة (؟).

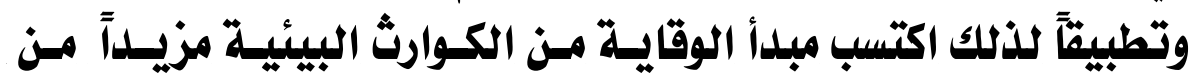

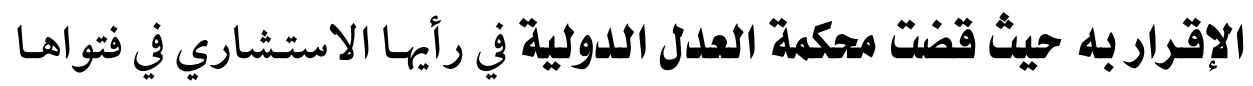
بشأن مدى مشروعية استخدام الأسـلحة النووية أو التهديـد بها عـام 1997

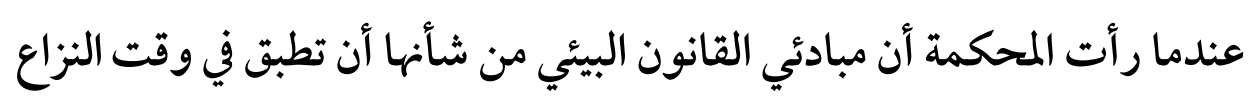
المسلح فضلاً عن تطبيقها وقت السلم من أجل الوقاية من الكوارث البيئية.

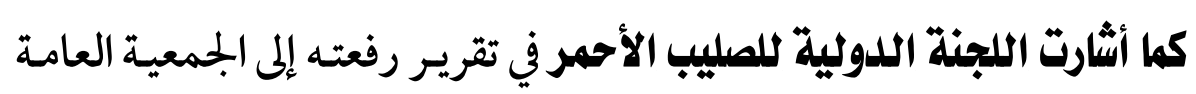
للأمم المتحدة عام بو 199 بشأن حماية البيئة من النزاع المسلح إلى المبلدأ الوقـائي في

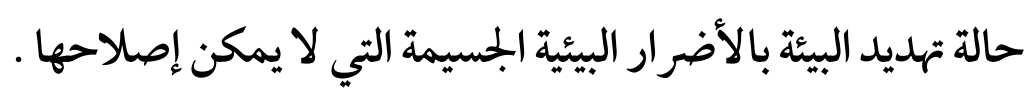

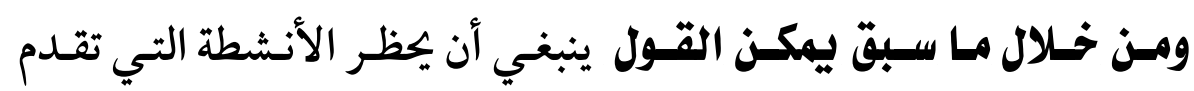

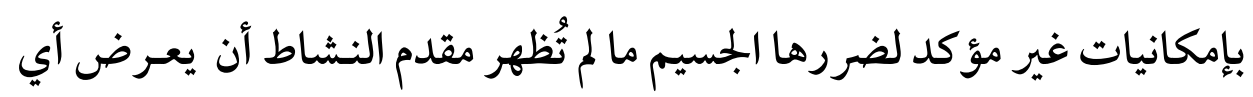
خطر ملموس من الضرر في البت في كيفية تطبيق هذا المبدأ.

(1) راجع في ذلك :المادةب فقرة ؟ ،ه مـن اتفاق رابطة جنوب أمسم جنوب شرق أسيا

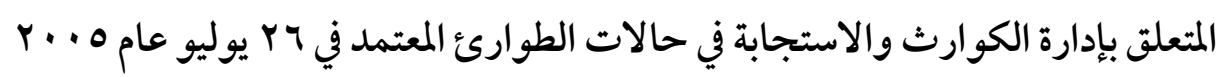
(2) RAMBAUD Patrick, Un nouveau principe du droit communautaire , Le principe de précaution, Édition Bruylant, Bruxelles, 2001, p 315. 


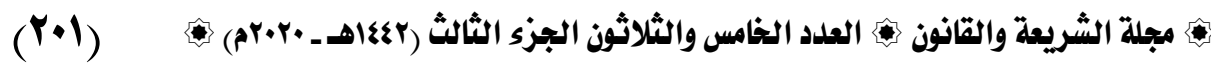
ويبقى السؤال هل تميز مبدأ الوقاية عن غيره من المبادئ من حيث أخطاره

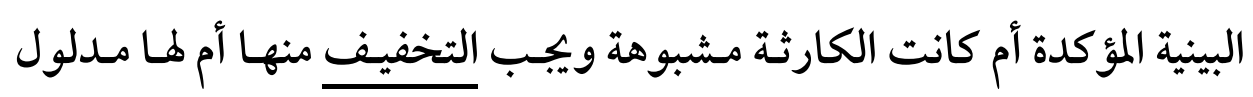

نتعرف على ذلك من خلال مبدأ التخفيف الذي نتناوله في الفرع التالي:

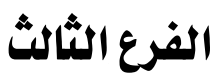

\section{مبلدأ التخفيف من الكوارث البيئية}

مـن المستقر عليـة أن مبـدئي - الحيطة ، والوقايـة - مـن الكـوارث البيئية ،

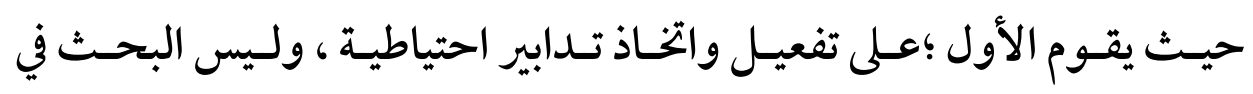

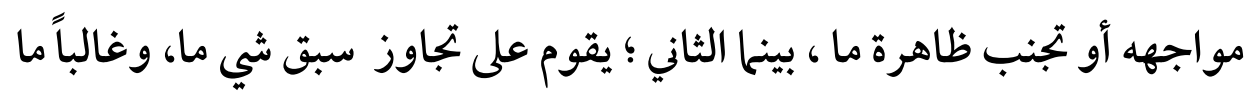

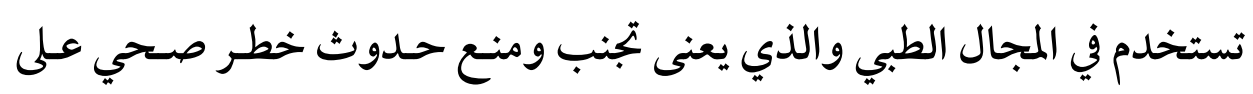

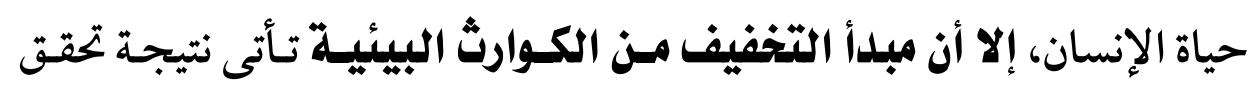

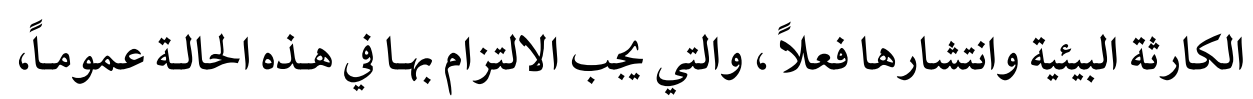
سواءً كانت من صنع الإنسان أو مـن صـنع الطبيعة ، وذلك مـن أجـل تقليل واليل حدة حجم الخسائر البشرية إلى الحد الأدنى إن لم يكن القضاء عليها (1).

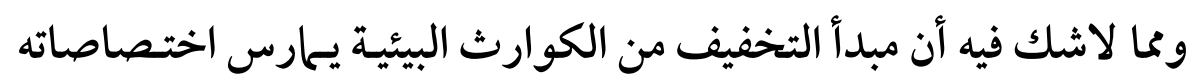

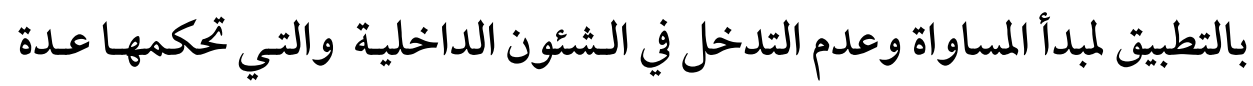
مبادئ تبين الحدود التي لا يمكن للدولة تخطيها عند ممارستها لاختصاصاتها موقف الإقليم، ومن ثم فهي قواعد سلوكية يجب مر اعاتها .

(1) FERETTI Alain, Principe de précaution et dynamique d'innovation, Étude du Conseil économique, social et environnemental, Mandature 2010-2015, Bureau du 12 novembre, France, 2013, p 12. 
وعلى الرغم من انتشار التطور التكنولوجي الذي يشهـده المجتمـع في شـى فئى المجالات إلا أنة في الحقيقة غاب عن البشرية الإحاطة بكل شيء بل بل تزيـد يوماً

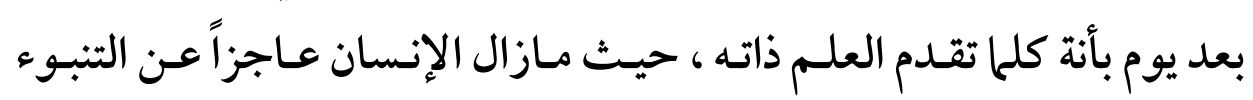

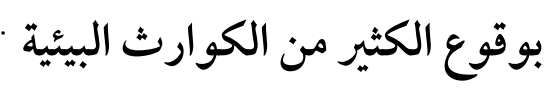

وتطبيقاً لذلك ما شهده العالم من انتشار الويـاء الفيروسي المسمى بكرونـا كوفيد 19 حيث يعد من أخطر الكوارث التي تلحق بالإنسان والبيئة أضراراً يعجز الوقف عنها نتيجة تهديد حياة الأشخاص للخطر.

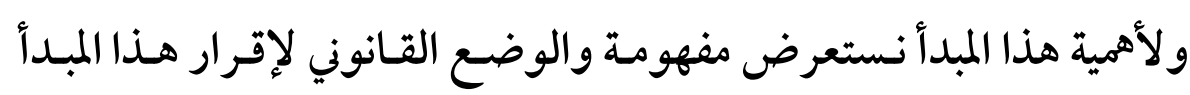
ومدى إلزامية مواجهة الكوارث البيئية وذلك فيها يلي:

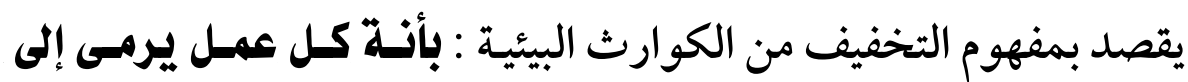
الحد من أثر الكوارث الطبيعية على السكان والاقتصاد (1).

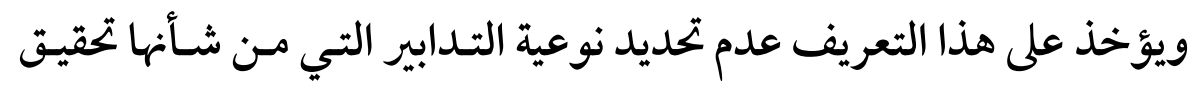
الغرض الذي من أجلة تم الاتفاق علية، وهـو الحـد مـن أثـار الكـوارث البيئيـة والتي تندرج تحت مفهوم التخفيف . كما عرفته الإستراتيجية الدولية للحد من الكوارث الطبيعية على أنة التدابير الهيكلية وغير الهيكلية للحـد مـن الأثر السلبي للمخـاطر الطبيعية والتدهور البيئي والمخاطر التكنولوجية (†).

(1) راجع في ذلك: الاتفاق المبرم بين الأعضاء في رابطة دول الكاربى للتعاون الإقليمي بشأن الكوارث الطبيعية.

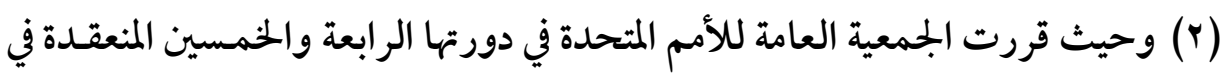

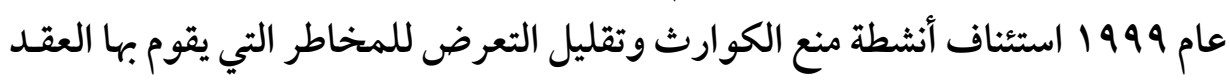




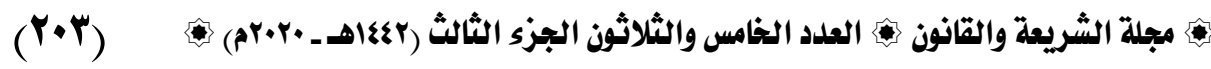

ويرجع النص على مبدأ التخفيف من الكوارث البيئية في القانون الدولي إلى الئ

$$
\text { إبرام عدد من الاتفاقيات الدولية . }
$$

حيث نص إعلان الألفية الصادر في سبتمبر عـام . . . . ب هـدفين رئيسين

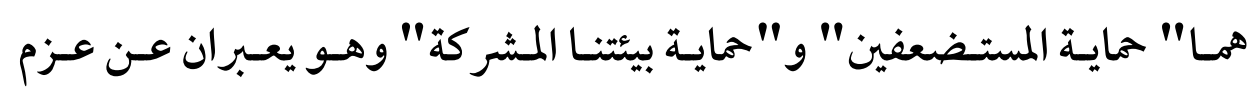
المجتمع الدولي على التعاون الدولي من أجل التخفيف من الكوارث البيئة.

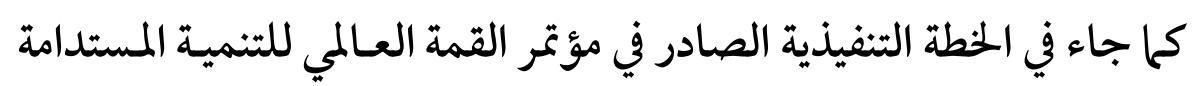

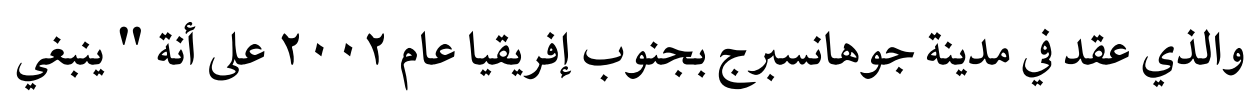

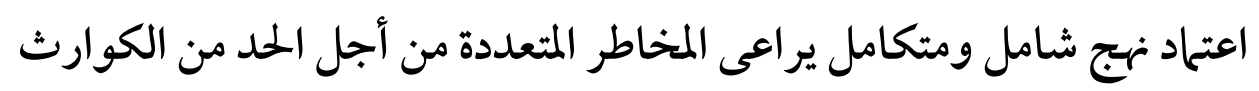
الطبيعية ، بـا في ذلك الاتقاء منها والتخفيف من أثارها"

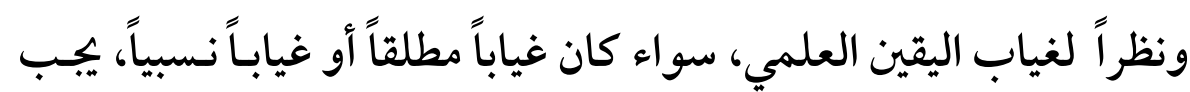
ألا يكون حجة للتأخير في اتخاذ إجراءات كفيلة بدرء الضرر البيئي، (1).

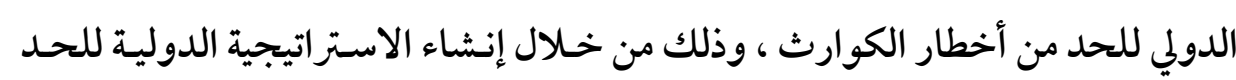

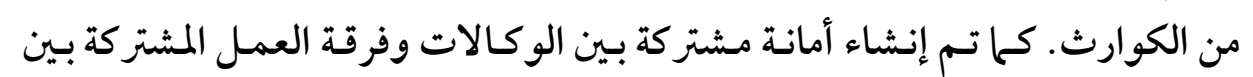

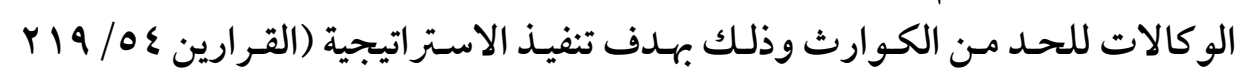

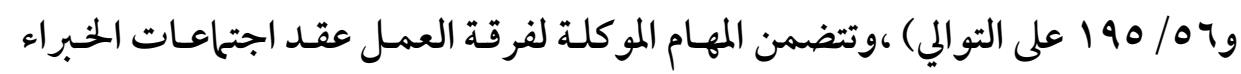

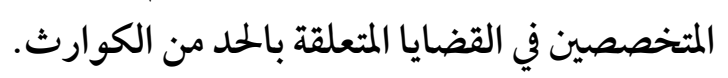

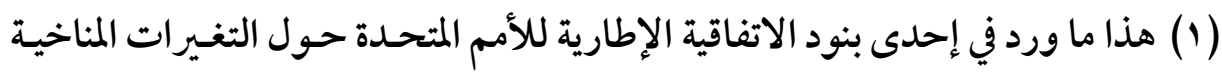
الإطارية لعام 1999. 19.

Déclaration de Rio, l'or de la conférence des nations unies sur l'environnement et le développement (sommet de la terre) du 03 au 14 Juin 1992, Art 15 de la déclaration de rio de 1992 stipule comme suit : " pour protéger l'environnement, des mesures de précaution doivent être largement appliquées par les Etats selon leurs capacités. En cas de risque de dommages graves ou irréversibles, l'absence de 
ومن حيث مدى إلزامية مبدأ التخفيف من الكوارث البيئيـة نجـد أنـة يقـوم

على اتخاذ طائفة واسعة من التدابير نظراً لتأثر الحالة الصحية للإنسان من جراء

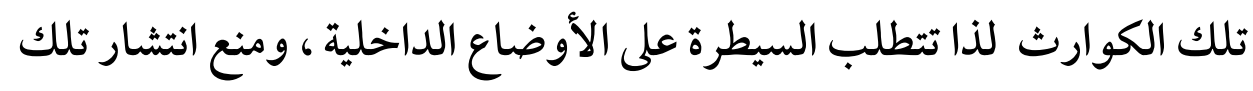
الأوبئة ومكافحتها مـن أجل حيـاة الأشـخاص ولعـل أن تقوم تلك التـدابير

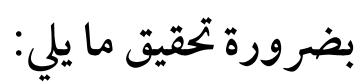

\section{• فرض حظر التجوال للأشخاص : ل}

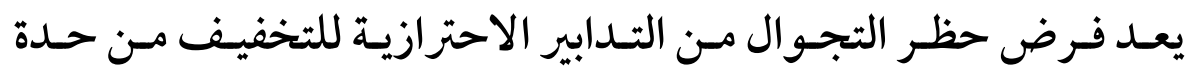

الكوارث والأوبئة المنتشرة بيئياً، بغض النظر عـن وسئ ائلة ؛ بريـاً، أو جويـاً، أو

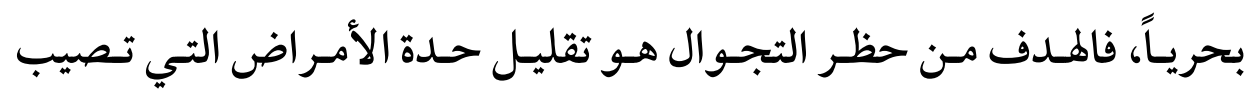
الإنسان من جر اء تلك الكوارث.

فإذا كانت قواعد القانون الدولي تؤكد على أن الحق في الإقامة والتنقل حق مـن حقـوق الإنسان بموجـب المـادة ب ا مـن العهـد الـدولي للحقـوق المدنيـة والسياسية ، كما أن هذا الحق بموجب القانون المادة ع مـن العهد ذاته هـو حق بـ قابل للتحليل منة في ظل الظروف الاستثنائية والطارئة التي تمر بها الأوطان(1).

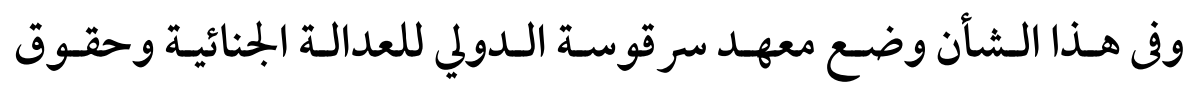
الإنسان ما يعرف بمبادئ سرقوسة وهي مبادئ غير ملزمة تبناها بجلس الأمـم المتحدة الاقتصادي والاجتحاعي عام ع^19 ا وتضمنت ضـو ابط لضبط الحرية

certitude scientifique absolue ne doit pas servir de prétexte pour remettre à plus tard l'adoption de mesures effectives visant à prévenir la dégradation de l'environnement.

(1) راجع في ذلك المادة ؛ وكذا المادة r ا من العهد الدولي للحقوق المدنية والسياسية. 


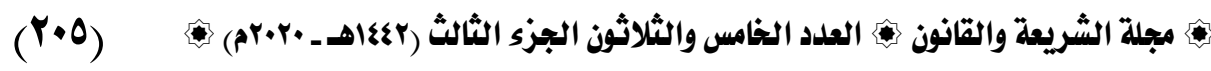
الفردية في حالات الطوارئ الصحية، حيث قررت بـأن القيود المفروضسة على العلى

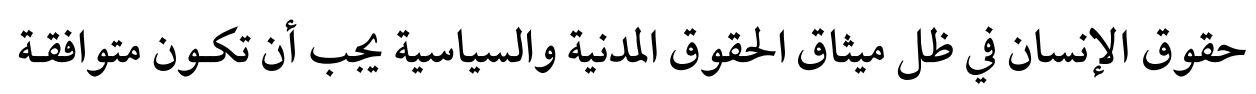

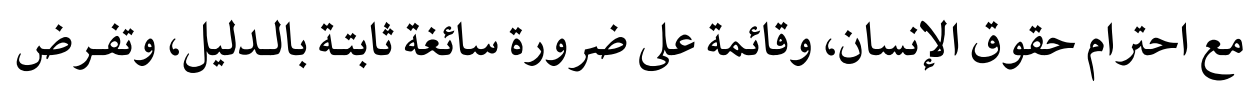
تدريجياً وبشكل مناسب وملائم. ومن الأسباب السائغة التي قد تستند إليها الدولة لتقيـد حقـوق الإنسان

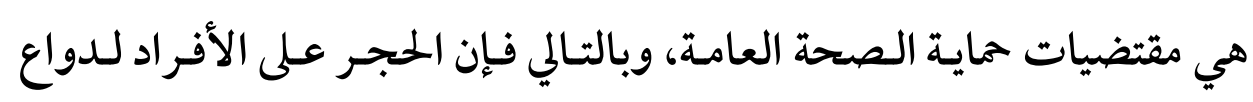

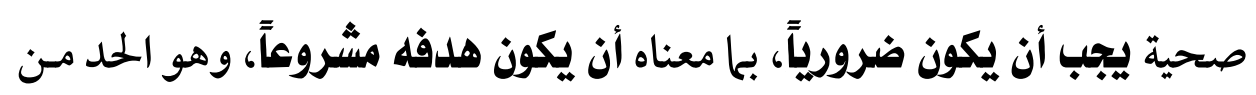

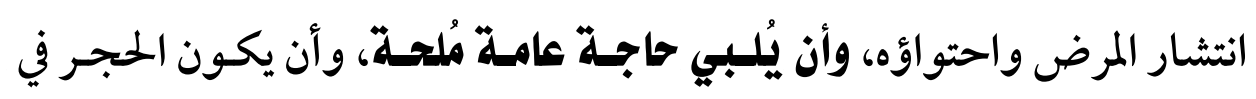

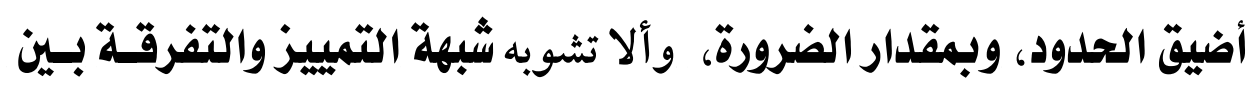

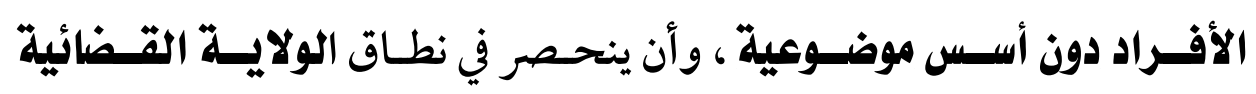
jurisdiction • الحجر الصحي ليلأشخاص في القانوز اللدولي.

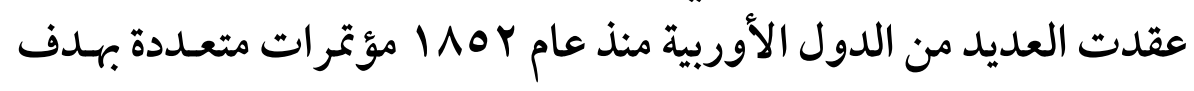

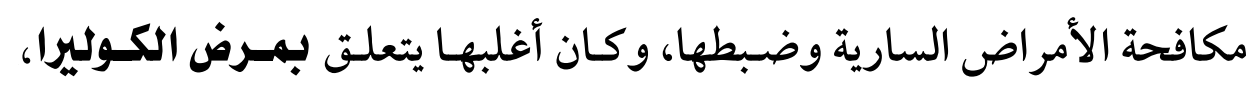

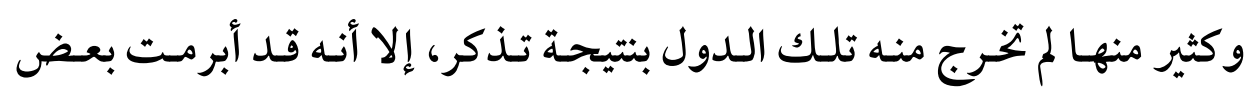

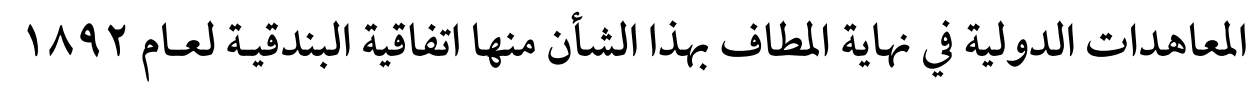
والتي تتعلق بمرض الكوليرا في طريق قنـاة السويس، واتفاقية عـام به \ا في شأن مرض الكوليرا في الدول الأوربية، واتفاقية بـاريس لعـام ع9 1 ا في شـأن مرض الكوليرا في طرق مرور الحجاج. 


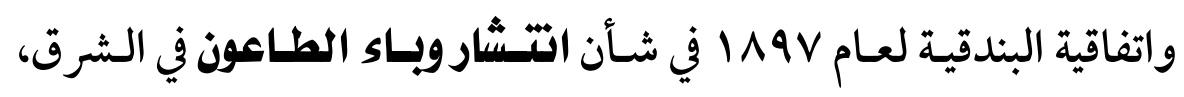

والمؤتمر الـذي عقـد على مستوى دولي لتحديــ الخطـوات والإجـراءات التي

يتوجب اتخاذها للحيلولة دون انتشار الطاعون في أوروبا وانتقاله إليها.

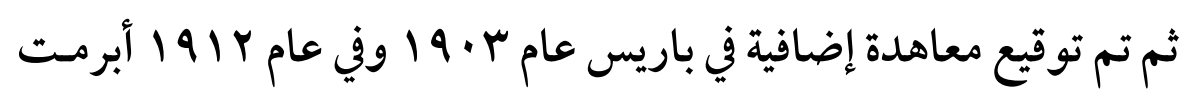

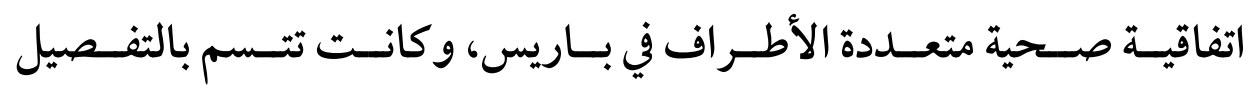

والاستيعاب ووضعت كبديل عن كافة الاتفاقيات والمعاهـدات السابقة لها،

وقد وقعت عليها • ؛ دولة وتتكون الاتفاقية من • 17 مادة، كما تبادل المصادقة

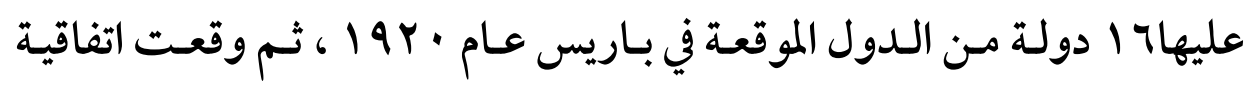

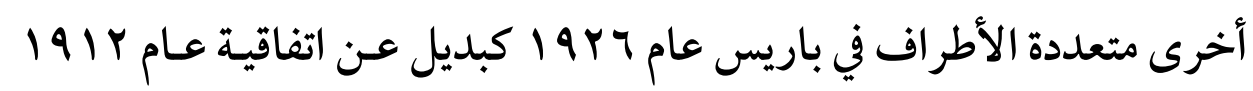
ووقع عليها Nه دولة من مختلف دول العالم وتتكون من IVY مادة. ومن خلال ما سبق يمكن القول باستقر اء الوضع القانوني لمواجهه الكوارث

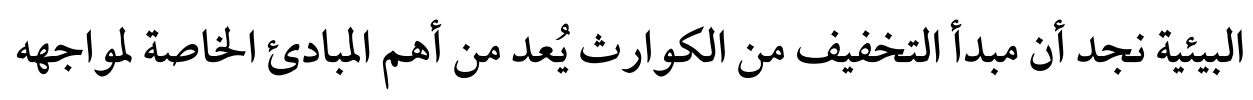
الكوارث البيئية التي تؤثر على صحة الإنسان .

إلا أن باستقر اء الوضع القانوني للمبادئ الوقائية لمواجهه الكـوارث البيئية البئية

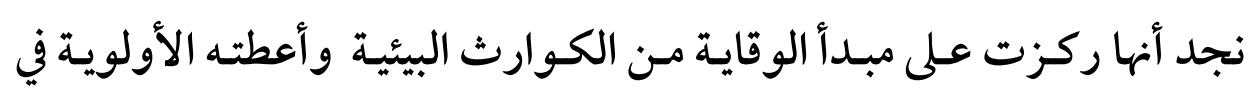

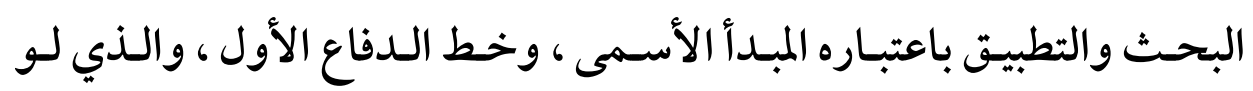

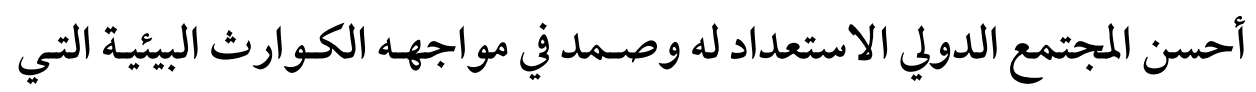

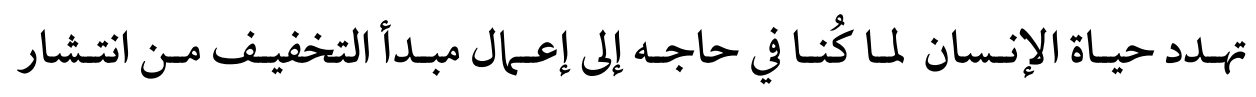

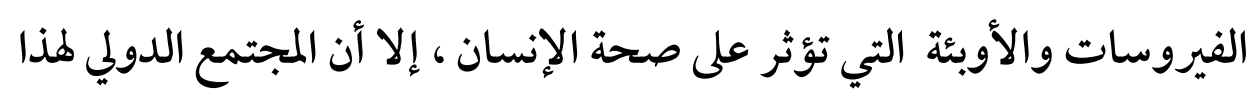

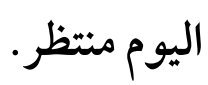




$$
\text { من الكوارث البيئية البية }
$$

حرى بالذكر حرصت العديد من الحقوق التي أقرتها المواثيق والاتفاقيات

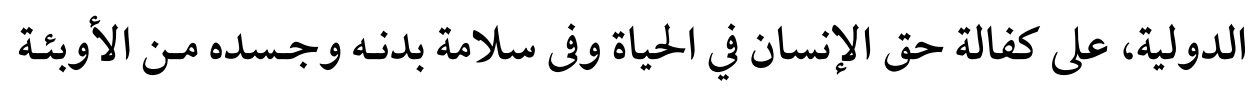
والفيروسات التي تؤثر على حياة الأشخاص (')، ولا يمكن للإنسان التمتع بهذا لإندان

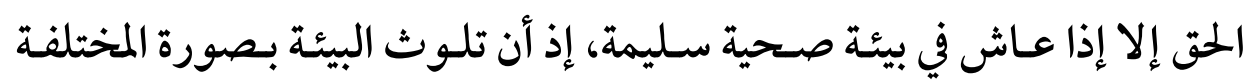

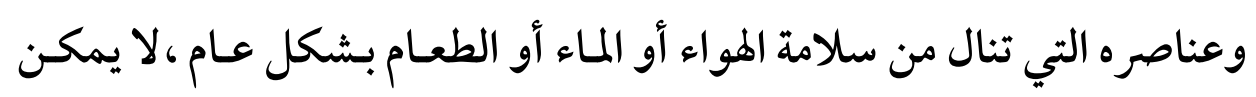
للإنسان ممارسة حقه في الحياة وفى سلامة بدنه على الوجه الأكمل وذلك ئكل يجعل سلامة البيئة مسألة ضرورية للتمتع بالحق في الحياة وفى سلامة الجسد (†).

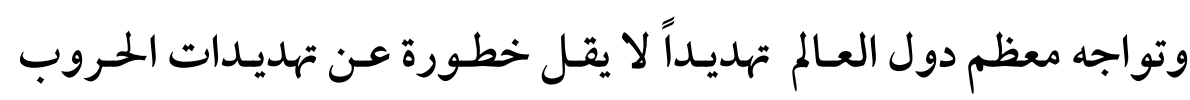

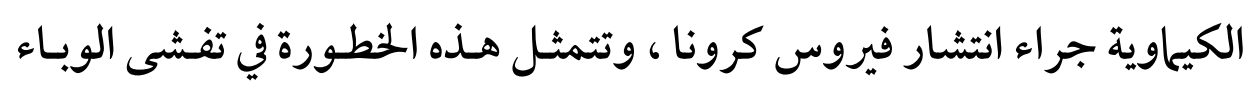

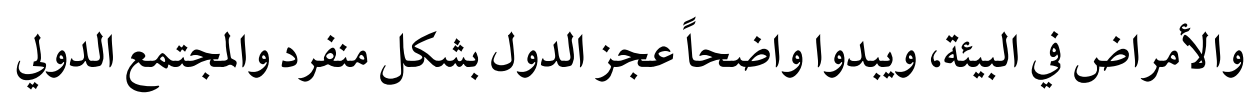
بشكل عام على مواجهه هذا التحدي الخطير لأسباب تتمثل في عـدم السيطرة على هذه المخاطر وقت ظهوره.

(1) Sanjeev, Khagram \& others, From the environmental and human security to sustainable security and development. Journal of Human Development, Vol. 4, No. 2, July 2003. pp. 291-292.

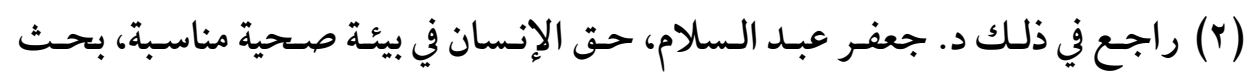

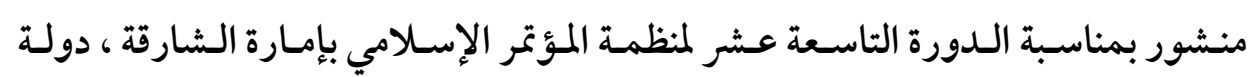

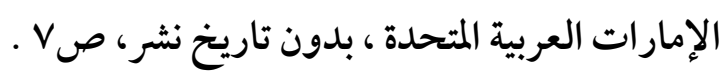


وليس بالإمكـان اسـتقر اء مستقبل التعامـل مـع هـذه التحـديات لأسـباب

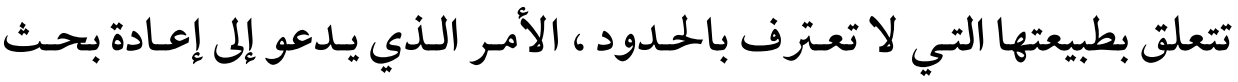

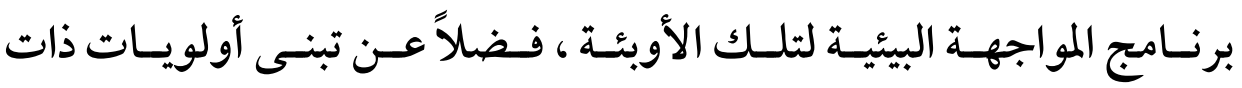

مستهدفات وقائيسة توسـع قاعـدة العمـل الأهـلي وتعـزز مسـاهمة المجتمعـات المحلية ومشار كة الفرد بشكل مباشر .

ونتيجة لهذا الأمـر لم يكـن بإمكـان المجتمـع الـدولي المعـاصر أن يتغافل دور

المنظلات الدولية والإقليمية في ترقية ومكافحة الأوبئة مـن أجـل حمايسة الإنسان من تلك الكوارث ، وعلى ذلك يمكننا بيان الآليات الدولية لحماية الإنسان مـن الكوارث البيئية من خلال المطلبين التاليين :

المطلب الأول : دور المنظمات الحكومية في حمايـة الأشــخاص مـن الكـوارث

المطلب الثاذي:دور المنظمات غير الحكومية في حماية الأشخاص من الكوارث

تقتضى الإنسانية منع المعاناة البشرية حيثها وجـدت و التخفيـف منهـا بهـف تئف

حماية الحيـاة والصحة ، و كفالة الاحـترام للإنسسان وتعزيـز التفـاهم والصداقة و التعـاون(') فضلاً عـن احـتلال القـضايا الإنـسانية مكانـة بـارزة في السـياسة الدوليـة، ومـن أسـباب تعـاظم دور القـضايا الإنسـانية ذلك أنـة عنـدما تواجـه

(1) Déclaration de Rio sur l'environnement et le développement, Déclaration de principles relatifs aux forêts, conférence des Nations Unies sur l'environnement et le développement, Nations Unies, New York, 1993, pp 61-65. 


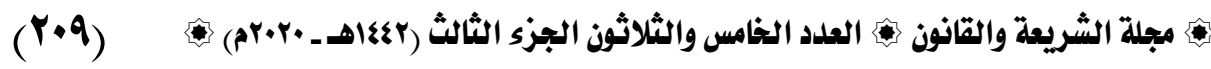
حكومات العالم مطالب القيام بعمل صعب كثيرا ما تكون الوسائل الإنسانية

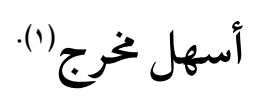

ومن الجحير بالذكر تهتم المنظحات الدولية بكل الحالات التي لها تأثير مباشر

على الإنسان وصحته، رغم التنوع في المنظات الدولية من عامة إلى إقليمية ومن

متخصصة إلى مـنظات غير حكومية؛ كل هذه المنظات أعطت قيمـة فعلية للبيئة وأدرجتها ضمن أهدافها التي تأسست منها ،لكسون البيئة هي حق مـن حقوق الإنسان وتعد من الجيل الثالث لحقوق الإنسان (†). وعلى ذلك نتناول دور المنظلات الدولية لحماية الإنسان من الكوارث البيئية من خلال الفرعين التاليين:

الفرع الأول: دور منظمة الأمم المتحلدة في حماية الأشـخاص مـن الكـوارث الفرع الثاني: دور منظمة الصحة العالمية في حماية الأشخاص من الكـوارث البيئية. - الفرع. البيئية.

(1) د.أمد أبو الوفا، الوسيط في قانون المنظلات الدولية ، دار الثقافة العربية ، القـاهرة

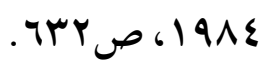

(2) Marcelo Dias Varella . Le role des O. N. G. dans le developpemens du droit international de lenvironnement, journal du droit mternatianal , Janver fevier- mars 2005, n1/2005, p 42. 
$($ (r). حماية الأشخاص في حالات الكوارث البيئية في القانون الدولي

\section{الفرع الأول الأول \\ دور منظمة الأمم المتحدة الأول \\ في حماية الأشخاص من الكوارث البيئية}

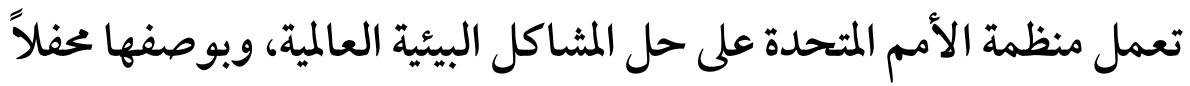

دولياً لبناء توافق الر أي والتفاوض على الاتفاقات، فضلاً عن معالجتها مشاكل

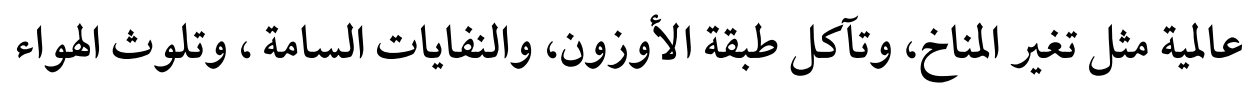
والماء، فهذه مشاكل إن لم تعالج، لن يمكن للأسـواق والاقتصاديات أن تـدوم

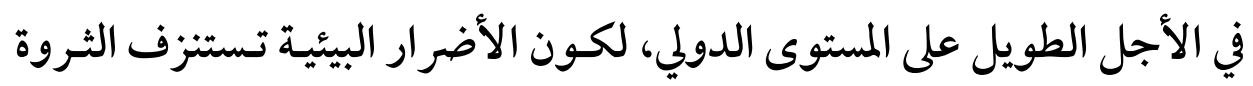
الطبيعية التي يقوم عليها نمو الإنسان وبقاؤه (1).

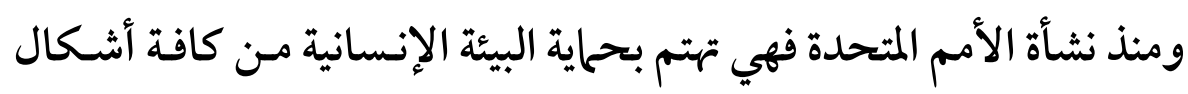

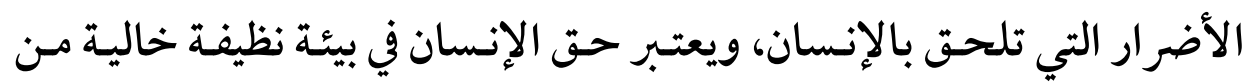

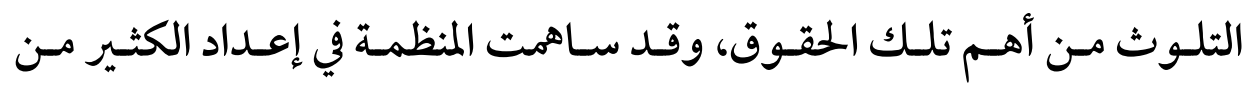

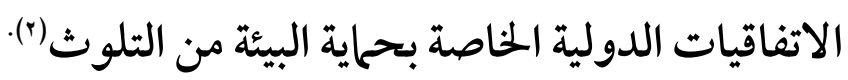

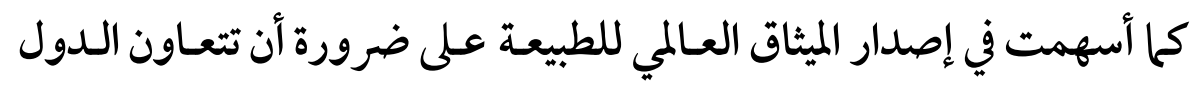
والمنظات والأفرادوالهيئات غير الحكومية من أجل المحافظة على الطبيعة من خلال

أنشطة مشتركة، وحث الدول على عقد معاهدات دولية تستهدف حماية البيئة (r).

(1) "Mapping human rights obligations relating to the enjoyment of a safe, clean, healthy and sustainable environment: focus report on human rights and climate change"(June 2014) www.ohchr.org/Documents/Issues/Environment/MappingReport/Cli mateChangemapping15-August.docx .

$$
\text { راجع في ذلك المادة Y r من عصبة الأمم المتحدة. }
$$

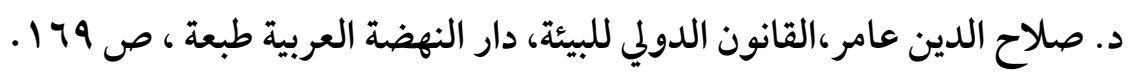




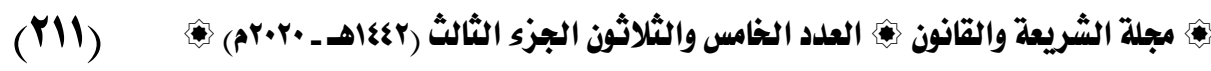

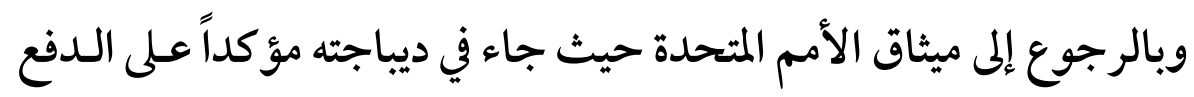
بالرقى الاجتماعي قدما ورفع مستوى الحياة إلى جو من الحريـة أفسح في سبيل

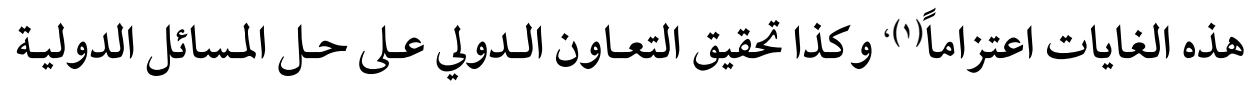
ذات الصبغة الاقتصادية والثقافية والإنسانية (())، غبة في تهيئة دواعي الاستقر ار والرفاهية للأشخاص (r) أن

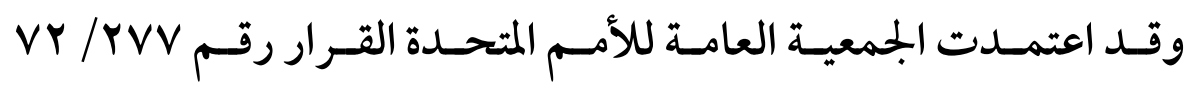
بشأن"وضع ميثاق عالمي للبيئة" يهدف إلى توفير إطـار شـامل للقـانون البيئي

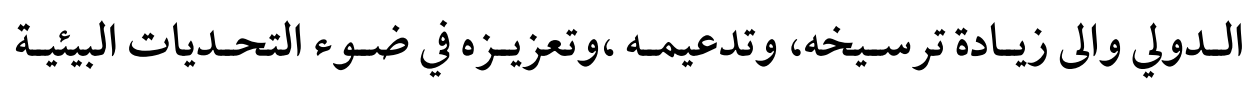

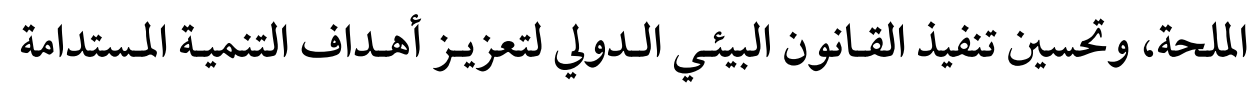
و كذلك الأهداف والغايات البيئية المثفق عليها عالمياء).

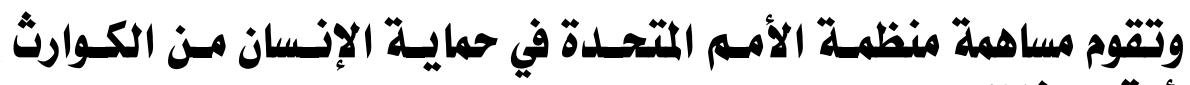

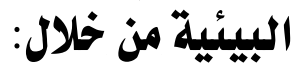

\section{أولاً: برنامج الأمم المتحلدة للبيئة (UNEP).}

يعتبر برنـامج الأمـم المتحـدة الإنهائي شبكة التنميـة العالميـة التابعة للأمـم

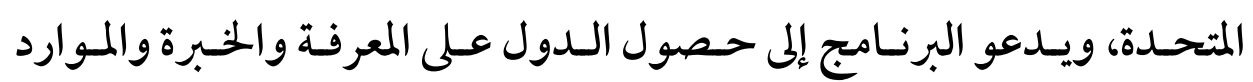
لمساعدة الشعوب على بناء حياة أفضل.

$$
\begin{aligned}
& \text { (1) راجع في ذلك: ديباجة ميثاق الأمم المتحدة. } \\
& \text { (r) راجع في ذلك: الفصل الأول من ميثاق الأمم المتحدة. } \\
& \text { (Y) راجع في ذلك: الفصل التاسع من ميثاق الأمم المتحدة. }
\end{aligned}
$$

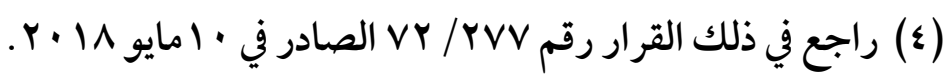


(rIT) حماية الأشخاص في حالات الكوارث البيئية في القانون الدولي

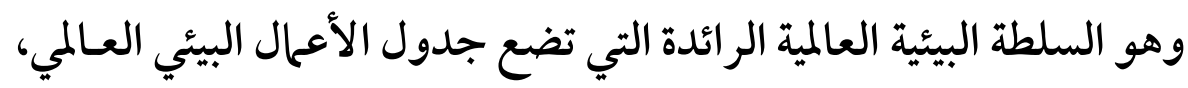
وتعـزز التنفيـذ المتسـق للبعـد البيئي للتنميـة المستدامة داخـل منظومـة الأمـم المتحدة، وتعمل كمناصر رسمي للبيئة العالمية'). كما يقـوم البرنـامج على تشجيع الشر اكة في رعاية البيئة مـن خـلال إلهـام وإعلام وتمكين الأمم والشعوب لتحسين نوعية حياتهم دون المساس بأجيال

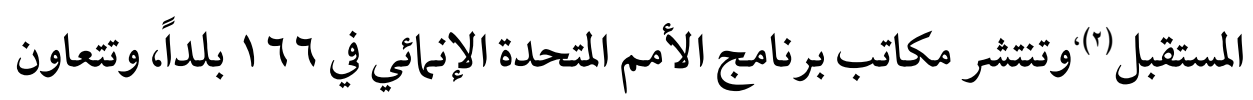

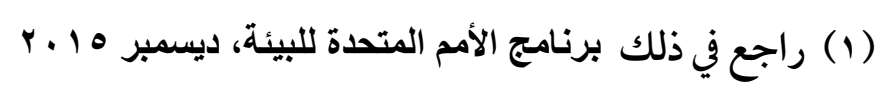

\section{-Climate Change and Human Rights}

www.unep.org/NewsCentre/default.aspx?DocumentID=26856\&Artic leID $=3563$

-Unless We Act Now: the Impact of Climate Change on Children www.unicef.org/publications/index_86337.html.

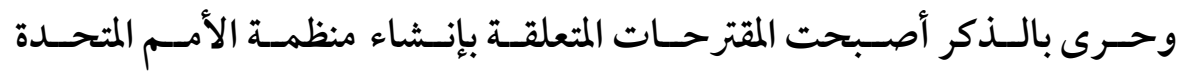

للبيئة ( UNEO) ) تشكك في فعالية برنامج الأمم المتحدة البيئي الحسالي (UNEP) في

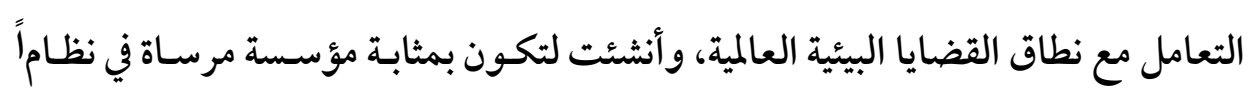
لإدارة البيئية العالمية (GEG) ، وفنشلت في تلبية هذه المطالب، لقد أعيق برنامج الأمسم المتحدة للبيئة بسبب لقبه كبرنامج بدلاً من وكالة متخصصة مثل منظمة التجارة العالمية أو

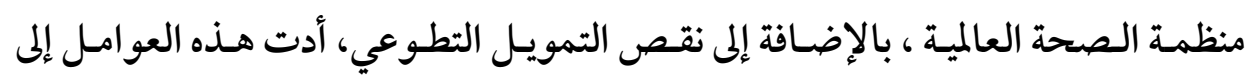

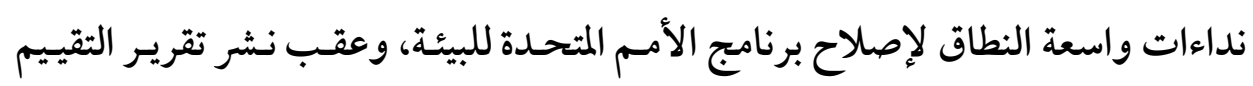

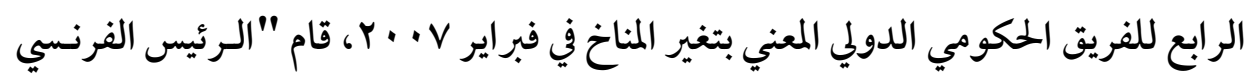

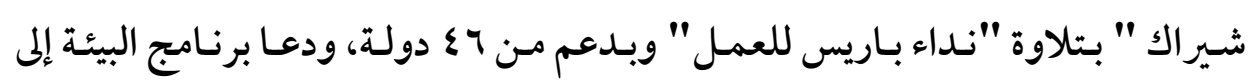

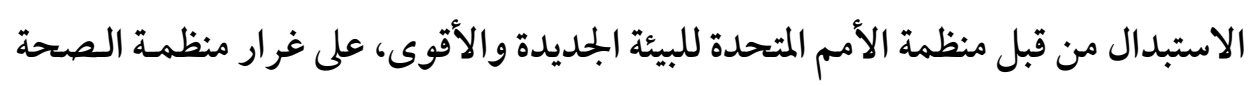




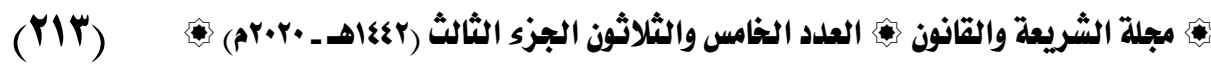

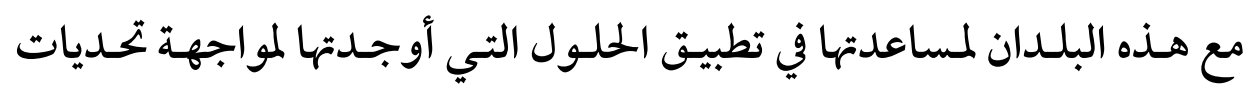

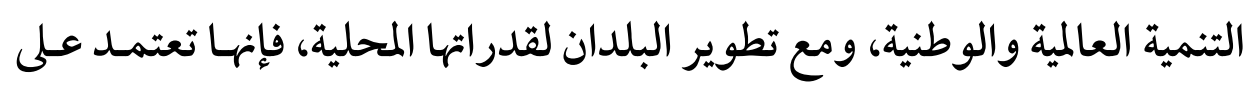

برنامج الأمم المتحدة الإنحائي (1).

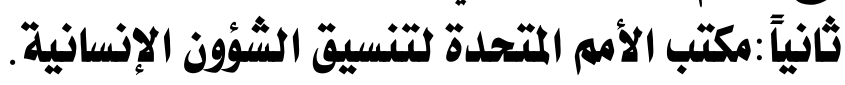

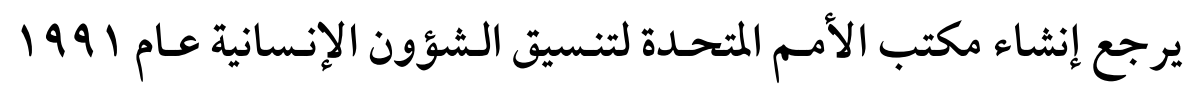

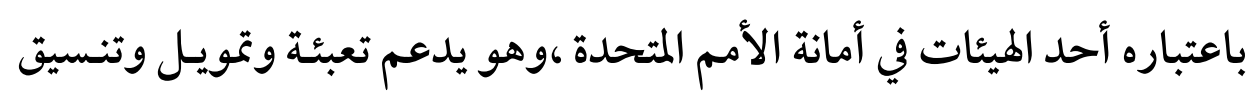

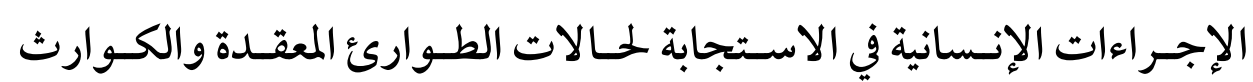
الطبيعية.

ير أس منسق شؤون الإغاثة الطارئة مكتب الأمم المتحـدة لتنسيق الشؤون

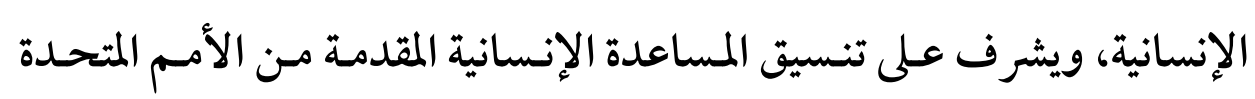
لحالات الطوارئ المعقدة والكوارث الطبيعية.

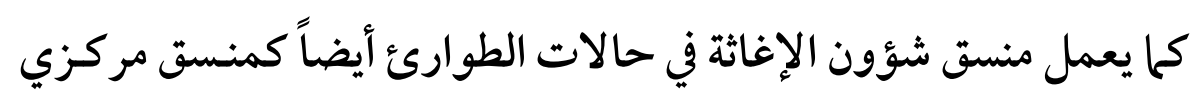
لأنشطة الإغاثة الحكومية وغير الحكومية الدولية. وترجـع العلاقـة بـين المفوضـية ومكتـب الأمــم المتحـــة لتنسيق الـشؤون الإنسانية إلى أوائل التسعينيات وهي علاقة واسعة النطاق، تشمل المشاركة في

العالميـة، و تـضمنت الـدول الـ ب ه دول الاتحـاد الأوروبي ولم تـشمل الولايـات المتحــدة الأمريكية و البرازيل وروسيا والهند والصين، وهي أكبر خمس انبعاث لغازات الدفيئة .

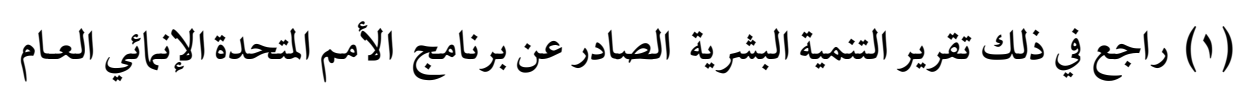

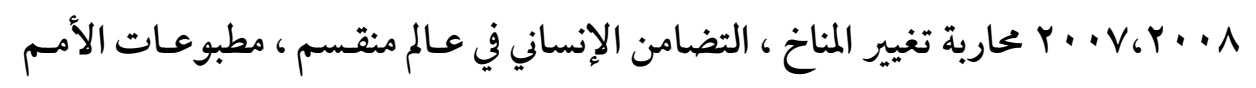
المتحدة ، صه ؟ . 
(r)\&)

حماية الأشخاص في حالات الكوارث البيئية في القانون الدولي

نهج المجموعات الخاص بالأمم المتحدة لأزمات النزوح الداخلي لوضع آليات مشتر كة للتنسيق الإنساني.

وحرى بالذكر شهد إصلاح منظومة الأمم المتحـدة في العقد الماضي إنشاء نهج المجموعات، فضلاً عن آليات جديدة للتمويل الإنساني.

وقـد أتاحـت ركـائز الإصـلاح هـذه للمفوضسية ومكتـب تنسيق الشؤون

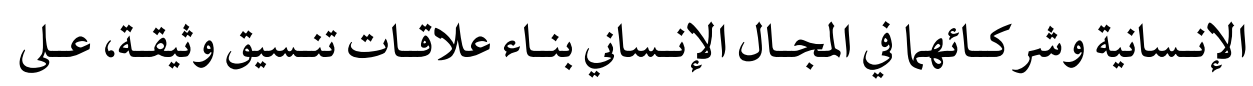

الصعيدين الميداني والعالمي ·

ومع ذلك، من خلال اللجنة الدائمة المشتركة بين الوكـالات - وهي آلية

تحديـد التنسيق المشترك بـين الوكـالات - تستطيع المفوضسية ،ومكتـب الأمـم

المتحدة لتنسيق الشؤون الإنسانية، صنع وتطوير المنتجـات التي يعتمـد عليها أعضاء اللجنة الدائمـة المشتركة بـين الوكـالات للتوجيه المعياري والعملي في المجالات كتقيم الاحتياجات وإدارة المعلومات والإنذار المبكر والتأهب ونوع الجنس والإجراءات الإنسانية والجهود المشتر كة لحشد الدعم. كما يدير مكتب الأمم المتحـدة لتنسيق الشؤون الإنسانية أيضاً الصندوق الإسله المركزي لمواجهة الطوارئ ،وهـو آلية تمويل جمـاعي تستفيد منهـا الوكالات الإنسانية التابعة للأمم المتحدة، وتستطيع المفوضية الحصول على التمويل مـن هذا الصندوق لعملياتها على المستوى المحلي. 


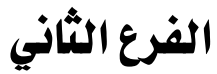

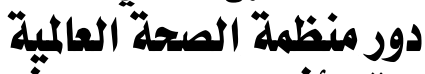 \\ في حماية الأشخاص من الكوارثٌ البيئية}

من الجدير بالذكر أن هناك دور واضح على الصعيد الدولي منـوط بالدوائر

الصحية لمنظمة الصحة العالمية ينبغي لها تأديته في حماية صحة الناس وعافيتهم من آثار الكوارث البيئية ، مـن أجل الاستجابة الشاملة الجاريـة على مستوى

منظومة الأمم المتحدة، وذلك بإتاحة خبرتها في الميدان الصحي (1).

وتعلد منظمة الصحّة العالمية (who) (r) هي السلطة التوجيهية والتنسيقية

ضـمن منظومـة الأمـم المتحـدة فيليا يخص المجـالَ الصحي، والحمايـة الصحية

للإنسان على المستوى الـدولي، وهي مسئولة عن تأديةِ دورٍ قيـادي في معالجـة

المسائل الصحية العالمية، وتصميم برنـامج البحوث الصحية ووضـع القواعد

والمعايير وتوضيح الخيارات السياسية المسندة بالبيّنات وتوفير الدعم التقني إلى

البلدان ورصد الاتجاهات الصحية وتقييمه من أجل حماية الإنسان (r).

(1) د.سعد السيد، منظمة الصحة العالمية، بجلة الأمن والحياة ، جامعـة نايف للعلوم

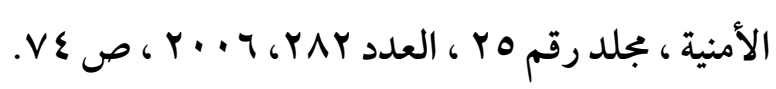

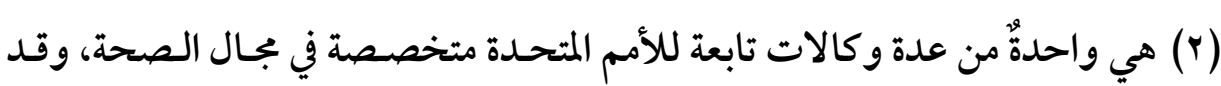

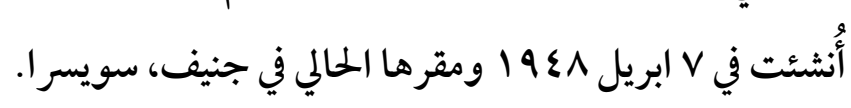

(3) World Healeh Organisation M Global Strategy for health for all by the year 2000 - health for all, No, 3, 1981. 
(Y17) حماية الأشخاص في حالات الكوارث البيئية في القانفز الدولي

وتتمتع منظمة الصحة العالمية بالشخصية القانونية الدولية التي تمنحها الحق في إجراء اتفاقيات مع كافة دول العـالم ، فضلاً عـن دورهـا البـارز في مكافحـة الكثير من الأوبئة والأمر اضع التي تثؤثر على صحة الإنسان(1).

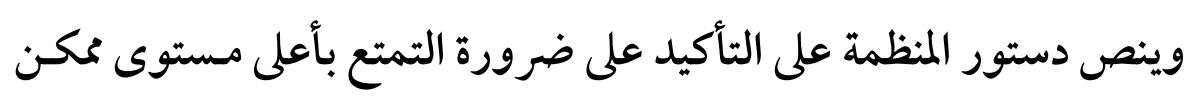

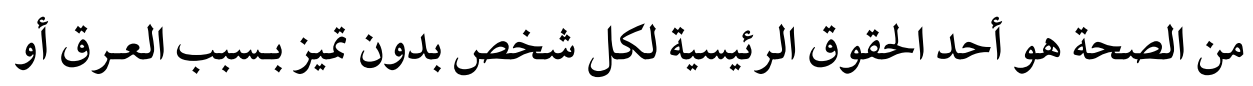

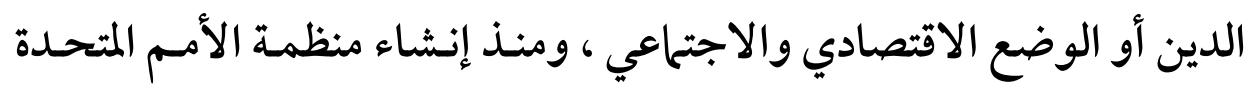

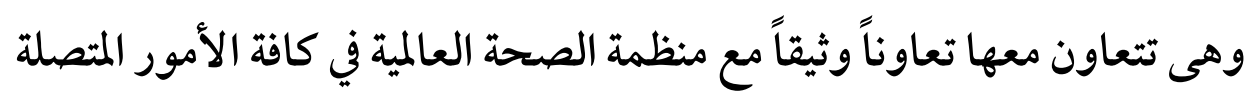
بالرعاية الصحية (†). وقد بذلت منظمة الصحةُ في القرن الحادي والعشرين جهودهـا في التعـاون

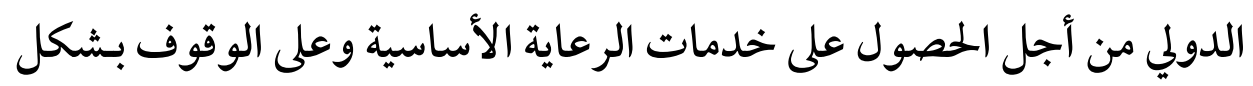
جماعي لمواجهة الكوارث عبر الوطنية(؟).

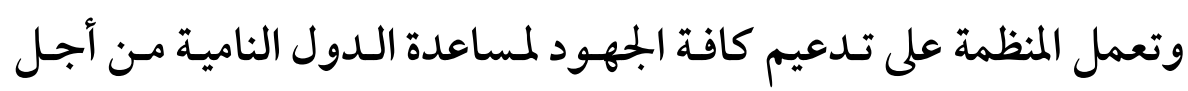
الوقاية من الأمر اض والأوبئة والتغلب على ارتفـاع نسبة الوفيـات، وتكريس الجههود مـن أجـل تـــعيم الأنشطة بهـدف حمايـة الـدول مـن انتشار الأوبئسة

(1. دبد الكريم علوان، الوسيط في القانون الدولي العام ، دار الثقافة ، الكتاب الثالث،

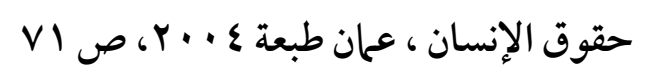

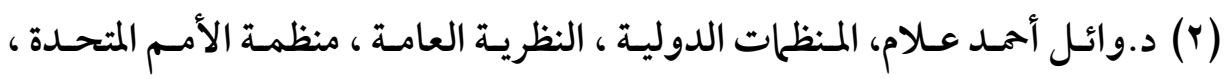

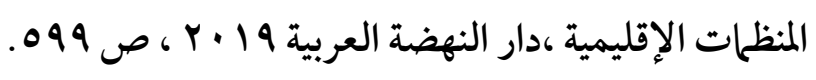

(3) The Editors of Encyclopedia Britannica, World Health Organization, 2020, available on:

https://www.britannica.com/topic/World-Health Organization 


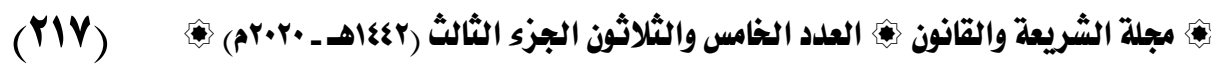

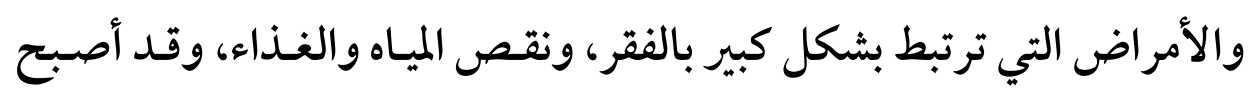

هدف المنظمة هو الصحة للجميع معبراً عن إرادة حقيقية لمعظم دول العالم (1). فكـان لهـا الفضضل في القـضاء عـلى بعـض الأمـر اض العديـدة ، مثل رعايـة الأمومة والطفولة ، ووضع برنامج لتنظيم النسل، والوقاية من مرض السيدا؛

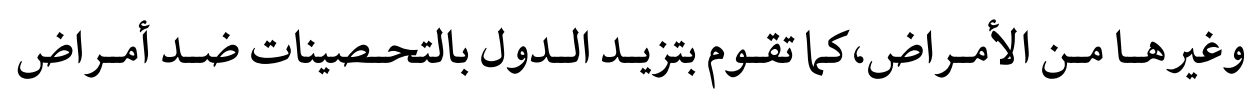
الــفتيريا ، والحـصبة، والـسعال الــيكى، والتيتـانوس، وشــلل الأطفــال ، وأنفلونزا الطيور والخنازير، وفى الآونة الأخير جائحة كرونا كوفيد 9 أو، ومن هذا المنطلق أضحى هدف المنظمة واضحاً بإيقاف هذا المرض واعتراض انتقاله من إنسان لأخر وذلك مـن خـلال احتواء هـذا المرض على المستوى العـالمي، ولانجاز هذا الهدف تقوم المنظمـة بتوصيل المعلومات الصحية والإرشـادات الدقيقة على المستوى الدولي لإتباعها والسير طبقا لتعلياتها من أجل حماية الأشخاص على المستوى الدولي(؟).

(1) د.علوانى مبارك، دور المنظات الدولية المتخصصة والمنظات الغير حكومية في حماية

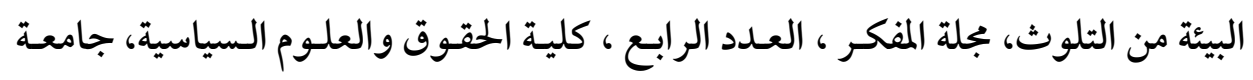

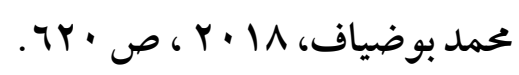
(r) د.أبو الخير عطية، الضمانات القانونية الدولية والوطنية لحماية حقوق الإنسان، دار

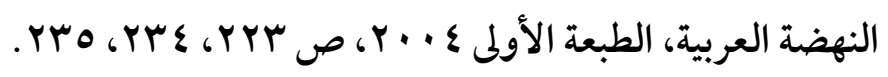


(rIA) حماية الأشخاص في حالات الكوارث البيئية في القانفز الدولي

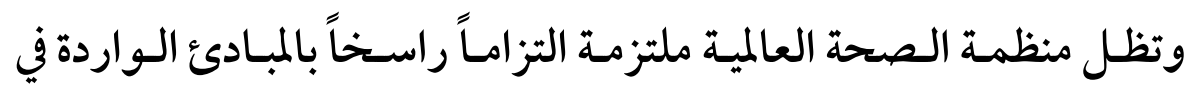
ديباجة دستورها(1)وذلك من أجل تحقيق الأهداف التالية.

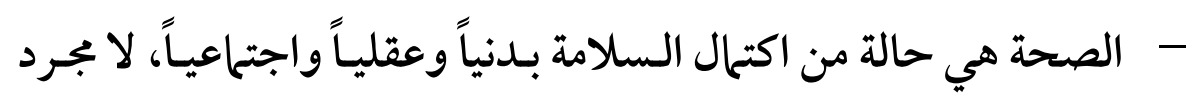
انعدام المرض أو العجز.

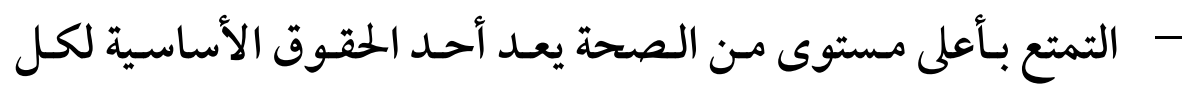
إنـسان، دون تميـز بـسبب العنـصر أو الــين أو العقيـدة الـسياسية أو الحالـة الاقتصادية أو الاجتحاعية.

- - صحة جميع الشعوب أمر أساسي لتحقيق السلم والأمن الصحي، وهي تعتمد على التعاون الأكمل للأفراد والدول. - ما تحققه أية دولة في ججال تحسين الصحة وحمايتها أمر له أهميته للجميع.

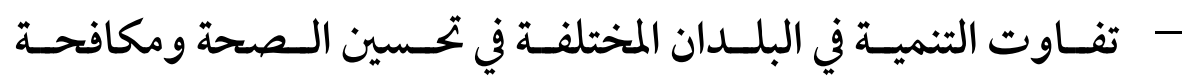
الأمر اض، ولا سيا الأمراض السارية، خطر على الجميع.

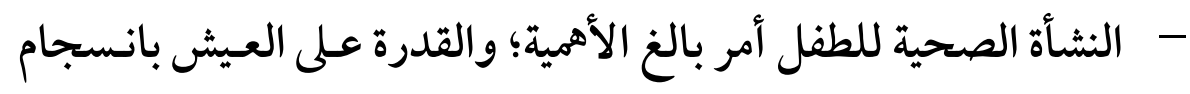
في بيئة كلية متغيرة أمر جوهري لهذه النشأة.

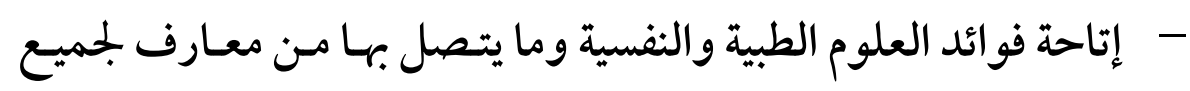
الشعوب أمر جوهري لبلوغ أعلى المستويات الصحية.

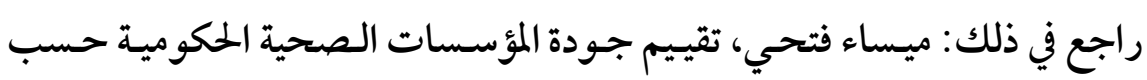

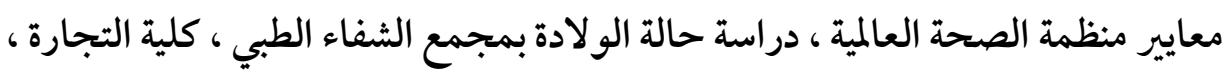

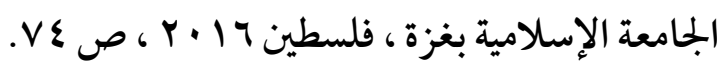




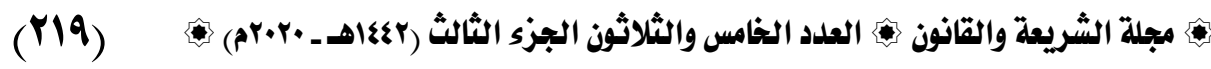
- الر أي العام المستنير والتعاون الإيجابي من الجمهور لهما أهمية قصوى في لهي تحسين صحة البشر.

- الحكومات مسئولة عن صحة شعوبها ولا يمكن الوفاء بهذه المسؤولية إلا باتخاذ تدابير صحية واجتحاعية كافية.

ومن خـلال مـا سـبق يمكـن القـول أن منظمـة الصحة العالميـة هي السلطة

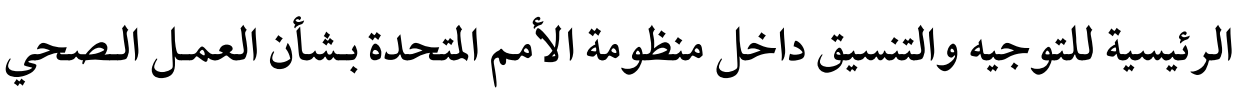

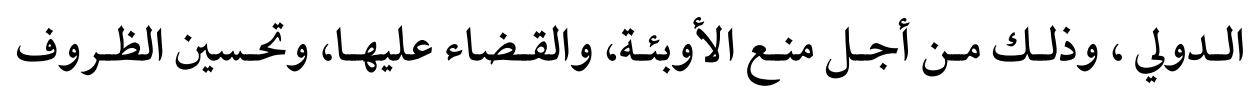
الغذائية، والصحية، والبيئية للأشخاص على المستوى المدونه، والدولي،كحا توفر الإغاثة

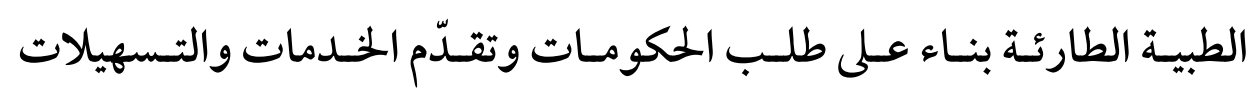
للمجموعات من ذوي الاحتياجات الخاصة. المطلب الثاني دور المنظمات غير التحكومية المئي في حماية الأشخاص من الكوارث البيئية

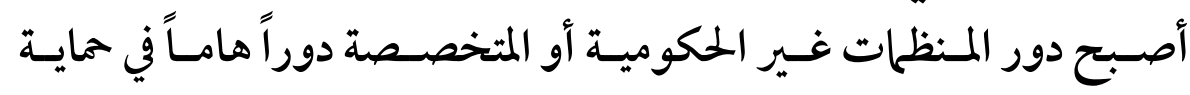
الإنسان من الكوارث البيئية على المستوى الدولي ، حيث أنها في الوقت الحاضر تتمتع بعلاقات تعاون كبيرة ومهمة في العديد من الأطر اف الدولية التي تطلع لمئل بممارسة دور هام في بجال عملية التنمية البيئية المستدامة (')

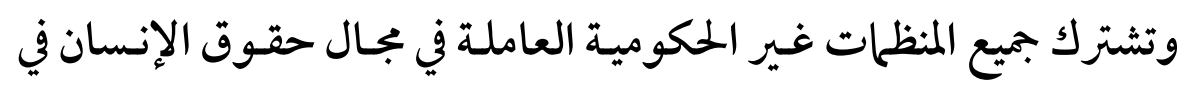
هدف مشترك وهو جمع المعلومات وتسجيلها وعرضها على الحكومات للتأثير

(1) Gaëlle BRETON-LE GOFF l'influence des organisations non gouvernementales sur la négociation de quelques instruments internationaux, éditions YVON Thomson, BRUXELLES, 2001, p 14. 
(rr.) حماية الأشخاص في حالات الكوارث البيئية في القانوز الدولي في سياساتها نحـو الأفر اد(1)،كلما عهـدت عصبة الأمـم المتحـدة على أهميـة دور

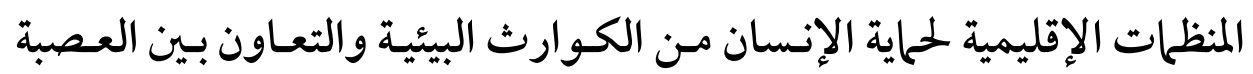

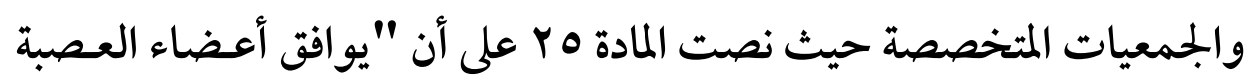

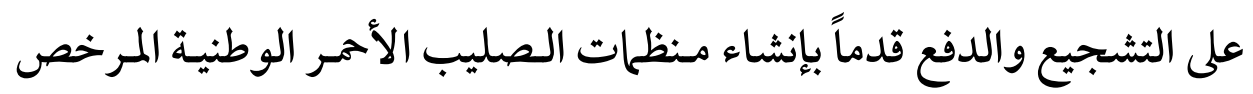
بها، والتي تستهدف تحسين الصحة ، ومنع الأمراض ، وتخفيف الآلام في أنحاء

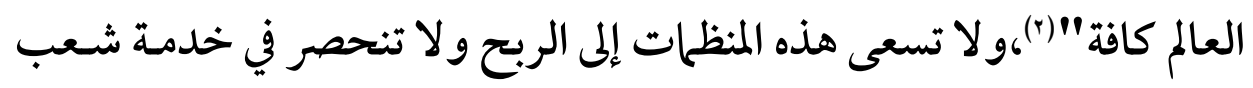

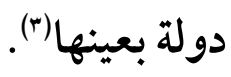
وعسلى ذلك يمكنتـا أن نبـين دور المـنظات الإقليميـة لحلايـة الإنسان مـن الكوارث البيئية من خلال الفرعين التاليين:

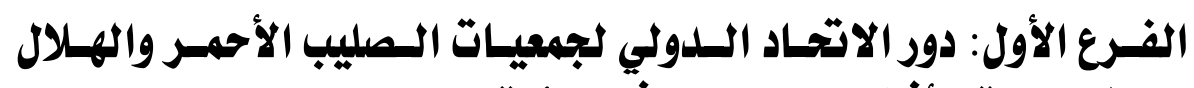

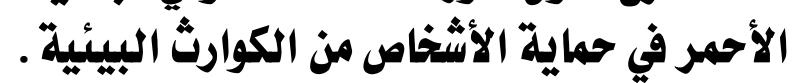
الفرع الثاني: دور المنظمات الطبية غير الأخام الحكومية في حماية الأشخاص من الكوارث البيئية.

(1) د.أبو الخير عطية، الضمانات القانونية الدولية والوطنية لحماية حقوق الإنسان، مرجـع سابق ،ص rrv راجع في ذلك المادة ه ro من عهد عصبة الأمم المتحدة.

في هذا المعنى :د.بحمد طلعت الغنيمى، الغنيمى في التنظيم الدولي ، منشأة المعارف

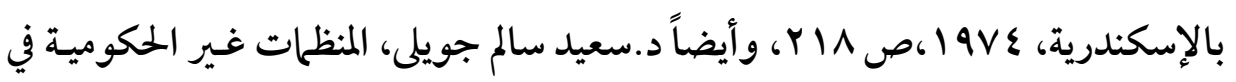

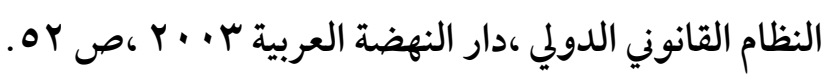




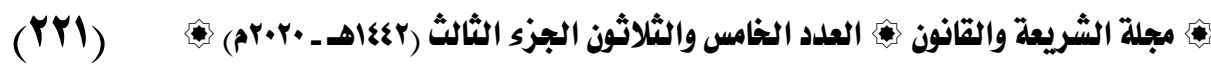

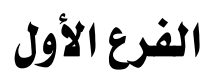

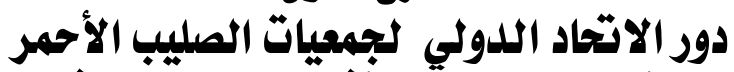

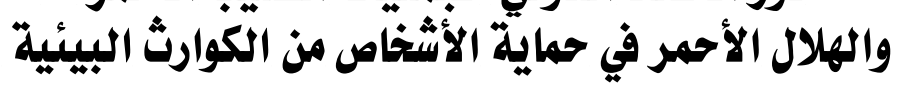

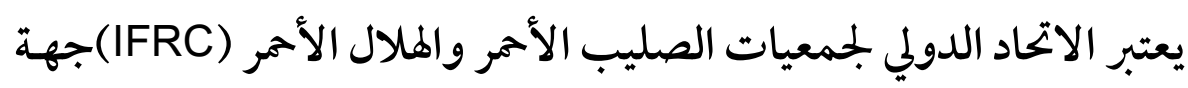

رائدة في بجال العمل الإنساني وهو يتكون من شبكة فريـدة مـن المتطوعين على

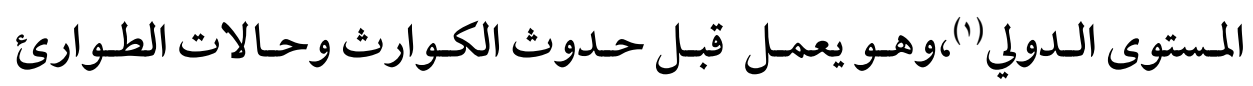

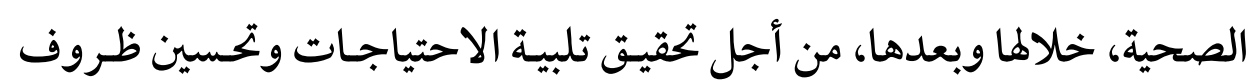

$$
\text { المعيشة للمتضررين من جراء أية كوارث وأزمات صحية (r). }
$$

ويعد الاتحاد من المنظمات الدولية غير الحكوميـة والتي تتمتع بالشخصية

القانونية الدولية نظراً لما يقوم به من أعحال إنسانية في زمـن الكسوارث التي تهم

البشرية بأكملها(r) ويقوم بذلك دون تحيُّز إلى أي جنسية، أو عرق، أو جنس، أو

مُعتقد ديني، أو طبقة اجتهاعية، أو رأي سياسي، والاتحـاد مُلتزم بشعار إنقـاذ

(1) د.بحمود توفيق، حماية الإنسان في حالات الكوارث الطبيعية في القانون الدولي العام

والشريعة الإسـلامية، رسـالة دكتوراه جامعـة القـاهرة ،منشوره بـ دار النهضة العربيـة

$$
\text { . EV0 מ }
$$

(ץ) د.أبو الخير عطية، الضمانات القانونية الدولية والوطنية لحماية حقوق الإنسان،مرجع

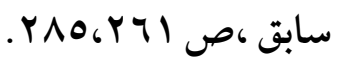

(ץ) د.سعيد سالم جويلى، المنظات غير الحكومية في النظام القانوني الدولي ،مرجع سـابق 


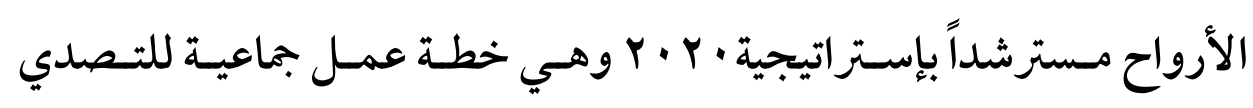

للتحديات الإنسانية والتنموية الكبرى خلال هذا العقد (1).

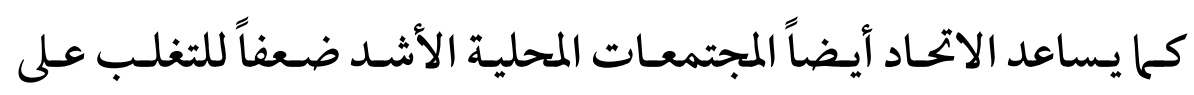

الأزمات من خلال أنشطة التأهـب لتلك الكـوارث، وتشمل تعزيز قـدرات

أعضائه من جمعيات الصليب الأحمر والهلال الأحمر على تنفيذ بـرامج فعالة في مجال الإغاثة الطارئة والتأهـب للكوارث والرعاية الصحية والمجتمعيـة، كـا يمثل هذه الجمعيات على المستوى الدولي.

ويسشمل العمـل الـذي قامـت بـه فعـلاًا الحركـة الدوليسة إلى دعـم أنسشطة

الجمعيات الوطنية لصالح السكان المستضعفين مـن تعزيز خـدمات الرعايـة

الصحية، وإشراك المجتمعات المحلية، والتأهب للكوارث البيئية (†).

ويتضمن ذلك زيادة الإمدادات في المرافق الصحية، وتوسيع نطاق بـرامج

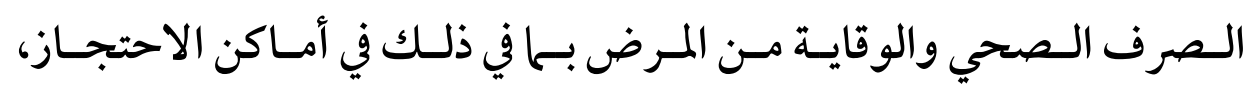

ويضضم الاتحـاد حـوالي • 10 بلــاً عـلى المستوى الـدولي، ويرجـع تأسيسه إلى عـام

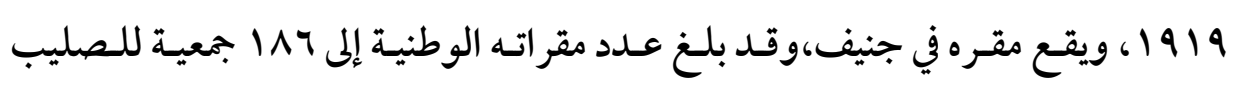

$$
\text { الأحمر والهلال الأحمر وحوالي • } 10 \text { مليون متطوع. }
$$

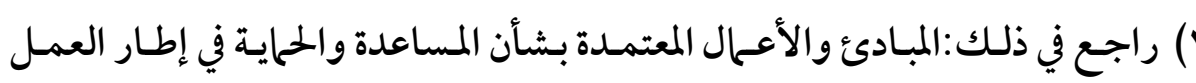

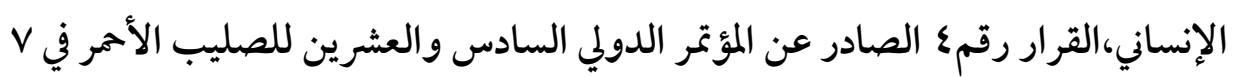




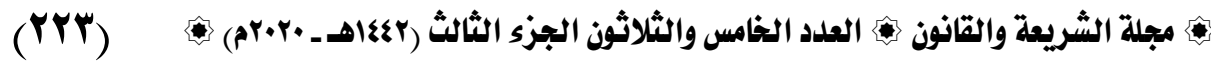

والتخفيف من الآثار الاقتصادية والاجتهاعية لتفشي المرض مـن خلال ضهان حصول المجتمعات المحلية على الخدمات الأساسية (').

كما يقدم الاتحاد الدعم إلى الدول في تنفيذ توجيهات منظمة الصحة العالمية

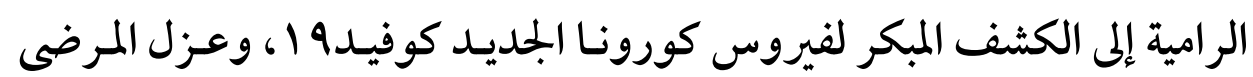
ومعالجتهم، وتتبع اتصالاتهم.

وتحذر المنظمتان مـن أن وقفت الانتشار العـالمي السريع للجائحة يتطلب

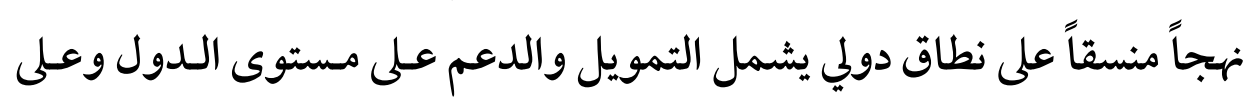
المستويات الوطنية.

ولا يخفـى الجهـود العظيمـة للهيئـات والجمعيـات العربيـة للهـلال الأحمـر

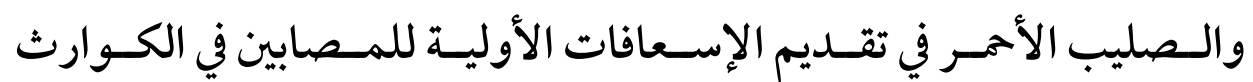
والصراعات المسلحة، وتقديم المساعدات الإغاثية، ولقد بدا هذا الأمر واضحاً

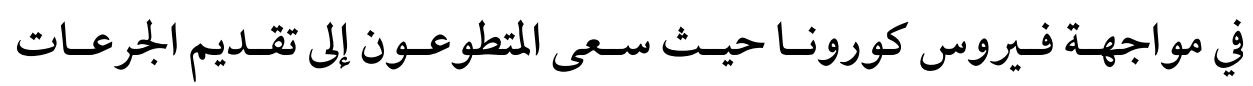

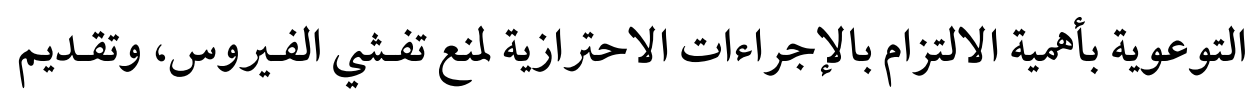
المساعدات اللازمة للمتضررين مـن الجائحة، وتواصل الهيئات والجمعيـات الوطنية حر اكها الفاعل في تطوير أعمالهـا الإنسانية وثتخفيف المعانـاة المستمرة للملايين الذي يعيشون في مناطق النزاعات والكوارث والصر اعات المسلحة، وحث أطر اف الصراع على احتر ام مبادئ القـانون الـدولي الإنساني وتسهيل وصول جميع مقدمي المساعدات الإنسانية لتوزيـع المساعدات المنقـذة للحيـاة،

(1) Sudore el . " Limited literacy and mortaliy in the elderly : the health , aging and body . composition study " Journal of General Internal Medicine, vol . 
(Yrs) حماية الأشخاص في حالات الكوارث البيئية في القانوز الدولي

ودعم إجراءات وآليات التنسيق لتوطين العمل الإنساني ليكون أكثر شـمولية في معالجة التحديات الإنسانية المتزايدة وضمان كفاءة وفعالية سرعة الاستجابة لتجنـب تعطل سـبل العسيش وتحسين جـودة الحيـاة وتـوفير استجابة سريعـة للاحتياجات الإنسانية.

ومن خلال ما سبق يمكن القول يجبـ مضاعفة الجههود لإبـراز أهمية نشر

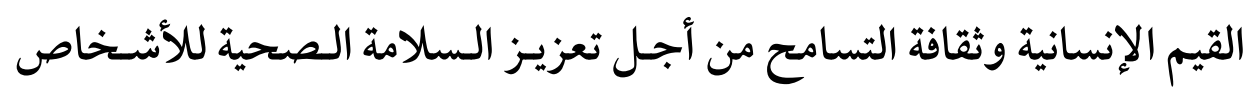

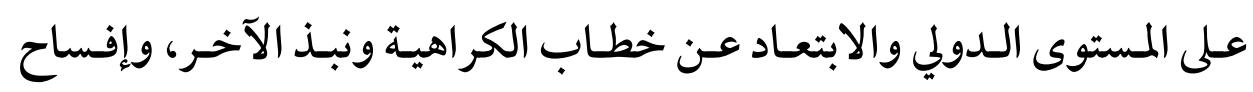
المجال أمام العاملين في المجال الإنساني مـن مسعفين ومقـدمي المواد الإغاثية

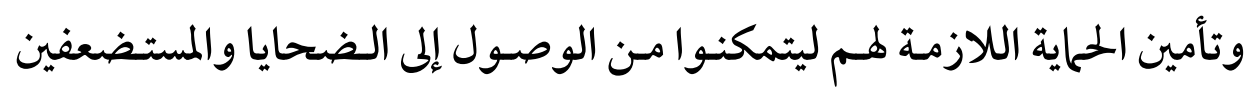
وتقديم الخدمات الإغاثية لفم.

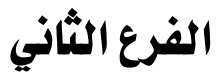

\section{دور المنظمات الطبية غيرِي الحكومية}

\section{في حماية الأشخاص من الكوارث البئيئية الجكرمية}

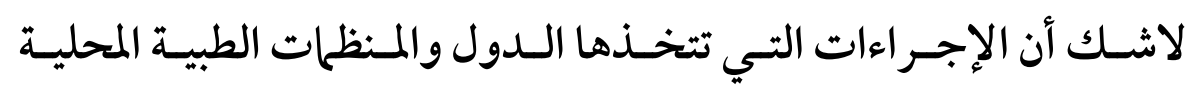
والدولية في مواجهة الكوارث البيئة إلا أنه لا يمكنها منع الوبـاء مـن الانتشار

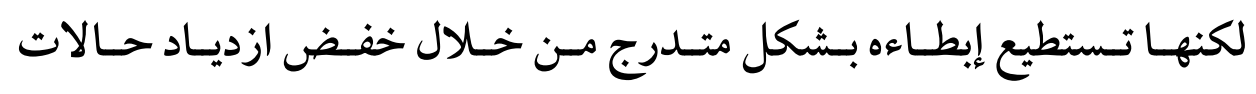
الإصابات وتقليل عدد الحالات الحادة التي على النظم الصحية التعامل معها في

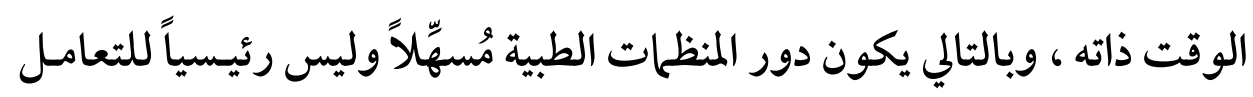

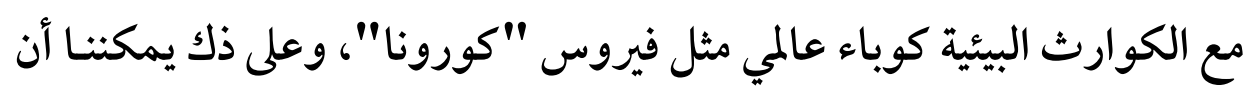

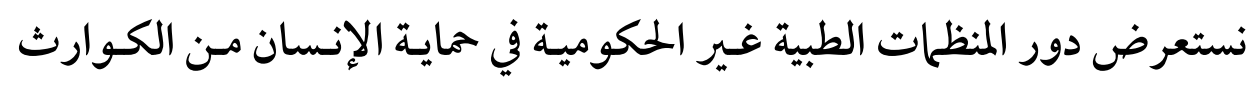

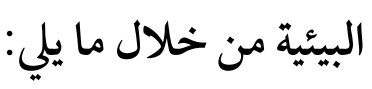




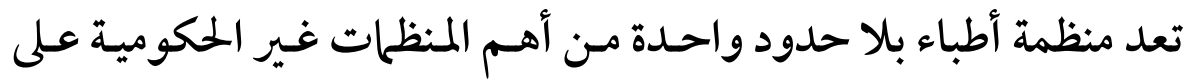
الصعيد الدولي، وتتمثل مهمتها الأساسية في تقديم المساعدات الطبية الطارئة للمجتمعـات المتضررة مـن أزمـات مختلفـة في العـالم، سـواء كانـت صر اعـات مسلحة أو كوارث بيئية أو أمراض وبائية (1)،و هي منظمة طبية إنسانية دولية

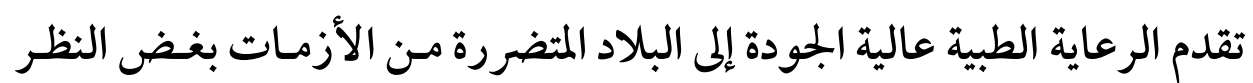
عن اختلاف الجنس أو دين أو الانتحاء السياسي للمصابين أو المرضى.

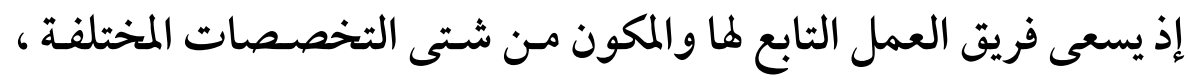
بـاختلاف الفـرق الطبيـة للانخــر اط في مواقع نائيسة وبيئـات قاسـية مـع مـوارد ومر افق محدودة، مع علمهم بمخاطر بعض المهام التي توكل إليهم، على نحو

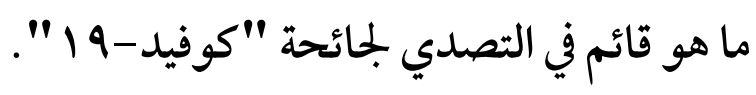
ويقوم عمل المنظمة على التعـاون بدرجـة رئيسية مـع خبراء اللوجستيات

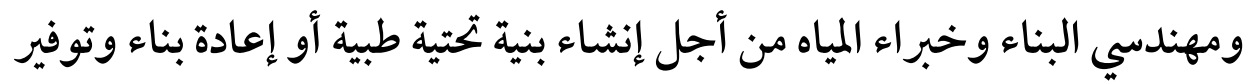

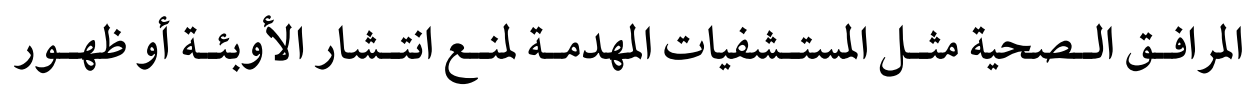

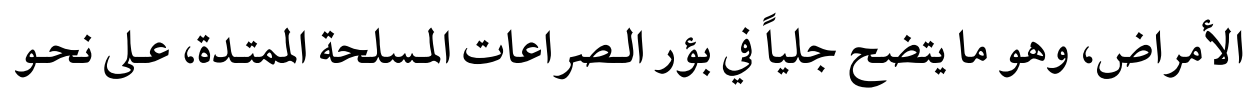
يضاعف من الأعباء الملقاة على عاتق المنظمة لتشمل أيضاً توفير المساعدات 
(YYY) حماية الأشخاص في حالات الكوارث البيئية في القانفز الدولي الغذائية للسكان الذين تشردهم الصراعات وتجبرهم على المجرة بحثاً عن فئن المأوى (1) وعلى ذلك يهكن القـول أنـه يواجـه الأطبـاء وأطقـم التمـريض العـاملون

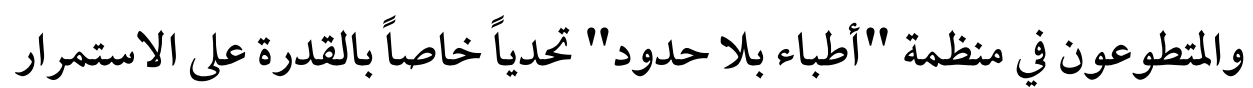

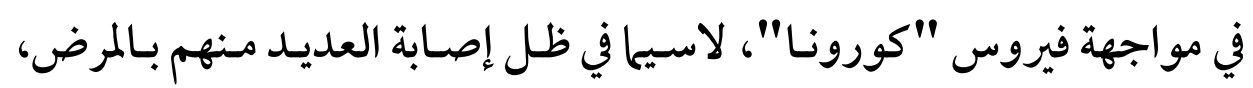

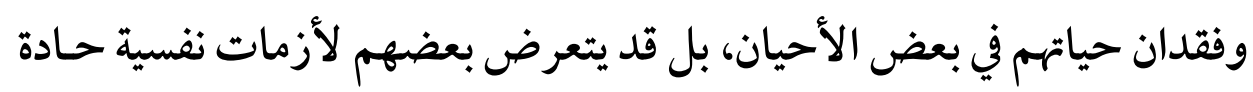

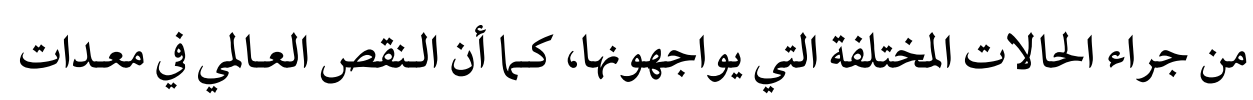
الوقاية الشخصية تعرض حياتهم للخطر.

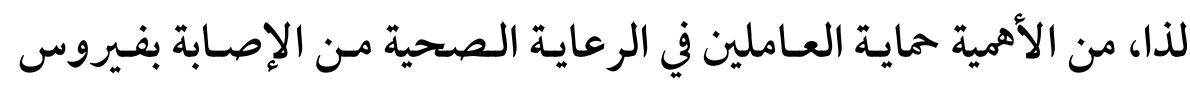

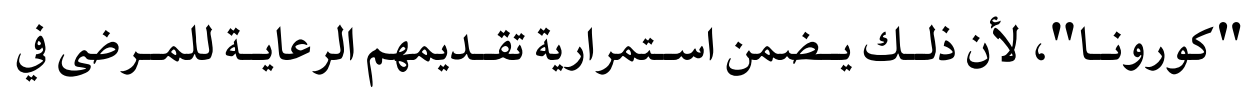
احتياجاتهم الصحية سواء ارتبطت بـ"كرونا" أو غيره من الأمراض المزمنة.

(1) وتجدر الإشارة أن منظمة أطباء بـلا حسدود لديها مكاتـب في 19 بلـداً على المستوى

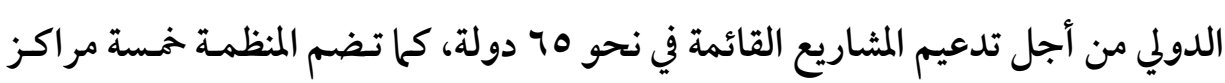

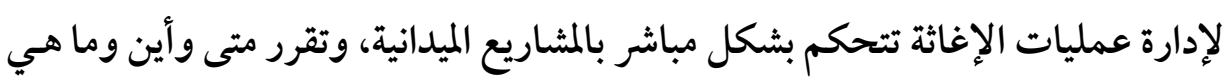

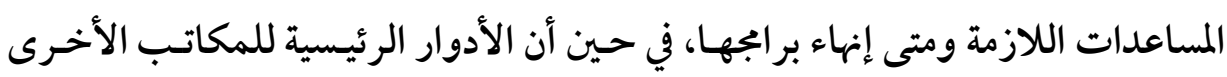

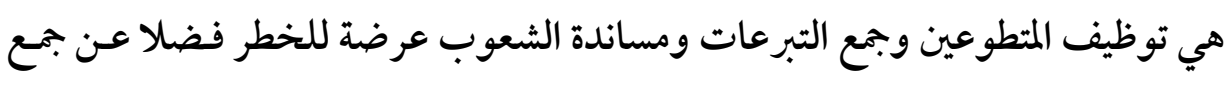

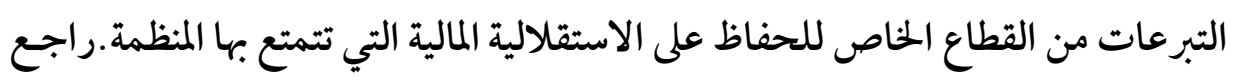

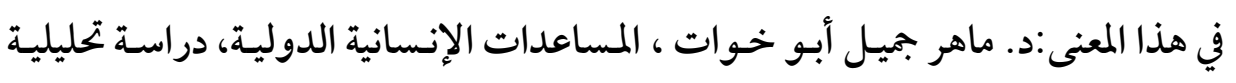

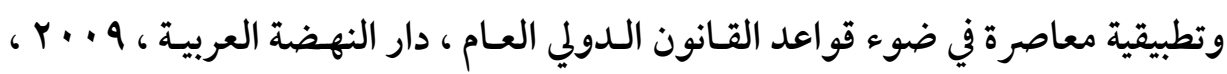

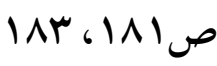




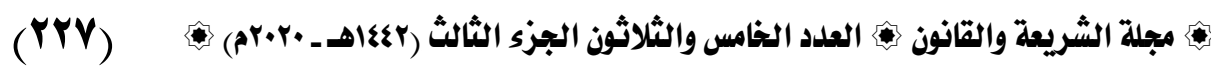

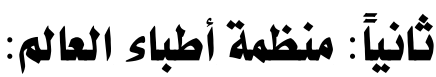

منظمة أطباء العالم MDM هي منظمـة فرنسية غير هادفة للـربح إنسانية

دولية تقدم الرعاية الطبية الطارئة وطويلة الأجل للسكان الضعفاء مع الدعوة

إلى المساواة في الحصول على الرعاية الصحية في جميع أنحاء العالم (1).

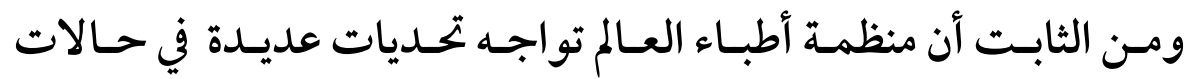

الكوارث البيئية خاصة فيلا يتعلق بالرعاية الصحية للأشـخاص عسلى المستوى

الدولي من أجل اتخاذ تدابير الوقاية مـن العـدوى الوبـائي ومكافحتها وخاصسة "التباعد الاجتهاعي" "وفحص المرضى لتحديد أعر اض الوياء ، وإنشاء نقـاط عزل في المرافق، وإجـراء دورات تدريبيـة في إدارة تـدفق المرضى بالتـسيق مـع السلطات الصحية المحلية ومنظمة الصحة العالمية، في بعض الأحيـان، وتـوفير الدعم النفسي الاجتهاعي للمرضى وعائلاتهم. وتوا جه منظمة أطباء العـالم حزمـة مـن التحـديات خـلال تصدي فريق عملها في مناطق خختلفة لجائحة "كورونا"، مثل ضـفف القـدرة عـلى السيطرة على انتشار المرض، وتـوفير الـدعم للأشـخاص في بيئـات غـير مستقرة، وعـدم توافر الإمدادات الخاصة ببعض المواد الأساسية، ونقص تبـادل الخـبرات بـين أطباء المنظمة، وحماية العاملين في بجال الرعاية الصحية، وسيطرة الجحاعـات مـا دون الدولة على المنافذ بشكل يُعقّد من فرص الحصول على التراخيص اللازمـة

(1) تأسست في عام •191 مـن قبـل بجموعـة من 10 طبيـب فرنسي، بـا في ذلك برنار كوشنار بعد أن كان قد غادر منظمة أطباء بلا حدودMSF التي كان قد شارك في تأسيسه

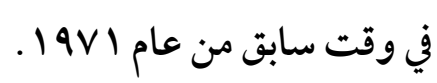


(YYA) حماية الأشخاص في حالات الكوارث البيئية في القانون الدولي

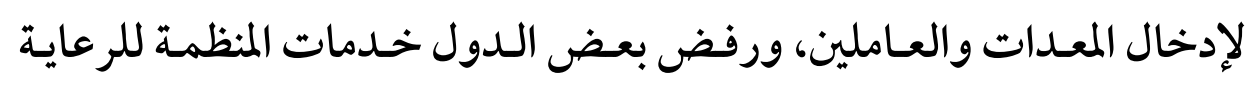
الصحية باعتبارها "جهة أجنبية". وتهـدف المنظمـة إلى تـوفير الرعايـة الطبيـة الطارئـة في الوقـت المناسـب خالية من القيود القانونية والإدارية، والعمل مـع السكان المحليين لضمان

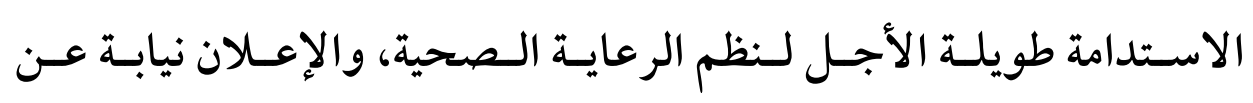
المجتمعات المستفيدة (1) - (1)

(1) وحرى بالذكر يرجع الدافع لتأسيس MDM انقسام كوشنير من منظمة أطباء بلا

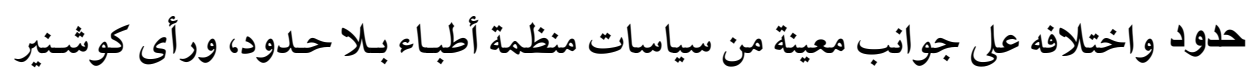
أن منظمة أطباء بلا حدود تخلت عن مبدأ المؤسسين من témoignage ("الشهادة") ،

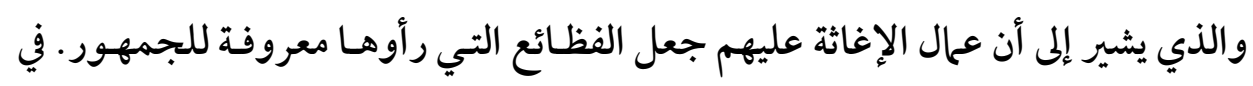

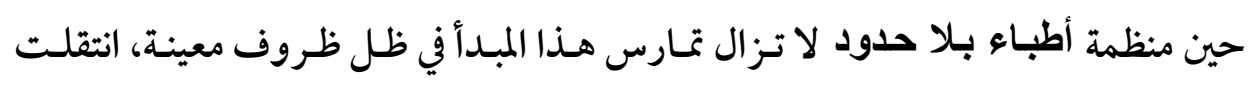

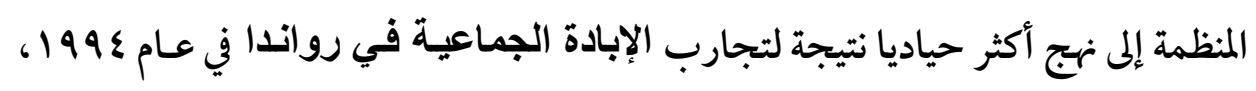
وعلى النقيض من هذا التحول في سياسة منظمة أطباء بلا حدود، أطباء حول العالم (أطباء العالم) تذكر على أنه لا يمكن فصل المساعدات الإنسانية عن السياسة، خشية أن يساء استخدامها من قبل السياسيين ، راجع في ذلك موقع المنظمة متاح على الر ابط الالكتروني التالي: /http://mdm-international.org 


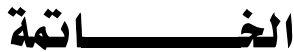

تعتبر قضية حمـاية الأشـخاص في حــالات الكـــارث البيئيـة في القـانون

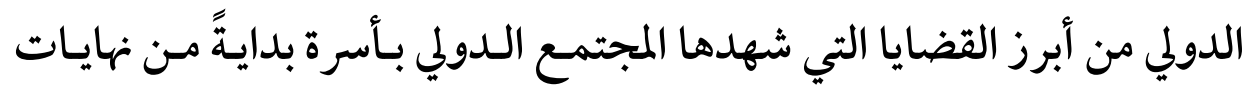

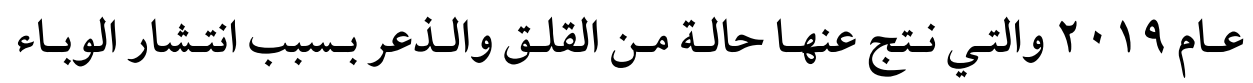
العالمي "فيروس كورونا" المستجد والمعرف بـ 19 COVID، والذي صـنفته منظمة الصحة العالمية واعتبرته حالة طارئة للصحة العامة على المستوى الدولي لارتباطها بالوجود البشري ؛ حيث عجزت المنظومة الصحية في معظم البلـدان

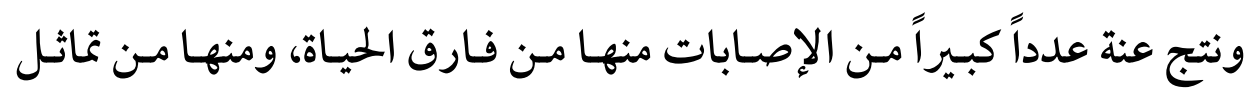
للشفاء، لذلك قامت المنظمات الدولية جاهده بعمل خطة في مقدمتها بوضـع آلية حماية الإنسان من هذا الوباء العالمي والمحافظة على التنمية الصحية العالمية

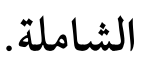
لذلك كان من الضرورة الملحة للمجتمع الدولي التضامن سـواء كـان مـن

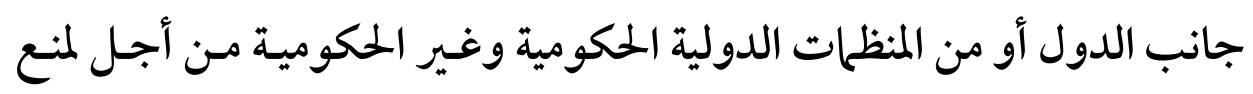

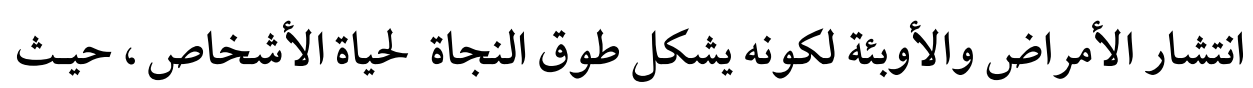

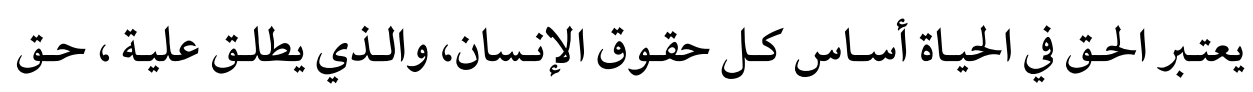

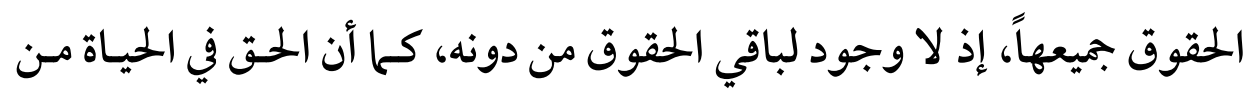

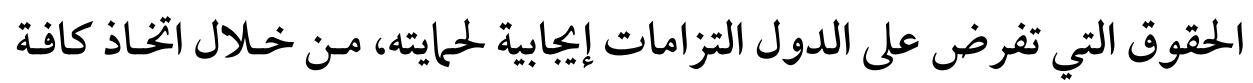
التدابير للحد من الوفيات الناتجة عن انتشار الأوبئة وغيرها من الأسباب.

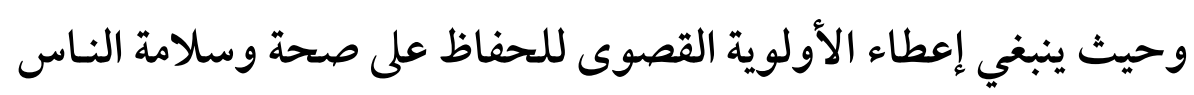

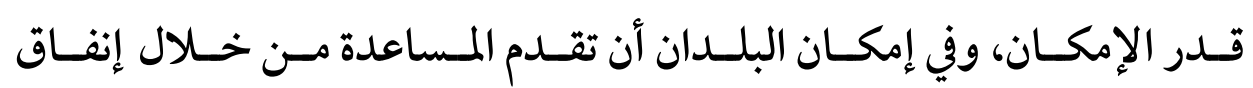


(Yr॰) حماية الأشخاص في حالات الكوارث البيئية في القانون الدولي المزيد لدعم نُظمها الصحية، بها ذلك الإنفاق على معـدات الوقاية الشخصية،

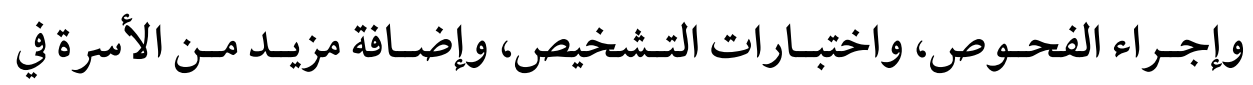

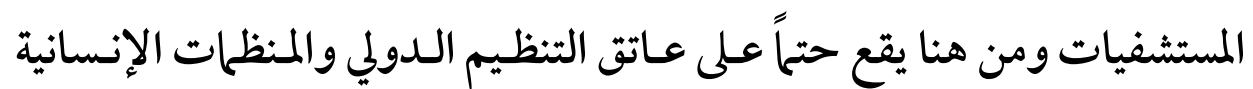

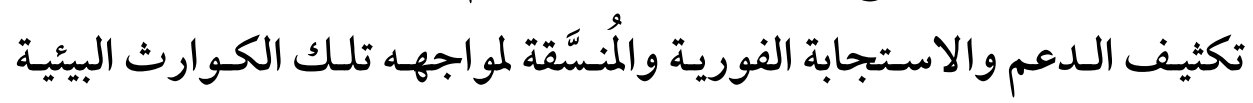
العالمية من أجل حماية الأشخاص من تك الكوارث. وقد تناولنا في الدارسة ثلاث مباحث المبحث الأول: مفهوم الكوارث البيئية في القانون الدولي ، وفية تعرفنا على المقصود بالكوارث البيئية في القانون الدولي

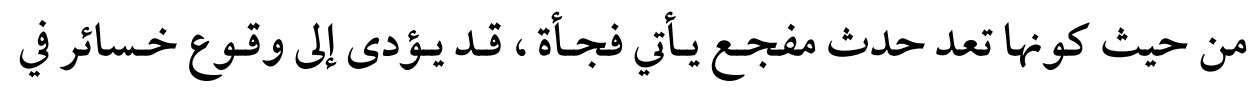

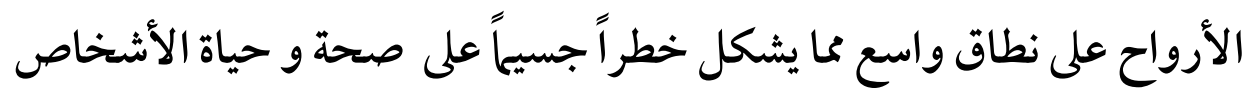

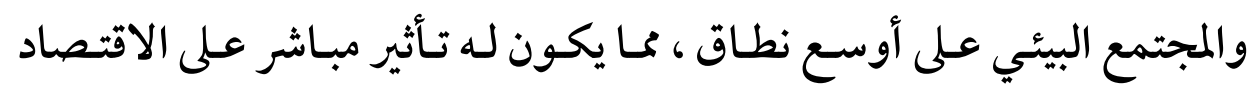
القومي والاجتهاعي . كما بينا التميز بين الكوارث البيئة وغيرها مـن الكـوارث مـن أجسل معرفة

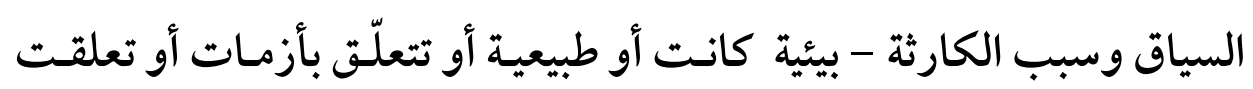
بحالات طارئة - وليس نطاقها، ومدى احتياجات المتأثرين بها، حتى يتسنى تطبيق القانون الدولي الإنساني.

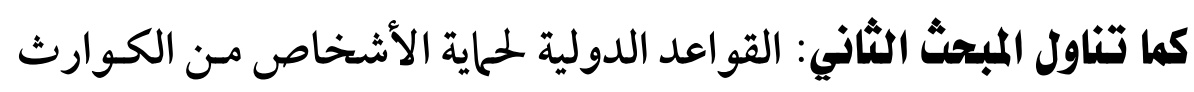
البيئية في القانون الدولي ، وفية بينا المبادئ الإنسانية لمواجهه الكوارث البيئية في

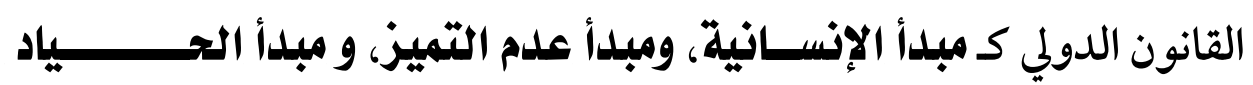

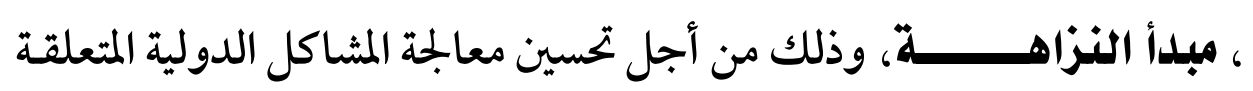

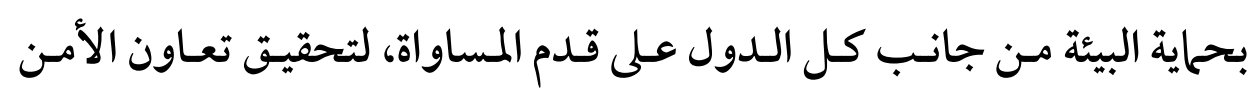




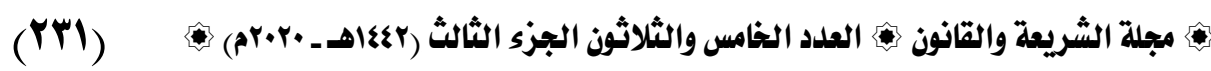

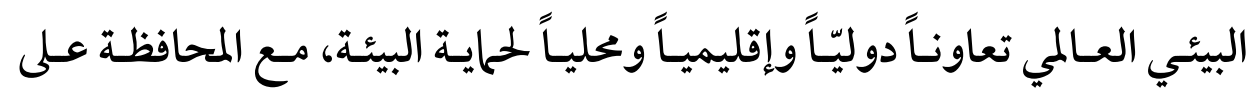

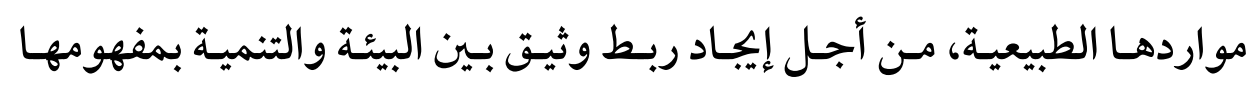
الشامل سواء في البلدان المتقدمة أو النامية. سواء تعلقت تلـك المبادئ الإنسانية لمواجهـه الكـوارث البيئية في القـانون

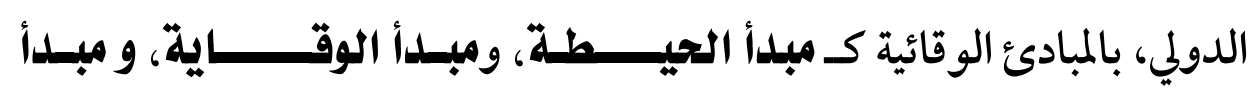
التخفيف وذلك من أجل تحقيق السلم البيئي، وتحقيق المصالحة بين الإنسان وبيئته. كما تناولنا في المبحث الثالث الآليات الدولية لحماية الأشخاص من الكوارث

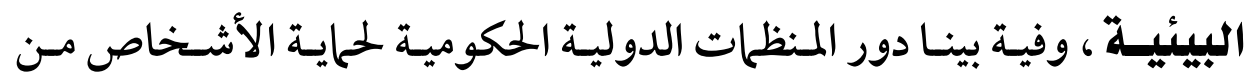
الكوارث البيئية، سواءُ كانت تلك المنظمات منها دور منظمـة الأمـم المتحـدة في

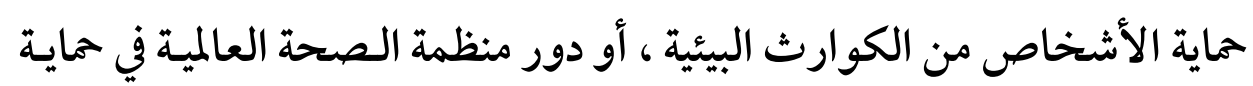
الأشخاص من الكوارث البيئية. كما بينا دور المنظات الدولية غير الحكومية لحماية الأشخاص من الكوارث الحئيه

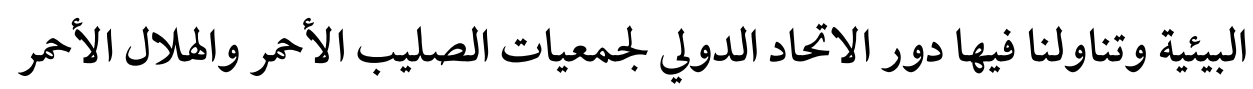
في حمايـة الأشـخاص مـن الكـوارث البيئيـة ، وكـذا دور المنظلمات الطبيـة غـير

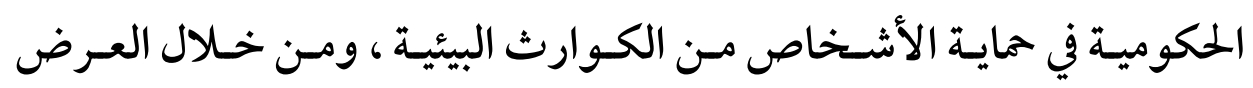
السابق توصلنا في بحثنا إلي عدة نتائج وتوصيات سنوردها علي النحو التالي : 
(THY) حماية الأشخاص في حالات الكوارث البيئية في القانون الدولي أولا :ـ النتائج

- - نستنتج أن تأثير تغير البيئة على تركيز ملوثات المهواء، يمكن أن يؤدي

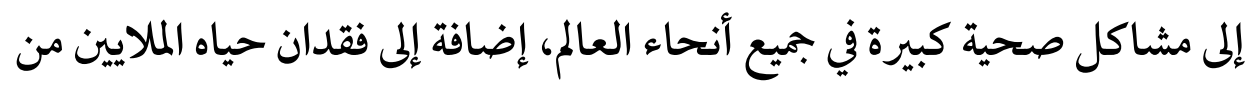
البشر بسبب تلوث المواء سنوياً. - - نستنتج أن الحق في الصحة لا يعني حق الفرد في أن يكون سـلياً معافاً،

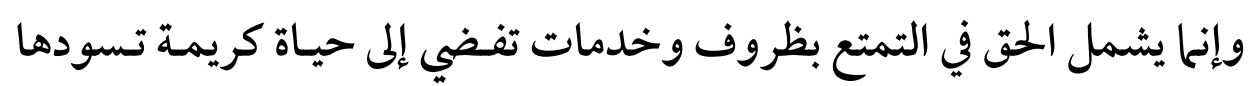

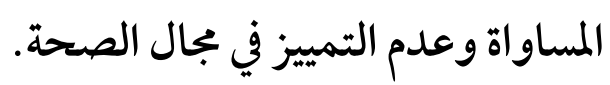

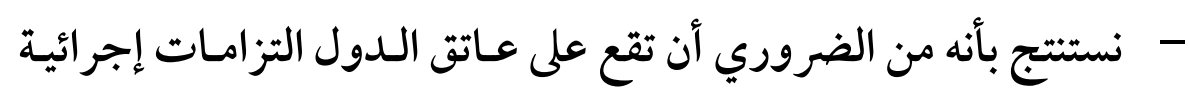

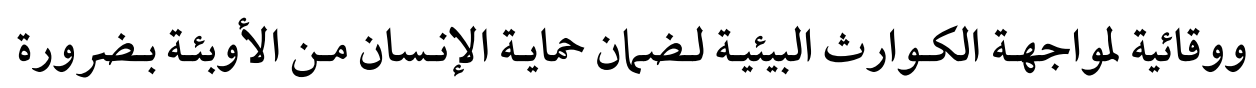

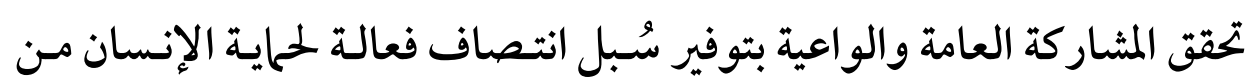
تلك الكوارث.

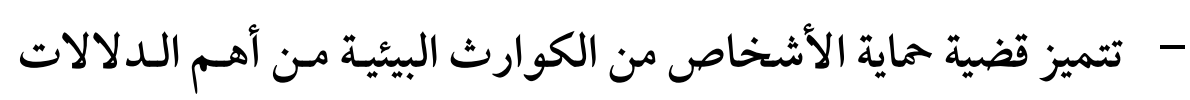

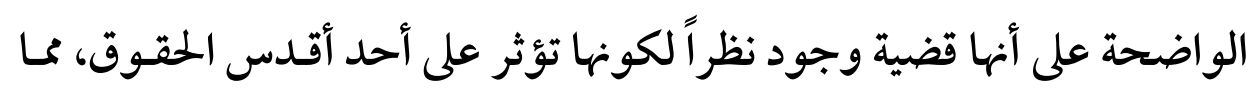
يتطلب ضرورة التدخل وبشكل فوري لوقف حد لهذه الآفة. - - تعتبر منظمة الصحة العالمية - الحـق في الصحة - بأنه حالة مـن الرفـاه

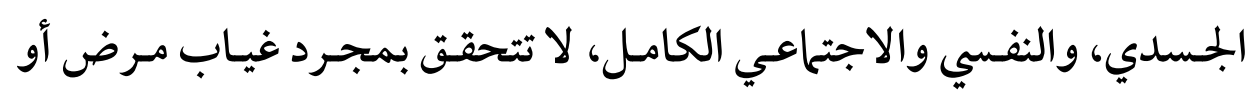

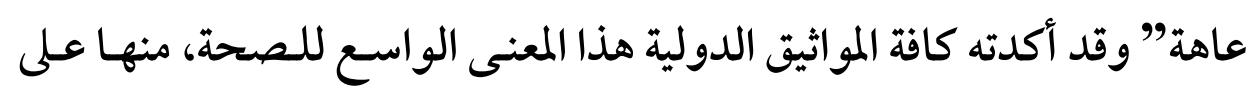

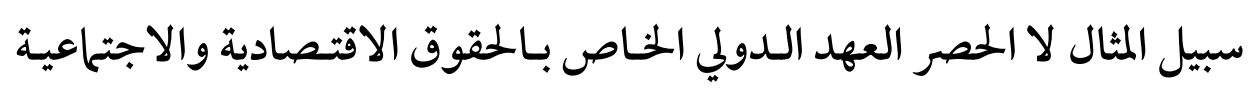
والثقافية والذي تضمنته المادة Y منه على أن تقر الدول الأطر اف في هذا العهد 


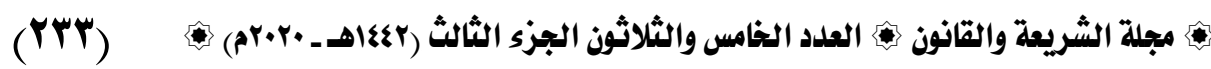

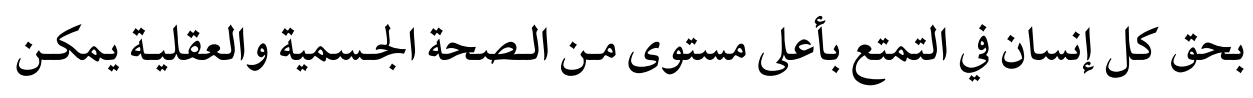
بلوغه.

\section{ثانياً: التوصيات.}

ينبغي أن تنفذ الدول تنفيذاً تاماً جميع الالتزامات التي تعهدت بهات فئيا

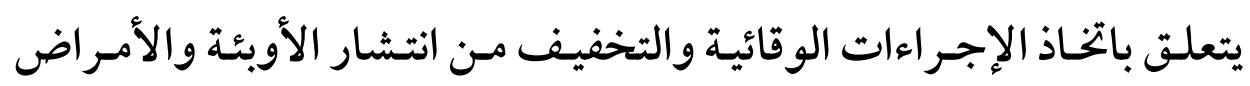

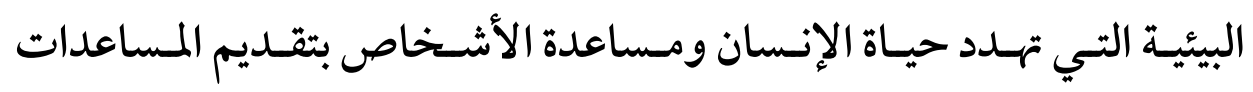
الإنسانية في بجالي الإغاثة والإنعاش.

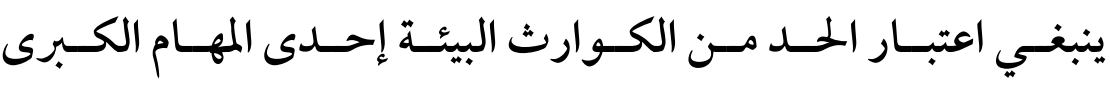

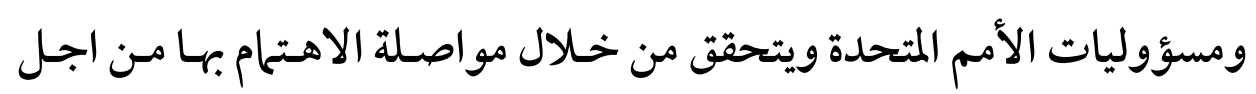

$$
\text { حماية الإنسان من جر اء تلك الكوارث. }
$$

هيب على الجهات الفاعلة في المجتمع الدولي المساعدة وعلى موظفيها

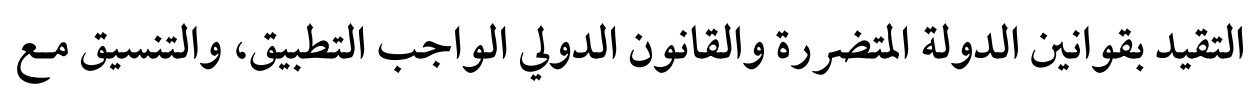
السلطات المحلية واحترام كرامة الإنسان للأشخاص المضارين مـن الكارثة في

$$
\text { جميع الأوقات؛ }
$$

• على الجهات الفاعلة المساعدة أن تكفل تقـديم مساعدتها للإغاثة مـن

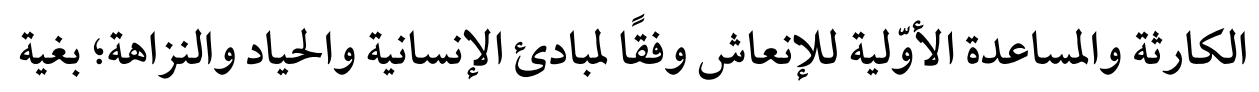

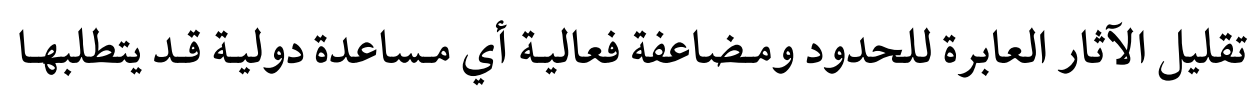


(TY乏) حماية الأشخاص في حالات الكوارث البيئية في القانون اللدولي

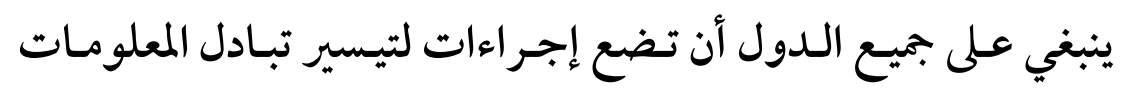

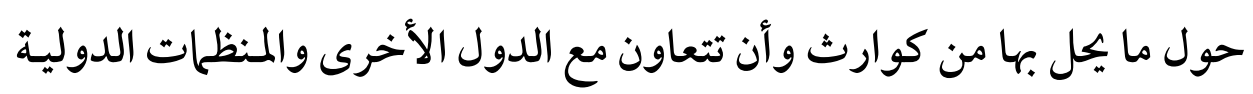
المعنية بالأنشطة الإنسانية.

هيجب على الدول أن تعتمد أُطراً شاملة قانونية ومؤسسية مـن أجل درء

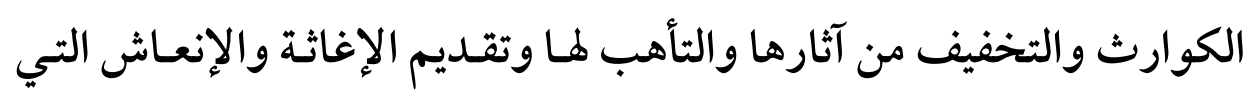

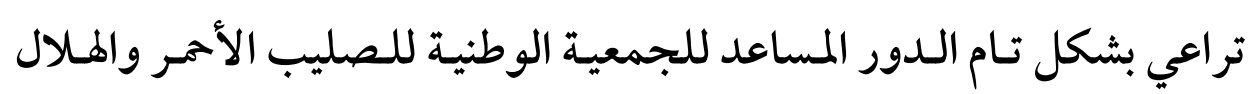
الأحمر.

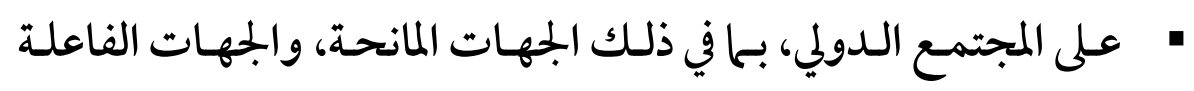

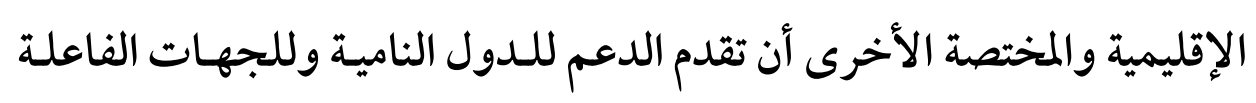

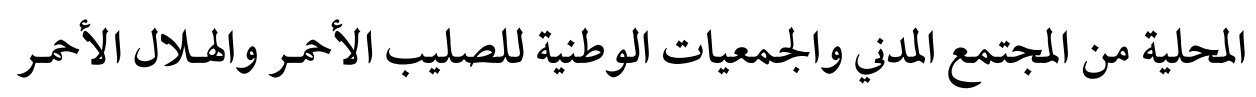

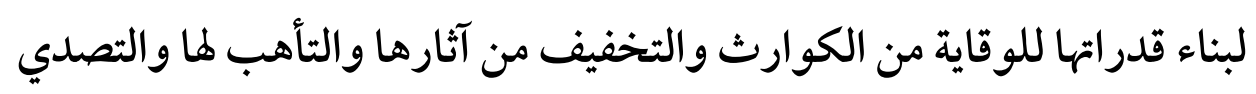

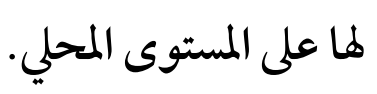




\section{قائمة المراجع - - مائ}

\section{أولاً: المراجع العربية.

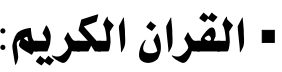

•د. إبراهيم العناني: النظام الدولي في مواجهة الأزمات والكـوارث، دار

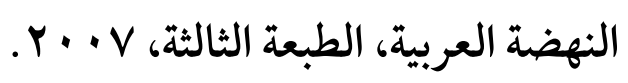

• د.أبو الخير عطية: الضملنات القانونية الدولية والوطنية لحماية حقوق

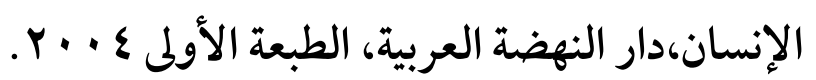

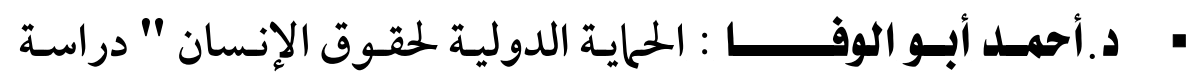

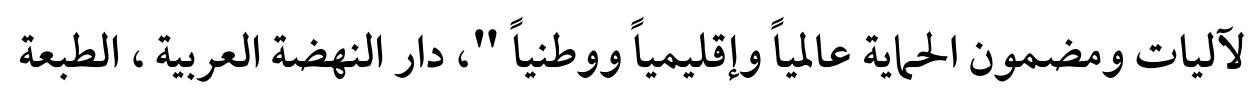

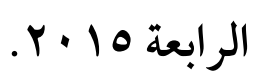

• د. أحمل أبـو الوفـا : الوسيط في قـانون المنظلات الدولية، دار الثقافة

$$
\text { العربية ، بدون تاريخ نشر. }
$$

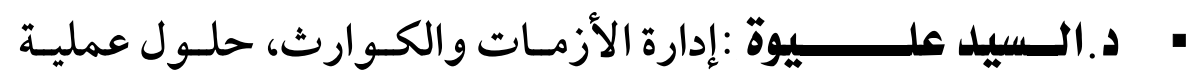
وأسـاليب وقائيسة، القـاهرة ، سلـسلة دليـل صــنع القــرار ، مركـز القـاهرة

$$
\text { لاستشارات } 1997 .
$$

• د. بوجلال صلاح الـدين: الحـق في المساعدة الإنسانية ، دراسـة مقارنـة في ضوء أحكـام القـانون الـدولي الإنساني وحقـوق الإنسان، دار الفكر الجـامعي

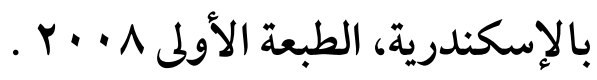


(rrY) حماية الأشخاص في حالات الكوارث البيئية في القانون الدولي

•د. جمــال حســـواش : التخطيط لإدارة الكوارث وأعحال الإغاثة، إيـراك

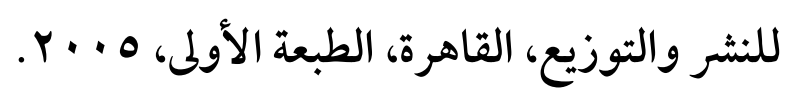

-د.زين اللدين عبد المقصود: البيئة والإنسان ،دراسة في مشكلات الإنسان

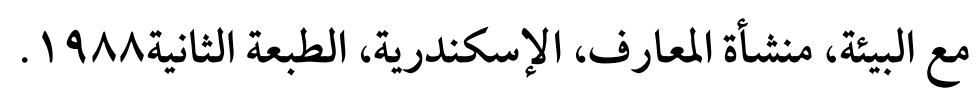

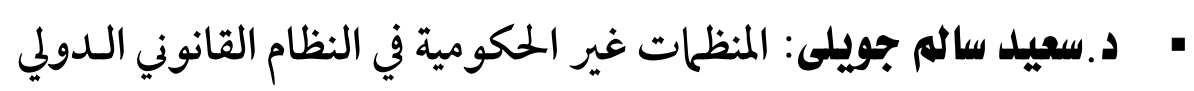

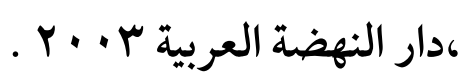

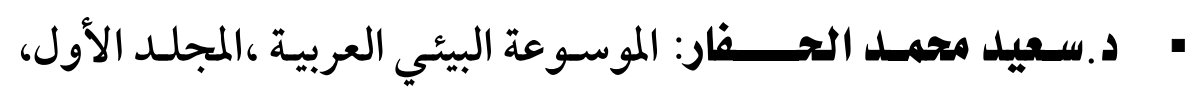

مطابع الدوحة الحديثة المحدودة 199V.

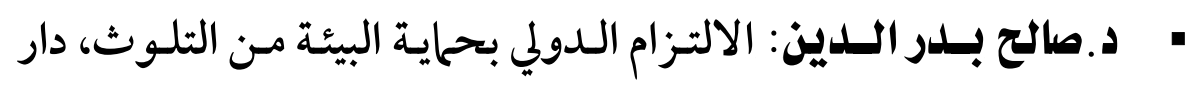

$$
\text { النهضة العربية، بدون تاريخ نشر. }
$$

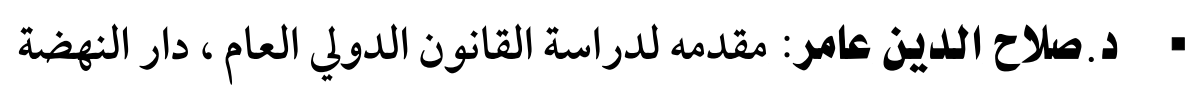

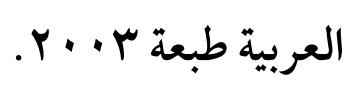

• د. محسـن افكـــيرين : القانون الدولي للبيئة، دار النهضة العربية، بدون

$$
\text { تاريخ نشر · }
$$

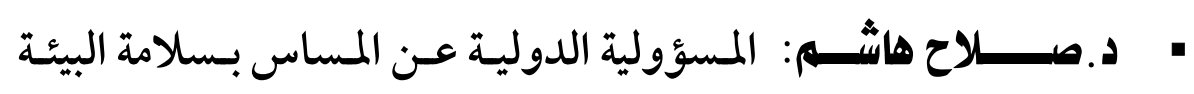

$$
\text { البحرية، رسالة دكتوراه، جامعة القاهرة، } 1991 \text {. }
$$

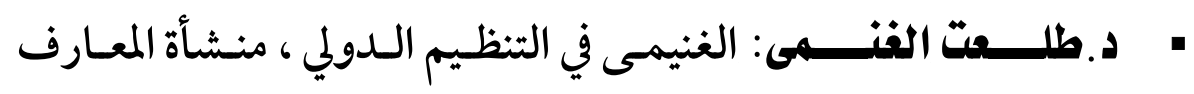

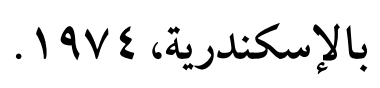

• د. عبد الحميد الشوربجى:شائبة عدم دستورية ومشروعية إعلان ومد

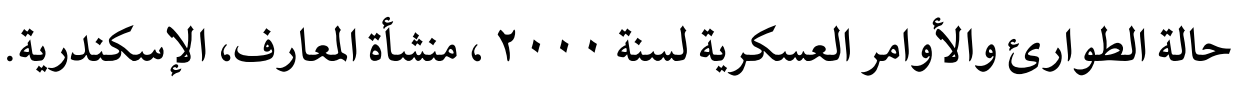




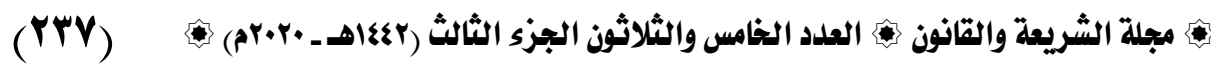

•د. عبد القـادر رزيق: التلوث البيئي غخاطر الحـاضر وتحـديات المستقبل ،

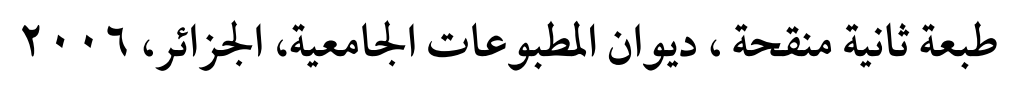

• د.عبــد الكـريم علــــــوان: الوسـيط في القـانون الـدولي العـام ، دار

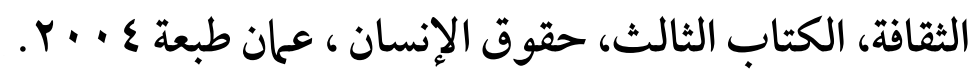

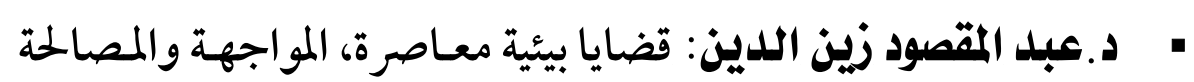

بين الإنسان وبيئته، دار النهضة العربية، بدون تاريخ نشر.

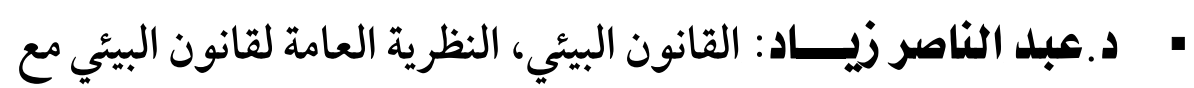

شرح الثريعات البيئية، الطبعة الأولى، دار الثقافة للنشر والتوزيـع، الأردن،

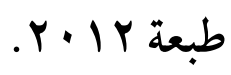

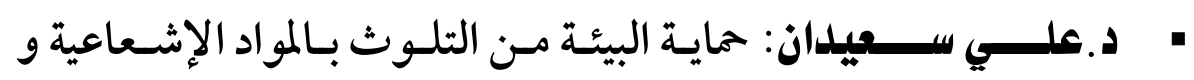

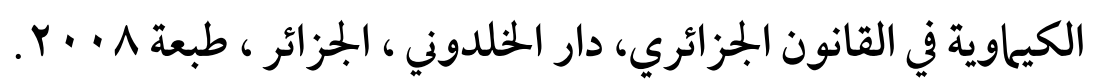

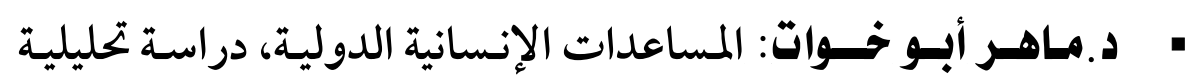

وتطبيقية معاصرة في ضوء قواعد القانون الدولي العـام ، دار النهضة العربية ،

.r. $q$

• د. محسسن أحمـل الخـري: إدارة الأزمـات مـنهج اقتصادي وإداري

للأزمات على مستوى الاقتصاد القومي والوحـدة الاقتصادية، القـاهرة مكتبـة

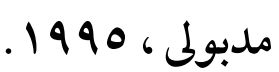

• د. محسـن افكـــريز : القانون الدولي للبيئة، طبعة الأولى ، دار النهضة

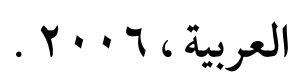


(rrA) حماية الأشخاص في حالات الكوارث البيئية في القانفو الدولي • د. محمسلد صـافى يوسـف: دارسـة في إطسار القـانون الـدولي للبيئة ، دار النهضة العربية ، الطبعة الأولى ،بدون تاريخ نشر.

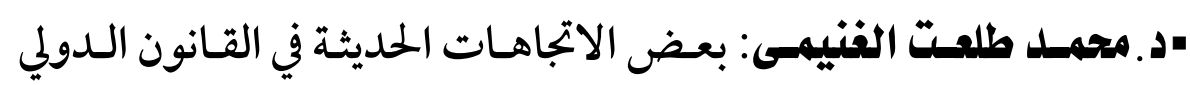

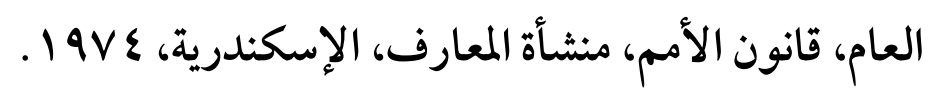

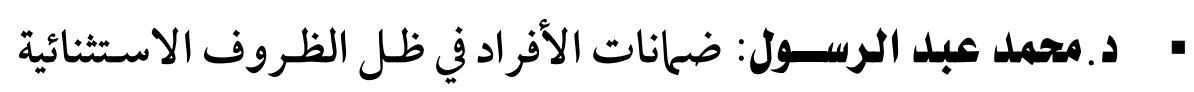

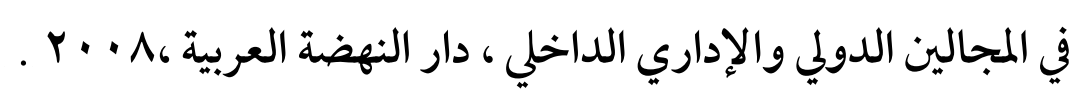

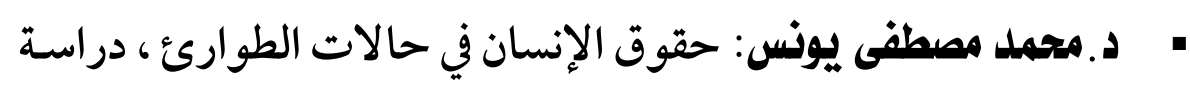
فقهية وتطبيقية معساصرة في ضسوء مبـادئي وقواعـد القـانون الدولي العـام ، دار

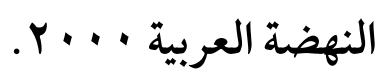

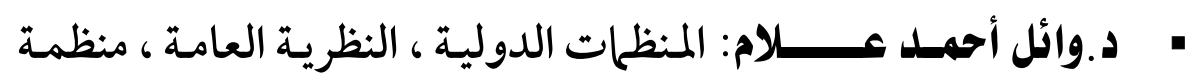

$$
\begin{aligned}
& \text { الأمم المتحدة ، المنظلات الإقليمية ،دار النهضة العربية } 9 \text { ا •.r. } \\
& \text { (ب) الرسائل العلمية: }
\end{aligned}
$$

• د.أبو الخير عطية: الالتزام الدولي بحماية البيئة البحريـة مـن التلوث، رسالة دكتوراه جامعه عين شمس، 1990.

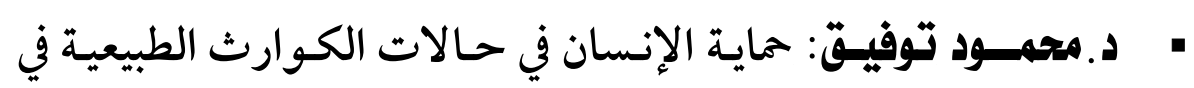
القـانون الـدولي العـام والـشريعة الإسـلامية، رسـالة دكتـور اه جامعـة القـاهرة

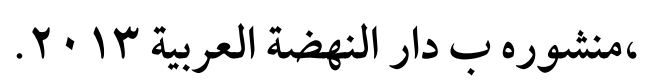
• د. منى صلاح اللدين : إدارة الأزمات في قطاع الغزل والنسيج ، رسـالة دكتوراه غير منشورة ، جامعة عين شمس ، كلية التجارة 1990. 


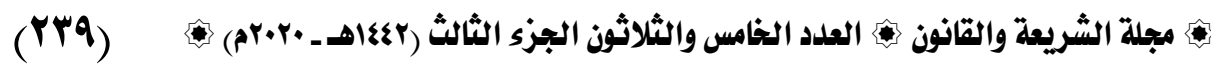

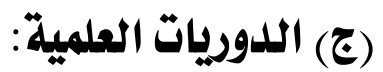

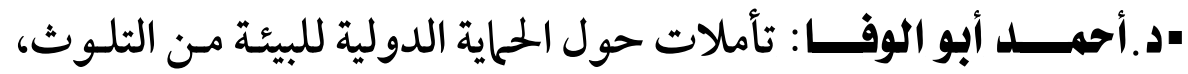

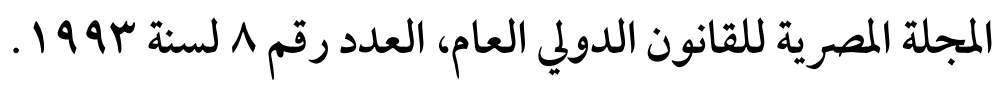

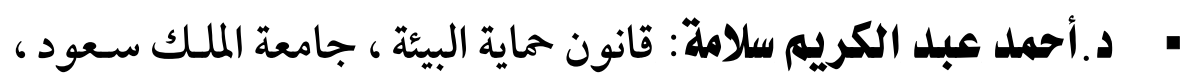

$.199 V$

-د. جسـال الـدين حسـواش: إدارة الأزمـات والكـوارث ضرورة حقيقيـة ،

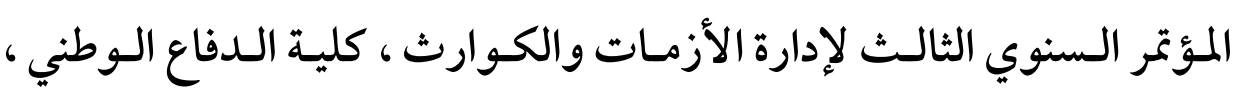

أكتوبر 1991

• د. جــعر عبلد السلام: حتق الإنسان في بيئة صسحية مناسبة، بحـث

منشور بمناسبة الدورة التاسعة عشر لمنظمة المؤتمر الإسلامي بإمـارة الشارقة ، دولة الإمارات العربية المتحدة ، بدون تاريخ نشر.

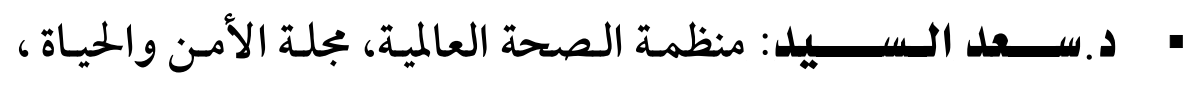

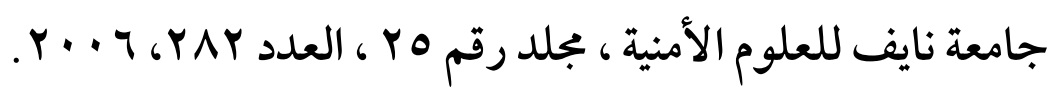
• علــوانى مبــــارك: دور المنظلات الدولية المتخصصة والمنظمات الغير حكومية في حماية البيئة من التلوث، مجلة المفكر ، العـد الرابع ، كلية الحقوق

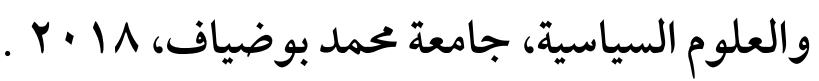

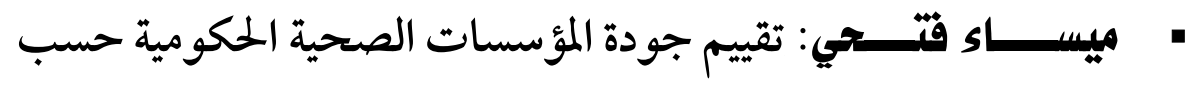

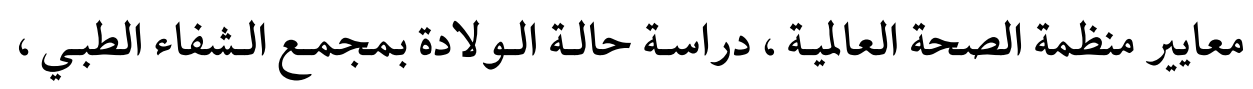

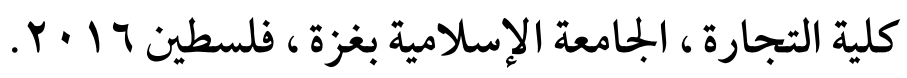




\section{حماية الأشخاص في حالات الكوارث البييئة في القانون اللدولي \\ المراجع الأجنبية: English References}

1. Allen L. Springer, The International of Pollution: Protection of the global Environment in a World of Sovereign States, Westport. Connecticut Quorum Books, 1983.

2. Arabic Compendium of International Law UNEP Environmental Law Publication, 1995.

3. Arie Trouwborst, Precautionary Rights and Duties of States Leiden, Martinus Nijhoff Publishers, 2006 .

4. BY THE DEPARTMENT FGLOBALCOMMUNICATIONS United Nations Mobilizes Globally in Fight against COVID19.https://www.un.org/ar/coronavirus.

5. C.I.J, Demande d'examen de la situation au titre du paragraphe 63 de l'arrêt rendu par la Cour le 20 décembre 1974, Recueil 1995 dans l'affaire des Essais nucléaires, affaire NouvelleZélande contre la France, p 23, Par douze voix contre trois, Dit que :" la Nouvelle demande en indication de measures conservatoires présentée par la Nouvelle-Zélande à la même date doit être écartée ». disponible sur le site de la C.I.J : www.CIJ.org

6. Cass R. Sunstein, Laws of Fear: Beyond the Precautionary Principle (New York, Cambridge University Press, 2005); Linda Cameron, "Environmental risk management in New Zealand is there scope to apply a. more generic framework?", New Zealand Treasury Policy Perspectives Paper 06/06 /2006

7. Charles R. BeiTZ ,The Idea of Humain Rights ,oxford universTy Press, New yourk, 2015

8. CHETRIT (Thierry), Le plan vigipirate: une illustration de cooperation civilo-militaire dans le domaine de la sécurité, Droit et Défense, $n^{\circ} 4,1995$.

9. CJCE, affaire National Farmers contre l'Union Européenne, affaire $\mathrm{N}^{\circ}$ C-157/96 du 5/5/1998, CJCE, Affaire Royaume-Uni contre La Commission Européenne, Affaire $\mathrm{N}^{\circ} \mathrm{C}-180 / 96$ du $5 / 5 / 1998$.

10. Claude Pilloud et al., Commentary on the Additional Protocols of 8 June 1977 to the Geneva Conventions of 12 August 1949 (Geneva: International Committee of the Red Cross, 1987), paragraph 2800,2801 (citing th "Proclamation of the Fundamental Principles of the Red Cross", adopted by resolution IX of the 20th International Conference of the Red Cross,Vienna 1965) 
11. Corfu Channel case (United Kingdom of Great Britain and Northern Ireland v. Albania), I.C.J.Reports 1949.

12. Daniel M, Schwartz \& others, The Environment and Violent Conflict: A Response to Gleditsch's Critique and Some Suggestions for Future Research, Environmental change and security project report, Issue 6, 2000.

13. DAVANTURE Sandrine, Les relations entre les règles des accords multilatéraux sur l'environnement et celles de l'OMC, Université Paris 2 Panthéon Assas, DEA, 2003.

14. DE LAUBADERE (André), Le contrôle juridictionnel du pouvoir discrétionnaire dans la jurisprudence récente du Conseil d'Etat, Mélanges, Waline, T II, Paris, 1974.

15. Droit de l'environnement,2e edition, Dollaz, Paris, 1991

16. EDLINGER Sophie, Les limites du principe de précaution à travers les jurisprudences de la Cour de justice des Communautés européennes et du Conseil d'Etat, D.E.A. de Droit International et Communautaire, Université de Droit et Santé de Lille II, 20022003.

17. FERETTI Alain, Principe de précaution et dynamique d'innovation, Étude du Conseil économique, social et environnemental, Mandature, Bureau du 12 novembre, France, 2015

18. Fidler, David P. "Governing Catastrophes: Security, Health and Humanitarian Assistance." International Review of the Red Cross 866 (June 2007)

19. FRANZ-XAVER Perrez, the world summit on sustainable development: environment, precaution and trade-a potential for success and/or failure, RECIEL, Avril 2003

20. H. Fischer, "International disaster response law treaties: trends, patterns, and lacunae" in IFRC, International disaster response law.principles and practice: reflections, prospects and challenges (2003),

21. Jean Pictet, The Fundamental Principles of the Red Cross Proclaimed by the Twentieth International Conference of the Red Cross, Vienna, 1965 Commentary (Geneva, Henry Dunant .Institute, 1979), pp. 21-27; also available from www.icrc.org

22. KAESSNER Eva Zbinden, Le Principe de précaution en suisse et au plan international, Document de synthèse du groupe de travail interdépartemental " Principe de précaution ", Suisse, Août 2003. 
23. Michel Bélanger, Droit international humanitaire général, Gualino éditeur, paris , 2e édition , 2007

24. MICHEL PRIEUR, Droit de l'environnement, DALLOZ,PARIS, 4 édition, 2001

25. N. de SADELEER, Les principes de pollueur-payeur, de prévention et de précaution, Essai sur la genèse et la portée juridique de quelques principles du droit de l'environnement, Bruylant, Bruxelles, Universités Francophones,-1999.

26. Patricia Buirette, Philippe Lagrange, le droit international humanitaire, la Découverte, paris, 2008

27. Peter MacAlister-Smith, Draft international guidelines for humanitarian assistance operations .Heidelberg, Germany: Max Planck Institute for Comparative Public Law and International Law, (1991).

28. RAMBAUD Patrick, Un nouveau principe du droit communautaire , Le principe de précaution, Édition Bruylant, Bruxelles, 2001.

29. Rone Rodiere, Martin Remond-Gouilloud ; La mer droits des hommes ou proie des etets, editions A .Pidone Paris, 1980

30. Rothe ‘Camilla! Schunk ‘Mirjam! Sothmann 'Peter؛ Bretzel ، Gisela؛ Froeschl، Guenter؛ Wallrauch 'Claudia؛ Zimmer ، Thorbjörn؛ Thiel، Verena؛ Janke ‘Christian "Transmission of 2019-nCoV Infection from an Asymptomatic Contact in Germany".New England Journal of Medicine. doi:10.1056/NEJMc2001468.

31. Rubin, Olivier; Dahlberg, Rasmus, A Dictionary of Disaster Management, A Dictionary of Disaster Management. Oxford University Press, 2017.

32. SCHMIDT Pia, signaux précoces et leçons tardives: le principe de précaution 1896-2000 quelques points récapitulatifs, AEE (Agence Européenne de l'Environnent), Copenhague, 2002

33. THIEFFRY Patrick, Le contentieux naissant des organismes génétiquement modifiés : précaution et measures de sauvegarde, RTDE (Revue Trimestrielle du Droit Européen) $\mathrm{n}^{\circ} \mathbf{1}$, France, 1999.

34. TROUCHE Angélique, Le principe de précaution entre unité et diversité étude comparative des systems communautaire et OMC, mémoire master 2 recherche droit européen, université Paris 1 panthéon Sorbonne, 2009.

35. UK Government Advice on Definition of an Emergency on 2007 


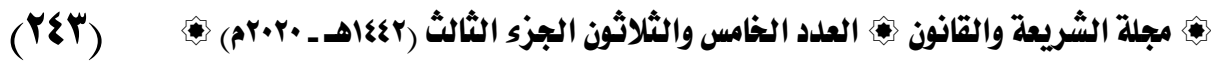

36. Y.Loussouarn et P.Bourel : Droit international privé, DOLLOZ, 3 siemme ed.1988

37. Jared M. Diamond, Collapse: How Societies Choose to Fail or Succeed, 2005

38. Massachusetts v. Environmental Protection Agency (U.S. Supreme Court, 2007)

39. Urgenda Foundation v. Kingdom of the Netherlands (District Court of The Hague, 2015 
(Yצ纟)

حماية الأشخاص في حالات الكوارث البيئية في القانون الدولي

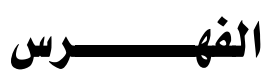

\begin{tabular}{|c|c|}
\hline الصفحة & 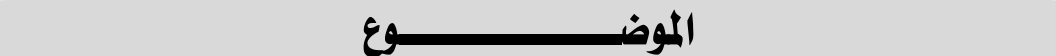 \\
\hline I $\mathrm{HV}$ & 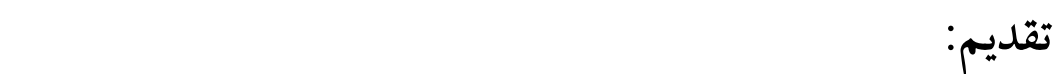 \\
\hline irq & 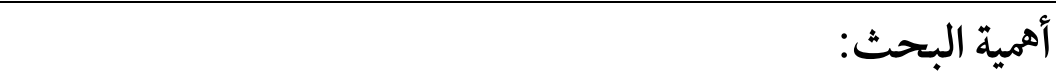 \\
\hline irq & إشكالية البحث. \\
\hline $1 \varepsilon$. & منهج البحث. \\
\hline $1 \varepsilon$. & 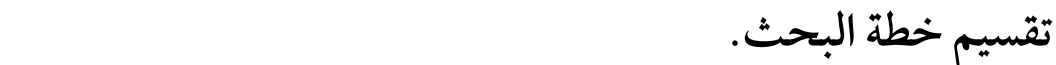 \\
\hline $1 \leqslant r$ & ث الأول: مفهــــوم الكـــــوارث البيئية في القـــانون الدولي . \\
\hline $1 \leqslant r$ & المطلب الأول : المقصود بالكوارث البيئية في القانون الدولي . \\
\hline $1 \leqslant \varepsilon$ & الفرع الأول: مفهوم الكوارث في القانون الدولي. \\
\hline 10. & ـع الثاني: مفهوم البيئية في المواثيق الدولية. \\
\hline $10 \xi$ & المطلب الثاني: التمييز بين الكوارث البيئة وغيرها من الكوارث . \\
\hline $10 \xi$ & الفرع الأول: التمييز بين الكوارث البيئية والكوارث الطبيعية. \\
\hline 101 & الفرع الثاني: التمييز بين الكوارث البيئية والتلوث البيئي. \\
\hline אד1 & الفرع الثالث: التمييز بين الكوارث البيئية والأزمات الإنسانية. \\
\hline ITV & الفرع الرابع: التمييز بين الكوارث البيئية وحالة الطوارئ. \\
\hline IV. & البيئية في القانون الثناني: القواعـد الدوليـة لحلايـة الأشـخاص مـن الكوارث \\
\hline
\end{tabular}




\begin{tabular}{|c|c|}
\hline الصفحة & 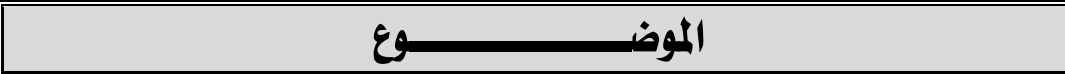 \\
\hline IVY & المطلب الأول: المبادئ الإنسانية لمواجهه الكوارث البيئية في القانون \\
\hline IVr & الأول: مبدأ الإنســــانية. \\
\hline IVT & الثاني: مبدأ عدم التميز. \\
\hline $1 \wedge$. & الثالث: مبدأ الحـــــــــــياد. \\
\hline IAr & الر ابع: مبدأ النزاهــــــــــة. \\
\hline $1 \wedge 1$ & ب الثاني: المبادئ الوقائية لمواجهه الكـوارث البيئية في القـانون \\
\hline 119 & الأول: مبدأ الحيــــة من الكوارث البيئية. \\
\hline 190 & الثاني: مبدأ الوقــــاية من الكوارث البيئية. \\
\hline$r+1$ & ع الثالث: مبدأ التخفيف من الكوارث البيئية. \\
\hline$r \cdot V$ & 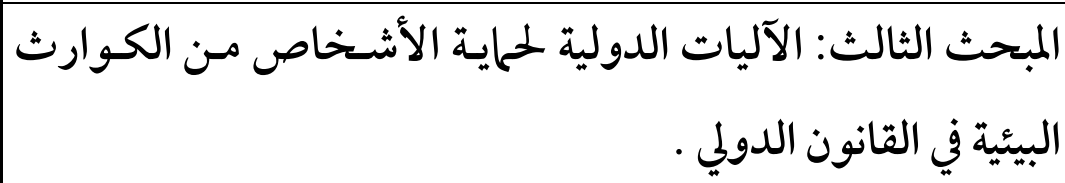 \\
\hline$r \cdot \Lambda$ & المطلب الأول: دور المنظلات الدوليـة الحلكومية لحلايـة الأشـخاص \\
\hline rl. & الكـرع الأول: دور منظمـة الأمـم المتحـدة في حمايـة الأشـخاص مـن \\
\hline
\end{tabular}




\begin{tabular}{|c|c|}
\hline$(\Gamma \leqslant\rceil)$ & حماية الأشخاص في حالات الكوارث البيئية في القانوز الدولي \\
\hline الصفحة & 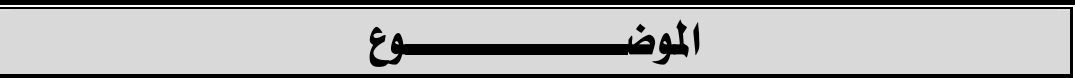 \\
\hline rlo & الكرع الثاني: دور منظمة الصحة العالميـة في حماية الأشـخاص مـن \\
\hline Y19 & 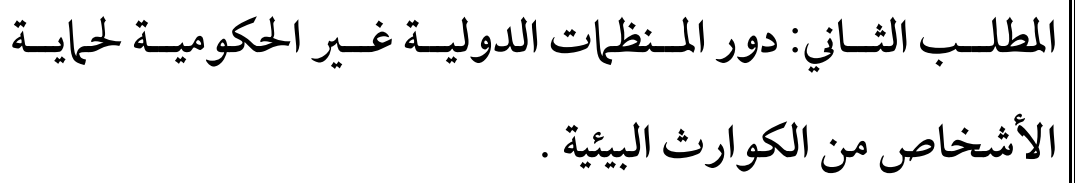 \\
\hline YYI & الألمرع في حماية الأشخ: دور الاتحاد الدولي لجمعيات الصليب الأحمر والهلال \\
\hline YY & الفرع الثاني: دور المنظمات الطبية غير الحكومية في ماية الأشخاص \\
\hline YYq & خاتمة البحث \\
\hline rrr & نتائج البحث: \\
\hline 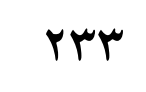 & توصيات البحث: \\
\hline rro & قائمة مراجع البحث : \\
\hline$r \leqslant \varepsilon$ & فهرست. \\
\hline
\end{tabular}

